\title{
Charakterisierung induzierter, kolorektaler Lebermetastasen in einem Mausmodell und Einfluss von Makrophagenphänotypen auf die Tumorprogression
}

\author{
Dissertation \\ zur Erlangung des mathematisch-naturwissenschaftlichen Doktorgrades \\ „Doctor rerum naturalium (Dr. rer. nat.)“ \\ im Promotionsprogramm Molekulare Medizin \\ der Georg-August-Universität Göttingen
}

vorgelegt von

Derya Bocuk

aus

Köln

Göttingen 2016 


\section{Mitglieder des Betreuungsausschusses (Thesis Committee)}

\section{Betreuerin}

Prof. Dr. med. Sarah König

Abteilung für Allgemein-, Viszeral- und Kinderchirurgie

Universitätsmedizin Göttingen

seit Februar 2016:

Institut für Medizinische Lehre und Ausbildungsforschung

Universitätsklinikum Würzburg

\section{Zweites Mitglied}

Prof. Dr. med. Frauke Alves

Abteilung für Hämatologie und Onkologie

Universitätsmedizin Göttingen

\section{Drittes Mitglied}

Prof. Dr. rer. nat. Tim Beißbarth

Abteilung für Statistische Bioinformatik

Institut für Medizinische Statistik

Universitätsmedizin Göttingen

Tag der Disputation: 


\section{AFFIDAVIT}

Hiermit erkläre ich, dass ich die vorliegende Dissertation mit dem Titel „Charakterisierung induzierter, kolorektaler Lebermetastasen in einem Mausmodell und Einfluss von Makrophagenphänotypen auf die Tumorprogression" selbständig verfasst und keine anderen als die angegebenen Hilfsmittel und Quellen benutzt habe.

Derya Bocuk

Göttingen, September 2016 


\section{Publikationsliste}

Bocuk D, Wolff A, Krause P, Salinas G, Bleckmann A, Hackl C, Beissbarth T, Koenig S (2016): The evolution of colorectal cancer cells forming metastases in the liver environment: expression of associated genes and pathways in a mouse model. [submitted]

Monin MB, Krause P, Stelling R, Bocuk D, Niebert S, Klemm F, Pukrop T, Koenig S (2016): The anthelmintic niclosamide inhibits colorectal cancer cell lines via modulation of the canonical and noncanonical Wht signaling pathway. J Surg Res 203 (1): S. 193-205. DOI: 10.1016/j.jss.2016.03.051.

\section{Publizierte Kongressbeiträge und Auszeichnungen:}

Bocuk D, Wolff A, Koenig S, Beissbarth T, Krause P (2016): Expression of genes and pathways associated with colorectal liver metastases in an orthotopic and syngeneic mouse model. Z Gastroenterol 2015; 53 - A4_8. DOI: 10.1055/s-0035-1568067.

(GASL Posterpreis 2016 im Themenbereich „Tumore, Leberchirurgie und Transplantationen)

Bocuk D, Krause P, Niebert S, Pukrop T, Beissbarth T, Ghadimi M, Koenig S (2015): Mouse models of colorectal and mammary cancer liver metastases and microenvironmental interplay with tumor-associated macrophages (TAMs). Z Gastroenterol 2015; 53 - A4_34. DOI: $10.1055 / s-0034-1397186$. 


\section{Inhaltsverzeichnis}

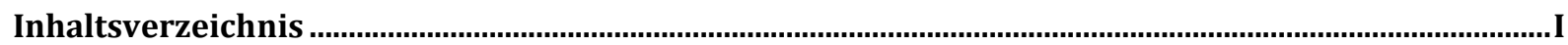

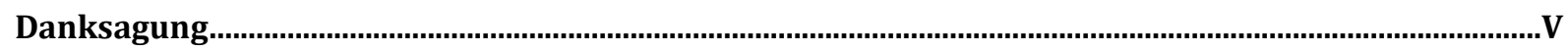

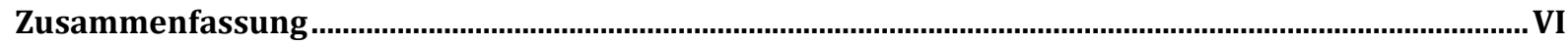

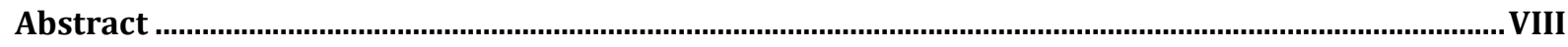

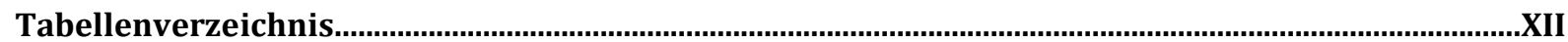

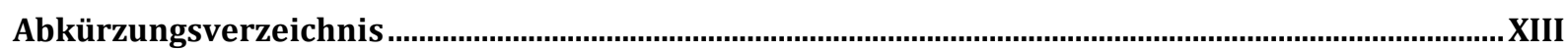

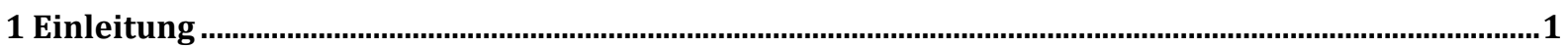

1.1 Das Kolorektalkarzinom - Inzidenz, Ätiologie und Risikofaktoren ................................................................1

1.2 Pathogenese des Kolorektalkarzinoms ..................................................................................................................

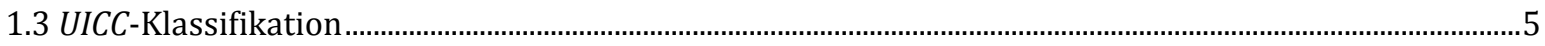

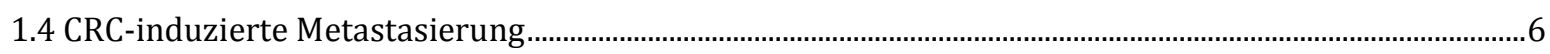

1.5 Therapie und Prognose des Kolorektalkarzinoms............................................................................................10

1.6 Die Leber als immunologisches Organ ............................................................................................................11

1.6.1 Entstehung und Funktion von Makrophagen...........................................................................................13

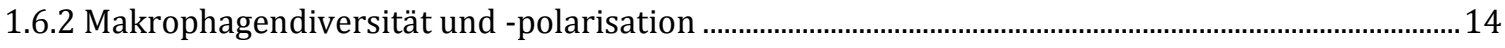

1.6.3 Bimodale Rolle der Makrophagen .........................................................................................................

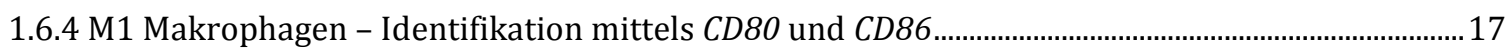

1.6.5 M2 Makrophagen - Identifikation mittels CD163 und CD206 ............................................................18

1.6.6 Allgemeine Makrophagenmarker - Identifikation mittels CD11b, F4/80 und CD68 …....................19

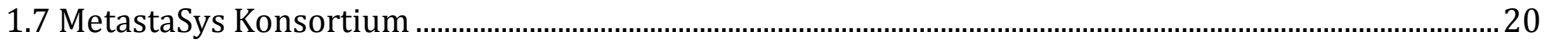

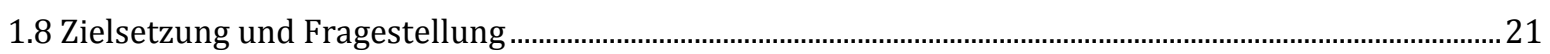

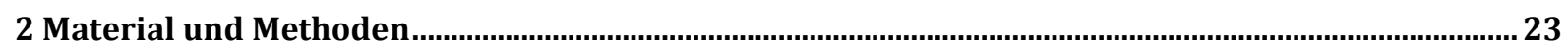

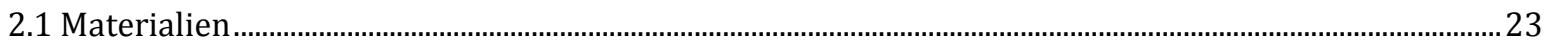

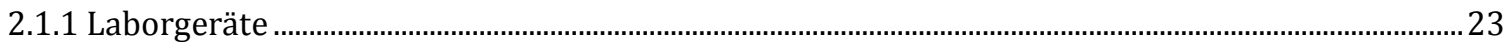

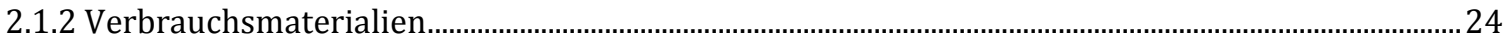

2.1.3 Chemikalien und rekombinante Proteine ...................................................................................................26

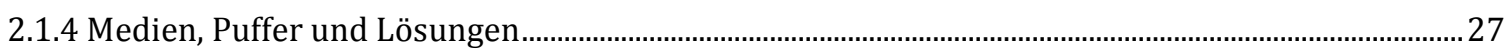

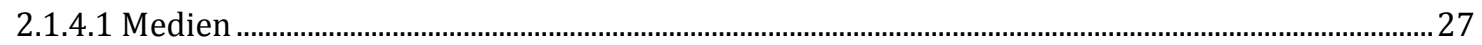

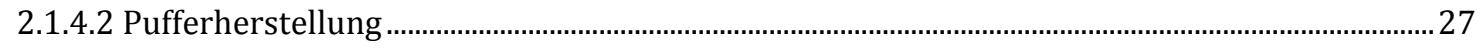

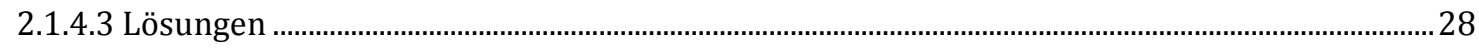

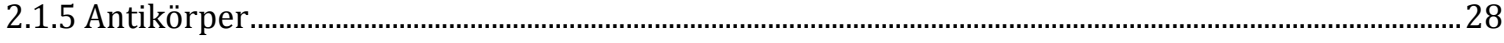

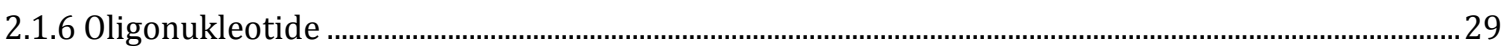

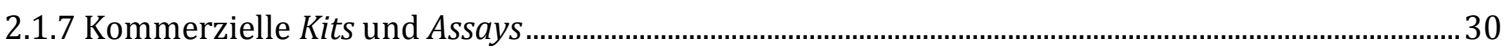

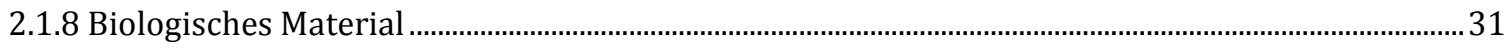

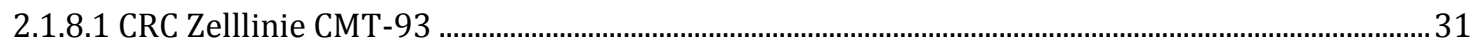

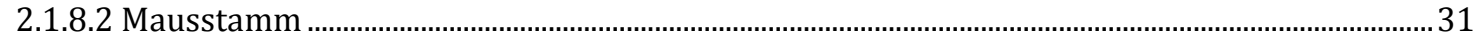




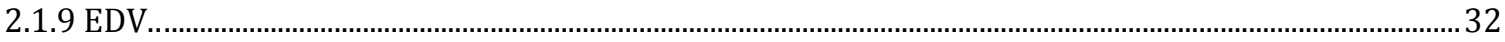

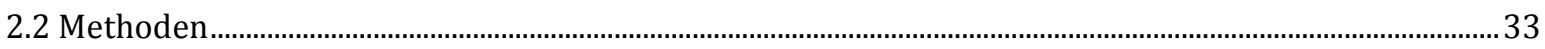

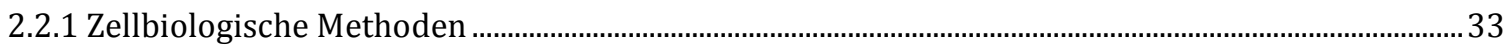

2.2.1.1 Kulturbedingungen eukaryotischer Zellen ..................................................................................33

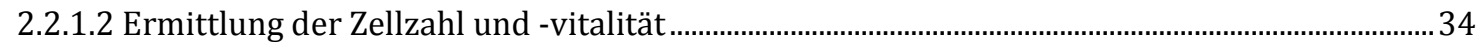

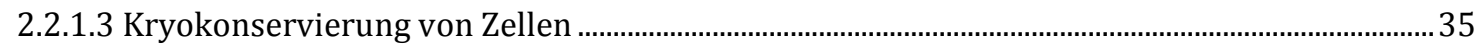

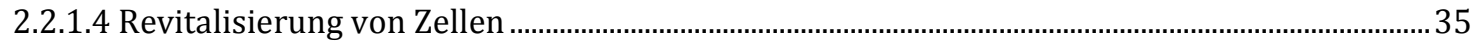

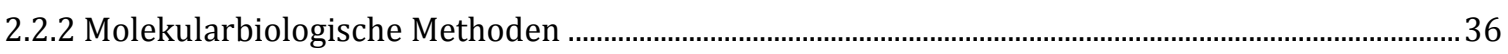

2.2.2.1 RNA Extraktion aus Gewebe ......................................................................................................... 36

2.2.2.2 RNA Extraktion aus eukaryotischen Zellen ........................................................................................37

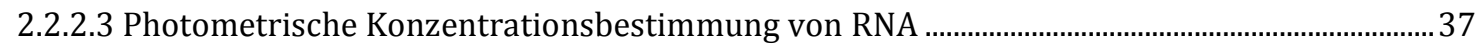

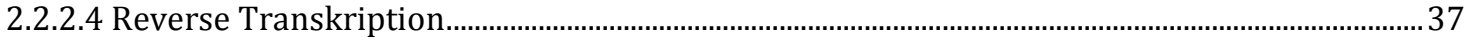

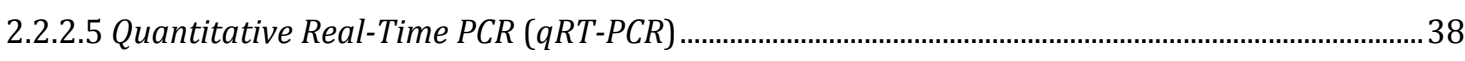

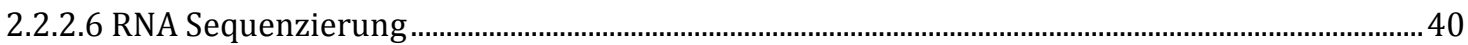

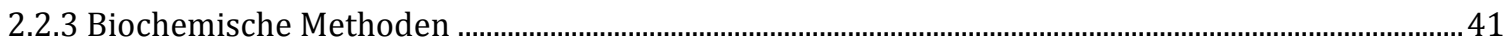

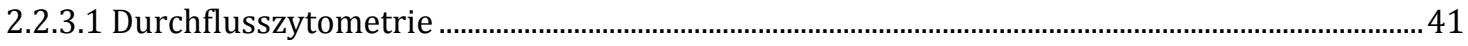

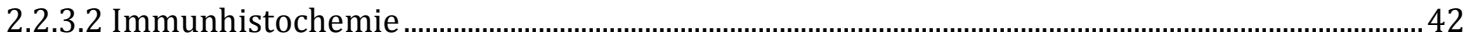

2.2.3.3 Messung der Viabilität und Proliferation anhand eines MTS Assays .........................................45

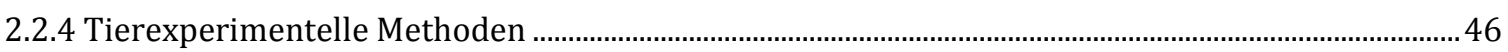

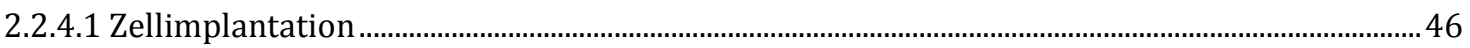

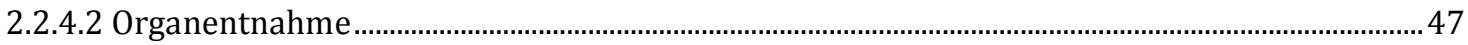

2.2.4.3 Isolation von BMDMs (Bone Marrow Derived Monocytes) .............................................................. 48

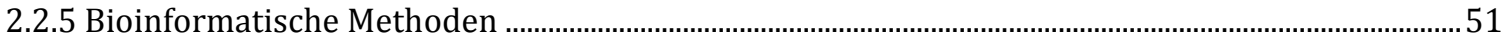

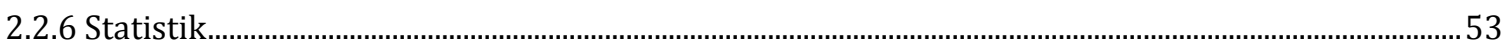

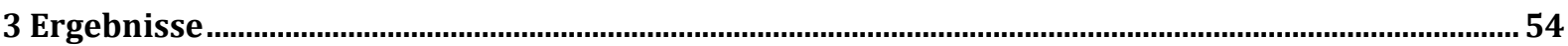

3.1 Etablierung eines Mausmodells zur Untersuchung von Lebermetastasen induziert durch die

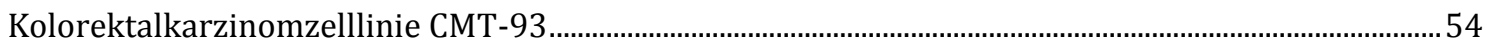

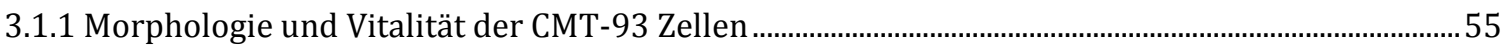

3.1.2 Einfluss verschiedener Implantationsmethoden auf den Metastasierungserfolg von CMT-93

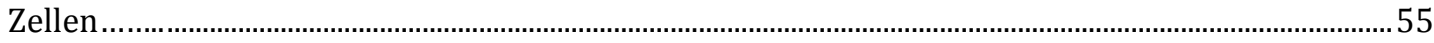

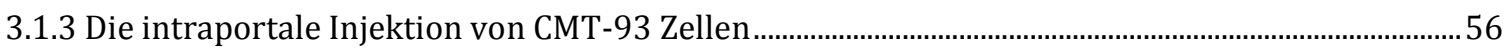

3.1.4 Phänotypische Eigenschaften von CMT-93 induzierten Lebermetastasen .........................................57

3.2 Expression von Genen und Signalwegen assoziiert mit CRC-induzierten Lebermetastasen..................58

3.2.1 Vergleich von CMT-93 Zellen und CMT-93 induzierten Lebermetastasen anhand bioinformatischer Genexpressionsanalysen........................................................................................ 58

3.2.2 Anwendung einer Selektionsliste relevanter Metastasen-assoziierter Gene auf die Genexpressionsdaten 62

3.2.3 Gene Ontology Analyse zur Identifikation von besonders aktiven Signalwegen .

3.3 Analyse des frühen, mittleren und späten Metastasierungsstadiums während der Kolonisation der Mausleber durch CMT-93 Zellen 
3.3.1 Makroskopische und mikroskopische Charakterisierung verschiedener Metastasierungsstadien im zeitabhängigen Verlauf der Leberkolonisation.

3.3.2 Molekularbiologische Charakterisierung von CMT-93 induzierten Metastasen im zeitabhängigen Verlauf der Leberkolonisation

3.3.2.1 Einfluss verschiedener Metastasierungsstadien auf die Morphologie und das Gewicht der Leber.

3.3.2.2 Expression von Metastasen-assoziierten Genen in verschiedenen Stadien der Metastasenformation

3.3.2.3 Expression von leber- und tumorspezifischen Genen und MMP-7 als Vertreter für „Extrazelluläre Matrixproteine“

3.3.2.4 Quantifizierung von Zellwachstums-, Proliferations- und Apoptosegenen ..... .73

3.3.2.5 Expression von Transkriptionsfaktoren/-regulatoren und EMT Markern 74

3.4 In vivo und in vitro Charakterisierung der Interaktion von Makrophagenphänotypen und CMT-93

Tumorzellen.

3.4.1 Bioinformatische Analysen zur Expression von Metastasen-assoziierten Genen und

Makrophagenphänotypen

3.4.1.1 Expression von Metastasen-assoziierten Genen in verschiedenen Arealen von CMT-93 kolonisierten Mauslebern

3.4.1.2 Expression von M1 und M2 Makrophagen in verschiedenen Arealen von CMT-93 induzierten Lebermetastasen.

3.4.2 Histologische Untersuchungen zur Lokalisation von Makrophagenphänotypen im Verlauf der Metastasenformation

3.4.3 Quantifizierung der Expression von M1 und M2 Makrophagen im Verlauf der Metastasenformation

3.5 In vitro Analysen zur Charakterisierung der Interaktion von Makrophagenphänotypen und CMT-93

Tumorzellen 85

3.5.1 Differenzierung und Polarisation von knochenmark-stämmigen Monozyten isoliert aus dem murinen Femur Richtung M1 und M2 Makrophagen

3.5.2 Einfluss des konditionierten Mediums von Makrophagenphänotypen auf die Zellviabilität von CMT-93 Tumorzellen

3.5.2.1 Inkubation von CMT-93 Zellen mit konditionierten Medien aus Isolation I ..............................90

3.5.2.2 Inkubation von CMT-93 Zellen mit konditionierten Medien aus Isolation II

3.5.2.3 Einfluss der konditionierten Medien von Makrophagenphänotypen auf die Expression von Metastasen-assoziierten Genen in CMT-93 Zellen

4.1 CMT-93 induziertes, syngenes und orthotopes Lebermetastasenmodell ...............................................95

4.2 Kolonisation der CMT-93 Zellinie in der Leber .....................................................................................95

4.3 Epitheliales und invasives Wachstumsmuster der CMT-93 induzierten Lebermetastasen...................96

4.4 Metastasierungspotential durch eine adaptive Hoch- und Herunterregulation von Genen..................98

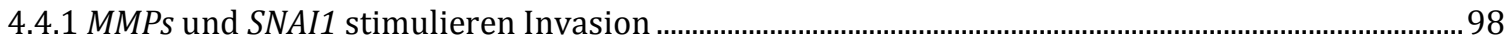

4.4.2 Chemokinrezeptoren und -liganden fördern Zellmigration und -wachstum ................................ 100

4.4.3 Integrine und Komponenten des Wht Signalweges steuern Zelladhäsion und Signaltransduktion 
4.4.4 Verminderte Caspase-3 und Fibronektin Expression ...................................................................... 101

4.5 Relevante Signalwege für die Formation von Lebermetastasen ........................................................... 102

4.6 Aggressivität von CMT-93 Zellen in verschiedenen Metastasierungsstadien ........................................ 103

4.6.1 Fibrin und Entzündungsreaktionen als initiale Mediatoren der Tumorinvasion .......................104

4.6.2 E-cadherin und Vimentin als Hauptmediatoren des zunehmend metastatischen Potentials.. 105

4.6.3 Aggressivität und das Invasionspotential von CMT-93 Zellen im frühen und späten

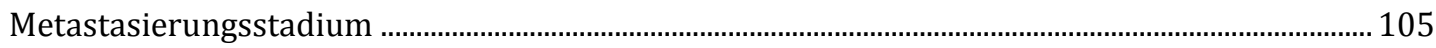

4.7 Divergierende Genexpressionsprofile von Tumor- und Lebergewebe ................................................. 107

4.8 Natur der Makrophagen mit zweischneidiger Interaktion ....................................................................... 109

4.8.1 Assoziation der Tumorprogression mit dem Zytokinprofil der Metastasen und der

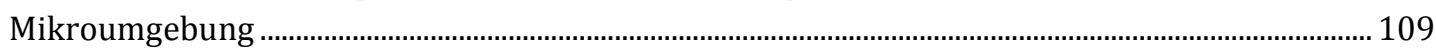

4.8.2 Tendenziell M2 geprägter Charakter der CMT-93 induzierten Lebermetastasen ......................... 110

4.8.3 Tumorstimulierender Einfluss von M2 konditioniertem Medium auf CMT-93 Zellen................. 113

4.9 Einfluss verschiedener Faktoren auf die Makrophagenpolarisation....................................................... 114

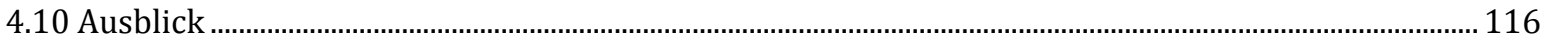

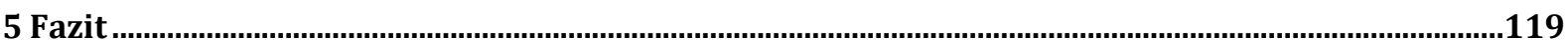

6 Literaturverzeichnis ..............................................................................................................................121

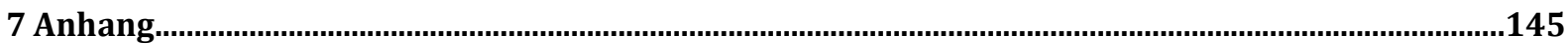




\section{Danksagung}

$\mathrm{Zu}$ allererst gebührt ein großer Dank meiner Doktormutter, Frau Prof. Dr. med. Sarah König, für ihr Vertrauen in meine Fähigkeiten, die vorzügliche Betreuung und ihre schier endlose Energie. Danke, dass Du immer die richtigen, motivierenden Worte gefunden, mir stets den Rücken gestärkt und dabei immer die richtige Balance zwischen einer intensiven Betreuung und dem Freiraum für meine eigenen Ideen gefunden hast. Ich bin sehr stolz, dass ich mit Dir arbeiten und von Dir lernen durfte.

Frau PD Dr. rer. nat. Petra Krause danke ich für die Einarbeitung in die tierexperimentellen Methoden und fachlichen Anregungen. Ein besonderer Dank gilt den Mitgliedern meines Thesis Committees, Frau Prof. Dr. med. Frauke Alves und Prof. Dr. rer. nat. Tim Beißbarth, die mich die letzten 3,5 Jahre stets mit ihrer Expertise, Motivation und konstruktiven Kritik begleitet haben.

Den MetastaSys Mitgliedern danke ich für die intensive Zusammenarbeit und das Vertrauen, das sie uns Doktoranden geschenkt und ihr Wissen aus so vielen Fachbereichen mit uns geteilt haben. Danke an Astrid Wachter, Darius Wlochowitz, Jetcy Arackal und Raquel Blazquez für den regen Austausch und eure Unterstützung. Ein ganz großes Dankeschön gebührt Alexander Wolff; ohne Deinen Beitrag wären Teile dieser Arbeit nicht entstanden und ich wäre um mein Bioinformatik„Grundwissen“ ärmer.

Besonders hervorheben möchte ich Sabine Niebert und Sabine Wolfgramm. Mein tiefster Dank gilt eurer Unterstützung, exzellenten Hilfestellung, Herzlichkeit, Loyalität und eurem Humor, mit denen ihr mich durch Höhen und Tiefen der letzten 3,5 Jahre begleitet habt. Ich bin sehr glücklich, euch als Freunde gewonnen zu haben.

Nicht zu vergessen sind Annette Witt, Caroline Breysach, Chan-Rong Lai, Malte Monin, Marina Komrakova, Ramona Castro-Machguth, Robin Stelling und Roswitha Streich, die mir stets mit Rat und Tat zur Seite gestanden haben; danke auch an euch!

Bei meinem Mentor, Dr. rer. nat. Arnd Steuernagel, bedanke ich mich ganz herzlich für zahlreiche Diskussionen über meine wissenschaftliche Arbeit und insbesondere über die Orientierung meines beruflichen Kompasses. Ich schätze sehr, dass ich von Ihrer Expertise und Erfahrung profitieren durfte.

Abschließend gilt mein tiefster Dank meiner Familie für die moralische, finanzielle und bedingungslose Unterstützung, den Rückhalt und die zeitweise nötige Ablenkung. Meinen Eltern, Fatma und Ferit, danke ich, dass sie mir und meinen Geschwistern aufopferungsvoll ermöglicht haben, unsere Ziele zu erreichen. Meiner Schwester Dilek und meinem Bruder Merih danke ich für die Motivation und den Rückhalt; danke, dass ihr so wahnsinnig tolle Vorbilder seid und mir immer wieder zeigt, wie sehr es sich lohnt, für die eigenen Ziele, Träume und Werte zu kämpfen. 


\section{Zusammenfassung}

Die Leber nimmt als Hauptzielorgan des metastasierenden Kolorektalkarzinoms (CRC) eine exponierte Rolle ein; bei mehr als 50 \% der betroffenen Patienten werden im Laufe ihrer Tumorerkrankung Lebermetastasen diagnostiziert, die trotz multimodaler Therapiekonzepte immer noch den fatalen Kranksheitsverlauf bestimmen. Zwecks Entwicklung neuer Therapiestrategien ist ein fundiertes Verständnis der Entstehungsmechanismen und des Genexpressionsprofils der Metastasen erforderlich. Makrophagen wird in diesem Kontext ein großer Einfluss auf die Tumorentstehung und progression zugeschrieben, weshalb von einer klinischen Relevanz der Makrophagenpolarisation auszugehen ist.

Im Rahmen der vorliegenden Arbeit wurde mit der CRC Zelllinie CMT-93 ein syngenes, orthotopes Lebermetastasenmodell in C57BL/6N Mäusen etabliert. Basierend auf RNA Sequenzierungsdaten und bioinformatischen Analysemethoden wurde eine Entwicklung und fein abgestimmte Adaptation der CMT-93 Zellen im Zuge ihrer Propagation im hepatischen Milieu nachgewiesen. Diese resultierte in divergierenden Genexpressionsprofilen zwischen Zelllinie und Metastasen. Von insgesamt 3329 differentiell exprimierten Genen wurden mittels einer Selektionsliste 32 signifikant exprimierte Gene identifiziert. Insbesondere Matrix-Metalloproteasen (MMP-2, -7, -9), Chemokinrezeptoren (CXCR2, CXCR4), Zelladhäsionsgene (ITGA6, ITGB3) sowie Wif1 als Feinregulator des kanonischen Wnt Signalweges nehmen eine bedeutende Rolle ein und tragen zum Invasions- und Metastasierungsprofil von CMT-93 Zellen unter dem Einfluss des Lebermilieus bei. Invasive und aggressive Eigenschaften der CMT-93 induzierten Lebermetastasen wurden insbesondere im frühen und späten Metastasierungsstadium nachgewiesen. Hier wurde u.a. die Expression der EMT Marker Vimentin, MMP-7 und CD44, Ki-67, NFkb1 und Stat3 untersucht. Eine Gene Ontology Analyse und RNA Sequenzierungsdaten verschiedener Leberareale zeigten, dass die vielschichtige Interaktion zwischen CMT-93 Zellen und der hepatischen Mikroumgebung u.a. durch immunregulatorische Prozesse gesteuert wird, die in veränderten Genexpressionsprofilen zwischen Zelllinie, Metastase und tumorumgebendem Gewebe resultiert. In Lebermetastasen konnte eine Mischpopulation aus M1 und M2 Makrophagen nachgewiesen werden, die einen tendenziell M2 geprägten Charakter aufweisen. Dieser ist höchstwahrscheinlich an einer Stimulation der invasiven Eigenschaften der Tumorzellen beteiligt. Durch $q R T-P C R$ und immunhistochemische Analysen konnten Hinweise gesammelt werden, dass nicht explizit die Quantität oder spezifische Lokalisation von Makrophagenphänotypen, sondern mutmaßlich eher das Zytokinprofil des Tumors und der Mikroumgebung und damit einhergehend der Polarisationsstatus der Makrophagen zum 
Metastasierungserfolg beiträgt. Eine Inkubation von CMT-93 Zellen mit konditionierten Medien der verschiedenen Makrophagenphänotypen bestätigte die Rolle sezernierter Faktoren. Eine indirekte Interaktion zwischen Tumorzelle und M2 Makrophagen reicht offensichtlich aus, um tumorstimulierende Eigenschaften, Aggressivität und Proliferationsfähigkeit der Zelllinie zu beeinflussen.

Somit wurden Gene und Signalwege identifiziert, die relevant sind für eine erfolgreiche Induktion und Progression von Lebermetastasen infolge der Implantation von CRC-Zellen. Eine Adaptation des Genexpressionsprofils der CMT-93 Zelllinie im Zuge der Leberkolonisation konnte nachgewiesen werden. Das molekulare Profil bzw. die Gensignatur der Metastasen korrelierte dabei in hohem Maße mit der Migrations- und Invasionsfähigkeit der Tumorzellen. Insbesondere die Anwendung bioinformatischer Methoden erwies sich dabei als nützliches Werkzeug zur Analyse von großen Datensätzen, die mittels RNA Sequenzierung generiert wurden. Diese werden nun zur Formulierung prädiktiver Modelle der Metastasierungsvorgänge genutzt, um deregulierte Gene und damit einhergehend die Aggressivität von Tumorzellen gezielt identifizieren und konsekutiv beeinflussen zu können. Eine Analyse der Makrophagenphänotypen und ihrer Interaktion mit Tumorzellen verdeutlichte den durchaus tumorstimulierend geprägten Charakter der CMT-93 induzierten Lebermetastasen und den Einfluss des Zytokinprofils auf die Tumorprogression. Eine weiterführende Untersuchung der Makrophagenpolarisation bedarf jedoch eine rigorose Charakterisierung der Phänotypen anhand weiterer spezifischer Marker. Die subtile Analyse wird Rückschlüsse der organspezifischen Einflüsse des Zytokinprofils auf die kolorektale Karzinogenese erlauben. 


\section{Abstract}

The liver is considered to be the primary target organ for hematogenous spread of colorectal cancer (CRC), as more than $50 \%$ of affected patients develop liver metastases during the course of their tumor disease. Due to the fact, that liver metastases do not respond sufficiently to current systemic therapies, there is a strong need for profound knowledge concerning the underlying mechanisms of metastases formation and their molecular profile aiming to generate new targeted therapy strategies. Based on their bimodal role and high level of plasticity macrophages are being considered to have a substantial impact on tumor progression. Thus, the polarization of macrophages is having a clinical relevance which has to be addressed in order to comprehend the tumor immunobiology and the underlying processes of generating macrophage phenotypes.

Within the scope of the present study a syngeneic and orthotopic liver metastasis model was established by inoculation of the colorectal cancer cell line CMT-93 via the portal vein in C57BL/6N mice livers. RNA Sequencing data and bioinformatical analysis demonstrated a clear evolution and well-orchestrated adaptation of the cell line on propagation in the liver environment resulting in diverging gene expression profiles of CMT-93 cells and corresponding metastases. 32 out of 3329 in total differentially expressed genes were identified by using a selection list to be significantly relevant for metastases formation. In particular, matrix metalloproteinases (MMP-2, -7, -9), chemokine receptors (CXCR2, CXCR4), cell adhesion genes (ITGA6, ITGB3) as well as Wif1 as a component of the canonical Wnt signaling pathway enhance the invasiveness and metastatic potential of CMT-93 cells. An invasive and aggressive growth pattern of CMT-93 induced liver metastases was revealed, especially in the early and late stage of metastases formation, by upregulation of genes/proteins such as Vimentin, MMP-7 and CD44 as EMT markers as well as Ki-67, NFkB1 and Stat3. Gene Ontology analysis and RNA Sequencing data of different liver areas determined immunoregulatory processes, among others, being responsible for a brisk and many-faceted interaction between CMT-93 cells and their hepatic microenvironment resulting in diverging gene expression profiles of the cell line, metastases and tumorsurrounding tissue. Analyses also revealed a mixed population of M1 and M2 macrophage phenotypes localized in liver metastases with a tendentially M2-shaped character. RNA Sequencing, $q R T-P C R$ and immunohistochemical analysis displayed the cytokine profile of tumors and their microenvironment concomitant with the polarization status of macrophages having a huge impact on metastases formation rather than an accurate number or specific localization of macrophage phenotypes. Coculture experiments of CMT-93 cells with conditioned media of macrophage phenotypes verified the role of secreted factors. An 
indirect, non-physical interaction between tumor cells and M2 macrophages is obviously sufficient to promote tumor stimulating properties, aggressiveness and proliferation abilities of tumor cells.

Taken all together genes and pathways have been identified, which can be considered to be involved in CRC induced liver metastases. CMT-93 cells displayed a well-orchestrated adaptation of their gene expression profile during the colonization of a foreign organ. A strong correlation of the gene signature of liver metastases with migration and invasiveness of tumor cells has been demonstrated. In particular, the implementation of bioinformatical methods turned out to be a great tool to analyze large amounts of data derived from RNA sequencing. Those data sets are now being used to establish predictive models for metastases formation. Thus, a targeted modification or inhibition of dysregulated genes followed by a diminished aggressiveness of tumor cells will be enabled. An analysis of macrophage phenotypes and their interaction with tumor cells elucidated a rather tumor promoting character of CMT-93 induced liver metastases and the impact of the cytokine profile on tumor progression. Nevertheless, a rigorous characterization of macrophage phenotypes and their polarization status needs to be addressed in further studies by using additional specific markers. Hereby, we will be able to deepen our knowledge regarding the organ specific influence of cytokine profiles in the context of colorectal cancer. 


\section{Abbildungsverzeichnis}

Abb. 1.1: Vogelstein-Hypothese zur genetischen Entstehung des sporadischen Kolorektalkarzinoms..........3

Abb. 1.2: Schritte der Entstehung von CRC-induzierten Lebermetastasen ............................................................9

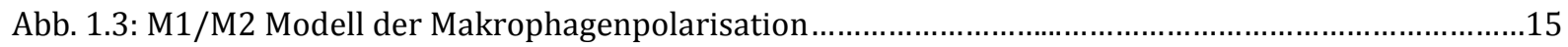

Abb. 2.1: Intraportale Implantation von Tumorzellen......................................................................... 47

Abb. 3.1: Schema der Etablierungsschritte eines in vivo Modells zur Untersuchung von Mamma- und CRCinduzierten Lebermetastasen.........................................................................................

Abb. 3.2: Morphologie und Vitalität von CMT-93 Zellen nach Applikation mit einer Micro-Fine ${ }^{\mathrm{TM}}$ Insulinspritze . .55

Abb. 3.3: Makroskopische und mikroskopische Charakterisierung von CMT-93 induzierten

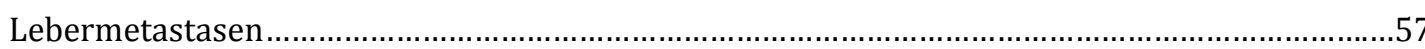

Abb. 3.4: Schematische Darstellung der Probenentnahme der CMT-93 induzierten Lebermetastasen.......59

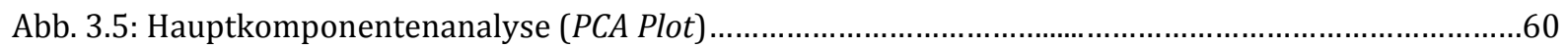

Abb. 3.6: Heatmap mit den Top 120 DEGs zwischen der CMT-93 Zelllinie, den CMT-93 induzierten Lebermetastasen und den makroskopisch tumorfreien Mauslebern. 61

Abb. 3.7: Heatmap zur Darstellung des Expressionsmusters von 32 Genen, die mit der Entstehung von

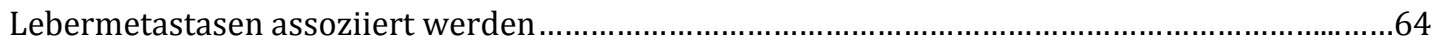

Abb. 3.8: Überblick der hochregulierten Gene in funktionellen Gruppen .....................................................66

Abb. 3.9: Überblick der herunterregulierten Gene in funktionellen Gruppen ...............................................66

Abb. 3.10: Darstellung der Top 20 Signalwege aus der GO Kategorie „Biologische Prozesse“ “.......................67

Abb. 3.11: Repräsentative ex vivo Aufnahmen von CMT-93 induzierten Lebermetastasen und entsprechenden Proben der Sham-operierten Mäuse

Abb. 3.12: Immunhistochemische Aufnahmen von CMT-93 induzierten Lebermetastasen und entsprechenden tumorentfernten Leberbereichen in verschiedenen Stadien der Metastasenformation

Abb. 3.13: Repräsentative ex vivo Aufnahmen von CMT-93 induzierten Lebermetastasen, die auf molekularbiologischer Ebene charakterisiert wurden

Abb. 3.14: Boxplot zum Vergleich des Lebergewichts von C57BL/6NCrl Mäusen nach CMT-93 Injektion..72

Abb. 3.15: Expression von Metastasen-assoziierten Genen im zeitlichen Verlauf der Leberkolonisation...75

Abb. 3.16: Boxplot zur molekularbiologischen Charakterisierung der verschiedenen Leberareale . .77

Abb. 3.17: Heatmap zur Darstellung von 126 differentiell exprimierten Genen in verschiedenen Leberarealen.

Abb. 3.18: Boxplot zur Genexpressionsanalysen von M1 und M2 Makrophagen in verschiedenen

Leberarealen.

Abb. 3.19: Histologische Lokalisation von allgemeinen Makrophagenmarkern in verschiedenen Metastasierungsstadien ...81

Abb. 3.20: Histologische Lokalisation von M1 und M2 Makrophagen im Verlauf der Metastasierung 82

Abb. 3.21: Expression von Makrophagen-spezifischen Genen in verschiedenen Stadien der Metastasenformation 
Abb. 3.22: Makroskopische Kontrolle des Differenzierungsstadiums von nicht-polarisierten

Makrophagen .85

Abb. 3.23: Durchflusszytometrische Kontrolle des Differenzierungsstatus von nicht-polarisierten Makrophagen 86

Abb. 3.24: Durchflusszytometrieanalyse zur Kontrolle der M1 und M2 Polarisation 89

Abb. 3.25: Überprüfung der Zellviabilität von CMT-93 Zellen nach Inkubation mit konditioniertem Medium aus Isolation I. 90

Abb. 3.26: Überprüfung der Zellviabilität von CMT-93 Zellen nach Inkubation mit konditioniertem Medium aus Isolation II. . .91

Abb. 3.27: Expression von zehn CRC-assoziierten Genen nach Inkubation mit konditionierten Medien der Makrophagenphänotypen 93

Abb. 8.1: Vegrößerte Aufnahmen der Metastasen aus Abb. 3.12. . .149

Abb. 8.2: Vegrößerte Aufnahmen der Metastasen aus Abb. 3.19. 150

Abb. 8.3: Vegrößerte Aufnahmen der Metastasen aus Abb. 3.20 .151 


\section{Tabellenverzeichnis}

Tab. 1.1: UICC-Klassifikation des kolorektalen Karzinoms........................................................................5

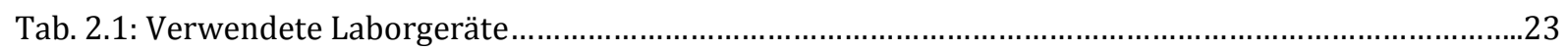

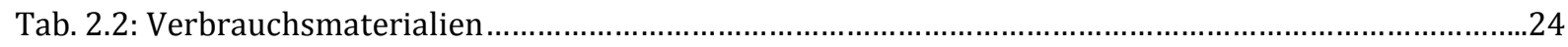

Tab. 2.3: Chemikalien und rekombinante Proteine ....................................................................................26

Tab. 2.4: Kulturmedium der verwendeten Zellinien ........................................................................27

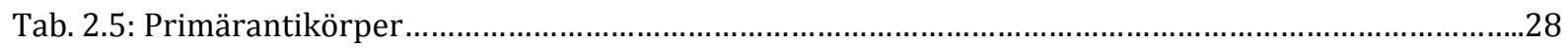

Tab. 2.6: Fluoreszenzfarbstoff-gekoppelte Antikörper und Isotypkontrollen ...........................................28

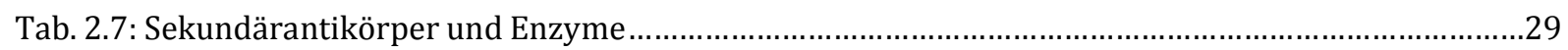

Tab. 2.8: Übersicht der verwendeten Oligonukleotide für $q R T-P C R$ Experimente.....................................29

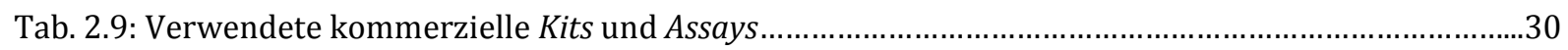

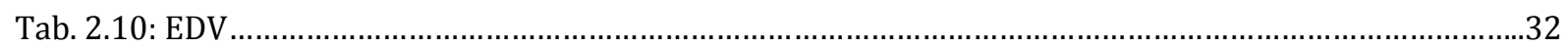

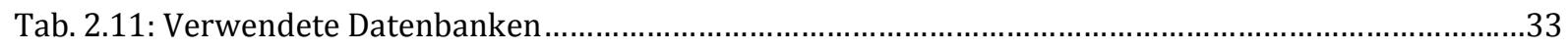

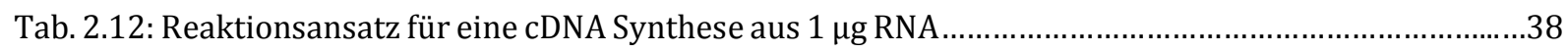

Tab. 2.13: Reaktionsansatz pro Gen für eine $q R T$-PCR Analyse......................................................................39

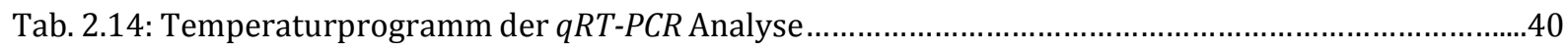

Tab. 2.15: Entparaffinieren und färben von Paraffinschnitten der Lebermetastasen ...................................44

Tab. 3.1: Vergleich verschiedener Implantationsmethoden zur Formation von CRC-induzierten

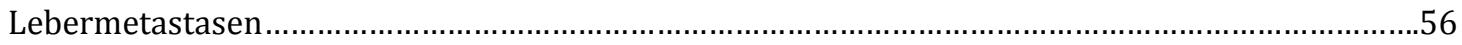

Tab. 3.2: Qualitätskontrolle der sequenzierten Maus- und Zelllinienproben ............................................59

Tab. 3.3: Anzahl differentiell exprimierter Gene zum Vergleich der CMT-93 Zellen mit den CMT-93

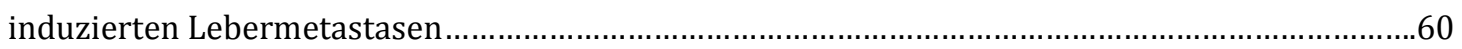

Tab. 3.4: Liste von 119 Metastasen-assoziierten Genen aus zehn funktionellen Gengruppen......................62

Tab. 3.5: Überblick über die selektionierten, signifikanten CRC-assoziierten Gene zwischen

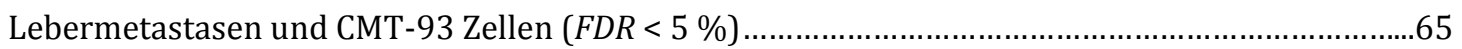

Tab. 3.6: Genliste zur molekularen Charakterisierung der CMT-93 induzierten Lebermetastasen...............70

Tab. 3.7: Genliste von Immunzellen für die RNA Sequenzierung .................................................................76

Tab. 3.8: Monozytenisolation I - Vergleich der Expressionsprofile der polarisierten (M1 und M2) und nicht-

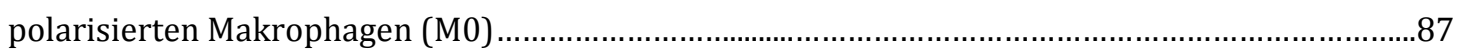

Tab. 3.9: Monozytenisolation II - Vergleich der Expressionsprofile der polarisierten (M1 und M2) und

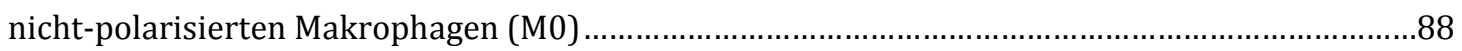

Tab. 3.10: Vergleich des Expressionsprofils der Makrophagen aus Isolation I und II...............................88

Tab. 8.1: Liste von 119 Metastasen-assoziierten Genen mit Angabe der entsprechenden funktionellen Gengruppe und Ensembl ID..... 145 


\section{Abkürzungsverzeichnis}

5-FU

Abb.

ad.

AEC

$A P C$

Aqua bidest

Aqua dest.

Axin2

B2M

$b c l$

BCL9

BMBF

$b p$

$B R A F$

bzw.

ca.

CASP3

CCLX

$C D x x$

cDNA

$c-M y c$

$\mathrm{CO}_{2}$

CPS1

CRC

CTLA-4

CTNNB1

$C_{t}$-Wert

CXCLX

CXCRX

CYP

DEG

DKK2

DMEM

DMSO

DNA

ECM

EdgeR

EDTA

EDV
5-Fluoruracil

Abbildung

addiere

3-Amino-9-ethylcarbazol

Adenomatous-polyposis-coli

Aqua bidestillata; zweifach destilliertes Wasser

Aqua destillata; destilliertes Wasser

Axin-related protein

B2-Mikroglobulin

base call files

B-cell CLL/lymphoma 9 protein

Bundesministerium für Bildung und Forschung

base pair; Basenpaar

B-Raf proto-oncogene

beziehungsweise

circa

Caspase-3

Chemokine (C-C motif) ligand $x$

Cluster of Differentiation

complementary DNA; komplementäre DNA

$v$-myc avian myelocytomatosis viral oncogene homolog

Kohlenstoffdioxid

Carbamoylphosphat-Synthase 1

Colorectal Cancer; Kolorektalkarzinom

Cytotoxic T-lymphocyte-associated Protein 4

Catenin (cadherin associated protein), beta 1

threshold cycle

Chemokine (C-X-C motif) ligand $x$

Chemokine ( $C$-X-C motif) receptor $x$

Cytochrom $\mathrm{p} 450$

Differentielle Genexpressionsanalyse; differentiell exprimierte Gene

Dickkopf WNT signaling pathway inhibitor 2

Dulbecco's modified eagle medium

Dimethylsulfoxid

Desoxyribonucleic acid; Desoxyribonukleinsäure

Extracellular matrix; extrazelluläre Matrix

Empirical Analysis of Digital Gene Expression Data in $R$

Ethylendiamintetraacetat

Elektronische Datenverarbeitung 


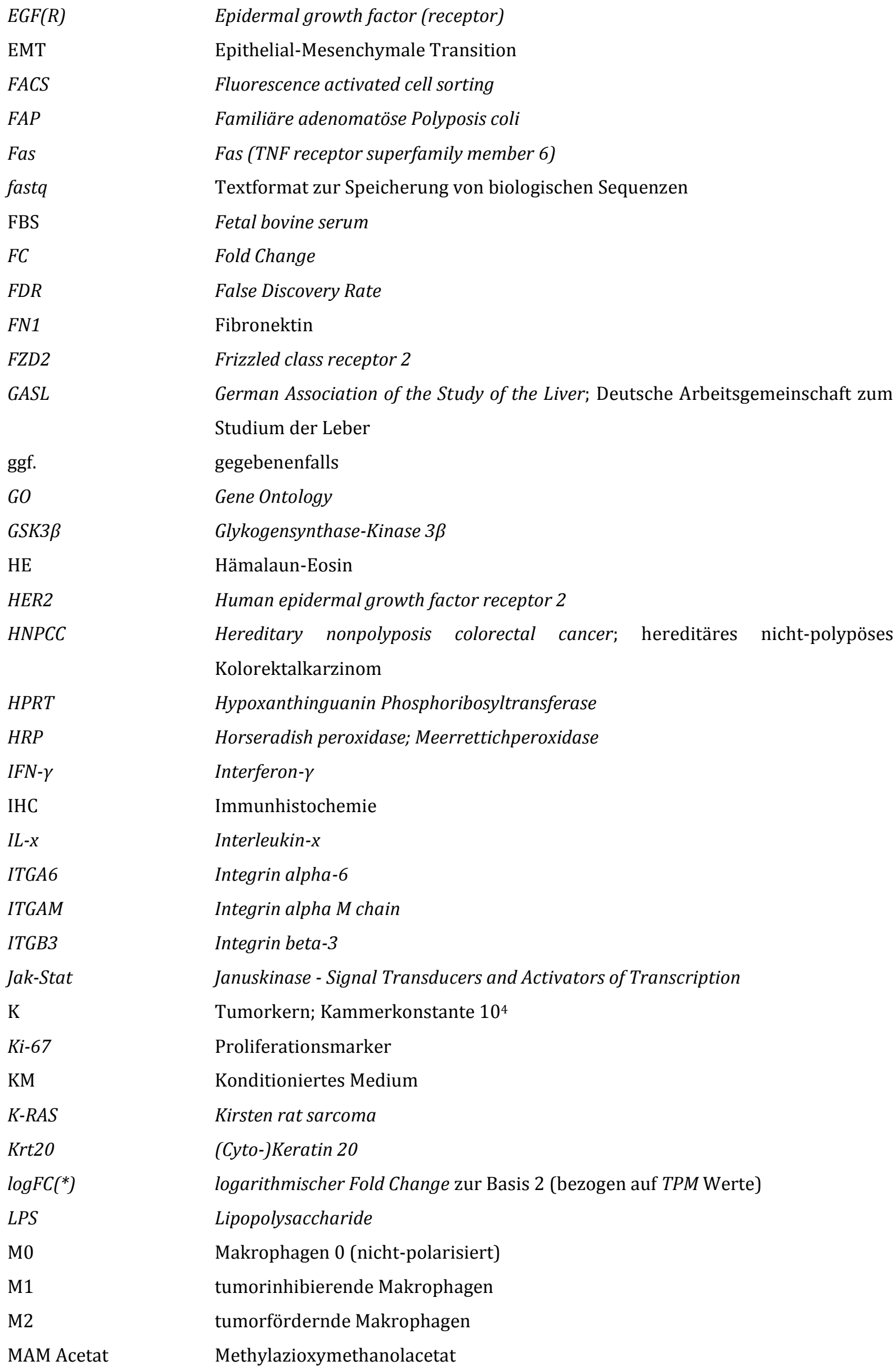

Fluorescence activated cell sorting

Familiäre adenomatöse Polyposis coli

Fas (TNF receptor superfamily member 6)

Textformat zur Speicherung von biologischen Sequenzen

Fetal bovine serum

Fold Change

False Discovery Rate

Fibronektin

Frizzled class receptor 2

German Association of the Study of the Liver; Deutsche Arbeitsgemeinschaft zum Studium der Leber

gegebenenfalls

Gene Ontology

Glykogensynthase-Kinase $3 \beta$

Hämalaun-Eosin

Human epidermal growth factor receptor 2

Hereditary nonpolyposis colorectal cancer; hereditäres nicht-polypöses Kolorektalkarzinom

Hypoxanthinguanin Phosphoribosyltransferase

Horseradish peroxidase; Meerrettichperoxidase

Interferon- $\gamma$

Immunhistochemie

Interleukin- $x$

Integrin alpha-6

Integrin alpha M chain

Integrin beta-3

Januskinase - Signal Transducers and Activators of Transcription

Tumorkern; Kammerkonstante $10^{4}$

Proliferationsmarker

Konditioniertes Medium

Kirsten rat sarcoma

(Cyto-)Keratin 20

logarithmischer Fold Change zur Basis 2 (bezogen auf TPM Werte)

Lipopolysaccharide

Makrophagen 0 (nicht-polarisiert)

tumorinhibierende Makrophagen

tumorfördernde Makrophagen

Methylazioxymethanolacetat 


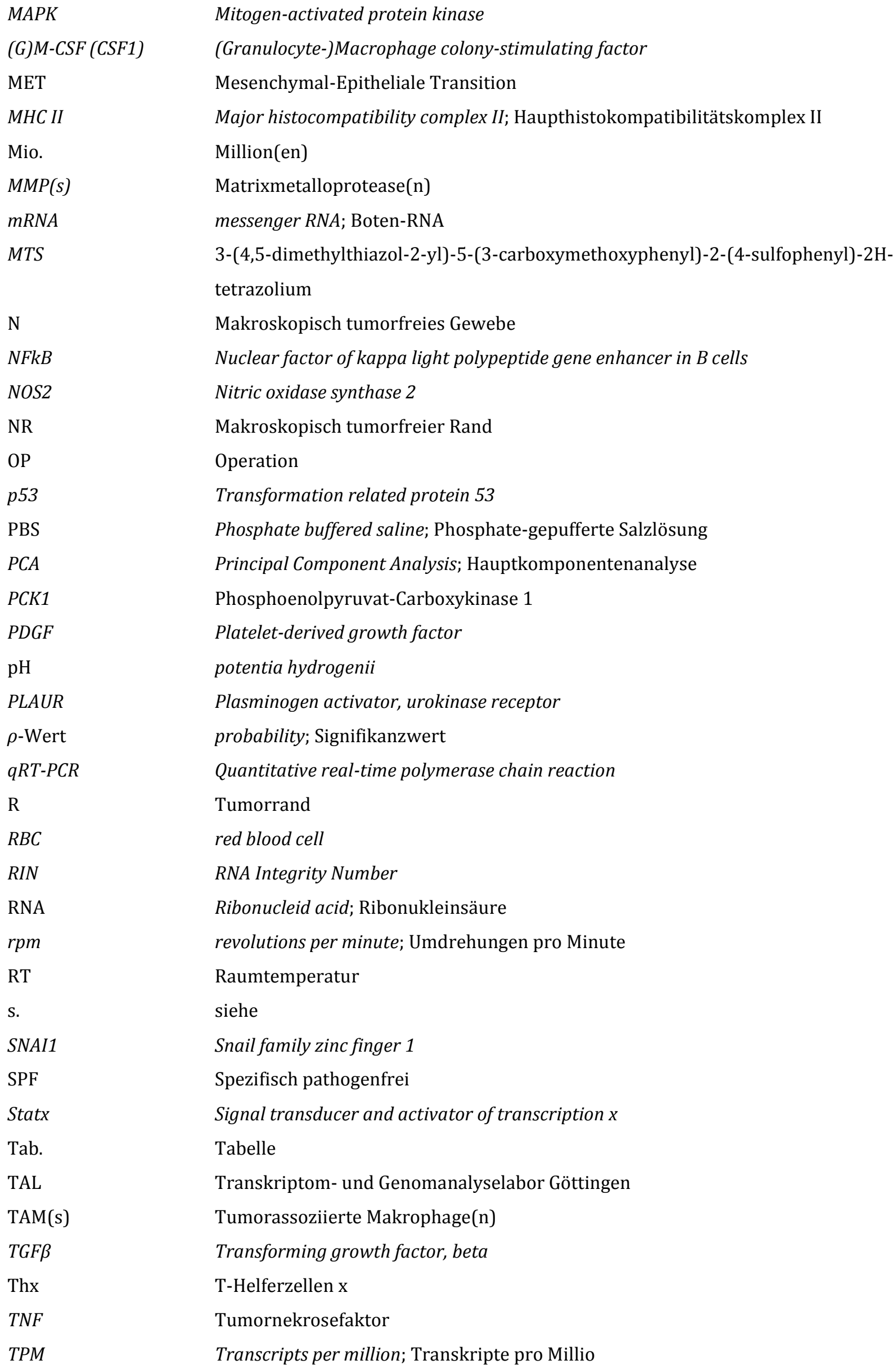

(G)M-CSF (CSF1)

MET

MHC II

Mio.

$M M P(s)$

$m R N A$

MTS

$\mathrm{N}$

$N F k B$

NOS2

NR

OP

p53

PBS

PCA

PCK1

$P D G F$

$\mathrm{pH}$

PLAUR

$\rho$-Wert

$q R T-P C R$

$\mathrm{R}$

$R B C$

RIN

RNA

rpm

RT

S.

SNAI1

SPF

Statx

Tab.

TAL

TAM(s)

$T G F \beta$

Thx

TNF

TPM

(Granulocyte-)Macrophage colony-stimulating factor

Mesenchymal-Epitheliale Transition

Major histocompatibility complex II; Haupthistokompatibilitätskomplex II

Million(en)

Matrixmetalloprotease(n)

messenger RNA; Boten-RNA

3-(4,5-dimethylthiazol-2-yl)-5-(3-carboxymethoxyphenyl)-2-(4-sulfophenyl)-2Htetrazolium

Makroskopisch tumorfreies Gewebe

Nuclear factor of kappa light polypeptide gene enhancer in B cells

Nitric oxidase synthase 2

Makroskopisch tumorfreier Rand

Operation

Transformation related protein 53

Phosphate buffered saline; Phosphate-gepufferte Salzlösung

Principal Component Analysis; Hauptkomponentenanalyse

Phosphoenolpyruvat-Carboxykinase 1

Platelet-derived growth factor

potentia hydrogenii

Plasminogen activator, urokinase receptor

probability; Signifikanzwert

Quantitative real-time polymerase chain reaction

Tumorrand

red blood cell

RNA Integrity Number

Ribonucleid acid; Ribonukleinsäure

revolutions per minute; Umdrehungen pro Minute

Raumtemperatur

siehe

Snail family zinc finger 1

Spezifisch pathogenfrei

Signal transducer and activator of transcription $x$

Tabelle

Transkriptom- und Genomanalyselabor Göttingen

Tumorassoziierte Makrophage(n)

Transforming growth factor, beta

T-Helferzellen $\mathrm{x}$

Tumornekrosefaktor

Transcripts per million; Transkripte pro Millio 
TRS

Twist

u.a.

UICC

$\operatorname{VEGF(R)}$

VE-Wasser

VS.

WHO

Wif1

Wnt

$W P(s)$

Z

z.T.

\section{Maßeinheiten:}

$\%$

${ }^{\circ} \mathrm{C}$

$\mathrm{cm}$

g

G

h

$\mathrm{Hz}$

$\mathrm{kg}$

l

mg

$\min$

$\mathrm{ml}$

$\mathrm{mm}$

$\mathrm{mM}$

$\mathrm{N}$

$\mathrm{n}$

ng

$\mathrm{nm}$

Sek.

$\mu \mathrm{g}$

$\mu \mathrm{l}$

$\mu \mathrm{m}$
Target Retrieval Solution

Basic helix-loop-helix transcription factor

unter anderem

Union international contre le cancer; Internationale Vereinigung gegen Krebs

Vascular endothelial growth factor (receptor)

vollentsalztes Wasser

versus

World Health Organization; Weltgesundheitsorganisation

Wht inhibitory factor 1

Wingless-type MMTV integration site family

Work Package(s)

Anzahl gezählter Zellen in vier Großquadraten

zum Teil

Prozent

Celsius

Zentimeter

Gramm; g-force (Fallbeschleinigung)

Gauge; Maßeinheit für Kanülendurchmesser

Stunden

Hertz

Kilogramm

Liter

Milligramm

Minute(n)

Milliliter

Millimeter

Millimolar

Stoffmengenkonzentration mol/l

Anzahl

Nanogramm

Nanometer

Sekunden

Mikrogramm

Mikroliter

Mikrometer 


\section{$1 \quad$ Einleitung}

\subsection{Das Kolorektalkarzinom - Inzidenz, Ätiologie und Risikofaktoren}

Krebserkrankungen des Dickdarms, des Mastdarms und seltenere Tumorerkrankungen des Afters werden unter dem Begriff Darmkrebs zusammengefasst (Robert Koch Institut 2012). Mehr als $95 \%$ dieser Erkrankungen stellen maligne Neoplasien des Dickdarms dar, die insbesondere das Colon und das Rektum betreffen, und in die Kategorie des kolorektalen Karzinoms (CRC) eingeordnet werden. Mit einer jährlichen Inzidenz von etwa 746.000 und 614.000 neuen Fällen bei Männern bzw. Frauen stellt das kolorektale Karzinom hinter dem Bronchial- und Mammakarzinom die dritthäufigste Krebserkrankung weltweit dar (Globocan 2012). In Deutschland erkrankten 2012 mehr als 62.000 Menschen an Darmkrebs, davon etwa 54 \% Männer und ca. 46 \% Frauen (Robert Koch Institut 2012). Das Erkrankungsrisiko wird durch eine Reihe von Faktoren erhöht. Demnach sind insbesondere Menschen in fortgeschrittenem Alter betroffen; mehr als $50 \%$ der Patienten sind älter als 70 Jahre, während lediglich $10 \%$ vor dem 55. Lebensjahr eine entsprechende Diagnose erhalten (Paschos et al., 2010; Robert Koch Institut, 2012). Weitere Faktoren wie Darmpolypen, Übergewicht, Tabakkonsum, Bewegungsmangel, Alkoholkonsum und eine Fehlernährung in Form von übermäßiger Kalorienzufuhr, ballaststoffarmer und fett- sowie fleischreicher Kost, können ebenfalls das Erkrankungsrisiko erhöhen (Haggar \& Boushey, 2009; Robert Koch Institut 2012). Trotz regionaler Abnahme der Mortalitätsraten durch frühzeitige Erkennung, verbesserte Therapiemöglichkeiten und gesteigerte Wahrnehmung der Bevölkerung (Edwards et al., 2009; Bosetti et al., 2011), stellte im Jahr 2012 das Kolorektalkarzinom mit 9 $\%$ die vierthäufigste Krebstodesursache dar (Globocan 2012). Die relative 5-JahresÜberlebensrate liegt weltweit bei 50 - 60 \% in beiden Geschlechtern (Machii \& Saika, 2014). Das Überleben und die Prognose werden dabei maßgeblich von der Metastasierung des Tumors beeinflusst. Bei mehr als 50 \% der betroffenen Patienten werden im Laufe ihrer Tumorerkrankung Lebermetastasen diagnostiziert (Jemal et al., 2007); dabei gelangen Tumorzellen in Folge einer hämatogenen Metastasierung über die Vena portae (Pfortader) in das hepatische Milieu und können schließlich die Leber kolonisieren (Chamber et al., 2002). In 20 - $25 \%$ der Fälle handelt es sich um synchrone Metastasen, die während der initialen Diagnose des Ursprungstumors detektiert werden. Bei weiteren 50 - 60 \% der Patienten können innerhalb von zwei Jahren nach der Erstdiagnose metachrone Lebermetastasen 
diagnostiziert werden, die im weiteren Verlauf der Behandlung bzw. als Folge eines Rezidivs entstanden sind (Fong et al., 1996; Kemeny, 2006; Leporrier et al., 2006; Cardona et al., 2013).

\subsection{Pathogenese des Kolorektalkarzinoms}

Die Entstehung des Darmkrebses resultiert aus verschiedenen genetischen Mutationen ausgehend von benignen Adenomen (Polypen) des Dickdarms (Muto et al., 1975; Kinzler \& Vogelstein, 1996). Lediglich 10 \% dieser Adenome entwickeln sich in einem Zeitraum von 5 10 Jahren zu einem Karzinom (Kozuka et al., 1975; Davies et al., 2005). Nichtdestotrotz beeinflussen u.a. Größe, histologischer Typ und Entdifferenzierungsgrad der Adenome die Entartungstendenz (O’Brien et al., 1990). Kolorektale Karzinome entstehen in etwa 90 - 95 $\%$ der Fälle sporadisch in Folge von neoplastischen Entwicklungsprozessen des Darmepithels, die initiiert werden durch die Akkumulation von genetischen Mutationen (Fearon \& Vogelstein, 1990). Neben der sporadischen Form werden zwei hereditäre Formen des Karzinoms beschrieben, die in etwa 5 - $10 \%$ der Fälle vorzufinden sind und zu einem früheren Zeitpunkt diagnostiziert werden können als die sporadische Form (Lynch \& Chapelle, 2003; Coleman \& Tsongalis, 2006). Verursacht werden sie entweder durch erbliche Prädispositionen, wie eine Keimbahnmutation, und resultieren in dem hereditären nichtpolypösen Kolorektalkarzinom (HNPCC) (Kinzler \& Vogelstein, 1996). HNPCC wird in der Regel um das 45. Lebensjahr diagnostiziert und kann die Entstehung weiterer gastrointestinaler Karzinome induzieren. Oder es treten aufgrund einer Mutation des Tumorsuppressorgens Adenomatous-polyposis-coli (APC) spezifische genetische Syndrome auf, die eine obligate Präkanzerose wie der Familiären adenomatösen Polyposis coli (FAP) initiieren. Betroffene Patienten entwickeln in jungen Jahren Adenoma in erheblicher Anzahl; werden diese nicht behandelt, kann um das 40. Lebensjahr ein Kolorektalkarzinom detektiert werden (Weitz et al., 2005). Auch die chronisch-entzündlichen Darmerkrankungen Colitis ulcerosa und Morbus Crohn können das Risiko für die Entstehung eines Kolorektalkarzinoms erhöhen; dies trifft auf etwa $5 \%$ der an CRC-erkrankten Patienten zu (Weitz et al., 2003).

Der Entstehungsvorgang wurde in den frühen 1950er Jahren in dem sogenannten Konzept der Adenom-Karzinom-Sequenz zusammengefasst (Jackman \& Mayo, 1951) und die damit einhergehende Gewebeveränderung erstmals mittels einer endoskopischen Polypektomie bewiesen (Deyhle, 1980). Vogelstein und Fearon entwickelten im Zuge dessen ein genetisches Stufenmodell zur Veranschaulichung der kolorektalen Karzinogenese (Vogelstein et al., 1988; Fearon \& Vogelstein, 1990; Vogelstein \& Kinzler, 1993; Fearon, 2011). Demnach induziert die 
Aktivierung von Protoonkogenen und die Inaktivierung von Tumorsuppressorgenen eine Entwicklung des normalen Epithels zu einem Kolorektalkarzinom. Nach der VogelsteinHypothese sind mindestens sieben genetische Veränderungen zu erwarten, bevor eine kolorektale Tumorprogression initiiert wird (Kinzler \& Vogelstein, 1996). In Abbildung (Abb.) 1.1 ist das Stufenmodell für das sporadische Kolorektalkarzinom dargestellt.

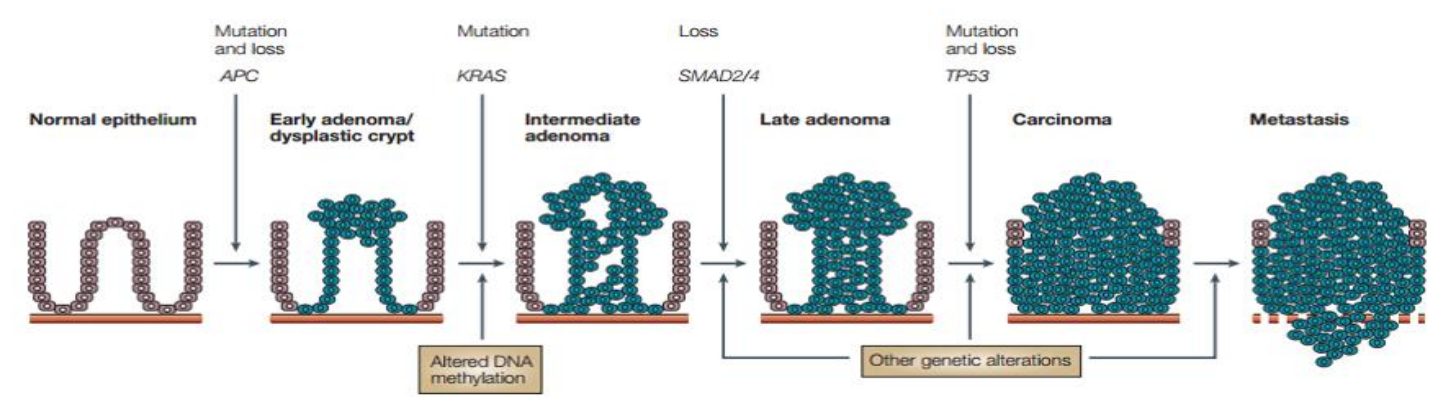

Abb. 1.1: Vogelstein-Hypothese zur genetischen Entstehung des sporadischen Kolorektalkarzinoms. Dargestellt ist die neoplastische Progression des normalen Darmepithels zu Adenomen gefolgt von der dysplastischen Progression zum kolorektalen Karzinom. Verursacht wird die Karzinogenese durch eine Reihe von akkumulierten Genmutationen, beginnend mit der initialen konstitutiv aktivierenden $A P C$ Mutation. Das Kolorektalkarzinom kann schließlich durch weitere genetische Veränderungen in einer Metastasierung resultieren. Abb. nach Davies et al., 2005.

Eines der Schlüsselgene der kolorektalen Karzinogenese stellt das APC Gen dar, welches als Bestandteil des Wht Signalweges ein unkontrolliertes Zellwachstum verhindert (Nagase \& Nakamura, 1993). Im Zusammenhang mit dem CRC wird dem APC Protein eine besondere Rolle zugeschrieben, da etwa 50 \% der Menschen, die eine entsprechende Mutation des Gens aufweisen, kolorektale Adenome entwickeln (Ransohoff \& Lang, 1991). Eine APC Mutation wurde erstmals in FAP Patienten nachgewiesen und als entscheidender Initiator („Gatekeeper“) für die sporadische Karzinogenese identifiziert (Kinzler \& Vogelstein, 1997; Davies et al., 2005).

In über $80 \%$ der sporadischen Kolorektalkarzinome ist eine APC Mutation nachweisbar (Miyoshi et al., 1992; Powell et al., 1992; Smith et al., 1993), die zu einer Akkumulation des zweiten Schlüsselgens $\beta$-catenin im Zellkern führt. Diese resultiert in einer Aktivierung des Wht Signalweges und somit in einer stimulierten und unkontrollierten Zellproliferation (Smits et al., 1999), die eine Neoplasie des Darmepithels begünstigt. Mutationen im $\beta$-catenin Gen CTNNB1 können in $10 \%$ der kolorektalen Karzinome nachgewiesen werden; diese können den Abbau der GSK3 $\beta$ Phosphorylierungsstellen verursachen, die eine konstitutive Aktivierung des Wnt Signalweges zur Folge hat (Morin et al., 1997). 
Der epidermal growth factor receptor (EGFR) Signalweg ist ebenfalls an der Tumorentwicklung und -progression beteiligt. Sobald Liganden an EGFR binden, werden Zellzyklus-kontrollierende Gene reguliert. In der EGFR-Signalkaskade befindet sich u.a. das Protoonkogen Kirsten rat sarcoma (K-RAS) downstream des EGF-Rezeptors. Eine Mutation dieses Gens tritt in 40 - 50 \% der Kolorektalkarzinome auf und aktiviert konstitutiv den mitogen-activated protein kinase (MAPK) Signalweg, so dass die Zellproliferation stimuliert wird (Bos et al., 1987; Adreyev et al., 1998). Die Karzinogenese wird in diesem Fall nur initiiert, wenn die Mutation im Anschluss an eine APC Mutation auftritt (Vogelstein \& Kinzler, 2004), weshalb das Gen als prädiktives Onkogen für metastasierte Kolorektalkarzinome in der Routinediagnostik etabliert ist (Lièvre et al., 2006; Stintzing et al., 2009). Bei einer fehlenden K-RAS Mutation können CRC Patienten beispielsweise mit dem monoklonalen Antikörper Cetuximab behandelt werden. Dieser bindet EGFR und inhibiert dessen Aktivität, so dass die Zellproliferation und somit die Tumorprogression deutlich verlangsamt werden (Humblet, 2004; Heinemann et al., 2009).

Transforming growth factor beta (TGF $\beta$ ) ist ein Zytokin, das anti-proliferative Eigenschaften in epithelialen Zellen hat und über den SMAD Signalweg Apoptose induzieren kann (Massagué, 2008). SMAD Proteine leiten Signale der TGF $\beta$ Liganden in den Zellkern und aktivieren die Transkription von Apoptose-spezifischen Genen. Sind beispielsweise SMAD 2 und/oder SMAD 4 mutiert, findet eine unkontrollierte Zellproliferation statt (Fleming et al., 2013), die in einer Karzinogenese resultiert.

Ein weiteres Gen, dass häufig an der Tumorentstehung beteiligt ist, stellt das p53 Gen dar. Dieser Tumorsuppressor ist im Zuge der DNA-Reparatur und Apoptose von zentraler Bedeutung; in 50 - 70 \% der Kolorektalkarzinome, jedoch nicht in Adenomen, ist das Gen mutiert vorzufinden (Fearon \& Vogelstein, 1990; Iacopetta, 2003). Daher ist davon auszugehen, dass die Genmutation zu einem späten Zeitpunkt der Karzinogenese initiiert wird. Als Folge werden defekte Zellen nicht mehr repariert und kein kontrollierter Zelltod eingeleitet, so dass eine deregulierte Zellproliferation stattfindet und somit eine Neoplasie eingeleitet wird (Davies et al., 2005).

Zusätzlich zu dem Stufenmodell nach Fearon und Vogelstein sind sogenannte De novo Karzinome beschrieben, die durch flache Läsionen ohne adenomatöse Reste charakterisiert sind. Sie werden vermutlich durch alternative genetische Veränderungen mit beispielsweise weniger K-RAS Mutationen hervorgerufen (Kudo et al., 2000; Umetani et al., 2000).

Histologisch werden nach $W H O$-Klassifikation drei Darmkrebstypen unterschieden; $95 \%$ werden demnach in die Kategorie der Adenokarzinome zugeordnet, zu denen etwa 85 - 95 \% 
der kolorektalen Karzinome gehören. Diese entwickeln sich aus dem Drüsengewebe des Darmepithels und weisen azinäre sowie papilläre Strukturen auf. Anhand des WHO GradingSystems werden sie in vier Differenzierungsgrade eingeordnet. Des Weiteren werden zwei Unter- bzw. Sonderformen beschrieben. Das muzinöse Adenokarzinom wird in $10-15 \%$ der Fälle diagnostiziert und zeichnet sich durch eine erhebliche Anzahl schleimbildender Zellen aus. Das Siegelringkarzinom hat eine Häufigkeit von $1 \%$; hier verursachen Zellen eine übermäßige intrazelluläre Ansammlung von Schleim, so dass sie eine siegelringähnliche Form einnehmen (Durst \& Rohen, 1998).

\section{$1.3 \quad$ UICC-Klassifikation}

Anhand der Vorgaben der „Internationalen Vereinigung gegen Krebs“ (Union internationale contre le cancer, UICC) werden Tumore nach einer Prognose-orientierten TNM-Klassifikation basierend auf statistischen Untersuchungen in Stadien unterteil. Auf diese Weise wird eine prognostische Aussage über die Tumorerkrankung und die weitere Therapie ermöglicht. In Tabelle (Tab.) 1.1 sind die UICC-Stadien des Kolorektalkarzinoms gemeinsam mit der entsprechenden TNM-Klassifikation und den 5-Jahres-Überlebensraten erfasst.

Tab. 1.1: UICC-Klassifikation des kolorektalen Karzinoms. T entspricht dem Tumor; je höher die Zahl, desto stärker die Ausbreitung des Tumors in der Darmwand oder im umliegenden Gewebe. N entspricht Nodus; je höher die Zahl, desto mehr Lymphknoten sind betroffen. M entspricht Metastasen und spiegelt mit M0 das Fehlen bzw. mit M1 das Vorhandensein von Fernmetastasen wider (modifiziert nach Wittekind \& Meyer, 2010).

\begin{tabular}{ll|lll}
\hline UICC-Klassifikation & \multicolumn{2}{l}{ TNM-Klassifikation } & \\
Stadium & $\begin{array}{l}\text { 5-Jahres- } \\
\text { Überlebensraten }\end{array}$ & Tiefeninvasion & Lymphknotenbeteiligung & Fernmetastasen \\
\hline $\mathbf{0}$ & & $\mathrm{T}$ (s & $\mathrm{N} 0$ & $\mathrm{M} 0$ \\
Ia, Ib & $\sim 80-100 \%$ & $\mathrm{~T} 1, \mathrm{~T} 2$ & $\mathrm{~N} 0$ & $\mathrm{M} 0$ \\
II & $\sim 60-80 \%$ & $\mathrm{~T} 3, \mathrm{~T} 4$ & $\mathrm{~N} 0$ & $\mathrm{M} 0$ \\
III & $\sim 30-60 \%$ & $\mathrm{~T} 1-\mathrm{T} 4$ & $\mathrm{~N} 1, \mathrm{~N} 2$ & $\mathrm{M} 0$ \\
IV & $\sim 0-57 \%$ & $\mathrm{~T} 1-\mathrm{T} 4$ & $\mathrm{~N} 1-\mathrm{N} 3$ & $\mathrm{M} 1$ \\
\hline
\end{tabular}

Im Rahmen dieser Arbeit wurde die hämatogene Metastasierung in das hepatische Milieu induziert, um die Formation von Fernmetastasen des Kolorektalkarzinoms (Tab. 1.1, grau hinterlegt) und die umliegende Tumormikroumgebung zu analysieren. 


\subsection{CRC-induzierte Metastasierung}

Die Metastasierung ist das Resultat eines mehrstufigen Prozesses, bei dem sich maligne Zellen des Primärtumors absiedeln, über verschiedene Routen in weitere Organe gelangen und sich an die jeweilige Mikroumgebung anpassen (Wan et al., 2013). Das Vorhandensein derartiger Fernmetastasen hat einen erheblichen Einfluss auf die Prognose bzw. das Überleben des Patienten (s. Tab. 1.1 Stadium IV). Denn trotz Fortschritte in chirurgischen Techniken und verbesserter multimodaler Therapiekonzepte, sterben $90 \%$ der betroffenen Patienten an den Folgen progressiver Metastasen, die resistent sind gegen aktuelle Therapien (Sporn, 1996; Langley \& Fidler, 2007). Die molekularen Mechanismen, die in Tumorzellen metastatische Eigenschaften induzieren, sind noch weitestgehend ungeklärt. Nichtsdestotrotz kann die Metastasierung als eine komplexe Interaktion zwischen Tumorzellen, dem umliegenden Gewebe und dem Immunsystem betrachtet werden (Van den Eynden et al., 2013). 1889 beschrieb Stephen Paget anhand seiner Seed-and-Soil Theorie die Präferenz von Tumorzellen für bestimmte Organe. Diesen Organotropismus studierte er an Autopsiedaten von Brustkrebspatientinnen, die zu einem übermäßigen Anteil Knochenmetastasen aufwiesen. Er folgerte daraus, dass eine Metastasierung ermöglicht bzw. begünstigt wird, wenn Tumorzellen („seed") eine spezifische Affinität für die Mikroumgebung des Zielorgans (,,soil") haben (Paget, 1889). In diesem Kontext werden heute Progenitorzellen, tumor-initiierende Zellen, Krebsstammzellen und metastatische Zellen als „seed“ beschrieben, während „soil“ über den Wirtsorganismus, das Stroma, die Nische oder die organspezifische Mikroumgebung definiert wird (Langley \& Fidler, 2007; Talmadge \& Fidler, 2010).

Der Metastasierungsprozess wird anhand von zwei Modellen beschrieben. Nach dem linearen Progressionsmodell der Metastasierung findet aus dem Primärtumor eine metastatische Dissemination zu einem späten Zeitpunkt der Karzinogenese statt (Chambers et al., 2002). Demnach könnte ein extrinsischer Selektionsprozess maligne Zellen des Primärtumors auswählen, die metastatische Fähigkeiten aufweisen. Diese würden weitere Mutationen akkumulieren, die ihnen einen Überlebensvorteil bieten. Sofern sie eine passende Nische („soil“) gefunden haben, könnten sie somit weitere Organe kolonisieren und dort erneut ihr Genexpressionsprofil anpassen, so dass heterogene Tumore entstehen (Nguyen et al., 2009; Talmadge \& Fidler, 2010). Metastase und Primärtumor würden dennoch aufgrund des gemeinsamen Ursprungs Ähnlichkeiten in ihrem Genexpressionsprofil aufweisen (Weigelt et al., 2003). 
Nach dem parallelen Progressionsmodell der Metastasierung entwickeln sich disseminierte Zellen unabhängig vom Primärtumor zu einem frühen Zeitpunkt der Karzinogenese. Demnach kolonisieren verschiedene Tumorklone parallel unterschiedliche Organe (Klein, 2009). Folglich weisen Primärtumor und Metastase deutliche Unterschiede in ihrem Genexpressionsprofil auf (Vecchi et al., 2008). Dies wird durch aktuelle Sequenzierungsstudien belegt, die signifikante Unterschiede im Expressionsprofil von Primärtumor und Metastase verdeutlichen (Shah et al., 2009).

Die anfangs beschriebene Akkumulation von genetischen Mutationen in verschiedenen Stadien der Tumorprogression korrelieren mit der Aggressivität einer Tumorzelle („seed“). In Vergleichsanalysen zeigten Expressionsprofile von metastatischen und nicht-metastatischen Zellen differentiell exprimierte Gene, die assoziiert werden mit dem Metastasierungspotential der Zelle (Yokota, 2000). Anfang der 1980er wurden bereits phänotypische Veränderungen und Resistenzen gegenüber Chemotherapeutika in verschiedenen Subklonen einer Melanommetastase beschrieben. Man vermutete, dass metastatische Zellen im Gegensatz zu benignen Zellen eine erheblich hohe Anzahl an spontanen Mutationen akkumulieren können und dadurch eher $\mathrm{zu}$ phänotypischen Veränderungen sowie Resistenzen neigen (Talmadge et al., 1984). Aktuelle Transkriptomanalysen in humanen Adenokarzinomen und entsprechenden Metastasen deuten an, dass das Genexpressionsprofil des Primärtumors prognostische Aussagen über die Aggressivität der Metastase ermöglichen und dass das Vorhandensein von spezifischen Genmustern im Primärtumor eine schlechte Prognose für den Patienten darstellt (Ramaswamy et al., 2003; Lim et al., 2015). Dies würde bedeuten, dass nicht nur vor Ort stattfindende spontane Mutationen in malignen Zellen der Metastase die Aggressivität bestimmen; auch früh in der Karzinogenese akkumulierte Mutationen im Primärtumor würden demnach die Metastasierungsfähigkeit einzelner Zellen und somit die Patientenprognose definieren.

Neben den Eigenschaften der Tumorzelle, beeinflusst die Mikroumgebung im Zielorgan der Metastase („soil“) ebenfalls den Erfolg der Metastasierung und das Ausmaß der Aggressivität. Im Zusammenhang mit Mamma- und Kolorektalkarzinomen ist beispielsweise bekannt, dass beide Tumorentitäten in der Lage sind trotz unterschiedlicher epidemiologischer Merkmale hämatogen in das Gehirn und in die Leber zu metastasieren. Sie unterscheiden sich jedoch in der Organpräferenz; demnach metastasiert der besonders aggressive basal-like Brustkrebssubtyp („triple-negative“; Östrogen-, Progesteron- und HER2-Rezeptoren fehlen) bevorzugt in das Gehirn, während über 50 \% der CRC Patienten Lebermetastasen entwickeln (Schouten et al., 2002; Jemal et al., 2007). Diese unterschiedliche Präferenz wird 
möglicherweise verursacht durch gewebespezifische Gegebenheiten, die das Metastasieren von verschiedenen Tumorentitäten stark oder begrenzt begünstigen. Die tatsächlich zugrundeliegenden Mechanismen und Ursachen sind jedoch weitestgehend ungeklärt.

Der Metastasierungsvorgang zeichnet sich durch sequentielle Schritte aus, der mit dem Ablösen der Tumorzellen aus dem Zellverband beginnt. In Abb. 1.2 ist die Route der Kolorektalkarzinomzellen aus dem Darm über die Pfortader in die Leber dargestellt. Die hämatogene Streuung der Tumorzellen resultiert hier in der Formation von hepatischen Metastasen. Das Kolorektalkarzinom liegt zunächst als Folge einer lokalen Invasion in einem lockeren, undifferenzierten Zellverband vor und interagiert mit dem Stroma. In Stadium IV ist der Tumor in der Lage über Gefäße des Lymph- und Blutsystems Fernmetastasen zu induzieren. Hierfür lösen sich Tumorzellen aus dem Zellverband, indem sie mit Hilfe von Proteasen einen proteolytischen Abbau der Extrazellulären Matrix (ECM) hervorrufen; Cadherine und Catenine begünstigen ebenfalls den Abbauvorgang (Brooks et al., 2010). Matrix-Metalloproteasen werden dabei sowohl von Tumorzellen und Fibroblasten exprimiert als auch von Makrophagen synthetisiert (Ito et al., 1995; Swallow et al., 1996). Die Wanderung der Zellen wird durch einen Phänotypwechsel begünstigt, der in einer EpithelialMesenchymalen Transition (EMT) resultiert. Tumorzellen können durch die Herunterregulation von Adhäsionsmolekülen, wie E-cadherin, und das Auflösen von Zellkontakten ihre epithelialen Eigenschaften verlieren, um die Migration bzw. die Zellmotilität zu erleichtern (Guarino et al., 2007). Mit Hilfe von Integrinen heften sie sich an die Basalmembran und migrieren zu Endothelzellen der Blutbahn. Bei einer hämatogenen Metastasierung folgt nun die Intravasation in ein Blutgefäß. Im Falle der Formation von Lebermetastasen gelangen die Zellen in die Vena portae und werden als zirkulierende Tumorzellen durch das Blutsystem in das hepatische Milieu geführt, indem sie an endotheliale Adhäsionsmoleküle binden (Zetter, 1993). Dabei nutzen sie über Selektine auch die Interaktion mit Thrombozyten, die den Tumorzellen die Adhäsion und Migration in das Parenchym des Zielorgans erleichtern (Haeuselmann et al., 2016). In der systemischen Blutzirkulation sind sie Einflüssen, wie mechanischem Druck, Kollision mit anderen Zellen und Immunzellangriffen ausgesetzt (Vekemans \& Braet, 2005). Überleben sie diese, heften sie sich in der Leber angekommen erneut mit Hilfe von Integrinen und Adhäsionsproteinen an Endothelzellen der Blutbahn, migrieren durch die Basalmembran und gelangen im Zuge der Extravasation mit Hilfe von Kollagenasen und Membranrezeptoren, wie beispielsweise CD44, in das hepatische Stroma (Brooks et al., 2010). Parallel dazu müssen Tumorzellen den Abwehrmechanismen des Immunsystems entgehen und Apoptosemechanismen inhibieren 
(Bacac \& Stamenkovic, 2008). Es findet nochmals ein Phänotypwechsel in Form einer Mesenchymal-Epithelialen Transition (MET) statt; maligne Zellen können nun wieder ZellZell-Kontakte eingehen und invasiv zunächst zu einer Mikrometastase wachsen (Yang \& Weinberg, 2008). Sie induzieren eine Neubildung von Blutgefäßen (Angiogenese), um eine Versorgung mit Nährstoffen zu gewährleisten und kolonisieren die Leber, so dass sie schließlich zu einer klinisch detektierbaren Läsion wachsen und dabei hepatisches Gewebe verdrängen (Zetter et al., 1993; Brooks et al., 2010).

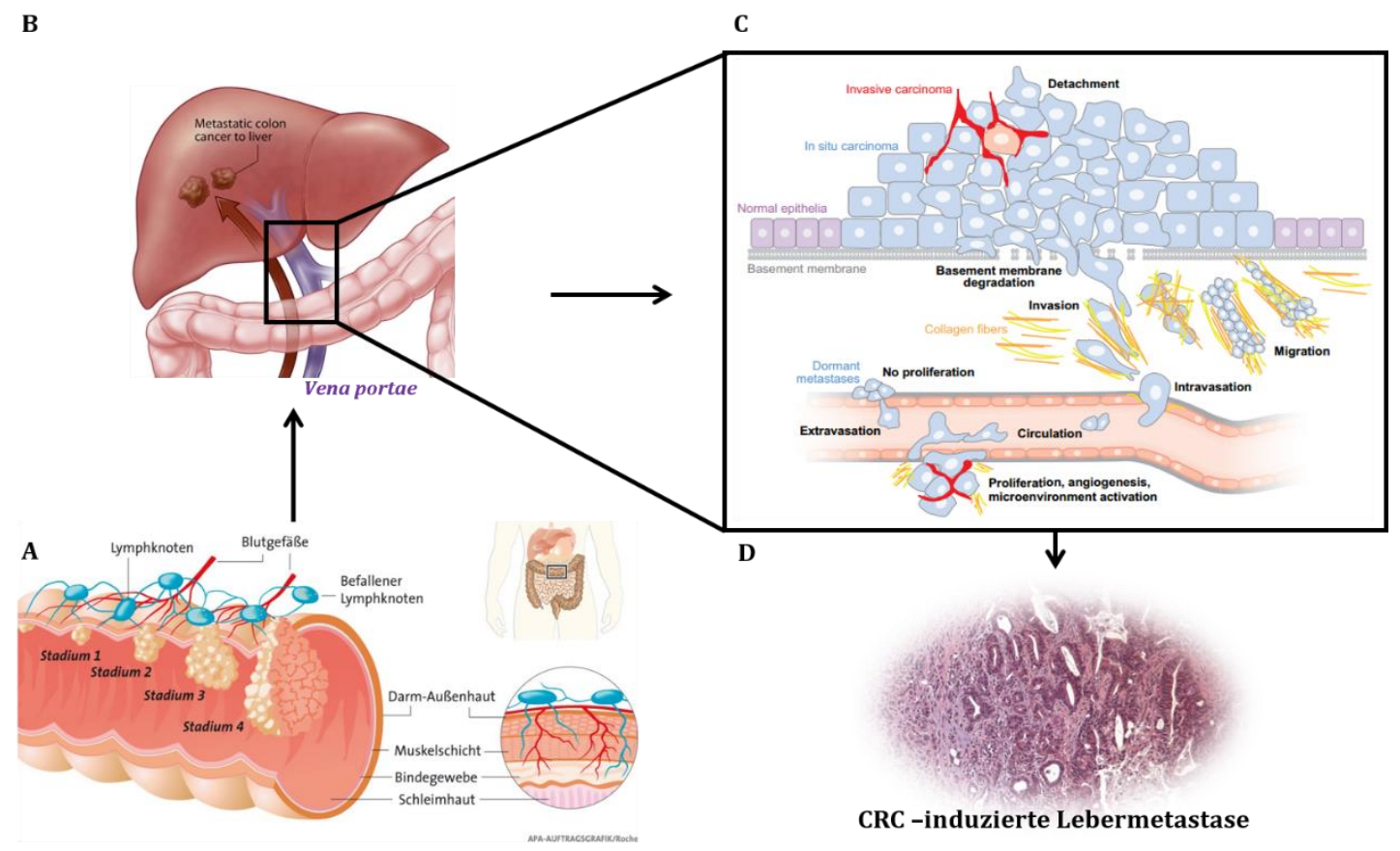

Abb. 1.2: Schritte der Entstehung von CRC-induzierten Lebermetastasen. Disseminierte Tumorzellen des Kolorektalkarzinoms Stadium IV ( $\left.\mathbf{A}^{\mathbf{1}}\right)$ gelangen in die Vena portae und werden im Zuge der Blutzirkulation in die Leber transportiert ( $\mathbf{B}^{2}$ ). Dort migrieren sie in das Zielgewebe ein (C modifiziert nach Bacac \& Stamenkovic, 2008) und proliferieren im hepatischen Milieu, so dass ein neuer Zellverband aus malignen Zellen entsteht (D).

Die Metastasierung ist ein höchst ineffizienter Vorgang, da lediglich 0,01 \% der zirkulierenden Tumorzellen in das Zielgewebe gelangen und dort Metastasen formen (Fidler, 1970). Insbesondere die Initiation des Zellwachstums im Zielorgan scheint der kritischste Schritt für disseminierte Tumorzellen zu sein (Chambers et al., 1995). Ein Teil dieser Zellen geht dort in eine Latenzzeit über (dormacy), wenn sie eine ungünstige Mikroumgebung vorfinden,

\footnotetext{
1 (C) Roche Austria_APA-Darstellung_Darm; (C) Roche Austria_APA-Darstellung_Darmkrebs

2 Illustration Copyright (C) 1998-2003 by The Johns Hopkins Health System Corporation and The Johns Hopkins University; used with permission from the Johns Hopkins Division of Gastroenterology and Hepatology (www.hopkinsmedicine.org/gi). Illustration created by Mike Linkinhoker.
} 
während andere beispielsweise die Initiation der Angiogenese verfehlen (Barkan et al., 2010). Bei ruhenden Tumorzellen wird vermutet, dass sie durch eine komplexe Kombination aus intrinsischen und extrinsischen Prozessen aktiviert werden und proliferieren (Li et al., 2007). Diese Prozesse induzieren eine genetische Weiterentwicklung und Adaptation sowie eine Selektion der Tumorzellen, die ihre Mikroumgebung am besten nutzen können (Allan et al., 2006). Folglich ist der Metastasierungserfolg nicht nur von den Eigenschaften der Tumorzelle alleine abhängig, sondern auch von der Interaktion zwischen Tumorzelle und Mikroumgebung.

\subsection{Therapie und Prognose des Kolorektalkarzinoms}

Das kolorektale Karzinom wird sowohl chirurgisch als auch medikamentös behandelt. Das therapeutische Konzept richtet sich dabei nach der Lokalisation sowie dem Stadium des Tumors. Die chirurgische Resektion des Primarius erfolgt im frühen, lokal begrenzten Stadium sowie auch in der Regel im späten Stadium nach der Induktion von Fernmetastasen. Ziel ist dabei eine En-Bloc-Resektion des Primärtumors gemeinsam mit den tumoradhärenten Organen inklusive der Entfernung von mindestens 12 Lymphknoten, um das regionäre Lymphabflussgebiet zu eliminieren. Eine medikamentöse Behandlung in Form einer adjuvanten Chemotherapie mit 5-Fluoruracil (5-FU) bzw. eine Kombination aus 5-FU, Folinsäure und Oxaliplatin wird ab Stadium II bzw. III empfohlen. Mit fortschreitendem Stadium nimmt jedoch die 5-Jahres-Überlebensrate deutlich ab (siehe Tab. 1.1) (S3-Leitlinie Kolorektales Karzinom 2014).

Im Falle des metastasierten Kolorektalkarzinoms können die Heilungschancen ebenfalls durch operative Eingriffe in Form einer hepatischen Resektion erhöht werden, so dass die relative 5-Jahres-Überlebensrate bei 25 - 40 \% liegt (Jonas et al., 2007; Paschos et al., 2010). Eine derartige Resektion von Lebermetastasen ist jedoch nur möglich, wenn im Anschluss an die Resektion genügend Organparenchym übrigbleibt. Dieser Eingriff ist daher lediglich bei einem Drittel der Patienten durchführbar (Bentrem et al., 2005; Koshariya et al., 2007). Können Metastasen nicht behandelt werden, reduziert sich die Lebenserwartung auf weniger als ein Jahr (McLoughlin et al., 2006). Erschwerend kommt hinzu, dass 70 \% der Resektionen im Zuge der Leberregeneration das Tumorwachstum stimulieren, so dass Rezidive begünstigt werden (Harun et al., 2014). Eine medikamentöse Behandlung erfolgt hier in Form einer neoadjuvanten Chemotherapie, um vor einem chirurgischen Eingriff eine Verkleinerung der Metastase $\mathrm{zu}$ erzielen und die operative Resektion $\mathrm{zu}$ erleichtern. Eine adjuvante 
Chemotherapie schließt sich an die Resektion der Metastase an, um eventuell bereits nichtdetektierbare, disseminierte Zellen des Primärtumors innerhalb der Restleber oder auch in anderen Organen abzutöten. Eingesetzt werden auch hier die Zytostatika 5-Fu, Folinsäure und Oxaliplatin. Des Weiteren können gegen EGFR gerichtete monoklonale Antikörper wie Cetuximab und Panitumumab bzw. der gegen VEGF (Vascular Endothelial Growth Factor) gerichtete Antikörper Bevacizumab verwendet werden. Falls inoperable Metastasen vorhanden sind, wird eine palliative Chemotherapie als lebensverlängernde und lebensqualitätserhaltende Maßnahme empfohlen (S3-Leitlinie Kolorektales Karzinom 2014).

Die Metastasierung stellt somit den stärksten prognostischen Faktor des Kolorektalkarzinoms dar und hat einen erheblichen Einfluss auf die Überlebensraten. Da zirkulierende sowie ruhende Tumorzellen bildgebend noch nicht detektiert und im diagnostischen Vollbild befindliche Metastasen resistent auf systemische Therapien reagieren können (Saunus et al. 2011), besteht ein großer Bedarf, neue Diagnostik- und Therapiestrategien zu entwickeln, fundiertes Wissen zum molekularen Profil und zu den Entstehungsmechanismen der Metastasen zu erlangen. Darauf basierende, neue Therapieansätze könnten gezielt die Prognose und Überlebenswahrscheinlichkeit verbessern und Mortalitätsraten minimieren.

\subsection{Die Leber als immunologisches Organ}

Da die Leber das initiale bzw. postoperative Hauptzielorgan des metastasierenden Kolorektalkarzinoms darstellt, wird nun der Aufbau und die Funktion des Organs in diesem Abschnitt näher betrachtet.

Makroskopisch wird die Leber in vier Lappen unterteilt; diese sind umgeben von einer bindegewebigen Außenhülle, die als Glisson-Kapsel bezeichnet wird. Die Leber besteht aus Leberläppchen, die eine Zentralvene mit konzentrisch angeordneten Leberbälkchen beinhalten. Letztere bestehen wiederum aus säulenartig aufgereihten parenchymalen Zellen (Hepatozyten), die durch blutgefüllte Lebersinusoide voneinander getrennt sind (AbdelMisih \& Bloomston, 2010). Hepatozyten stellen mit ca. 60 \% die größte Zellgruppe dar und machen etwa 80 \% des gesamten Lebervolumens aus (Vekemans \& Braet, 2005). Die nichtparenchymalen Zellen haben einen Anteil von 20 - $40 \%$ und bestehen aus sinusoidalen Endothelzellen (50 \%), Kupfferzellen (20\%), Lymphozyten (25\%), biliären Zellen (5\%) und Sternzellen/Ito-Zellen (<1 \%) (Racanelli \& Rehermann, 2006). Jeweils drei Leberläppchen 
bilden gemeinsam sogenannte Glisson-Trias und enthalten zwei blutzuführende Gefäße sowie intrahepatische Gallengänge (Abdel-Misih \& Bloomston, 2010).

Als das größte Stoffwechselorgan und die größte Verdauungsdrüse im menschlichen Organismus steuert die Leber maßgeblich die Verwertung von Nahrungsbestandteilen, die Synthese von lebenswichtigen Proteinen sowie den Abbau und die Ausscheidung von Giftstoffen und Stoffwechselprodukten (Abdel-Misih \& Bloomston, 2010). Die Versorgung erfolgt über zwei große Blutgefäße. Während die Leberarterie (Arteria hepatica propria) sauerstoffreiches Blut vom Herzen transportiert und somit die Bindung an die systemische Blutzirkulation gewährleistet, stellt die Pfortader (Vena portae) die Verbindung zum Gastrointestinaltrakt her und transportiert 80 \% der hepatischen Blutzufuhr (Bowen et al., 2005; Vekemans \& Braet, 2005). Nährstoffe, mikrobielle Bestandteile, aber auch potenziell schädliche Pathogene aus Magen und Darm gelangen auf diesem Wege in die Leber. Gleichzeitig werden auch Hormone der Bauchspeicheldrüse und Abbauprodukte der Milz befördert. Abbauprodukte des Blutes werden schließlich über Lebergallengänge ausgeschieden (Abdel-Misih \& Bloomston, 2010). Da das Organ kontinuierlich potenziellen Pathogenen und Nahrungsmittelantigenen ausgesetzt ist, muss es gleichzeitig als komplexes immunologisches Organ agieren (Bowen et al., 2005). Auch maligne Zellen stellen in diesem Sinne eine potentielle Gefahr dar. Disseminierte Zellen des Kolorektalkarzinoms werden über die Pfortader in das hepatische Milieu geführt. Dort angekommen, passieren sie zunächst endotheliale Zellen, die die Lebersinusoide umgeben. Dann gelangen sie in den sogenannten Disse'schen Raum, der den Stoffaustausch zwischen der Blutzirkulation und den Hepatozyten gewährleistet. Nach der Migration durch die Basallamina gelangen die Zellen in das Parenchym und somit auch in Kontakt zu den Hepatozyten (Racanelli \& Rehermann, 2006) und formen dort eine Mikro- und schließlich Makrometastasen.

Bei der Primariusresektion des Kolorektalkarzinoms können vitale Tumorzellen aufgrund der Manipulationen während des chirurgischen Eingriffs über die Pfortader in das hepatische Milieu ausströmen (Roberts et al., 1960). Hinzu kommt, dass ein chirurgischer Eingriff auch eine transiente postoperative Schwächung des Immunsystems induzieren kann, welche schließlich die Migration der Zellen in die Leber weiter begünstigt (Sasson \& Sigurdson, 2002).

Um sich vor potenziellen Pathogenen schützen zu können, ist die Leber an der peripheren Immunregulation beteiligt (Bowen et al., 2005). Sie enthält eine Reihe von Immunzellen, die dem adaptiven und angeborenen Immunsystem zuzuordnen sind. Dazu gehören T-Zellen (63 \%), Natürliche Killerzellen (31\%), leberresidierende Makrophagen (Kupfferzellen) (20\%) 
und B-Zellen (6 \%) (Racanelli \& Rehermann, 2006). Ihre Hauptfunktion besteht darin, eine effektive Immunantwort gegenüber Pathogenen sowie eine immunologische Toleranz gegenüber harmlosen Antigenen zu initiieren. Diejenigen Faktoren, die eine nötige Balance determinieren, sind jedoch weitestgehend ungeklärt (Bowen et al., 2005).

Neben den bereits vorhandenen, residierenden Makrophagen, werden im Zuge einer Immunantwort, wie beispielsweise als Reaktion auf eine Entzündung oder eine Karzinogenese, weitere Makrophagen aus dem Blut bzw. aus weiteren Geweben rekrutiert (Tacke \& Randolph, 2006). Trotz einer Vielzahl von immunregulatorischen Prozessen, die in der Leber stattfinden und an denen diverse Zellen des Immunsystems beteiligt sind, liegt der Fokus dieser Arbeit auf der Rolle der residierenden und rekrutierten Makrophagen. In den folgenden Abschnitten wird nun das Spektrum der Makrophagenphänotypen und ihre Funktion beschrieben.

\subsubsection{Entstehung und Funktion von Makrophagen}

Makrophagen sind ca. $20 \mu \mathrm{m}$ große, amöboid bewegliche, einkernige Zellen, die ursprünglich bereits 1863 von Kranid Slavjanski in Lungenbläschen von Kaninchen entdeckt wurden (Slavjansky, 1863). Ihre phagozytierenden Eigenschaften wurden 1880 erstmals von Ilya Metchnikoff beschrieben, der somit die Bedeutung der Zellen für die Immunantwort prägte (Nathan, 2008). Dabei handelt es sich um plastische Zellen, die in allen Geweben vorzufinden sind und unterschiedlichste Aufgaben im hämatopoetischen System übernehmen, wie beispielsweise die Zerkleinerung von Zellrückständen oder körperfremden Strukturen durch Phagozytose. Ihre Hauptfunktion ist die Verarbeitung und Präsentation von Antigenen dieser Strukturen, um auf diese Weise eine Antwort des adaptiven Immunsystems zu initiieren. Des Weiteren sind sie auch an der Induktion und Heilung von Entzündungsprozessen sowie an Gewebereparaturmechanismen beteiligt und tragen somit erheblich zur Aufrechterhaltung der Homöostase bei (Mosser \& Edwards, 2008).

Makrophagen gehen aus der Differenzierung von evolutiv hochgradig konservierten Monozyten hervor, die sich im Zuge von Stimuli aus myeloiden Vorläuferzellen im Knochenmark entwickeln und ausgeschwemmt werden (Geissmann et al., 2010). Monozyten zirkulieren somit im Blutkreislauf, sind jedoch in erheblicher Anzahl sowohl in der Milz als auch in der Lunge vorzufinden, so dass sie bei Bedarf in weitere Gewebe rekrutiert werden können (Swirski et al., 2009). In Folge eines Stimulus, wie beispielsweise einer Infektion oder eine Entzündung, erfolgt mittels Chemotaxis eine Monozytenrekrutierung zum Infektionsort, wo sie durch weitere Stimuli zu antigenpräsentierenden Zellen bzw. Makrophagen 
differenzieren. Die Differenzierung findet unter dem Einfluss von Antigenen und Wachstumsfaktoren, wie pro-inflammatorischen Zytokine, statt (Tacke \& Randolph, 2006). Der Großteil der Makrophagen ist ortsständig und somit an ein spezifisches Gewebe gebunden; so sind Kupfferzellen nur in der Leber vorzufinden, während Mikrogliazellen im Gehirn lokalisiert sind (Davies et al., 2013). Anhand ihrer Oberflächenproteine, sowie ihres Zytokin- und Genexpressionsprofils, können Monozyten und Makrophagen durchflusszytometrisch und immunhistochemisch identifiziert und differenziert werden; im murinen System eignen sich da beispielsweise u.a. CD11b und F4/80 (Tsou et al., 2007; Francke et al., 2011).

\subsubsection{Makrophagendiversität und -polarisation}

Je nachdem, welchem Stimulus Zellen ausgesetzt sind, entstehen verschiedenartige reife Makrophagen, die sich in ihrem Expressionsprofil unterscheiden und verschiedene immunologische Aufgaben erfüllen (Mantovani et al., 1992; Gordon \& Taylor, 2005; Mantovani et al., 2007). Stimuli können von der lokalen Mikroumgebung ausgehen und hervorgerufen werden durch Zellschäden, aktivierte Lymphozyten, mikrobielle Bestandteile oder auch eine Zytokinsekretion. So wurde in den 1990er Jahren entdeckt, das Interleukin (IL)-4 in Makrophagen ein anderes Expressionsprofil induziert als Interferon (IFN)- $\gamma$ und Lipopolysaccharide (LPS). Folglich entstand das Konzept der klassisch (IFN- $\gamma$ ) und alternativ aktivierten Makrophagen (IL-4) (Stein et al., 1992; Martinez und Gordon, 2014). In den darauffolgenden Jahren wurde die Makrophagendifferenzierung im Kontext des Arginin- und Ornithinmetabolismus weiter charakterisiert, so dass Mills et al. 2000 die Klassifikation in M1 und M2 Makrophagen vorschlugen. In der wissenschaftlichen Gemeinschaft folgte daraufhin diesbezüglich ein Konsens: die M1 Klassifikation beinhaltet klassisch aktivierte Makrophagen, die inflammatorische bzw. entzündungsfördernde Funktionen aufweisen (Sindrilaru et al., 2011). Alternativ aktivierte Makrophagen werden hingegen in die M2 Klassifikation zugeordnet und zeichnen sich durch anti-inflammatorische bzw. entzündungshemmende Funktionen aus (Solinas et al., 2009). Letztere wurden 2004 nochmals in M2a, M2b, M2c und M2d Subtypen unterteilt (Mantovani et al., 2004). Abbildung 1.3 zeigt eine Übersicht verschiedener Stimuli, die eine Makrophagenpolarisation initiieren. 


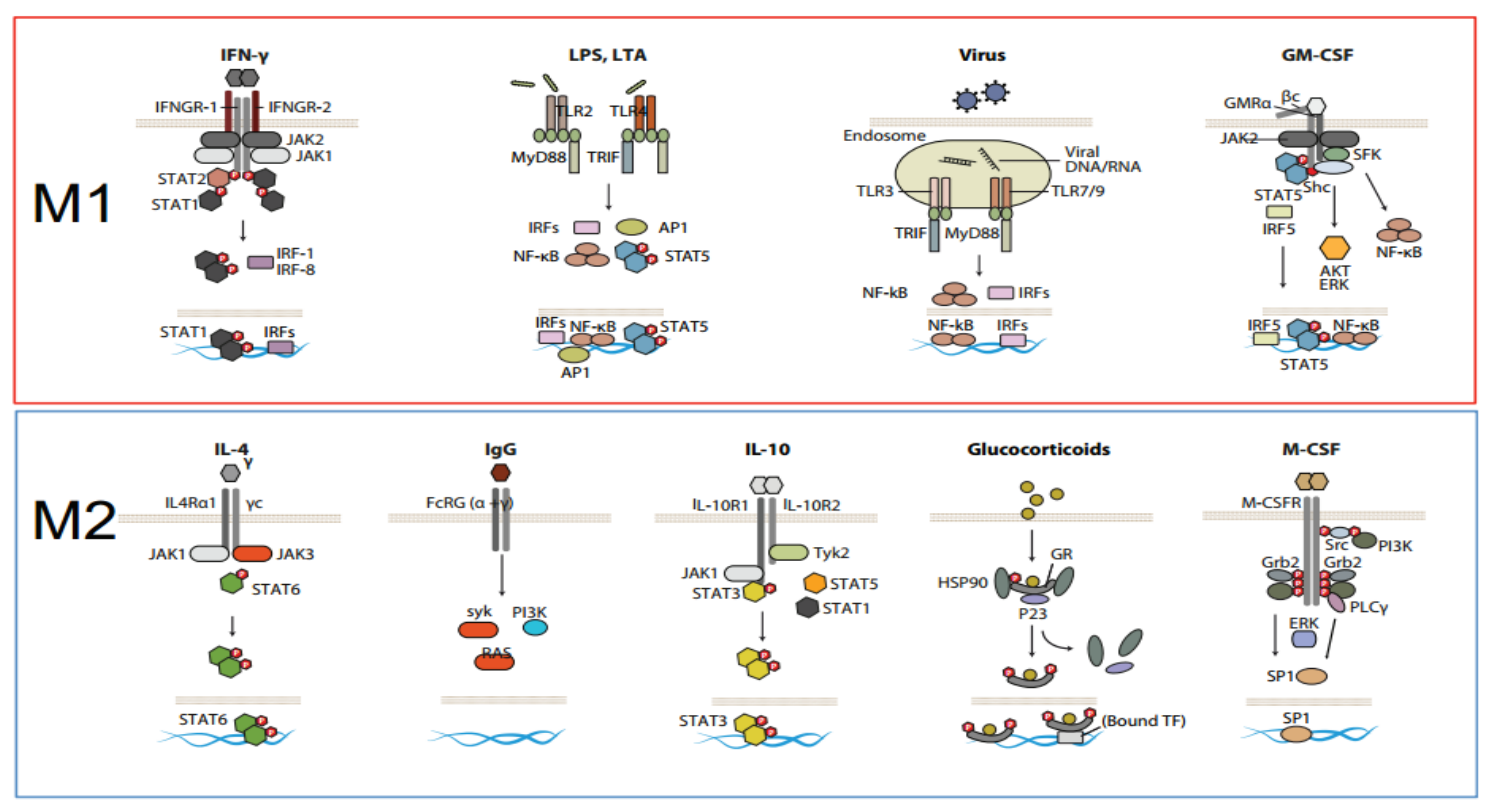

Abb. 1.3: M1/M2 Modell der Makrophagenpolarisation. Je nach Stimulus werden Makrophagen zum M1 oder M2 Phänotypen polarisiert. In Folge der Polarisation werden Signalkaskaden initiiert, so dass unterschiedliche Rezeptoren und Signalmoleküle an der Signalübertragung beteiligt sind. Abb. nach Martinez \& Gordon, 2014.

Das M1/M2 Modell der Makrophagen hat zwar heute immer noch seine Gültigkeit, wird jedoch auch kontrovers diskutiert, da eine derartige Kategorisierung nicht das komplette Spektrum der Makrophagen erfasse und als allzu sehr vereinfacht betrachtet wird. Demnach sind „M1 und M2 Makrophagen nicht als klonal distinkte Zellpopulationen zu betrachten, sondern als extreme Ausprägungen eines phänotypischen Kontinuums“ (zitiert nach Niedobitek et al., 2015; Mills et al., 2000). So wurden neben den M1 und M2 Subtypen auch tumorassoziierte Makrophagen (TAMs) beschrieben, die zwar aufgrund ihres Expressionsprofils zum M2 Subtypen tendieren, allerdings weder in die eine noch in die andere Klassifikation eindeutig einzuordnen sind (Solinas et al., 2009; Qian \& Pollard, 2010).

\subsubsection{Bimodale Rolle der Makrophagen}

Monozyten und insbesondere Makrophagen werden im Zusammenhang mit verschiedenen Erkrankungen kontroverse Rollen zugeschrieben. Im Zuge der Karzinogenese beispielsweise sind sie einerseits verantwortlich für eine adäquate Immunantwort auf Tumorzellen; andererseits können sie eine unterstützende und tumorfördernde Rolle einnehmen (Bailey et al., 2007). Die Ursache für diese paradoxe Rolle liegt in der funktionellen Plastizität der Zellen. Denn der M1/M2 Subtyp ist kein Dauerzustand (steady state) der Makrophagen. Je nach Stimulus, den sie aus ihrer Mikroumgebung erhalten, können sie ihr Genexpressionsprofil 
ändern und somit in die Klasse der M1 bzw. M2 Makrophagen eingeordnet werden (Martinez et al., 2008). Im Kontext von Mammakarzinomen wurde beschrieben, dass das Tumorgewebe zur Hälfte von Makrophagen kolonisiert vorliegen kann (Mukhtar et al., 2011). Dabei interagieren sie mit einer Reihe von Zellen wie Endothelzellen und Fibroblasten und sind somit am Invasions- und Metastasierungsvorgang von malignen Zellen beteiligt (Solinas et al., 2009). Sica et al. beschrieben 2008, dass während der Tumorprogression ein Phänotypwechsel stattfindet und M1 Makrophagen durch M2 Makrophagen ersetzt werden; jedoch konnten sie nicht abschließend klären, ob dabei M1 Makrophagen in Folge von Stimuli ihr Genexpressionsprofil und somit ihren Phänotypen geändert haben oder ob M2 Makrophagen einfach verstärkt rekrutiert wurden (Sica et al., 2008). Studien von Mosser und Edwards legen nahe, dass Stimuli einen Phänotypenwechsel initiieren (Mosser \& Edwards, 2008). Davis et al. konnten eine Repolarisationsfähigkeit der Makrophagen vom M2 zum M1 Phänotypen in vitro bestätigen; die Polarisation findet demnach zügig und in Abhängigkeit vom Chemokinprofil der Mikroumgebung statt, so dass auf transkriptionaler und translationaler Ebene Veränderungen nachweisbar sind (Davis et al., 2013). Diese Stimuli können auch von Tumorzellen initiiert werden (Bottazzi et al., 1983); sie können mit Hilfe von Signalproteinen wie M-CSF, Chemokin CCL2 und VEGF Monozyten aus dem Blut in das Tumorgewebe rekrutieren und mit Hilfe von $I L-3$ und $M-C S F$ zu TAMs differenzieren (Allavena et al., 2008; Solinas et al., 2009). Regulatorische T-Helferzellen, Fibroblasten und neoplastische Zellen des Tumorgewebes schütten des Weiteren TGF $\beta$ und $I L-10$ aus, so dass TAMs sich schließlich zu M2 Makrophagen entwickeln (Allavena et al., 1998; Solinas et al., 2009). CCL2 sticht hier besonders heraus, da es neben Tumorzellen auch von Makrophagen und Fibroblasten sezerniert wird; folglich können TAMs mittels einer CCL2 Sekretion weitere Makrophagen rekrutieren (Mantovani, 1994; Siveen \& Kuttan, 2009). Im Zusammenhang mit dem Ovarialkarzinom und dem Meningeom ist eine Korrelation von CCL2 und einer hohen TAM Anzahl beschrieben, die mit einer schlechten Prognose einhergeht (Negus et al., 1995; Sato et al., 1995). Weitere wichtige Chemokine bzw. Wachstumsfaktoren für die Rekrutierung von Monozyten sind CCL5, CCL7, CXCL8, CXCL12 und PDGF (Balkwill, 2004).

Da viele Erkrankungen wie chronische Entzündungen, Fibrose und Krebs durch eine dysregulierte Funktion der Makrophagen gefördert werden (Murray \& Wynn, 2011; Gordon \& Taylor, 2005), besteht ein großer Bedarf, die zugrundeliegenden molekularen Mechanismen der Makrophagenpolarisation $\mathrm{zu}$ verstehen und diese ggf. in vivo $\mathrm{zu}$ manipulieren. Auf diese Weise könnte die Entstehung von Erkrankungen besser verstanden und diese gezielter therapiert werden (Arnold et al., 2014). Die Makrophagenfunktion im Kontext des kolorektalen Karzinoms wird jedoch kontrovers diskutiert und ist nicht 
abschließend geklärt. Einige Studien zeigen, dass eine hohe Makrophagendichte in der Invasionsfront der Tumorzellen mit weniger Metastasen und einer besseren Prognose korreliert (Forssell et al., 2007; Zhou et al., 2010). Weitere Arbeiten beschreiben jedoch, dass eine Makrophageninfiltration des Kolorektalkarzinoms mit einem fortgeschrittenen Tumorstadium und einer höheren Anzahl an Metastasen assoziiert ist (Barbera-Guillem et al., 2002; Bacman et al., 2007; Bailey et al., 2007).

Im Rahmen dieser Arbeit wurde die Verteilung der M1 und M2 Makrophagen im Zuge der Karzinogenese des Kolorektalkarzinoms untersucht, da in der Tumorprogression M1 Makrophagen tumorinhibierende und M2 Makrophagen tumorstimulierende Eigenschaften zugeschrieben werden (Ma et al., 2010; Zhang et al., 2011). Um das erwähnte breite Makrophagenspektrum zu begrenzen, wurden neben drei allgemeinen auch jeweils zwei M1 bzw. M2 Makrophagenmarker ausgewählt. Über eine Quantifizierung der Genexpression bzw. immunhistochemisch wurde die Anzahl der Makrophagensubtypen sowie ihre Lokalisation im Tumorgewebe untersucht. Im Folgenden werden nun die entsprechenden Marker vorgestellt.

\subsubsection{M1 Makrophagen - Identifikation mittels CD80 und CD86}

Der M1 Phänotyp zeichnet sich durch eine hohe Produktion an pro-inflammatorischen Zytokinen aus, um u.a. eine Immunantwort auf Pathogene und mikrobielle Bestandteile zu initiieren (Murray \& Wynn, 2011). Sie werden allgemein als mikrobizid, zytotoxisch, tumorinhibierend und pro-inflammatorisch charakterisiert und haben somit einen schädlichen Einfluss auf u.a. Pathogene und maligne Zellen (Arnold et al., 2014). Als Antwort auf Entzündungsreaktionen und Erkrankungen wie u.a. Alzheimer, Asthma und Herzinfarkt produzieren sie hochreaktive Sauerstoff- und Stickstoffverbindungen und verursachen somit einen oxidativen bzw. nitrosativen Stress (MacMicking et al., 1997). Des Weiteren interagieren sie mit Th1 Zellen, eine Subgruppe der T-Helfer-Zellen, und fördern ihre Immunantwort (Mosser, 2003).

Die Polarisation von Makrophagen zum M1 Phänotypen erfolgt unter dem Einfluss von LPS, $I F N-\gamma$ und granulocyte-macrophage colony stimulating factor (GM-CSF). Dies hat zur Folge, dass M1 Makrophagen vermehrt pro-inflammatorische Zytokine wie $I L-1-\beta, I L-12, I L-18, I L-$ 23 und Tumornekrosefaktor (TNF) sezernieren (Arnold et al., 2014). Dadurch wird eine antigenspezifische Immunantwort von T-Helfer-Zellen (Th1 und Th17) induziert. M1 Makrophagen exprimieren in hohem Ausmaß eine Reihe von Oberflächenproteinen, anhand 
derer sie identifiziert werden können. Dazu gehören Haupthistokompatibilitätskomplexe der Klasse II (Major Histocompatibility Complex II, MHC II) sowie die Kostimulatoren CD80 (B7-1) und CD86 (B7-2); letztere sind notwendig für die Initiation der T-Zell-Aktivierung und eignen sich folglich zur Detektion von pro-inflammatorischen M1 Makrophagen (Linsley \& Ledbetter 1993; Mosser, 2003). Anhand ihrer Synthese von hochreaktiven Stickstoffverbindungen können sie ebenfalls nachgewiesen werden, da sie mit Hilfe des Enzyms nitric oxide synthase (NOS2 oder iNOS) vermehrt Stickstoffmonoxid produzieren (MacMicking et al., 1997; Arnold et al., 2014). Das Chemokinrezeptorprofil erlaubt ebenfalls eine Identifikation; M1 Makrophagen sezernieren die Chemokine CXCL9 und CXCL10, um Th1 Zellen zu rekrutieren (Mantovani et al., 2004).

\subsubsection{M2 Makrophagen - Identifikation mittels CD163 und CD206}

M2 Makrophagen zeichnen sich durch die Produktion von anti-inflammatorischen Zytokinen aus und verhindern eine adäquate Immunantwort, da sie die T-Zell-Proliferation inhibieren (Mosser, 2003). Sie sind vermehrt beteiligt an Gewebereparatur sowie -umbauprozessen und fördern somit auch die Tumorentwicklung (Wynn, 2004; Mantovani et al., 2007). Die Polarisation von Makrophagen in Richtung M2 Phänotyp wird begünstigt durch Pilz- und Helmintheninfektionen, apoptotische Zellen, $M-C S F, I L-4, I L-10, I L-13$ und TGF $\beta$ (Stein et al., 1992; Mantovani et al., 2007). Folglich werden vermehrt $I L-10, I L-12$, CCL17 und CCL22 sezerniert (Mantovani et al., 2007). Die Zellen zeichnen sich durch ineffiziente antigenpräsentierende Eigenschaften aus (Goerdt \& Orfanos, 1999). Eine hohe Expression an Scavenger-, Mannose- und Galaktoserezeptoren ist ebenfalls charakteristisch (Solinas et al., 2009). Des Weiteren sezernieren sie die Chemokine CCL7, CCL22 und CCL24 als Liganden für Chemokinrezeptoren (Balkwill, 2004).

Als M2-spezifische Marker werden u.a. der Scavengerrezeptor CD163 und der Mannoserezeptor CD206 beschrieben, die an der Immunregulation beteiligt sind und im Rahmen dieser Arbeit als Marker verwendet wurden (Hirata et al., 2011; Kurahara et al., 2013). CD163 wird von Zellen monozytärer Abstammung exprimiert und insbesondere im Zuge von Entzündungsreaktionen hochreguliert, so dass über diesen Parameter die Aktivierung der Makrophagen kontrolliert werden kann (Van den Heuvel et al., 1999; Fabriek et al., 2005; Onofre et al., 2003).

CD206 (MRC1, MR) wird von Makrophagen, unreifen dendritischen Zellen, Epithelzellen und Endothelzellen der Milz und Leber exprimiert. Im Tumorgewebe ist der Rezeptor ebenfalls nachweisbar; dort bindet er Tumorliganden, wodurch TAMs ihre $I L-10$ Produktion steigern 
und die CCL3 Sekretion reduzieren. Folglich werden weniger T-Zellen rekrutiert und somit die Immunantwort geschwächt (Allavena et al., 2010; Azad et al., 2014).

\subsubsection{Allgemeine Makrophagenmarker - Identifikation mittels $C D 11 b, F 4 / 80$ und CD68}

Differenzierte Makrophagen können anhand von Oberflächenproteinen identifiziert werden, die universell von allen Makrophagen exprimiert werden, unabhängig davon, ob es sich um den M1 oder M2 Phänotypen handelt. Dazu gehören die Oberflächenrezeptoren $C D 11 b$ und CD68. Das Membranprotein F4/80 wird ebenfalls von einem Großteil der reifen Makrophagen exprimiert (Murray \& Wynn, 2011).

CD11b (integrin alpha $M$ chain, ITGAM) ist an adhäsiven Interaktionen von Monozyten, Makrophagen und Granulozyten beteiligt, so dass im Zuge der Immunantwort Prozesse wie Phagozytose, zelluläre Aktivierung und Chemotaxis induziert werden. Des Weiteren initiiert das Protein gemeinsam mit CD18 die zelluläre Migration (Solojov et al., 2005).

Das Membranprotein F4/80 ist u.a. in Kupfferzellen, in der roten Pulpa der Milz, Mikroglia und Langerhans-Zellen der Haut vorzufinden (Austyn \& Gordon, 1981). Es besitzt in seiner Sequenz eine Adhäsions- und Signaldomäne, so dass es sehr wahrscheinlich durch die Adhäsion an bisher noch nicht identifizierte Oberflächenproteine als Signalmolekül agiert (McKnight et al., 1998). Zirkulierende Monozyten exprimieren ebenfalls F4/80, jedoch liegt hier ein deutlich geringeres Expressionslevel vor, weshalb das Protein die Unterscheidung von Monozyten und Makrophagen erlaubt (Austyn \& Gordon, 1981).

CD68 (Macrosialin) gehört zur Familie der lysosomenassoziierten Membranglykoproteine (Lamp), da es überwiegend von intrazellulären Lysosomen von Gewebemakrophagen, wie den Kupfferzellen oder Mikroglia, exprimiert wird (Holness \& Simmons, 1993). Da das Protein auch in Tumoren gut nachweisbar ist, kann es zur Identifikation von Makrophagen im Tumorgewebe verwendet werden (Meng et al., 2014). Spezifische Funktionen sind weitestgehend unbekannt; sie werden jedoch mit der Bindung an Lektine und Selektine assoziiert (Holness \& Simmons, 1993). 


\subsection{MetastaSys Konsortium}

Die vorliegende Arbeit wurde im Rahmen des „MetastaSys Konsortiums“ angefertigt, welches als Verbundprojekt gefördert wird vom Bundesministerium für Bildung und Forschung (BMBF; Projektnummer 0316173A) und eingegliedert ist in die Initiative „e:Bio Innovationswettbewerb Systembiologie“.

MetastaSys beinhaltet 11 Work Packages (WPS), die anhand verschiedener Methoden die Lokalisation und das Schicksal von Metastasen untersuchen, um relevante molekulare Marker und Signalwege in Tumorzellen und in ihrer Umgebung zu identifizieren, die eine bedeutende Rolle für die Metastasierung von Tumoren einnehmen. Ziel ist es, durch Hochdurchsatzmethoden gewonnene Daten mathematisch zu modellieren und diese zur Formulierung prädiktiver Modelle zu Metastasierungsvorgängen zu nutzen. Auf Grundlage dieser Erkenntnisse könnten neue medizinische Therapien entwickelt und Grundlagenwissen über den Einfluss von genetischen Faktoren und der Mikroumgebung auf die Metastasierung vertieft werden.

Im Rahmen des Konsortiums wurde die Metastasierung des Mamma- und Koloretalkarzinoms in das Gehirn und in die Leber im Mausmodell untersucht. Beide Tumorentitäten weisen gemeinsame Dysregulationen hinsichtlich ihrer EGFR und Wht Signalwege auf, unterscheiden sich jedoch, wie zuvor bereits beschrieben, in ihrem Organotropismus. Folglich eignen sie sich für eine Untersuchung der Tumor-Stroma-Interaktion in der jeweiligen Mikroumgebung und der beteiligten Signalwege, um so den Einfluss des Tumors (seed) und des Zielorgans (soil) auf die Metastasierung zu determinieren. Nachdem eine geeignete Mamma- und Kolorektalkarzinomzelllinie identifiziert und bezüglich ihres EGFR und Wnt Status charakterisiert wurde, erfolgte die Etablierung eines murinen Metastasenmodells im Gehirn und in der Leber. Wildtypzelllinien wurden genetisch modifiziert, so dass eine Überexpression bzw. ein Knockdown von EGFR respektive $\beta$-catenin erzielt wurde. Somit kann der funktionelle Einfluss der Modifikation auf die Metastasierung untersucht und generierte Daten gemeinsam mit den Daten der humanen Proben in ein mathematisches prädiktives Modell eingegliedert werden. Das Lebermetastasenmodell wurde von WP4 im Rahmen dieser Arbeit etabliert und im Zuge dessen die bimodale Rolle und Immunassoziation der Makrophagenphänotypen mit den Lebermetastasen untersucht. 


\subsection{Zielsetzung und Fragestellung}

Die Induktion von Fernmetastasen wird als der stärkste und ungünstigste prognostische Faktor beim Kolorektalkarzinom betrachtet. Da Metastasen resistent auf systemische Therapien reagieren können, besteht ein großer Bedarf das Verständnis über die bisher weitestgehend ungeklärten molekularen Entstehungsmechanismen der Metastasen und ihre Interaktion mit dem hepatischen Umfeld zu vertiefen. Makrophagen nehmen als Teil des Immunsystems in diesem Kontext eine bedeutende Rolle ein. Klinische Studien zeigen, dass Makrophagen erheblich an der Tumorprogression beteiligt sind; etwa 80 \% der Arbeiten weisen eine Korrelation zwischen der Makrophagendichte und einer schlechten Patientenprognose auf (Bingle et al., 2012; Qian \& Pollard, 2010).

Im Rahmen des MetastaSys Konsortiums wurde in der vorliegenden Arbeit in einem Subprojekt die Evolution der kolorektalen Karzinomzelllinie CMT-93 im hepatischen Milieu untersucht (Seed-and-Soil-Theorie). Dabei wurde die Formation von CRC-induzierten Mikround Makrometastasen analysiert und auf Basis von Metastasen-assoziierten Genen ein Expressionsprofil der Metastase und ihrer Mikroumgebung erstellt. Da im Kontext des metastasierten Kolorektalkarzinoms die Rolle der Makrophagenphänotypen weitestgehend ungeklärt ist, wurde ihre Funktion auf molekularer und zellbiologischer Ebene untersucht.

Folgende Fragestellungen wurden dabei adressiert:

1. Weisen Zelllinie, Metastase und tumorumgebendes Lebergewebe im Zuge der Metastasierung ein ähnliches Genexpressionsprofil auf? Welche Gene werden hochbzw. herunterreguliert?

2. Unterscheiden sich Mikro- und Makrometastasen phänotypisch und molekularbiologisch hinsichtlich ihrer Expression von Metastasen-assoziierten Genen bzw. Proteinen?

3. Werden M1- und M2-spezifische Gene im Zuge der Metastasenformation in bestimmten Leberarealen verstärkt exprimiert?

4. Werden in verschiedenen Stadien der Metastasierung unterschiedliche Makrophagenphänotypen rekrutiert und wo sind diese lokalisiert? 
5. Lassen sich M1 und M2 Makrophagen aus knochenmark-stämmigen Monozyten der C57BL/6NCrl Mäuse und anschließender in vitro Prägung generieren?

6. Welchen Einfluss haben konditionierte Medien der Makrophagenphänotypen auf die Vitalität und Genexpression von CMT-93 Zellen? 


\section{Material und Methoden}

\section{$2.1 \quad$ Materialien}

\subsubsection{Laborgeräte}

Tab. 2.1: Verwendete Laborgeräte

\begin{tabular}{|c|c|}
\hline Gerätschaft & Hersteller \\
\hline Aesculap Operationsbesteck & B. Braun Melsungen AG, Melsungen \\
\hline Aesculap Schermaschine Favorita & B. Braun Melsungen AG, Melsungen \\
\hline Agilent 2100 BioAnalyzer & $\begin{array}{l}\text { Agilent Technologies, Santa Clara, Kalifornien } \\
\text { (USA) }\end{array}$ \\
\hline BD FACSCanto ${ }^{T M}$ II Flow Cytometer & BD Biosciences, Heidelberg \\
\hline Begasungsbrutschrank BB 6060, BB 6220 & Heraeus, Hanau \\
\hline cBot System & Illumina Inc., San Diego, Kalifornien, USA \\
\hline Dewar Transportgefäß Typ B & KGW Isotherm, Karlsruhe \\
\hline Digitale Taschenwaage & Dipse, Oldenburg \\
\hline Digitalthermometer & TFA Dostmann GmbH, Wertheim \\
\hline Dräger Vapor ${ }^{\circledR} 2000$ Verdampfer & Drägerwerk AG \& Co. KGaA, Lübeck \\
\hline Durchlichtmikroskop Axiostar & Carl Zeiss Microscopy GmbH, Göttingen \\
\hline Durchlichtmikroskop Axioskop 2 Plus & Carl Zeiss Microscopy GmbH, Göttingen \\
\hline Durchlichtmikroskop Leica DM IRBE & Leica Mikrosysteme Vertrieb GmbH, Wetzlar \\
\hline Eismaschine & Ziegra Eismaschinen $\mathrm{GmbH}$, Isernhagen \\
\hline Feinwaage & Sartorius AG, Göttingen \\
\hline Fragment Analyzer $^{T M}$ & Advanced Analytical, Heidelberg \\
\hline Gefrierbehälter Mr. Frosty ${ }^{\mathrm{TM}}$ & Thermo Fisher Scientific, Schwerte \\
\hline Gefrierschrank $\left(-20^{\circ} \mathrm{C}\right)$ & Liebherr GmbH, Biberach \\
\hline Gefrierschrank $\left(-80^{\circ} \mathrm{C}\right)$ & Sanyo, Wiesloch \\
\hline Gewebeeinbettautomat Leica EG 1160 & Leica Instruments GmbH, Nussloch \\
\hline Gewebehomogenisator TissueLyser LT & Qiagen GmbH, Hilden \\
\hline Gewebeinfiltrationsautomat Leica TP1020 & Leica Biosystems GmbH, Nussloch \\
\hline Heißluftsterilisator ST 6060 & Heraus, Hanau \\
\hline Heiz- und Wärmeplatte 14801 & Mc Labor, Albstadt \\
\hline HiSeq2000 Sequenzierer & Illumina Inc., San Diego, Kalifornien, USA \\
\hline Inkubationsbad Typ 1012 & $\begin{array}{l}\text { GFL-Gesellschaft für Labortechnik mbH, } \\
\text { Burgwedel }\end{array}$ \\
\hline Inverses Mikroskop Primovert & Carl Zeiss Microscopy GmbH, Göttingen \\
\hline Kamera IXUS 1000 HS & Canon Deutschland GmbH, Krefeld \\
\hline Kühlschrank & Robert-Bosch Hausgeräte GmbH, Gerlingen \\
\hline
\end{tabular}




\begin{tabular}{|c|c|}
\hline Kryostat CM1950 & Leica Biosystems GmbH, Nussloch \\
\hline Magnetrührer & Heidolph Instruments GmbH, Schwabach \\
\hline Microtom HM 340E & Thermo Fisher Scientific, Schwerte \\
\hline Mikroliterpipetten $(10 / 100 / 1000 \mu \mathrm{l})$ & Eppendorf AG, Hamburg \\
\hline Mikroskopie-Kamera AxioCam ERc 5s & Carl Zeiss Microscopy GmbH, Göttingen \\
\hline Mikroskopie-Kamera Leica DC 100 & Leica Mikrosysteme Vertrieb GmbH, Wetzlar \\
\hline Mikrowellenherd Micromat & AEG Hausgeräte, Berlin \\
\hline Mikrozentrifuge Biofuge Fresco $^{\text {TM }} 17$ & Heraeus, Hanau \\
\hline MultiGourmet Dampfgarer & De'Longhi GmbH, Neu-Isenburg \\
\hline Multilable Plate Reader VICTOR ${ }^{T M}$ X4 & PerkinElmer Office, Rodgau \\
\hline Nalgene ${ }^{\circledR}$ CryoBox $^{\mathrm{Tm}}$ & Sigma-Aldrich, München \\
\hline NanoDrop ${ }^{\circledR}$ ND-1000 Spectrophotometer & Peqlab Biotechnology GmbH, Erlangen \\
\hline Operationslampe Hanaulux & Heraeus, Hanau \\
\hline pH-Meter PB-11 & Sartorius AG, Göttingen \\
\hline Pipettierhilfe & Hirschmann Laborgeräte, Eberstadt \\
\hline Plexiglasbehälter & Wissenschaftliche Werkstätten der UMG \\
\hline Reagenzglasschüttler / Vortexmischer & Breda Scientific, Breda (NL) \\
\hline SnuggleSafe Wärmekissen & SnuggleSafe Lenric C21, West Sussex (UK) \\
\hline Sicherheitswerkbank HERAsafe & Heraeus, Hanau \\
\hline Stickstofftank & Schuett-biotec GmbH, Göttingen \\
\hline Thermocycler T1 & Biometra GmbH, Göttingen \\
\hline Thermomixer Compact & Eppendorf AG, Hamburg \\
\hline 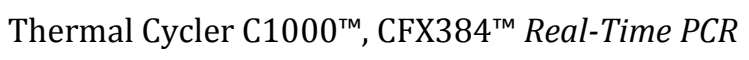 & Bio-Rad GmbH, München \\
\hline \multicolumn{2}{|l|}{ Detection System } \\
\hline Tischautoklav & Zirbus Technology GmbH, Bad Grund / Harz \\
\hline Tischzentrifuge Labofuge $\mathrm{e}^{\mathrm{TM}} 400 \mathrm{R}$ & Heraeus Hanau \\
\hline Zählkammer Neubauer - Improved & LO Laboroptik, Friedrichsdorf \\
\hline
\end{tabular}

\subsubsection{Verbrauchsmaterialien}

Tab. 2.2: Verbrauchsmaterialien

\begin{tabular}{ll}
\hline Material & Hersteller \\
\hline 6-well Zellkulturschalen & Greiner Bio-One GmbH, Frickenhausen \\
6-well Zellkulturschalen & Sarstedt AG, Nümbrecht \\
96-well Zellkulturschalen & Greiner Bio-One GmbH, Frickenhausen \\
Auslaufpipetten $(2 / 5 / 10 / 25 / 50 \mu \mathrm{l})$ & Starlab GmbH, Hamburg \\
Chirurgisches Nahtmaterial, & Johnson \& Johnson Medical GmbH, \\
Coated Vicryl Plus, 4-0, 1.5 Ph. Eur., & Norderstedt \\
SH-1 plus, 22 mm 1/2c, 70 cm & \\
Deckgläser 18x18 mm & Paul Marienfeld GmbH, Lauda-Königshofen \\
\hline
\end{tabular}




\begin{tabular}{|c|c|}
\hline Deckgläser (24x32 mm, 24x48 mm) & Menzel, Braunschweig \\
\hline EDTA-Röhrchen 1,3 ml & Sarstedt AG, Nümbrecht \\
\hline Einbettkassetten & Kabe Labortechnik, Nümbrecht \\
\hline Einmalskalpelle & Dahlhausen, Köln \\
\hline Einmalkanülen Sterican ${ }^{\circledR}$ Gr. 17 & B. Braun Melsungen AG, Melsungen \\
\hline Einmalspritzen $(1 \mathrm{ml})$ & BD Biosciences, Heidelberg \\
\hline Färbetröge (Glas) für Objektträger & Carl Roth GmbH, Karlsruhe \\
\hline Filtropur S 0.2 & Sarstedt AG, Nümbrecht \\
\hline Hamilton Injektionsspritze Model 1702 & B. Braun Melsungen AG, Melsungen \\
\hline Kryoröhrchen 1,8 ml & Sarstedt AG, Nümbrecht \\
\hline Medizinisches Pflaster Durapore & $3 \mathrm{M}$, Neuss \\
\hline Micro-Fine $^{\mathrm{TM}}$ Insulinspritzen U-100, $30 \mathrm{G}$ & BD Biosciences, Heidelberg \\
\hline Objektträger Superfrost Plus 25x75 mm & Menzel, Braunschweig \\
\hline Ohrlochzange & Carl Roth GmbH, Karlsruhe \\
\hline Krankenunterlagen 40x60 cm & Hartmann, Heidenheim \\
\hline Mullkompressen $10 \times 10 \mathrm{~cm}$ & Fuhrmann, Much \\
\hline PCR-Platten (384-well) & Thermo Fisher Scientific, Schwerte \\
\hline Pipettenspitzen (1 / 10 / 100 / 1000 Ml) & Starlab GmbH, Hamburg \\
\hline qRT-PCR Plate Seals & Thermo Fisher Scientific, Schwerte \\
\hline Reaktionsgefäß $(0,6 \mathrm{ml})$ & Biozym, Oldenburg \\
\hline Reaktionsgefäß (1,5 / 2 ml) & Sarstedt AG, Nümbrecht \\
\hline Reaktionsgefäß (5 ml) & Eppendorf AG, Hamburg \\
\hline Rundbodenröhrchen $5 \mathrm{ml}$ & BD Biosciences, Heidelberg \\
\hline Schraubbecher $100 \mathrm{ml}$ & Sarstedt AG, Nümbrecht \\
\hline \multirow[t]{2}{*}{ Spongostan Standard (70x50x10 mm) } & Johnson \& Johnson Medical GmbH, \\
\hline & Norderstedt \\
\hline Stahlkugeln „Stainless Steel Beads“, 5 mm & Qiagen, Hilden \\
\hline Wattestäbchen $150 \mathrm{~mm}$ & Karl Beese, Barsbüttel \\
\hline Zellkulturflaschen (T-75) & Starlab GmbH, Hamburg \\
\hline Zellkulturschalen 35x10 mm & Sarstedt AG, Nümbrecht \\
\hline Zellkulturschalen CytoOne $e^{\circledR} 35 \times 10 \mathrm{~mm}$ & Starlab GmbH, Hamburg \\
\hline Zellschaber $25 \mathrm{~cm}$ & Sarstedt AG, Nümbrecht \\
\hline Zellsiebe Falcon ${ }^{\circledR} 70 \mu \mathrm{m}$ & Corning GmbH, Wiesbaden \\
\hline Zellstofftupfer $(4 \times 5 \mathrm{~cm})$ & Hartmann, Heidenheim \\
\hline Zentrifugenröhrchen (15 / 50 ml) & Sarstedt AG, Nümbrecht \\
\hline
\end{tabular}




\subsubsection{Chemikalien und rekombinante Proteine}

Tab. 2.3: Chemikalien und rekombinante Proteine

\begin{tabular}{|c|c|}
\hline Chemikalie & Hersteller \\
\hline Accumax / Accutase & Sigma-Aldrich, München \\
\hline Aceton & Carl Roth GmbH, Karlsruhe \\
\hline Aquatex Eindeckmittel & Merck KGaA, Darmstadt \\
\hline Antibody Diluent & Dako GmbH, Hamburg \\
\hline Chloroform & Merck KGaA, Darmstadt \\
\hline DePeX & Serva Electrophoresis GmbH, Heidelberg \\
\hline DMSO & AppliChem, Darmstadt \\
\hline Eosin & Merck KGaA, Darmstadt \\
\hline Essigsäure & Carl Roth GmbH, Karlsruhe \\
\hline Ethanol 642 & Frohn, München \\
\hline Ethanol Rotipuran $\geq 99,8$ \%, p.a. & Carl Roth GmbH, Karlsruhe \\
\hline Fetal Bovine Serum Superior & Biochrom GmbH, Berlin \\
\hline Fishblock & SurModics BioFx, Eden Prairie (USA) \\
\hline Formalin $37 \%$ & Merck KGaA, Darmstadt \\
\hline Hämatoxylin & Merck Millipore, Darmstadt \\
\hline Isopropanol & Merck KGaA, Darmstadt \\
\hline L-Glutamin $(200 \mathrm{mM})$ & Biochrom GmbH, Berlin \\
\hline $\begin{array}{l}\text { Lipopolysaccharide (LPS) von Escherichia coli } \\
\text { 026:B6 }\end{array}$ & Sigma-Aldrich, München \\
\hline Mayers Hämalaunlösung & Merck KGaA, Darmstadt \\
\hline Methanol & Carl Roth GmbH, Karlsruhe \\
\hline Methylbutanol & AppliChem, Darmstadt \\
\hline Natriumchlorid & Carl Roth GmbH, Karlsruhe \\
\hline Natriumchloridlösung (isoton 0,9 \%) & B. Braun Melsungen AG, Melsungen \\
\hline Natriumpyruvat $100 \mathrm{mM}$ & Merck KGaA, Darmstadt \\
\hline Natronlauge & Merck KGaA, Darmstadt \\
\hline PBS pH 7,4 (1x) & Thermo Fisher Scientific, Schwerte \\
\hline Penicillin/Streptomycin & Thermo Fisher Scientific, Schwerte \\
\hline peqGOLD Trifast ${ }^{\mathrm{TM}}$ & Peqlab Biotechnology GmbH, Erlangen \\
\hline$R B C$ Lysepuffer (10x) & BioLegend, Fell \\
\hline Rekombinantes murines Interferon- $\gamma$ & Hölzel Diagnostika, Köln \\
\hline Rekombinantes murines Interleukin-4 & Hölzel Diagnostika, Köln \\
\hline Rekombinantes murines $M-C S F$ & Hölzel Diagnostika, Köln \\
\hline $\operatorname{Rimadyl}^{\circledR}$ (Carprofen) & Pfizer GmbH, Berlin \\
\hline RNAse-freies Wasser & Sigma-Aldrich, München \\
\hline Salzsäure $5 \mathrm{~N}$ & Merck KGaA, Darmstadt \\
\hline
\end{tabular}




\begin{tabular}{ll}
\hline Sevorane (Sevofluran) & Abbott GmbH, Wiesbaden \\
Softa-Man Desinfektionsmittel & B. Braun Melsungen AG, Melsungen \\
Target Retrieval Solution (TRS) & Dako GmbH, Hamburg \\
Thilo Tears Augengel & Alcon Pharma, Freiburg \\
Triton X-100 & Merck KGaA, Darmstadt \\
Trypanblau & Sigma-Aldrich, München \\
Trypsin-EDTA (10x) & Merck KGaA, Darmstadt \\
Tris ultrapure & AppliChem, Darmstadt \\
Wasserstoffperoxid $30 \%$ & Merck KGaA, Darmstadt \\
Xylol & Avantor Materials, Pennsylvania (USA) \\
\hline
\end{tabular}

\subsubsection{Medien, Puffer und Lösungen}

\subsubsection{Medien}

Tab. 2.4: Kulturmedium der verwendeten Zelllinien

\begin{tabular}{lll}
\hline Zelllinie & Medium & Hersteller \\
\hline CMT-93 & DMEM High Glucose & Thermo Fisher Scientific, Schwerte \\
Makrophagen & DMEM & Biochrom GmbH, Berlin \\
\hline
\end{tabular}

\subsubsection{Pufferherstellung}

\section{FACS Puffer:}

$\begin{array}{ll}\text { PBS } 1 \mathrm{x} & 98 \mathrm{ml} \\ \text { FBS } & 2 \mathrm{ml}\end{array}$

\section{$\underline{R B C}$ Lysepuffer:}

Aqua bidest $\quad 90 \mathrm{ml}$

RBC Lysepuffer 10x $10 \mathrm{ml}$

\section{Tris-Puffer:}

Aqua bidest

Tris ultrapure

Natriumchlorid

$9 \mathrm{~g}$

Der pH-Wert wurde mit Hilfe von 5N Salzsäure auf 7,6 eingestellt. 


\subsubsection{Lösungen}

\section{Formalin $4 \%$ :}

PBS 1x

Formalin $37 \%$

\section{Eosin:}

Eosin

Aqua dest.

Essigsäure
$832 \mathrm{ml}$

$108 \mathrm{ml}$

$5 \mathrm{~g}$

$500 \mathrm{ml}$

$1-2$ Tropfen

\subsubsection{Antikörper}

\section{Primärantikörper}

Tab. 2.5: Primärantikörper

\begin{tabular}{|c|c|c|c|c|c|}
\hline Antigen & Spezies & Klon & Verdünnung & Katalognr. & Hersteller \\
\hline$\beta$-catenin & Kaninchen & & $1: 50$ & $14-6765$ & $\begin{array}{l}\text { eBioscience, Frankfurt a. } \\
\text { M. }\end{array}$ \\
\hline$C D 11 b$ & Ratte & $5 \mathrm{C6}$ & $1: 50$ & MCA711G & BD Biosciences, Heidelberg \\
\hline$C D 44$ & Ratte & IM7 & $1: 1000$ & 550538 & BD Biosciences, Heidelberg \\
\hline$C D 68$ & Ratte & FA-11 & $1: 50$ & ab53444 & Abcam, Cambridge (UK) \\
\hline$C D 163$ & Kaninchen & M-96 & $1: 100$ & sc-33560 & Santa Cruz, Heidelberg \\
\hline CD163 & Kaninchen & & $1: 100$ & bs-2527R & Biozol Diagnostica, Eching \\
\hline CD206 & Ratte & MR5D3 & $1: 200$ & MCA2235T & $\begin{array}{l}\text { BD Biosciences, } \\
\text { Heidelberg }\end{array}$ \\
\hline E-cadherin & Kaninchen & H-108 & $1: 50$ & sc-7870 & Santa Cruz, Heidelberg \\
\hline$F 4 / 80$ & Ratte & CI:A3-1 & $1: 100$ & MCA497R & $\begin{array}{l}\text { BD Biosciences, } \\
\text { Heidelberg }\end{array}$ \\
\hline$K i-67$ & Kaninchen & SP6 & $1: 200$ & 275R-14 & $\begin{array}{l}\text { Cell Marque, Rocklin, } \\
\text { Kalifornien (USA) }\end{array}$ \\
\hline Vimentin & Kaninchen & EPR3776 & $1: 1000$ & ab92547 & Abcam, Cambridge (UK) \\
\hline
\end{tabular}

Tab. 2.6: Fluoreszenzfarbstoff-gekoppelte Antikörper und Isotypkontrollen. Alle Fluoreszenzfarbstoff-gekoppelten Antikörper und Isotypkontrollen wurden von der Firma BioLegend, Fell, erworben.

\begin{tabular}{llllll}
\hline Antigen / Isotyp & Spezies & Klon & Isotyp & Verdünnung & Katalognr. \\
\hline CD11b Alexa Fluor 488 & Ratte & $\mathrm{M} 1 / 70$ & $\mathrm{IgG}_{2 \mathrm{~b}, \kappa}$ & $1: 2000$ & 101217 \\
CD68 Alexa Fluor 488 & Ratte & FA-11 & $\mathrm{IgG}_{2 \mathrm{a}}$ & $1: 2000$ & 137012 \\
\hline
\end{tabular}




\begin{tabular}{|c|c|c|c|c|c|}
\hline CD80 Alexa Fluor 647 & $\begin{array}{l}\text { Armenischer } \\
\text { Hamster }\end{array}$ & $16-10 \mathrm{~A} 1$ & IgG & $1: 2000$ & 104718 \\
\hline CD86 Alexa Fluor 488 & Ratte & GL-1 & $\operatorname{IgG}_{2 \mathrm{a}, \mathrm{\kappa}}$ & $1: 250$ & 105018 \\
\hline CD206 Alex Fluor 488 & Ratte & C068C2 & $\operatorname{IgG}_{2 \mathrm{a}, \mathrm{k}}$ & $1: 500$ & 141710 \\
\hline F4/80 Alexa Fluor 647 & Ratte & BM8 & $\operatorname{IgG}_{2 \mathrm{a}, \kappa}$ & $1: 2000$ & 123122 \\
\hline Alexa Fluor ${ }^{\circledR} 647$ & Armenischer & HTK888 & $\operatorname{IgG}$ & $1: 400$ & 400924 \\
\hline Isotypkontrolle & Hamster & & & & \\
\hline Alexa Fluor ${ }^{\circledR} 488$ & Ratte & RTK2758 & $\operatorname{IgG}_{2 \mathrm{a}, \mathrm{\kappa}}$ & $1: 400$ & 400525 \\
\hline \multicolumn{6}{|l|}{ Isotypkontrolle } \\
\hline Alexa Fluor ${ }^{\circledR} 488$ & Ratte & RTK4530 & $\operatorname{IgG}_{2 \mathrm{~b}, \mathrm{k}}$ & $1: 400$ & 400625 \\
\hline \multicolumn{6}{|l|}{ Isotypkontrolle } \\
\hline Alexa Fluor ${ }^{\circledR} 647$ & Ratte & RTK2758 & $\operatorname{IgG} 2 \mathrm{a}, \mathrm{\kappa}$ & $1: 400$ & 400526 \\
\hline Isotypkontrolle & & & & & \\
\hline
\end{tabular}

\section{Sekundärantikörper}

Tab. 2.7: Sekundärantikörper und Enzyme

\begin{tabular}{lllll}
\hline Antigen & Spezies & Verdünnung & Katalognr. & Hersteller \\
\hline Anti-rabbit biotinyliert & Esel & $1: 250$ & RPN104V & GE Healthcare, Freiburg \\
Anti-rat biotinyliert & Ziege & $1: 200$ & 405402 & BioLegend, Fell \\
Anti-rabbit & Ziege & $1: 400$ & A11008 & Thermo Fisher Scientific, \\
Alexa Fluor ${ }^{\circledR} 488$ & & & & Schwerte \\
Anti-rabbit HRP & & Ready-to-use & K4002 & Dako GmbH, Hamburg \\
Avidin HRP & & $1: 400$ & $18-4100-94$ & eBioscience, Frankfurt a. M. \\
\hline
\end{tabular}

\subsubsection{Oligonukleotide}

Tab. 2.8: Übersicht der verwendeten Oligonukleotide für $q R T$-PCR Experimente

\begin{tabular}{|c|c|c|c|}
\hline Gen & Sequenz $\left(5^{\prime} \rightarrow 3^{\prime}\right)$ & Accession Number & Produkt $[b p]$ \\
\hline \multirow[t]{2}{*}{$\beta 2$-Microglobulin } & ACC GGC CTG TAT GCT ATC C & NM_009735.3 & 111 \\
\hline & CGG GTG GAA CTG TGT TAC G & & \\
\hline \multirow[t]{2}{*}{ Caspase-3 } & ATG GCT TGC CAG AAG ATA CC & NM_001284409 & 93 \\
\hline & CCC GTC CTT TGA ATT TCT CC & & \\
\hline \multirow[t]{2}{*}{$C D 11 b$} & CCC ATC TGG CTT ATC TTA CCG & NM_001082960.1 & 78 \\
\hline & GCA GGC TTT ACA AAC CAA GG & & \\
\hline \multirow[t]{2}{*}{$C D 44$} & AGA CCC CAC ATCG CTA CAA GC & NM_009851.2 & 81 \\
\hline & CGT TCT GAA ACC ACG TCT CC & & \\
\hline \multirow[t]{2}{*}{$C D 68$} & TTG TGA CGG TAC CCA TCC C & NM_001291058.1 & 92 \\
\hline & TAC TCG GGC TCT GAT GTA GG & & \\
\hline CD80 & CTC TTT GTG CTG CTG ATT CG & NM_009855.2 & 107 \\
\hline
\end{tabular}




\begin{tabular}{|c|c|c|c|}
\hline & GGA GAG TTG TAA CGG CAA GG & & \\
\hline \multirow[t]{2}{*}{$C D 86$} & GAC CGT TGT GTG TGT TCT GG & NM_019388.3 & 94 \\
\hline & CCA ATA CGT TTG AGG AGA TGG & & \\
\hline \multirow[t]{2}{*}{ CD163 } & GGG CAA GCA TAA CTG TGA CC & NM_001170395.1 & 103 \\
\hline & TCC TGA ACA TCT GGA CAC TCC & & \\
\hline \multirow{2}{*}{ CD206 } & CCT GAG TGT CAC GGA GAT CC & NM_008625.2 & 82 \\
\hline & GAG TCC AAT CCA GAG TCC CG & & \\
\hline \multirow[t]{2}{*}{ Cyclin D1 } & GAG ACC ATT CCC TTG ACT GC & NM_007631.2 & 91 \\
\hline & TGA GCT TGT TCA CCA GAA GC & & \\
\hline \multirow[t]{2}{*}{ E-cadherin } & TCA TTG AGA GGG AGA CAG GC & NM_009864 & 91 \\
\hline & GAC ACG GCA TGA GAA TAG AGG & & \\
\hline \multirow[t]{2}{*}{$F 4 / 80$} & TGC TGG TTG AAT ACA GAG ACG & NM_010130.4 & 108 \\
\hline & CCT CAG AAC CCA CAG TGT CC & & \\
\hline \multirow[t]{2}{*}{$H P R T$} & GCA GTA CAG CCC CAA AAT GG & NM_013556.2 & 75 \\
\hline & GGC CTG TAT CCA ACA CTT CG & & \\
\hline \multirow[t]{2}{*}{ Ki-67 } & AGC AAG CCA ACA GAA TTT CC & NM_001081117.2 & 87 \\
\hline & ATC AGG GTC AGC ACA GAA GC & & \\
\hline \multirow[t]{2}{*}{ Krt20 } & AGT ACA AAA TGC CCA GTG CG & NM_023256.1 & 94 \\
\hline & ACG CAT TCC CCT CTC AGT CT & & \\
\hline \multirow[t]{2}{*}{$M M P-7$} & ACT GGA CTG ATG GTG AGG AC & NM_010810 & 170 \\
\hline & GCC TGC AAT GTC GTC CTT TG & & \\
\hline \multirow[t]{2}{*}{$N F k B 1$} & GCC TCA TGT TCA CAG CCT TC & NM_008689.2 & 115 \\
\hline & TTC AGG TTG GAT GCA TTC GG & & \\
\hline \multirow[t]{2}{*}{ PCK1 } & GGT ATC ATC TTT GGT GGC CG & NM_011044 & 108 \\
\hline & TGT GGC CTC AGA TCT CAT GG & & \\
\hline \multirow[t]{2}{*}{ Stat3 } & TGA TCA CCT TCG AGA CTG AGG & NM_011486 & 95 \\
\hline & CTG ACA GAT GTT GGA GAT CAC C & & \\
\hline \multirow[t]{2}{*}{ Vimentin } & AGA TCG ATG TGG ACG TTT CC & NM_011701.4 & 198 \\
\hline & TCC GGT ACT CGT TTG ACT CC & & \\
\hline
\end{tabular}

\subsubsection{Kommerzielle Kits und Assays}

Tab. 2.9: Verwendete kommerzielle Kits und Assays

\begin{tabular}{ll}
\hline Produkt & Hersteller \\
\hline AEC Substrate Kit & BD Biosciences, Heidelberg \\
Avidin/Biotin Blocking Kit & Thermo Fisher Scientific, Schwerte \\
CellTiter96 ${ }^{\circledR}$ AQueous One Solution Cell & Promega GmbH, Mannheim \\
Proliferation Assay (MTS) & \\
High Pure RNA Isolation Kit & Roche Diagnostics GmbH, Mannheim \\
iQ SYBR ${ }^{\circledR}$ Green Supermix & Bio-Rad GmbH, München \\
\hline
\end{tabular}




\begin{tabular}{ll}
\hline iScript cDNA Synthesis Kit & Bio-Rad GmbH, München \\
peqGold TriFast & Peqlab Biotechnology GmbH, Erlangen \\
QuantiFluor $^{\text {TM }}$ dsDNA System & Promega GmbH, Mannheim \\
QuantiTect Reverse Transcription Kit & Qiagen, Hilden \\
TruSeq RNA Library Preparation Kit v2 & Illumina Inc., San Diego, Kalifornien (USA) \\
\hline
\end{tabular}

\subsubsection{Biologisches Material}

\subsubsection{CRC Zelllinie CMT-93}

Im Rahmen des MetastaSys Konsortiums befand sich der Fokus dieser Arbeit auf CRCinduzierten Lebermetastasen. Die Zelllinie CMT-93 wurde von Frau Dr. med. Christina Hackl vom Universitätsklinikum Regensburg zur Verfügung gestellt. Die molekulare Charakterisierung der Zelllinie wurde durch WP2 durchgeführt und u.a. die Expression von $\beta$-catenin, Axin2 und c-Jun als Komponenten des Wht Signalweges nachgewiesen (WP2; Arackal, 2016). Aufgrund ihrer molekularen Eigenschaften und anhand einer morphologischen Charakterisierung der Metastasen (WP4) wurde sie als geeignete Zelllinie zur Etablierung eines darmkrebsinduzierten Lebermetastasenmodells identifiziert. Neben Implantationsexperimenten wurden die Tumorzellen auch für molekular- sowie zellbiologische Analysemethoden verwendet.

1977 wurde die murine CMT-93 Zelllinie von Franks und Hemmings etabliert (Franks \& Hemmings, 1978). Die Zellen stammen aus einer 19 Monate alten männlichen C57BL/icrf Maus mit einem polyploiden Rektumkarzinom, das induziert wurde durch intraperitoneale Injektionen von 1,2-Dimethylhydrazin oder Methylazioxymethanolacetat (MAM Acetat). Eine weitere Charakterisierung der Zelllinie bezüglich einiger relevanter Signalwege wurde 2010 von Kitamura et al. beschrieben (Wnt Signalweg aktiv, keine K-RAS und BRAF Mutation). Morphologisch handelt es sich um Zellen mit einem epithelialen Wachstumsmuster. In Kulturschalenböden bilden Einzelzellen einen einschichtigen Zellrasen, der innerhalb von etwa 72 - 96 Stunden eine Konfluenz von ca. 80 \% erreicht.

\subsubsection{Mausstamm}

Zur Etablierung eines syngenen und orthotopen Lebermetastasenmodells wurden Implantationsexperimente in einem Mausstamm durchgeführt, der möglichst dem ursprünglichen Hintergrund der Zelllinie entspricht. Ein syngenes Modell bietet den Vorteil, dass tierexperimentelle Eingriffe in Organismen mit vorhandenem bzw. intaktem Immunsystem durchführbar sind, da aufgrund der genetischen Identität der Zelllinie und des 
verwendeten Mausstammes keine Abstoßungsreaktionen zu erwarten sind. Des Weiteren kann auf diese Weise die Interaktion zwischen Tumorzellen und Immunsystem untersucht werden. Da der C57BL/icrf Mausstamm nicht mehr käuflich zu erwerben ist, wurden zunächst die Substämme C57BL/6N und C57BL/6J von verschiedenen Firmen für Implantationszwecke getestet. Nach Rücksprache mit Frau Dr. med. Christina Hackl wurden schließlich 10-Wochen alte weibliche Mäuse des Substammes C57BL/6NCrl (18 - 22 g) von der Firma Charles River, Sulzfeld, erworben, da in der Arbeitsgruppe ein CMT-93 induziertes Lebermetastasenmodell durch intrasplenische Implantation der Zelllinie im genannten Substamm bereits erfolgreich etabliert wurde (nicht publiziert). Die CMT-93 Zelllinie stammt zwar ursprünglich aus einer männlichen Maus, um jedoch im Rahmen des MetastaSys Konsortiums einen Vergleich mit den Mammakarzinom-induzierten Lebermetastasen durch 410.4 Zellen $\mathrm{zu}$ ermöglichen, wurden in diesem Fall weibliche C57BL/6NCrl Mäuse verwendet. Nach einer ein- bis zweiwöchigen Akklimatisierungsphase erfolgte schließlich die Implantation der Tumorzellen in die murine Pfortader. Die Tierhaltung und -versorgung sowie die Umsetzung der Tierexperimente wurden gemäß den Vorgaben des deutschen Tierschutzgesetzes und des Niedersächsischen Landesamts für Verbraucherschutz und Lebensmittelsicherheit durchgeführt. Den Tieren wurde phytoöstrogenarmes Futter (Ssniff, Soest) und Wasser ad libitum zur Verfügung gestellt. Die Haltung erfolgte in einem zwölfstündigen Hell-Dunkel-Rhythmus und gemäß den FELASA Empfehlungen unter kontrollierten spezifisch pathogenfreien (SPF) Bedingungen.

\subsubsection{EDV}

Tab. 2.10: EDV

\begin{tabular}{ll}
\hline Software & Hersteller / Quelle \\
\hline Adobe Photoshop CS4 Version 11.0 & Adobe Systems Inc., Kalifornien (USA) \\
BD FACSDiva ${ }^{T M}$ Software Version 6.1.3 & BD Biosciences, Heidelberg \\
BaseCaller Software & Illumina Inc., San Diego, Kalifornien, USA \\
CASAVA Software Version 1.8.2 & Illumina Inc., San Diego, Kalifornien, USA \\
CFX-Manager Software Version 3.1 & Bio-Rad GmbH, München \\
EdgeR & Robinson et al., 2010 \\
GraphPad Prism Version 6.04 & GraphPad Software, Inc., Kalifornien, USA \\
Leica FW 4000 & Leica Mikrosystem Vertrieb GmbH, Wetzlar \\
Microsoft Office 2010 & Microsoft, Redmond (USA) \\
Nano Drop 1000 Version 3.5.2 & Peqlab Biotechnology GmbH, Erlangen \\
Perkin Elmer 2030 Software Version 4.00 & PerkinElmer Office, Rodgau \\
R Programmiersprache Version 3.2.3 & www.r-project.org \\
\hline
\end{tabular}




\begin{tabular}{ll}
\hline RSEM Version 1.2.19 & Li, Dewey, 2011 \\
STAR-Aligner Version 2.4.0h & Dobin et al., 2012 \\
topGO package & Alexa, Rahnenfuhrer, 2016 \\
ZEN 2012 (blue edition) & Carl Zeiss Microscopy GmbH, Göttingen \\
\hline
\end{tabular}

Tab. 2.11: Verwendete Datenbanken

\begin{tabular}{ll}
\hline Datenbank & Webseite \\
\hline Ensembl & www.ensembl.org \\
ExPASy & www.expasy.org \\
GeneCards & www.genecards.org \\
Gene Ontology Database & www.geneontology.org \\
NCBI & www.ncbi.nlm.nih.gov \\
Reactome & www.reactome.org \\
\hline
\end{tabular}

\section{$2.2 \quad$ Methoden}

\subsubsection{Zellbiologische Methoden}

\subsubsection{Kulturbedingungen eukaryotischer Zellen}

Die Kultivierung der CMT-93 Zellen erfolgte in einem Begasungsbrutschrank bei $37^{\circ} \mathrm{C}$ in einer wasserdampfgesättigten Atmosphäre und einem $\mathrm{CO}_{2}$-Partialdruck von 5 \%. T-75Zellkulturflaschen mit je $15 \mathrm{ml}$ Kulturmedium wurden zur Expansion der Zellen benutzt. Das Medium der CMT-93 Zelllinie setzte sich wie folgt zusammen:

Dulbecco's Modified Eagle Medium (DMEM), High Glucose

$\begin{array}{ll}\text { Natriumbikarbonat } & 3,7 \mathrm{~g} / \mathrm{l} \\ \text { D-Glukose } & 4,5 \mathrm{~g} / \mathrm{l} \\ \text { L-Glutamin } & 1 \% \\ \text { FBS Superior } & 10 \% \\ \text { Natriumpyruvat } & 1 \mathrm{mM} \\ \text { Penicillin/Streptomycin } & 1 \mathrm{mg} / \mathrm{ml}\end{array}$

Die Passagierung der Zellen wurde alle drei bis vier Tage bei einer Konfluenz von ca. 80 \% steril durchgeführt. Hierzu wurde zunächst das Kulturmedium entfernt und der Zellrasen einmal mit PBS gewaschen, um FBS-Rückstände zu eliminieren. Nach Entfernung des Puffers, erfolgte die Zugabe von $1 \mathrm{ml}$ 1x Trypsin/EDTA Lösung. Nach einer 15- bis 20-minütigen 
Inkubation bei $37{ }^{\circ} \mathrm{C}$, lösten sich adhärente Zellen durch leichtes Klopfen an den Flaschenseiten ab. Die enzymatische Wirkung des Trypsins wurde durch die Zugabe von $5 \mathrm{ml}$ Kulturmedium neutralisiert. Nach abschließender Zentrifugation (900 rpm, $5 \mathrm{~min}$, RT) wurden die Zellen in frischem Kulturmedium resuspendiert und entweder die Zellzahl für in vivo / in vitro Experimente ermittelt oder Zellen im Verhältnis 1:10 in eine neue Kulturflasche überführt.

\subsubsection{Ermittlung der Zellzahl und -vitalität}

Um bei Implantationsexperimenten und weiteren Analysemethoden exakte Zellmengen einsetzen zu können, wurde im Anschluss an das Ablösen der Zellen durch Trypsin/EDTA die Zellzahl ermittelt. Hierzu wurde die Zellsuspension im Verhältnis 1:4 mit Trypanblau verdünnt, um tote Zellen identifizieren zu können; diese nehmen den blauen Diazofarbstoff aufgrund ihrer defekten Plasmamembran auf. $10 \mu \mathrm{l}$ der Mischung wurden unter das Deckglas einer Neubauerzählkammer überführt, die aus vier Großquadraten besteht. Zellen innerhalb dieser Großquadrate wurden gezählt und anhand folgender Formel die Zellzahl in einem Milliliter der Zellsuspension ermittelt:

Zellen/ml = (K x Z x Verdünnungsstufe $) /$ Zahl der Großquadrate

( $K=$ Kammerkonstante 10 $; Z$ = Anzahl gezählter Zellen in vier Großquadraten)

Je nach erwünschter Zellzahl wurden der Zellsuspension entsprechende Volumina entnommen.

Während der Durchführung von Zellimplantationsexperimenten, wurden Micro-Fine ${ }^{\mathrm{TM}}$ Insulinspritzen U-100 mit einem Außendurchmesser von 30 G (BD Biosciences, Heidelberg) verwendet. Um den Einfluss der Spritzen auf die Vitalität der CMT-93 Zellen untersuchen zu können, wurden Tumorzellen anhand von drei Applikationstechniken in eine Neubauerzählkammer überführt und der Anteil toter Zellen ermittelt: zügiges Spritzen in einem Zug, langsames Spritzen innerhalb einer Minute und Spritzen nach einer zweistündigen Inkubation auf Eis.

Dem oben beschriebenen Gemisch bestehend aus Zellsuspension und Trypanblau wurden mit einer Insulinspritze etwa $10 \mu \mathrm{l}$ entnommen und diese anhand der angegebenen drei Techniken in eine Neubauerzählkammer appliziert. Nach Ermittlung der Anzahl toter Zellen, 
wurde ihr relativer Anteil an der Gesamtzellzahl berechnet. Dementsprechend wurde die Applikationstechnik der Tumorzellen in in vivo Experimenten angepasst.

\subsubsection{Kryokonservierung von Zellen}

Implantationsexperimente wurden stets mit Zellen aus derselben Passage durchgeführt. Um zu gewährleisten, dass ausreichend Zellen vorhanden sind, wurden diese nach Erhalt in T-75Zellkulturflaschen expandiert und Aliquots bestehend aus etwa 4 - 5 x $10^{6}$ Zellen aus der gleichen Passage eingefroren. Bei einer Konfluenz von etwa 80 \% wurden CMT-93 Zellen abgelöst, zentrifugiert und in Einfriermedium resuspendiert, welches aus FBS mit 10 \% DMSO bestand. Jeweils $1 \mathrm{ml}$ der Zellsuspension wurde in Kryoröhrchen überführt und diese über Nacht in einem mit Isopropanol gefüllten Gefrierbehälter (Thermo Fisher Scientific, Schwerte) bei $-80{ }^{\circ} \mathrm{C}$ gelagert. Dieser Schritt gewährleistet ein langsames und somit schonendes Herunterkühlen der Zellen $\left(-1^{\circ} \mathrm{C} / \mathrm{min}\right)$. Am Folgetag wurden die Kryoröhrchen zwecks einer langfristigen Aufbewahrung in Stickstofftanks überführt.

\subsubsection{Revitalisierung von Zellen}

Eine Woche vor der Implantation von CMT-93 Zellen in C57BL/6NCrl Mäuse, wurde jeweils ein Aliquot der tiefgefrorenen Zellen revitalisiert. Die Zellen wurden zügig aufgetaut und in 5 ml Kulturmedium überführt. Anschließend wurde die Zellsuspension zentrifugiert (900 rpm, $5 \mathrm{~min}, \mathrm{RT}$ ) und das Zellpellet in $15 \mathrm{ml}$ Kulturmedium mit $1 \mathrm{mg} / \mathrm{ml}$ Penicillin/Streptomycin resuspendiert. Eine T-75-Zellkulturflasche wurde mit der Zellsuspension befüllt. Um DMSORückstände und bereits tote Zellen zu entfernen, wurde am Folgetag das Medium abgesaugt und die Zellen einmal kurz mit 1x PBS gewaschen. Es wurden jeweils $15 \mathrm{ml}$ frisches Kulturmedium ohne Antibiotikum hinzugefügt. Bis zur Implantation wurden die Zellen täglich lichtmikroskopisch kontrolliert und durch zwei Passagierungen expandiert. Am Tag der Implantation erfolgte schließlich eine Bestimmung der Zellzahl und -vitalität.

Für Kokulturexperimente der CMT-93 Zellen mit konditioniertem Medium der Makrophagen wurden die Tumorzellen im Grundmedium der Makrophagen (DMEM mit $1 \mathrm{~g} / \mathrm{l}$ Glukose, 10 \% FBS) revitalisiert. Auf diese Weise wurde der mögliche Einfluss zweier unterschiedlicher Medien auf die Zellen ausgeschlossen. Der FBS-Anteil des Mediums von $10 \%$ wurde eine Woche nach Revitalisierung sukzessive reduziert auf $5 \%$ und schließlich $1 \%$. Zur Durchführung der Kokulturexperimente wurden jeweils $1 \times 10^{6}$ CMT-93 Zellen in die Vertiefungen einer 6-well Zellkulturschale ausgesät und 24 Stunden bei $37^{\circ} \mathrm{C}$ inkubiert. Am Folgetag erfolgte die Zugabe von je $2 \mathrm{ml}$ konditioniertem Medium der 
Makrophagenphänotypen (siehe Kapitel 2.2.4.3). Nach 48 und 72 Stunden wurde schließlich eine RNA Extraktion aus den Tumorzellen durchgeführt.

\subsubsection{Molekularbiologische Methoden}

\subsubsection{RNA Extraktion aus Gewebe}

Die molekulare Charakterisierung der CMT-93 induzierten Lebermetastasen erfolgte u.a. durch eine quantitative Real-Time PCR ( $q R T-P C R)$. Vier Wochen post injectionem wurden Mauslebern für molekularbiologische Analysemethoden entnommen, in flüssigem Stickstoff schockgefroren und bei $-80^{\circ} \mathrm{C}$ gelagert. Für eine $q R T-P C R$ wurde aus der gesamten Leber RNA extrahiert; die Extraktion wurde mit Hilfe des gebrauchsfertigen peqGold TriFast ${ }^{\mathrm{TM}}$ (Peqlab, Erlangen) Reagenzes und nach dem Protokoll des Herstellers durchgeführt.

Hierzu wurden Mauslebern kurz bei $4{ }^{\circ} \mathrm{C}$ angetaut und in eine Zellkulturschale überführt. Mit Hilfe eines sterilen Skalpells wurde jede Leber zügig in drei gleich große Proben geteilt und diese erneut in kleinere Stücke geschnitten. Jede Probe wurde nun in ein $2 \mathrm{ml}$ Reaktionsgefäß überführt, welches bereits je $1 \mathrm{ml}$ des Reagenzes und eine Stahlkugel enthielt. Letzteres verursacht in Kombination mit einem Gewebehomogenisator eine Zerkleinerung der Proben (bei $50 \mathrm{~Hz}, 4$ Runden à 5 min mit jeweils 2 min Kühlpause zwischen den Runden), so dass ein dickflüssiges Homogenat entstand. Die drei Proben jeder Mausleber wurden schließlich in einem $5 \mathrm{ml}$ Reaktionsgefäß zusammengeführt. Aus dem Homogenat jeder Leber wurden 20 $\mu \mathrm{l}$ entnommen und in 1,5 ml Reaktionsgefäße mit $1 \mathrm{ml}$ peqGold TriFast ${ }^{\mathrm{TM}}$ Reagenz überführt. Diese wurde nun 5 min bei RT inkubiert; nach der Zugabe von $200 \mu$ l Chloroform wurden die Proben gut gemischt und erneut 15 min bei RT inkubiert. Im Anschluss folgte eine Zentrifugation für $5 \mathrm{~min}$ bei $12.000 \mathrm{~g}$ und $4{ }^{\circ} \mathrm{C}$. Dieser Schritt verursachte eine Phasentrennung; während sich die RNA in der oberen wässrigen Phase befand, folgte darauf eine Interphase und eine organische Phenolphase, in der DNA bzw. Proteine vorzufinden waren. Die obere wässrige Phase wurde nun in ein neues 1,5 ml Reaktionsgefäß überführt; für eine RNA-Präzipitation wurden $500 \mu \mathrm{l}$ Isopropanol hinzugefügt und 15 min bei $4{ }^{\circ} \mathrm{C}$ inkubiert. Durch einen 10-minütigen Zentrifugationsschritt bei $12.000 \mathrm{~g}$ und $4{ }^{\circ} \mathrm{C}$ wurde das RNA-Pellet sedimentiert und das Isopropanol entfernt. Es folgte die Zugabe von 75 \%igem Ethanol und eine erneute Zentrifugation für $10 \mathrm{~min}$ bei $12.000 \mathrm{~g}$ und $4{ }^{\circ} \mathrm{C}$. Um mögliche Phenolrückstände vollständig zu entfernen, wurde dieser Schritt insgesamt drei Mal durchgeführt. Das RNA-Pellet wurde schließlich bei $60^{\circ} \mathrm{C}$ getrocknet und in je $20 \mu \mathrm{l}$ RNasefreiem Wasser gelöst. Die Konzentration der extrahierten Gesamt-RNA konnte anschließend photometrisch ermittelt werden. Die dauerhafte Lagerung erfolgte bei $-80{ }^{\circ} \mathrm{C}$. 


\subsubsection{RNA Extraktion aus eukaryotischen Zellen}

Der Einfluss des konditionierten Mediums verschiedener Makrophagenphänotypen auf Tumorzellen wurde mittels einer $q R T-P C R$ untersucht. Nach dem Entfernen des Kulturmediums wurden CMT-93 Zellen zweimal mit PBS (1x) gewaschen und $500 \mu$ peqGold TriFast $^{\mathrm{TM}}$ Reagenz pro well einer 6-well Zellkulturschale hinzugefügt. Mit Hilfe eines Zellschabers wurden die Zellen vom Schalenboden gelöst und in ein 1,5 ml Reaktionsgefäß überführt. Die RNA Extraktion wurde nach dem zuvor beschriebenen Prinzip durchgeführt. Lediglich der Zentrifugationsschritt nach Isopropanolzugabe wurde auf 30 min verlängert.

Für Sequenzierungszwecke wurde die Gesamt-RNA aus CMT-93 Zellen durch WP2 zur Verfügung gestellt. Hier erfolgte die Isolation mit Hilfe des High Pure RNA Isolation Kits (Roche, Mannheim) und dem entsprechenden Protokoll des Herstellers.

\subsubsection{Photometrische Konzentrationsbestimmung von RNA}

Die Konzentration der extrahierten RNA wurde photometrische mit Hilfe des NanoDrop ${ }^{\circledR}$ ND1000 Spectrophotometers ermittelt, indem die Extinktion der Nukleinsäuren bei einer Wellenlänge von $260 \mathrm{~nm}$ gemessen wurde. Das Verhältnis der Absorption bei $260 \mathrm{~nm}$ und 280 nm spiegelt die Reinheit der RNA wider; wenn keine Protein- oder Phenolrückstände vorhanden sind, liegt dieser Wert idealerweise zwischen 1,9 und 2,2. Eine zusätzliche Kontrolle der Reinheit stellt die Messung der Absorption bei $260 \mathrm{~nm}$ und $230 \mathrm{~nm}$ dar. Dieses Verhältnis indiziert, ob eine Verunreinigung durch organische Substanzen vorliegt und wird im Bereich zwischen 1,8 und 2,2 erwartet.

\subsubsection{Reverse Transkription}

Das QuantiTect ${ }^{\circledR}$ Reverse Transcription Kit (Qiagen, Hilden) wurde verwendet, um aus RNA komplementäre, einzelsträngige cDNA für Genexpressionsanalysen mittels $q R T-P C R$ zu synthetisieren. Es kombiniert die Elimination genomischer DNA mit einer anschließenden reversen Transkription. Die cDNA Synthese wird katalysiert durch eine Reverse Transkriptase, eine RNA-abhängige DNA-Polymerase, so dass eine Sequenz entsteht, die der mRNA Sequenz entspricht. Anhand dieser Sequenz kann die Expression bestimmter Gene quantifiziert werden (Tab. 2.8). Die cDNA Synthese wurde pro Probe mit 1 - $3 \mu \mathrm{g}$ RNA durchgeführt. Die folgende Tabelle stellt den Reaktionsansatz zur Synthese von cDNA aus 1 $\mu \mathrm{g}$ RNA dar. In einem Endvolumen von $20 \mu \mathrm{l}$ entspricht $1 \mu \mathrm{l}$ cDNA 50 ng RNA. 
Tab. 2.12: Reaktionsansatz für eine cDNA Synthese aus $1 \mu \mathrm{g}$ RNA

\begin{tabular}{clll}
\hline Reaktionsansatz & Komponente & Volumen \\
\hline \multirow{2}{*}{ 1. Elimination der genomischen } & gDNA Wipeout Buffer (7x) & $2 \mu \mathrm{l}$ \\
& DNA & RNA-Template & $\mathrm{X} \mathrm{\mu \textrm {g }}$ \\
& RNase-freies $\mathrm{H}_{2} \mathrm{O}$ & ad. $14 \mu \mathrm{l}$ \\
& & Quantiscript Reverse Transkriptase & $1 \mu \mathrm{l}$ \\
2. Reverse Transkription & Quantiscript RT Buffer & $4 \mu \mathrm{l}$ \\
& & RT Primer Mix & $1 \mu \mathrm{l}$ \\
\hline
\end{tabular}

Der erste Reaktionsansatz wurde zunächst in einem T-1 Thermocycler (Biometra, Göttingen) für 2 min bei $42{ }^{\circ} \mathrm{C}$ erhitzt und sofort gekühlt. In diesem Schritt wurde durch den Wipeout Puffer genomische DNA aus dem Ansatz eliminiert. Der zweite Reaktionsansatz wurde anschließend zum Ersten hinzugefügt und für $15 \mathrm{~min}$ bei $42{ }^{\circ} \mathrm{C}$ im Thermocycler inkubiert. Durch eine zusätzliche Inkubation bei $95{ }^{\circ} \mathrm{C}$ für 3 min wurde die Reverse Transkriptase inaktiviert. Die cDNA Proben mit einem Gesamtvolumen von $20 \mu \mathrm{l}$ wurden abschließend gekühlt und dauerhaft bei $-20^{\circ} \mathrm{C}$ gelagert.

\subsubsection{Quantitative Real-Time PCR (qRT-PCR)}

Die Expression Metastasen-assoziierten Gene wurde mittels einer $q R T$-PCR untersucht. Wie bei einer herkömmlichen $P C R$ werden auch hier Nukleinsäuren vervielfältigt und zusätzlich die entstandene DNA quantifiziert. Hierzu wurden CMT-93 Zellen intraportal in C57BL/6NCrl Mäuse implantiert und Lebern 3, 14 und 28 Tage post injectionem entnommen. Im Anschluss an die RNA Extraktion und cDNA Synthese, wurde letztere als Matrize für die $q R T-P C R$ verwendet.

Die Quantifizierung erfolgte mit Hilfe des $i Q^{T M} S Y B{ }^{\circledR}$ Green Supermix Kits (Bio-Rad, München), das u.a. eine thermostabile Taq-Polymerase und den Fluoreszenzfarbstoff $S Y B R^{\circledR}$ Green I enthält, der mit doppelsträngiger DNA interkaliert. Durch Laseranregung emittiert der Farbstoff grünes Licht bei einer Wellenlänge von $521 \mathrm{~nm}$, welches anhand eines ThermalCyclers (Bio-Rad, München) in Echtzeit (real time) detektiert werden kann. In jeder Amplifikationsrunde nimmt somit bei steigender Menge des PCR-Produkts auch die Fluoreszenz zu. Die Zykluszahl, bei der die Fluoreszenzemission einen Schwellenwert (threshold) erreicht und signifikant über dem Hintergrundrauschen liegt, wird als $\mathrm{C}_{\mathrm{t}}$-Wert bezeichnet. Je höher dieser Wert ist (höhere Zykluszahl), desto weniger mRNA ist vorhanden, um genug DNA zu amplifizieren, deren Fluoreszenzsignal das Hintergrundrauschen übertrifft (Tichopad et al., 2003). Die Quantifizierung des Fluoreszenzsignals erfolgt in der exponentiellen Phase der $P C R$, da hier optimale Reaktionsbedingungen gewährleistet sind. 
Im Rahmen dieser Arbeit wurde eine relative Quantifizierung durchgeführt. Diese zeichnet sich aus durch die Messung von Referenzgenen (Housekeeping Gene), die als interne Kontrolle dienen und unabhängig von Versuchsbedingungen eine konstante Expression aufweisen sollten. Anhand der Signale dieser Gene können Normierungen vorgenommen und somit mögliche Unterschiede bezüglich der Ausgangsmenge der verwendeten RNA ausgeglichen werden. So kann die Expression eines Zielgenes einer behandelten Gruppe (Lebermetastasen) mit der einer Referenzgruppe (gesunde Lebern) verglichen und der Expressionsunterschied mit Hilfe der Expression des Referenzgens bestimmt werden. Die Expressionsunterschiede (fold change) wurden nach der $\Delta \Delta \mathrm{C}_{\mathrm{t}}$-Methode ermittelt; die Berechnung erfolgte mit Hilfe der CFX-Manager Software Version 3.1 (Bio-Rad, München) und folgender Formel:

$$
\begin{gathered}
\text { Fold Change }=2^{-\Delta(\Delta \mathrm{CT})} \\
\left.\Delta(\Delta \mathrm{CT})=\left[\mathrm{C}_{\mathrm{t}(\text { Zielgen })}-\mathrm{C}_{\mathrm{t}(\text { Referenzgen })}\right)\right]_{\text {Metastase }}-\left[\mathrm{C}_{\mathrm{t}(\text { Zielgen })}-\mathrm{C}_{\mathrm{t}(\text { Referenzgen })}\right] \text { Gesunde Leber }
\end{gathered}
$$

Als Referenzgene wurden $\beta 2$-Mikroglobulin (B2M) und Hypoxanthin-Guanin-Phosphoribosyltransferase (HPRT) verwendet. Die eingesetzten Oligonukleotide sind Tab. 2.8 zu entnehmen. Diese wurden so gewählt, dass die Schmelztemperaturen bei etwa $60{ }^{\circ} \mathrm{C}$ lagen. Die Zusammensetzung des Reaktionsansatzes pro Gen wird in Tab. 2.13 dargestellt. Jeweils $19 \mu \mathrm{l}$ dieses Ansatzes wurden in die Vertiefungen einer 384-Mikrotiterplatte pipettiert und jeweils $1 \mu \mathrm{l}$ cDNA hinzugefügt. Pro Gen wurde jede Probe in Form von Triplikaten gemessen inklusive einer Dreifachbestimmung ohne RNA-Template (non-template control) zur Kontrolle der Oligonukleotide. Anschließend wurde die Mikrotiterplatte versiegelt und zur Vereinigung der einzelnen Bestandteile kurz zentrifugiert. Die Messung erfolgte nach dem Protokoll in Tab. 2.14. Neben der Quantifizierung wurde auch eine Schmelzkurvenanalyse durchgeführt, anhand derer die Spezifität der PCR-Reaktion kontrolliert werden konnte. Die Datenauswertung erfolgte mit Hilfe der CFX-Manager Software Version 3.1 (Bio-Rad, München).

Tab. 2.13: Reaktionsansatz pro Gen für eine $q R T$-PCR Analyse

\begin{tabular}{ll}
\hline Komponente & Volumen $[\boldsymbol{\mu l}]$ \\
\hline $\mathrm{H}_{2} \mathrm{O}$ & 8 \\
$i Q^{\text {TM }}$ SYBR® Green $2 x$ & 10 \\
Forward Primer $[10 \mathrm{mM}]$ & 0,5 \\
Reverse Primer $[10 \mathrm{mM}]$ & 0,5 \\
cDNA & 1 \\
\hline
\end{tabular}


Tab. 2.14: Temperaturprogramm der $q R T$-PCR Analyse

\begin{tabular}{llll}
\hline Schritt & Temperatur $\left[{ }^{\circ} \mathrm{C}\right]$ & Zeit [min] & Anzahl der Zyklen \\
\hline Aktivierung der Taq-Polymerase & 95 & 5 & 0 \\
Denaturierung & 95 & 0,3 & 40 \\
Primerhybridisierung (Annealing) & 60 & 0,3 & 40 \\
Schmelzkurvenanalyse & $55-95$ & 13,3 & 0 \\
& $\left(+0,5^{\circ} \mathrm{C} / 10\right.$ Sek.) & & \\
\hline
\end{tabular}

\subsubsection{RNA Sequenzierung}

Die RNA Sequenzierung wurde im Rahmen dieser Arbeit vom Transkriptom- und Genomanalyselabor (TAL) in Göttingen unter der Leitung von Dr. Gabriela Salinas durchgeführt. Dabei handelt es sich um eine Hochdurchsatzmethode, bei der die Nukleotidabfolge der RNA ermittelt wird und Gene mit einer hoch- bzw. herunterregulierten Expression identifiziert werden können. Auf diese Weise kann das komplexe Transkriptom, also die Gesamtheit aller Gene, einer biologischen Probe zu einem bestimmten Zeitpunkt untersucht werden (Wang et al., 2009). So bietet sich folglich die Möglichkeit, den Einfluss verschiedener experimenteller Bedingungen, wie beispielsweise der Einfluss eines Medikaments oder einer Behandlung, auf molekularer Ebene vergleichen zu können.

Für Sequenzierungszwecke wurden $1 \times 10^{6}$ CMT-93 Zellen in 12-Wochen alte weibliche C57BL/6NCrl Mäuse implantiert und sieben Versuchstiere 28 Tage post injectionem getötet. Pro Tier wurden Proben aus folgenden Leberarealen entnommen: Tumorkern, Tumorrand, tumorfreier Rand und makroskopisch tumorfreies Gewebe. Die Proben wurden unmittelbar nach der Entnahme in sterile Kryoröhrchen überführt und in flüssigem Stickstoff schockgefroren. Als Kontrolle wurden CMT-93 Zellen sowie Sham-operierte C57BL/6NCrl verwendet. Letztere haben analog zur Tumorzellimplantation eine intraportale Injektion von jeweils $100 \mu \mathrm{l}$ PBS erhalten. Auf diese Weise konnte der Einfluss der reinen OP (ohne Tumorzellen) kontrolliert werden. Nach einer RNA Isolation und Bestimmung der RNAKonzentration wurden die Proben an das TAL weitergeleitet. Aufgrund der Instabilität der RNA erfolgte dort zunächst eine Qualitätskontrolle der Proben anhand eines Agilent 2100 BioAnalyzers (Agilent Technologies, USA) zur Überprüfung der RIN Werte (RNA Integrity Number). Auf einer Skala von 1 (komplett degradierte RNA) bis 10 (vollständig intakte RNA) wurde die RNA-Qualität bewertet, so dass die Sequenzierung mit möglichst qualitativ hochwertigem Material durchgeführt werden konnte (Schroeder et al., 2006). Zur Sequenzierung der Proben wurde 0,5 $\mu$ g der gesamten RNA fragmentiert. Mit Hilfe des TruSeq RNA Library Preparation Kit v2 (Illumina Inc., USA) wurde auf Basis der vorhandenen mRNA eine Sequenzierungsbibliothek erstellt. Das fluorometrische QuantiFluor ${ }^{T M}$ dsDNA System 
(Promega, Mannheim) wurde für eine exakte Quantifizierung der cDNA Libraries verwendet. Die finale Größe der cDNA Libraries wurde anhand eines Fragment Analyzers (Advanced Analytical, Heidelberg) ermittelt. Die Amplifizierung und Sequenzierung erfolgte schließlich anhand des cBot Systems und des HiSeq2000 Sequenzierers (Illumina Inc., USA), so dass Transkripte erfasst und in sogenannten Reads zusammengefasst wurden, bestehend aus Name, Sequenz und Eigenschaften (1 x 50 bp; ca. 30 Mio. Reads pro Probe). Sequenzierungsgraphiken wurden mit Hilfe der BaseCaller Software (Illumina Inc., USA) in bcl Daten umgewandelt. Anhand der CASAVA Software (Illumina Inc., USA) wurden schließlich fastq Daten generiert und diese via fastqc einer Qualitätskontrolle unterzogen. Die Zuordnung (mapping) der Transkripte zu Genen oder Genisoformen und das Zählen (counting) der Reads erfolgte mit Hilfe der STAR-Aligner Software (Spliced Transcripts Alignment to Reference) (Dobin et al., 2013) und dem Expectation-Maximization-Algorithmus implementiert in der RSEM Software (Li \& Dewey, 2011). Als Referenz für die Genzuordnung und -annotation wurde die Genomdatenbank Ensembl Mus musculus GRCh38 Version 78 verwendet.

\subsubsection{Biochemische Methoden}

\subsubsection{Durchflusszytometrie}

Die Durchflusszytometrie ist eine Methode zur quantitativen und qualitativen Analyse und Charakterisierung von Zellen. Die Methode beruht auf einer Antigen-Antikörper-Reaktion, bei der die Fluoreszenzemission von Fluorophor-konjugierten spezifischen Antikörpern detektiert wird. Mit Hilfe von Durchflusszytometriegeräten $($ FACS Gerät $=$ Fluorescence Activated Cell Sorting), bestehend aus einem Laser, Linsen, Spiegeln, Detektoren und Filtern, erfolgt die Signaldetektion. Zur Durchführung einer durchflusszytometrischen Analyse werden Zellen mit Hilfe eines Fluoreszenzfarbstoff-gekoppelten Antikörpers markiert und in einer Kapillare des FACS Geräts hydrodynamisch fokussiert. Es folgt eine Weiterleitung in eine Durchflusszelle, wo Zellen einzeln einen Laserstrahl passieren, der den Fluoreszenzfarbstoff anregt. Anhand der charakteristischen Emission des fluoreszierenden Antikörpers und der Lichtstreuung wird die Expressionsstärke eines spezifischen Antigens detektiert. Die Emissionseigenschaften sind u.a. abhängig vom Zellvolumen, von der -größe, granularität und -struktur und von intrazellulären Merkmalen. Sofern sich ihre Emissionsspektren unterscheiden, können mehrere Fluoreszenzfarbstoffe eingesetzt werden. 
Im Rahmen dieser Arbeit wurde anhand einer Oberflächenfärbung die Qualität und der Status von differenzierten und polarisierten Makrophagen untersucht. Die Messung erfolgte an einem BD FACSCanto ${ }^{\text {TM }}$ II Flow Cytometer (BD Biosciences, Heidelberg); zur graphischen und quantitativen Auswertung wurde die entsprechende BD FACSDiva ${ }^{\text {TM }}$ Software Version 6.1.3 (BD Biosiences, Heidelberg) verwendet. An Tag 7 und Tag 10 der Differenzierung bzw. Polarisation der Makrophagen wurde eine FACS Färbung durchgeführt. Hierzu wurden $1 \mathrm{x}$ $10^{6}$ Zellen in die Vertiefungen einer 6-well Zellkulturschale überführt und 48 Stunden mit den entsprechenden Zytokinen inkubiert (siehe Kapitel 2.2.4.3). Das Medium der Zellen wurde in ein $15 \mathrm{ml}$ Reaktionsgefäß überführt, adhärente Zellen einmal kurz mit PBS gewaschen und je $500 \mu \mathrm{l}$ Accutase (Sigma, Steinheim) hinzugefügt. Nach einer 5- bis 10-minütigen Inkubation bei $37^{\circ} \mathrm{C}$ wurden die Zellen von der Kulturschale gelöst und ebenfalls in die entsprechenden Reaktionsgefäße überführt. Es folgte eine 5-minütige Zentrifugation bei $1200 \mathrm{rpm}$ und $4{ }^{\circ} \mathrm{C}$. Die Zellen wurden von Mediumrückständen befreit und gewaschen, indem das Zellpellett in $1 \mathrm{ml}$ eiskaltem FACS Puffer resuspendiert und erneut zentrifugiert wurde. Nach Wiederholung dieses Waschschrittes wurden die Zellen gleichmäßig in die Vertiefungen einer 96-well Zellkulturplatte verteilt und diese $5 \mathrm{~min}$ bei $1200 \mathrm{rpm}$ und $4{ }^{\circ} \mathrm{C}$ zentrifugiert. Nach Entfernung des Überstandes folgte eine 30-minütige Antikörperinkubation (je $100 \mu \mathrm{l} /$ well) im Dunkeln bei $4{ }^{\circ} \mathrm{C}$. Das Hintergrundsignal des Primärantikörpers wurde mit Hilfe von Isotypkontrollen überprüft; die verwendeten Antikörper und Isotypkontrollen sind Tab. 2.6. zu entnehmen. Anschließend folgten zwei Waschschritte mit je $100 \mu \mathrm{l}$ FACS Puffer und einer 5-minütigen Zentrifugation bei $1200 \mathrm{rpm}$ und $4{ }^{\circ} \mathrm{C}$. Schließlich wurden die Zellen in je $100 \mu \mathrm{l}$ FACS Puffer resuspendiert und in $5 \mathrm{ml}$ Rundbodenröhrchen (BD Biosciences, Heidelberg), ebenfalls befüllt mit jeweils $100 \mu \mathrm{l}$ FACS Puffer, überführt. Im Falle der anti-CD163 Färbung folgte eine 30-minütige Inkubation mit dem Sekundärantikörper anti-rabbit Alexa Fluor ${ }^{\circledR} 488$ (Thermo Fisher Scientific, Schwerte). Die spezifische Bindung des Sekundärantikörpers wurde kontrolliert, indem der Inkubationsschritt mit dem Primärantikörper übersprungen wurde. Bis zur Messung am gleichen Tag wurden die Proben im Dunkeln bei $4{ }^{\circ} \mathrm{C}$ gelagert.

\subsubsection{Immunhistochemie}

Die morphologische Charakterisierung von Lebermetastasen erfolgte anhand von immunhistochemischen Färbung an Kryo- und Paraffinschnitten. Mikroskopiert wurden die Gewebeschnitte am Durchlichtmikroskop Axioskop 2 Plus (Carl Zeiss Microscopy GmbH, Göttingen). 


\section{Kryoschnitte:}

Zur Anfertigung von Kryoschnitten wurden Leberproben in Kryoröhrchen bei $-80{ }^{\circ} \mathrm{C}$ gelagert (siehe Kapitel 2.2.4.2). Um Gewebeschäden durch das Einfrieren möglichst gering zu halten, wurden die Kryoröhrchen unmittelbar nach der Organentnahme in einen Schraubbecher mit ca. $15 \mathrm{ml}$ Methylbutanol überführt. Dieser wurde mit Hilfe einer Zange 2 min in einem Dewar Transportgefäß mit flüssigem Stickstoff inkubiert, um auf diese Weise ein langsames und somit schonendes Einfrieren des Gewebes zu gewährleisten. Für immunhistochemische Färbungen wurden mit Hilfe des Kryostats CM1950 (Leica Biosystems, Nussloch) Schnitte mit einer Dicke von $5 \mu \mathrm{m}$ angefertigt und auf Superfrost Plus Objektträger (Menzel, Braunschweig) überführt. Diese wurden über Nacht getrocknet und am Folgetag 10 min in eiskaltem Aceton fixiert. Die langfristige Lagerung der Schnitte erfolgte bei $-80{ }^{\circ} \mathrm{C}$. Kurz vor einer Färbung wurden Schnitte in einem Färbetrog mit Tris Puffer rehydratisiert und ggf. mit Hilfe eines MultiGourmet Dampfgarers (De'Longhi, Neu-Isenburg) 30 min bei $97{ }^{\circ} \mathrm{C}$ in einer 10 \%igen Target Retrieval Solution (Tris/EDTA Puffer, pH 9) erhitzt (anti- $\beta$-catenin, anti-Ecadherin, anti-Ki-67 Färbung). Auf diese Weise wurde das Gewebe permeabilisiert und Epitope für spezifische Antikörper zugänglich gemacht. Im Falle der anti-CD206 Färbung erfolgte die Permeabilisierung mittels einer 0,5 \%igen Triton X-100 Lösung (10-minütige Inkubation bei RT). Endogene Peroxidase wurde bei allen Färbungen durch eine 20-minütige Inkubation mit 0,3 \% Wasserstoffperoxid in $70 \%$ Methanol und $30 \%$ Tris Puffer bei RT inaktiviert. Als Vorbereitung für eine Inkubation mit dem Sekundärantikörper Avidin HRP, wurden Schnitte ggf. mit einem 10-minütigen Avidin/Biotin Blockierungsschritt anhand eines Kits von Thermo Fisher Scientific vorbehandelt (anti-CD44, anti-CD11b, anti-CD68, anti-CD86, anti-CD163, anti-CD206, anti-F4/80 Färbung). Um kreuzreaktive Proteine zu blockieren, folgte eine 20-minütige Inkubation mit einem Fishblock (SurModics BioFx, Eden Prairie, USA) bei RT. Anschließend wurde eine Primärantikörperinkubation in einer Feuchtkammer bei 4 ${ }^{\circ} \mathrm{C}$ über Nacht durchgeführt. Primärantikörper wurden mit Hilfe eines Antikörperdiluenten (Dako, Hamburg) in der entsprechenden Verdünnung vorbereitet und sind Tab. $2.5 \mathrm{zu}$ entnehmen.

Am Folgetag wurde das Gewebe mit einem biotinylierten Sekundärantikörper eine Stunde bei RT inkubiert, gefolgt von einer ebenfalls einstündigen Inkubation mit Avidin HRP (anti-CD44, anti-CD11b, anti-CD68, anti-CD86, anti-CD163, anti-CD206, anti-F4/80 Färbung) oder der entsprechende HRP-gekoppelte Sekundärantikörper wurde für eine Stunde bei RT direkt aufgetragen (anti- $\beta$-catenin, anti-E-cadherin, anti-Ki-67, anti-Vimentin Färbung). Die Visualisierung der spezifischen Färbung erfolgte mit Hilfe eines AEC Substrate Kits (BD Biosciences, Heidelberg); dieses besteht aus dem chromogenen Substrat 3-Amino-9- 
ethylcarbazol und färbt das Zielantigen nach Oxidation mit Wasserstoffperoxid rot ein. Zellkerne wurden mittels einer Mayers Hämalaunlösung (Merck, Darmstad) angefärbt. Gewebeschnitte wurden abschließend mit Hilfe von Aquatex (Merck, Darmstadt) eingedeckt und über Nacht getrocknet. Kontrollfärbungen wurden durchgeführt, indem der Primärantikörper weggelassen und nur der Sekundärantikörper aufgetragen wurde. Als Kontrollgewebe wurden Leberschnitte von unbehandelten und von Sham-operierten Mäusen verwendet bzw. Schnitte entsprechender Organe (Darm, Milz) als Positivfärbung angefertigt. Mit Ausnahme der Hämalaun-Eosin (HE) Färbung, wurden alle Färbungen an Kryoschnitten durchgeführt.

\section{Paraffinschnitte:}

Paraffinschnitte wurden zum Zwecke einer HE Färbung angefertigt, um eine makroskopische Übersicht der CMT-93 induzierten Lebermetastasen zu erhalten. Hierfür wurden unmittelbar nach der Organentnahme Leberproben in Einbettkassetten überführt und ca. 24 Stunden in 4 \%igem Formalin fixiert. Im Anschluss folgte eine Probendehydratation in einem Gewebeinfiltrationsautomaten (Leica, Nussloch) und schließlich das Einbetten in Paraffin anhand eines Gewebeeinbettautomaten (Leica, Nussloch). Paraffinblöcke wurden langfristig bei RT gelagert. Zur Anfertigung von HE Färbungen wurden mit Hilfe des Microtoms HM 340E (Thermo Scientific, Schwerte) Schnitte mit einer Dicke von $2 \mu \mathrm{m}$ vorbereitet und auf Superfrost Plus Objektträger (Menzel, Braunschweig) überführt. Diese wurden trocken gelagert und kurz vor einer anstehenden Färbung $30 \mathrm{~min}$ bei $60^{\circ} \mathrm{C}$ inkubiert, um das Gewebe auf dem Objektträger zu fixieren. Das Protokoll zur Entparaffinierung und für HE Färbungen ist Tab. $2.15 \mathrm{zu}$ entnehmen. Im Anschluss an die Färbung wurden Gewebeschnitte mit Hilfe von DePeX (Serva Electrophoresis, Heidelberg) eingedeckt.

Tab. 2.15: Entparaffinieren und färben von Paraffinschnitten der Lebermetastasen

\begin{tabular}{llll}
\hline Schritt & Reagenz & Inkubationsschritte & $\begin{array}{l}\text { Inkubationsdauer } \\
\text { [min] }\end{array}$ \\
\hline \multirow{2}{*}{ Entparaffinieren } & Xylol & 2 & 7 \\
& Isopropanol & 1 & 5 \\
& Ethanol 98 \% & 1 & 5 \\
& Ethanol 75 \% & 1 & 5 \\
& VE-Wasser & 1 & 5 \\
\hline \multirow{2}{*}{ HE Färbung } & Mayers Hämalaunlösung & 1 & 5 \\
& VE-Wasser & 1 & 5 \\
& & 1 & kurz abspülen
\end{tabular}




\begin{tabular}{lll}
\hline Fließendes Leitungswasser & 1 & 5 \\
Eosin & 1 & 5 \\
VE-Wasser & 1 & kurz abspülen \\
Ethanol $60 \%$ & 1 & kurz eintauchen \\
Ethanol $75 \%$ & 1 & kurz eintauchen \\
Ethanol $98 \%$ & 1 & 5 \\
Isopropanol & 1 & 5 \\
Xylol & 2 & 5 \\
\hline
\end{tabular}

\subsubsection{Messung der Viabilität und Proliferation anhand eines MTS Assays}

Die Interaktion von Tumorzellen und Makrophagen wurde im Rahmen dieser Arbeit durch in vivo und in vitro Analysen untersucht. Die in vitro Analyse erfolgte anhand von Kokulturversuchen durch die Inkubation von CMT-93 Zellen mit konditioniertem Medium von Makrophagenphänotypen. Dabei handelt es sich um serumfreie Gewebekulturmedien, in denen Makrophagenphänotypen 24 Stunden inkubiert wurden und in dieser Zeit zelltypspezifische Faktoren sezernierten. Der Einfluss des konditionierten Mediums auf Tumorzellen wurde mittels einer qRT-PCR und eines CellTiter96 ${ }^{\circledR}$ AQueous One Solution Cell Proliferation Assays (MTS Assay, Promega, Mannheim) untersucht. Der Assay beinhaltet als Farbstoff eine Tetrazoliumverbindung [3-(4,5-dimethylthiazol-2-yl)-5-(3carboxymethoxyphenyl)-2-(4-sulfophenyl)-2H-tetrazolium, inner salt; MTS) sowie Phenazinethosulfat, die gemeinsam eine stabile Bindung hervorrufen. Mit Hilfe von Dehydrogenaseenzymen metabolisch aktiver Zellen wird die MTS-Verbindung in Formazan umgewandelt, welches löslich ist in Zellkulturmedium. Durch die Zugabe kleiner Mengen des Reagenzes zu Tumorzellen kann nach einer Inkubationsdauer von 1 - 4 Stunden die Formazanmenge kolorimetrisch bei $490 \mathrm{~nm}$ ermittelt werden, welche proportional ist zur Anzahl lebender Zellen.

Für Kokulturversuche wurden 5 x 103 CMT-93 Zellen, die zuvor in DMEM (1 g/l Glucose) und $1 \%$ FBS kultiviert wurden, in die Vertiefungen einer 96-well Zellkulturschale ausgesät und 24 Stunden bei $37^{\circ} \mathrm{C}$ inkubiert. Am Folgetag wurde das Kulturmedium entfernt und folgende Medien hinzugefügt:

Bedingung 1: $D M E M$ (mit $1 \%$ FBS) $+30 \%$ bzw. $50 \%$ M0 konditioniertes Medium Bedingung 2: DMEM (mit 1\% FBS) + 30 \% bzw. 50 \% M1 konditioniertes Medium Bedingung 3: DMEM (mit 1\% FBS) + 30 \% bzw. 50 \% M2 konditioniertes Medium Bedingung 4: DMEM $1 \%$ FBS

Bedingung 5: DMEM $10 \%$ FBS 
Das Experiment wurde drei Mal durchgeführt mit mindestens sechs Replikaten pro Bedingung. Tumorzellen wurden 24,48 und 72 Stunden bei $37^{\circ} \mathrm{C}$ inkubiert und ein MTS Assay nach dem Protokoll des Herstellers durchgeführt. Nach der entsprechenden Inkubationszeit wurde das Medium entfernt und pro well eine Mischung aus $20 \mu \mathrm{l}$ Reagenz und $100 \mu \mathrm{l}$ Kulturmedium hinzugefügt. Nach einstündiger Inkubation bei $37^{\circ} \mathrm{C}$ wurde mit Hilfe des Plattenphotometers Multilable Reader VICTOR ${ }^{\text {TM }}$ X4 (PerkinElmer Office, Rodgau) die Absorption bei $490 \mathrm{~nm}$ gemessen. Um die Absorption des Mediums zu korrigieren, wurde zusätzlich das Medium jeder Bedingung in Triplikaten ohne Zellen gemessen und der Mittelwert von den Absorptionsdaten der Zellen subtrahiert. Die Daten wurden in Relation zu Zellen gesetzt, die Medium mit 10 \% FBS erhalten haben. Daraus wurde schließlich der relative Anteil lebender Zellen unter den angegebenen Bedingungen berechnet.

\subsubsection{Tierexperimentelle Methoden}

\subsubsection{Zellimplantation}

Im Fokus der vorliegenden Arbeit befand sich u.a. die zeitabhängige Formation von Lebermetastasen induziert durch CMT-93 Zellen. Etwa zwei Stunden vor Implantation wurden CMT-93 Zellen abgelöst und gezählt. Pro Tier wurden jeweils 1 x $10^{6}$ Zellen gelöst in je $100 \mu \mathrm{l}$ PBS intraportal injiziert. Um den Zellschaden möglichst gering zu halten, wurden Zellen während den Operationen durchgehend auf Eis gelagert und Eingriffe zügig durchgeführt.

Vor dem Eingriff erhielten Mäuse eine subkutane Injektion von Carprofen (Rimadyl ${ }^{\circledR}$, Pfizer, Berlin) mit einer Dosierung von $5 \mathrm{mg} / \mathrm{kg}$ Körpergewicht. Nach etwa einer Stunde wurden die Tiere anhand des Narkosemittelverdampfers Dräger Vapor ${ }^{\circledR} 2000$ (Drägerwerk, Lübeck) unter konstanter Sevofluraninhalation (ca. $2 \mathrm{l} / \mathrm{min} \mathrm{O}_{2}$ und 4 Vol.-\% Sevolfuran) anästhesiert, das Gewicht dokumentiert und das Bauchfell anhand einer Aesculap Schermaschine (Braun, Melsungen) entfernt. Um ein Austrocknen der Augen zu verhindern, wurden kleine Mengen des Carbomerwirkstoffs Thilo-Tears Augengel aufgetragen. Ein starkes Abkühlen der Mäuse wurde verhindert, indem Eingriffe auf sogenannten SnuggleSafe Wärmekissen (SnuggleSafe Lenric C21, West Sussex, UK) durchgeführt wurden. Die Tiere wurden in Rückenlage positioniert und nach Desinfektion des Bauches Leberhilus und Pfortader anhand einer medianen Laparotomie freigelegt (Abb. 2.1). Mit Hilfe einer Micro-Fine ${ }^{\mathrm{TM}}$ Insulinspritze mit einem Durchmesser von 30 G (BD Biosciences, Heidelberg) wurden 1 x 106 CMT-93 Zellen in einem Volumen von $100 \mu \mathrm{l}$ PBS aufgezogen und innerhalb einer Minute langsam in die Pfortader injiziert. Als Kontrolltiere wurden Sham-operierte Mäuse verwendet, die eine 
intraportale Injektion von jeweils $100 \mu$ PBS ohne Tumorzellen erhalten haben. Um den Blutfluss aus der Eintrittswunde stillen zu können, wurde nach Entfernung der Insulinspritze die Wunde zügig mit Spongostan, einem Pad bestehend aus resorbierbarer Gelatine vom Schwein sowie Natriumlaurylsulfat, mit leichtem, aber stetigem Druck abgedeckt. Nach 2 min wurde die Blutung kontrolliert; bei einer bestehenden Hämostase wurde die Leber wieder in ihre ursprüngliche Position in der Bauchhöhle befördert und das Abdomen mit Hilfe eines resorbierbaren Fadens (Johnson \& Johnson Medical GmbH, Norderstedt) und durch Einzelknopfnaht zugenäht. Bei fortbestehender Blutung wurde die Wunde für weitere 2 min mit dem Pad abgedeckt. Im Anschluss wurde die Sevofluraninhalation durch die Zugabe von Sauerstoff ersetzt und Mäuse nach einem hauseigenen Ohrlochschema markiert. Die Tiere wurden in ihre Käfige überführt, welche auf einer $37{ }^{\circ} \mathrm{C}$ warmen Heizplatte aufgestellt wurden, um auch hier eine Unterkühlung zu vermeiden. Eine Woche nach dem Eingriff wurden die Tiere täglich kontrolliert und das Gewicht dokumentiert. Anschließend folgte eine wöchentliche Kontrolle bis zur Organentnahmen.

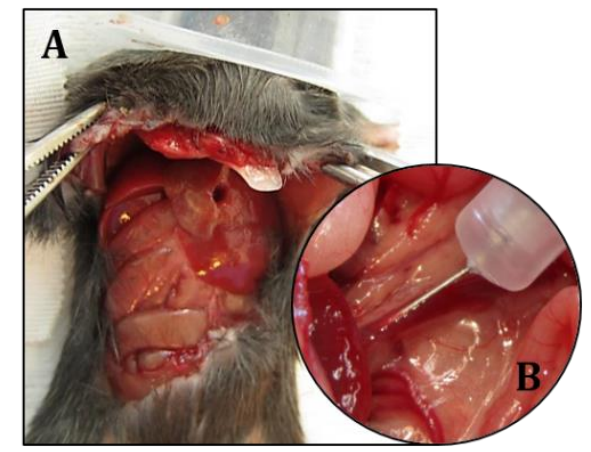

Abb. 2.1: Intraportale Implantation von Tumorzellen. Nach medianer Laparotomie (A) wurde die Vena portae freigelegt (B), so dass Tumorzellen mit Hilfe einer Micro-Fine ${ }^{\mathrm{TM}}$ Insulinspritze implantiert werden konnten (C).

Für eine intrasplenische Injektion der Tumorzellen wurde das Abdomen der Mäuse lateral geöffnet und die Milz freigelegt. Die Zellen wurden direkt mittels einer Insulinspritze in das Organ implantiert. Im Falle der subkapsulären Implantation wurden Zellen mit Hilfe einer Hamilton Injektionspritze (B. Braun, Melsungen) direkt unter die Kapsel des rechten Leberlappens implantiert. Bei einer subkutanen Implantation wurde die Flanke der Maus desinfiziert und 2,5 x $10^{6}$ Zellen anhand einer Insulinspritze injiziert.

\subsubsection{Organentnahme}

Für eine Organentnahme wurden Mäuse unter konstanter Sevofluraninhalation anästhesiert und das Gewicht dokumentiert. Nach Desinfektion des Bauches und medianer Laparotomie wurde die Bauchdecke seitlich weggeklappt und die Leber freigelegt. Vor einer Leberexplantation wurde das Zwerchfell geöffnet und ein Pneumothorax bzw. ein Kollaps der 
Lungenflügel hervorgerufen. Anschließend wurde die Vena cava superior, die in den rechten Vorhof des Herzens einmündet, geöffnet. Die Leber wurde zügig explantiert und photographisch dokumentiert. Ganze Lebern (qRT-PCR) bzw. Leberareale (RNA Sequenzierung) wurden schließlich in Kryoröhrchen überführt und in einem Dewar Transportgefäß (KGW Isotherm, Karlsruhe) mit flüssigem Stickstoff schockgefroren. Für immunhistochemische Analysen wurden Leberproben entweder mit Hilfe von Methylbutanol langsam eingefroren (Kryoschnitte) oder über Nacht in 4 \%igem Formalin fixiert (Paraffinschnitte).

\subsubsection{Isolation von BMDMs (Bone Marrow Derived Monocytes)}

Die Interaktion von Tumorzellen und Makrophagen wurde untersucht, indem knochenmarkstämmige Monozyten aus Mausfemora isoliert und zu Makrophagen differenziert wurden. Als Vorlage diente hier ein Videoartikel von Ying et al. aus dem Jahre 2013, welches nach Zhang et al. modifiziert angewandt wurde (Zhang et al., 2013). 9-Wochen alte weibliche C57BL/6NCrl Mäuse wurden durch eine zervikale Dislokation getötet, auf einem Korkbrett fixiert und mit Meliseptol der Hinterlauf desinfiziert. Die Felldecke wurde mittels einer Pinzette in der Medianlinie des Beckens angehoben und durch eine Schere ein Querschnitt angelegt, ohne die Bauchdecke zu verletzen. Die Schere wurde unter der Felldecke entlanggeführt, um den Knochen freizulegen. Das Femur wurde von Muskeln und Sehnen befreit und mit Hilfe eines Skalpells entnommen, ohne dabei die Knochenendköpfchen zu verletzen. Der Oberschenkelknochen wurde nun in eine Zellkulturschale (Sarstedt, Nümbrecht) überführt, mit Hilfe von sterilen Mullkompressen und Meliseptol desinfiziert und von Muskelresten befreit. Unter einer Sicherheitswerkbank (Heraeus, Hanau) wurde der Knochenmarkskanal durch Abschneiden der Knochenendköpfchen geöffnet. Der Knochen wurde an beiden eröffneten Enden mit je 2,5 ml kaltem FACS Puffer gespült und Zellen in einer sterilen Zellkulturschale aufgefangen. Mit dem zweiten Oberschenkelknochen wurde ebenso verfahren und die Zellen in die gleiche Zellkulturschale hinzugefügt. Im Anschluss wurden die Zellen durch ein $70 \mu \mathrm{m}$ Zellsieb (Corning, Wiesbaden) in ein $50 \mathrm{ml}$ Reaktionsgefäß passiert, um Zellklumpen, Knochen, Haare und/oder Gewebe zu entfernen. Das dreifache Volumen des auf RT aufgewärmten $R B C$ Lysepuffers wurde hinzugefügt; dieser enthält Ammoniumchlorid und wird zur Lyse von Erythrozyten eingesetzt. Es folgte eine Inkubation von 10 min auf Eis und eine 5-minütige Zentrifugation bei $500 \mathrm{~g}$ und $4{ }^{\circ} \mathrm{C}$. Das Zellpellet wurde in $5 \mathrm{ml}$ kaltem FACS Puffer resuspendiert und erneut zentrifugiert. Danach wurden Monozyten in $5 \mathrm{ml}$ Makrophagenmedium (DMEM $1 \mathrm{~g} / \mathrm{l}$ Glucose, $10 \%$ hitzeinaktiviertes FBS, $50 \mathrm{ng} / \mathrm{ml} M$-CSF, 1 \% Penicillin/Streptomycin) aufgenommen und Zellen gezählt. Die Zellsuspension wurde 
anschließend in eine beschichtete Zellkulturschale CytoOne ${ }^{\circledR}$ (Starlab, Hamburg) überführt und $5 \mathrm{ml}$ Medium hinzugefügt. Zellen von zwei weiteren Mäusen wurden nach dem gleichen Protokoll isoliert; die Inkubation erfolgte über Nacht bei $37^{\circ} \mathrm{C}$.

\section{Tag 1 nach Zellisolation:}

Zur Untersuchung der Morphologie wurden Aufnahmen der Zellen mit Hilfe des inversen Mikroskops Primovert (Carl Zeiss Microscopy GmbH, Göttingen) angefertigt. Der Überstand der Zellen, in dem sich die Monozyten befanden, wurde in ein $50 \mathrm{ml}$ Zentrifugenröhrchen überführt. Die Zellkulturschale wurde einmal kurz mit $5 \mathrm{ml}$ PBS gewaschen und dieser Rest ebenfalls in das Röhrchen hinzugefügt. Im Anschluss folgte eine 10-minütige Zentrifugation bei $1200 \mathrm{rpm}$ und RT. Das Zellpellet wurde in $10 \mathrm{ml}$ Makrophagenmedium (inklusive 50 $\mathrm{ng} / \mathrm{ml} M-C S F$ ) resuspendiert. Die zwei weiteren Zellkulturschalen wurden ebenso behandelt und Zellen vereinigt, so dass schließlich Monozytenpräparationen von drei Mäusen zusammengeführt wurden. Die Monozyten wurden nun auf acht Zellkulturschalen (Sarstedt, Nümbrecht) verteilt, das Medium auf $10 \mathrm{ml}$ aufgefüllt und bei $37^{\circ} \mathrm{C}$ kultiviert.

\section{Tag 3 nach Zellisolation:}

Zellen wurden erneut makroskopisch untersucht. Wenn sich zu diesem Zeitpunkt Monozyten zum Großteil auf dem Schalenboden abgesetzt hatten, wurde das Medium entfernt und durch frisches DMEM (inklusive $50 \mathrm{ng} / \mathrm{ml} M$-CSF) ersetzt. War dies nicht der Fall, wurden jeweils 5 ml frisches Medium dem bereits Vorhandenen hinzugefügt.

\section{Tag 7 nach Zellisolation:}

An Tag sieben nach der Isolation von Monozyten wurden erneut mikroskopische Aufnahmen am Primovert Mikroskop (Carl Zeiss Microscopy GmbH, Göttingen) angefertigt. Das Medium der Zellen wurde in $50 \mathrm{ml}$ Zentrifugenröhrchen überführt, Zellkulturschalen einmal kurz mit PBS gewaschen und ebenfalls in das Röhrchen hinzugefügt. Um nun adhärent wachsende Makrophagen vom Schalenboden zu lösen, wurde je $1 \mathrm{ml}$ Accutase pro Schale zugegeben und 5 - 10 min bei $37^{\circ} \mathrm{C}$ inkubiert. Trypsin/EDTA wurde nicht verwendet, um eine Beschädigung von Zelloberflächenproteinen zu verhindern, deren Expression anhand einer FACS Analyse untersucht werden sollte. Die Reaktion wurde durch die Zugabe von $5 \mathrm{ml}$ Makrophagenmedium gestoppt und die Zellsuspensionen der acht Zellkulturschalen vereinigt. Es folgte eine 10-minütige Zentrifugation bei $1200 \mathrm{rpm}$ und RT. Das Zellpellet wurde in $10 \mathrm{ml}$ Makrophagenmedium aufgenommen und in einer Neubauerzählkammer die Zellzahl ermittelt. Etwa 2 × $10^{6}$ Zellen wurden für eine FACS Analyse entnommen, um anhand 
einer anti-CD11b und anti-F4/80 Färbung sowie der entsprechenden Doppelfärbung den Differenzierungsstatus der Makrophagen zu untersuchen (Tab. 2.6).

Ein Teil der Zellen wurde in 6-well Zellkulturschalen für Suspensionszellen (Sarstedt, Nümbrecht) ausgesät mit jeweils 1 x $10^{6}$ Zellen/well, um sie zu verschiedenen Makrophagenphänotypen $\mathrm{zu}$ polarisieren und diese später durchflusszytometrisch analysieren zu können. Jeweils zwei wells wurden für folgende Ansätze vorbereitet: M0 Makrophagen (nicht-polarisiert), M1 Makrophagen, M2 Makrophagen und unbehandelte Zellen zur Einstellung des FACS Gerätes. Dem Medium der M1 Makrophagen wurden bereits $100 \mathrm{ng} / \mathrm{ml}$ LPS (Sigma-Aldrich, München) hinzugefügt; die restlichen Zellen wurden zunächst weiterhin mit $50 \mathrm{ng} / \mathrm{ml} M$-CSF kultiviert.

Ein weiterer Teil der Zellen wurde zur Herstellung von konditionierten Medien verwendet. Hierzu wurden je $3 \times 10^{6}$ Zellen in drei Zellkulturschalen ausgesät. Auch hier wurde einer Schale bereits $100 \mathrm{ng} / \mathrm{ml}$ LPS zur M1 Aktivierung hinzugefügt, während die restlichen Zellen mit $50 \mathrm{ng} / \mathrm{ml} M-C S F$ kultiviert wurden.

\section{Tag 8 nach Zellisolation:}

An Tag acht nach Zellisolation wurde das Medium der Zellen vorsichtig entfernt und je $2 \mathrm{ml}$ des Stimulationsmediums hinzugefügt:

M0 Makrophagen: frisches Makrophagenmedium + $50 \mathrm{ng} / \mathrm{ml} M-C S F$

M1 Polarisation: frisches Makrophagenmedium $+100 \mathrm{ng} / \mathrm{ml} L P S+50 \mathrm{ng} / \mathrm{ml}$ IFN- $\gamma$

M2 Polarisation: $\quad$ frisches Makrophagenmedium $+20 \mathrm{ng} / \mathrm{ml} I L-4$

Ausgesäte Zellen zur Herstellung von konditionierten Medien erhielten je $10 \mathrm{ml}$ frisches Medium nach dem obigen Schema.

\section{Tag 10 nach Zellisolation:}

Die Makrophagenpolarisation wurde schließlich anhand einer durchflusszytometrischen Analyse kontrolliert. Die Zellen wurden, wie unter Abschnitt 2.2.3.1 beschrieben, für eine FACS Analyse vorbereitet und die Expression von M1- und M2-spezifischen Markern kontrolliert. Die verwendeten Antikörper sind in Tab. 2.6 erfasst.

Zur Herstellung der konditionierten Medien wurde das Medium der Makrophagen entfernt und Zellen zweimal mit je 5 ml PBS gewaschen, um FBS-Rückstände zu eliminieren. Es wurden je $10 \mathrm{ml}$ serumfreies DMEM (1 g/l Glucose) ohne Zusätze hinzugefügt und die Zellen 
24 Stunden bei $37{ }^{\circ} \mathrm{C}$ inkubiert. Am Folgetag wurde das Medium der Zellen entnommen und $10 \mathrm{~min}$ bei $300 \mathrm{~g}$ und RT zentrifugiert. Der Überstand wurde in ein neues $50 \mathrm{ml}$ Zentrifugenröhrchen überführt und bei $-20{ }^{\circ} \mathrm{C}$ gelagert. Nach dem Auftauen wurde das konditionierte Medium durch einen Filtropur S 0.2 Filter mit 0,2 $\mu \mathrm{m}$ Porengröße (Sarstedt, Nümbrecht) sterilfiltriert und von präzipitiertem Protein befreit.

\subsubsection{Bioinformatische Methoden}

Die bioinformatische Auswertung der RNA Sequenzierungsdaten erfolgte in Kooperation mit der Abteilung für Statistische Bioinformatik am Institut für Medizinische Statistik der Universitätsmedizin Göttingen unter der Leitung von Prof. Tim Beißbarth (WP9).

Im Anschluss an die RNA Sequenzierung wurde anhand der Daten der CMT-93 induzierten Tumorkernproben zunächst eine Qualitätskontrolle durchgeführt. Hierzu wurden die Sequenzierungsdaten auf die Expression vier verschiedener Gene untersucht: Cytokeratin 20 (Krt20) diente als Surrogatparameter für Kolorektalkarzinomgewebe; als leberspezifische Gene wurden Phosphoenolpyruvat-Carboxykinase 1 (PCK1), Cytochrom p450 (CYP) und Carbamoylphosphat-Synthase 1 (CPS1) identifiziert. Nur Metastasen mit möglichst wenig Leberinfiltrat, d.h. mit geringen und vergleichbaren Expressionslevel der leberspezifischen Enzyme, wurden für weitere Analysezwecke verwendet.

Anhand der Durchführung einer Hauptkomponentenanalyse wurde die Struktur des Datensatzes visualisiert, indem durch die Verwendung eines mathematischen Algorithmus die Dimensionalität der Daten reduziert und parallel dazu die Varianz im Datensatz beibehalten wurde (Jolliffe \& Cadima, 2016). Zu diesem Zwecke wurden Richtungen bzw. Eigenvektoren, sogenannte Hauptkomponenten, identifiziert, in der maximale Variationen des Datensatzes zu finden sind (Ringnér, 2008). Im Rahmen dieser Arbeit wurden mit Hilfe der R-Programmiersprache (Version 3.2.3) die Eigenvektoren der Daten berechnet und die zwei Komponenten mit der höchsten Varianz gegeneinander aufgetragen. Auf diese Weise konnten Ähnlichkeiten bzw. Unterschiede zwischen biologischen Proben visualisiert und diese ggf. gruppiert werden.

Beim Vergleich der RNA Sequenzierungsdaten der CMT-93 Zellen mit den makroskopisch tumorfreien Leberarealen wurden hoch- bzw. herunterregulierte, differentiell exprimierte Gene identifiziert. Bei diesen Unterschieden wurde angenommen, dass sie hauptsächlich von der Genexpression der makroskopisch tumorfreien Leber resultieren. Folglich wurden diese Unterschiede und somit der Leberhintergrund beim Vergleich der Zelllinie mit den 
Tumorkernen herausgefiltert und leberbereinigte Sequenzierungsdaten erstellt. Anhand dieses Filterschrittes wurden mit hoher Wahrscheinlichkeit nur differentiell exprimierte Gene betrachtet, die sich tatsächlich zwischen der Zelllinie und den Tumorkernen unterscheiden, anstatt die allgemeinen Unterschiede zwischen Zellinie und Leber zu vergleichen.

Um nun in einem zweiten Schritt signifikante Genexpressionsunterschiede zwischen der CMT-93 Zelllinie und den CMT-93 induzierten Lebermetastasen zu identifizieren, wurde für jedes differentiell exprimierte Gen die Intensität (Mittelwert), der $\rho$-Wert, der logarithmische Fold Change zur Basis $2(\log F C$ ) und der logarithmische Fold Change zur Basis 2 bezogen auf Transcripts per Million (TPM) Werte (logFC*) berechnet. Die Berechnung erfolgte anhand des R-Programmpakets EdgeR (Empirical Analysis of Digital Gene Expression Data in R), anhand dessen eine Reihe von statistischen Methoden implementiert und so beispielsweise RNASequenzierungsdaten miteinander verglichen werden können (Robinson et al., 2010). Die statistische Auswertung der Software beruht auf einer Berechnung der negativen Binomialverteilung, welches für eine diskrete Wahrscheinlichkeitsverteilung angewandt wird. Die Expressionsergebnisse wurden als Mittelwert der TPMs wiedergegeben. Als zusätzliches statistisches Verfahren wurde die sogenannte False Discovery Rate (FDR) ermittelt, um die Wahrscheinlichkeit bzw. das Ausmaß von falsch-positiven Ergebnissen bei der Durchführung von mehreren Vergleichen zu kontrollieren. Bei der vorliegenden Arbeit wurde die $F D R$-Grenze bei $5 \%$ gesetzt. D.h. alle Expressionsergebnisse mit einer $F D R<0,05$ wurden als signifikant betrachtet.

Auf der Grundlage des „Tumor Metastasis RT2 Profiler PCR Arrays“ von Qiagen, Hilden, wurde eine Auswahlliste von 119 Genen erstellt, die mit CRC-induzierten Lebermetastasen assoziiert werden (siehe Anhang S. 146). Diese Liste wurde im Anschluss an die Differentielle Genexpressionsanalyse (DEG) als Filter angewandt, um ein Expressionsprofil des vorliegenden Datensatzes zu erstellen.

Ohne Filterliste und damit auf Basis der Grundgesamtheit der differentiell exprimierten Gene der CMT-93 Zellen und der Tumorkerne mit einer $F D R<5 \%$ wurde abschließend eine Gene Ontology (GO)- und Signalwegsanalyse durchgeführt. Hierbei wurde mit Hilfe von biologischen Ontologie-Datenbanken (www.geneontology.org) einzelnen Genen GO-Termini, sprich Annotationen, zugeordnet und anhand des R-Programmpakets topGO (Alexa \& Rahnenfuhrer, 2016) kontrolliert, welche GO-Termini in diesem Datensatz über- bzw. unterrepräsentiert und welche Signalwege somit besonders betroffen sind. Die 
Signifikanzwerte wurden durch einen exakten Test nach Fisher berechnet und $\rho$-Werte für die GO-Kategorie „Biologische Prozesse“ mit einem Signifikanzniveau von < 0,05 ermittelt.

\subsubsection{Statistik}

Falls nicht anders angegeben, wurden alle Experimente jeweils dreimal unabhängig voneinander durchgeführt. Berechnet wurden Mittelwert und Standardabweichung der Daten; in den Graphiken wurde die positive Standardabweichung abgebildet. Mit Hilfe des tTests wurden signifikante Unterschiede erfasst, diese anhand von drei Signifikanzniveaus definiert und an entsprechender Stelle mit Sternchen markiert: $\rho$-Wert $\leq 0,05 ;\left(^{*}\right) ; \rho$-Wert $\leq$ $0,01\left(^{* *}\right)$ und $\rho$-Wert $\leq 0,001(* * *)$. 


\section{Ergebnisse}

Nach erfolgreicher Etablierung eines murinen Lebermetastasenmodells wurde zunächst eine phänotypische Charakterisierung der Metastasen anhand von immunhistochemischen Färbungen durchgeführt. Ein Genexpressionsprofil wurde mittels RNA Sequenzierung und qRT-PCR erstellt; dabei lag das Hauptaugenmerk auf der Expression von Metastasenassoziierten Genen. Da bei Signalwegsanalysen „inflammatorische Antwort“ als eines der signifikant aktivsten Signalwege identifiziert werden konnte, wurde die Quantität und Lokalisation verschiedener Makrophagenphänotypen im Verlaufe der Metastasenformation ebenfalls immunhistochemisch und auf molekularbiologischer Ebene untersucht. Der indirekte Einfluss der Makrophagenphänotypen auf Tumorzellen wurde abschließend anhand von Kokulturversuchen der CMT-93 Zellen mit konditioniertem Medium der Makrophagen auf zell- und molekularbiologischer Ebene betrachtet.

\subsection{Etablierung eines Mausmodells zur Untersuchung von Lebermetastasen induziert durch die Kolorektalkarzinomzelllinie CMT-93}

Im Rahmen des MetastaSys Konsortiums wurde die Mammakarzinomzelllinie 410.4 und die Kolorektalkarzinomzelllinie CMT-93 bezüglich ihres Wht und EGFR Status als geeignete Tumorzelllinien zur Formation von Lebermetastasen identifiziert. Das Ausmaß der Tumorigenität und die Fähigkeit der Zelllinien zur Metastasierung wurden in einem syngenen, orthotopen Mausmodell anhand des Balb/c respektive C57BL/6N Mausstammes untersucht, wobei der Fokus dieser Arbeit auf dem CRC-induzierten Lebermetastasenmodell liegt (Abb. 3.1).

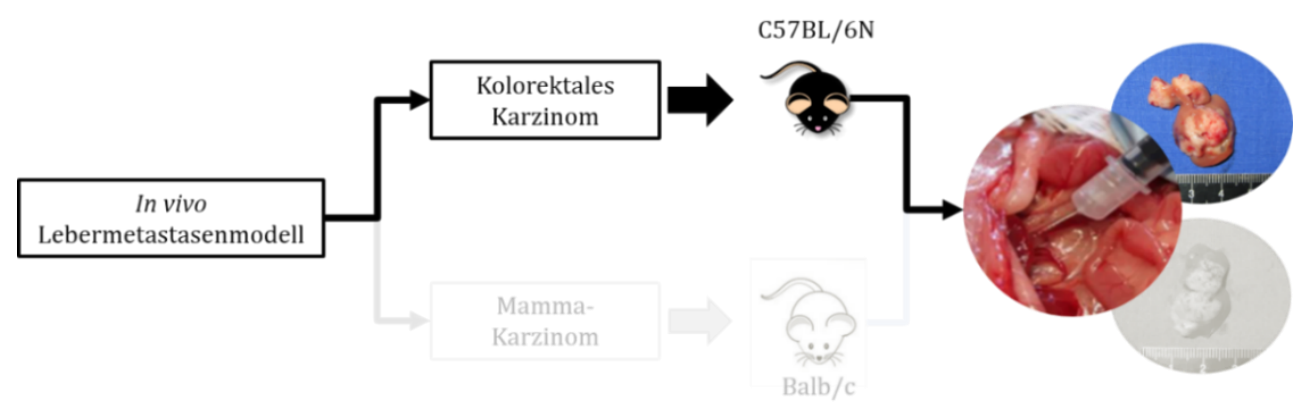

Abb. 3.1: Schema der Etablierungsschritte eines in vivo Modells zur Untersuchung von Mamma- und CRC-induzierten Lebermetastasen. Als Voraussetzung für CRC-induzierte Lebermetastasen wurde u.a. ein epitheliales Wachstumsmuster, die für CRC typischerweise hochregulierte $\beta$-catenin Genexpression und ein tumorigener Phänotyp definiert. 


\subsubsection{Morphologie und Vitalität der CMT-93 Zellen}

Wie Abb. 3.2 (A) zu entnehmen ist, wachsen CMT-93 Zellen in einem einschichtigen Zellrasen und weisen eine epitheliale Morphologie auf. Der mechanische Einfluss der verwendeten Insulinspritzen auf die Zellviabilität wurde berücksichtigt; bei den Applikationstechniken „Spritzen in einem Zug“ und „Spritzen nach 2 Stunden auf Eis“ betrug der Anteil toter Zellen an der Gesamtzellzahl 27 \% respektive 28 \% (B). Dieser Anteil konnte jedoch durch eine langsame Applikation innerhalb einer Minute auf $14 \%$ gesenkt werden. Folglich wurde die Applikationstechnik der CMT-93 Zellen in tierexperimentellen Eingriffen dem beschriebenen Resultat angepasst und Zellen während des Eingriffs langsam innerhalb einer Minute injiziert.

A

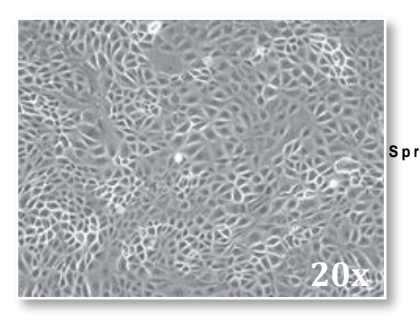

B

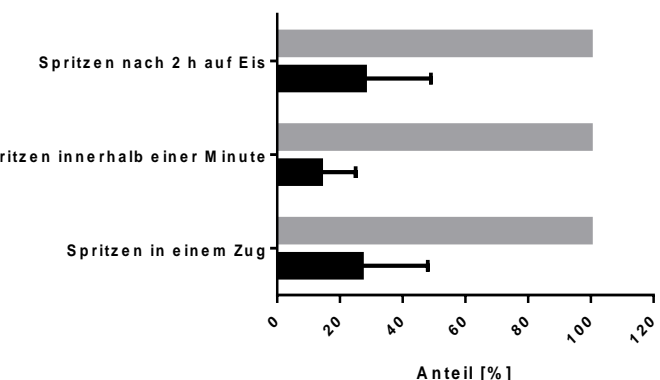

Gesamtzellzahl

Tote Zellen

Abb. 3.2: Morphologie und Vitalität von CMT-93 Zellen nach Applikation mit einer Micro-Fine ${ }^{\mathrm{TM}}$ Insulinspritze. (A) Polyploide CRC Zelllinie CMT-93 mit polygonaler Pflastersteinform (Abb. von WP2 zur Verfügung gestellt). (B) Das langsame Applizieren der Zellen innerhalb einer Minute wies den geringsten Anteil toter Zellen an der Gesamtzellzahl auf.

\subsubsection{Einfluss verschiedener Implantationsmethoden auf den Metastasierungserfolg von CMT-93 Zellen}

Nachdem CMT-93 Zellen auf zellmorphologischer und molekularbiologischer Ebene (WP2; Arackal, 2016) als geeignete Zelllinie zur Etablierung eines Lebermetastasenmodells identifiziert wurde, erfolgte die Analyse der Tumorigenität mittels tierexperimenteller Eingriffe. Wie in Kapitel 2.1.8.2 beschrieben, ist der Maussubstamm C57BL/icrf, aus der die CMT-93 Zelllinie ursprünglich stammt, nicht mehr käuflich erwerblich. Aufgrund der eigenen Resultate aus Vorversuchen in C57BL/6N und C57BL/6J Mäusen und den erfolgreichen Implantationsexperimenten von Frau Dr. Hackl, wurde der verwandte Maussubstamm C57BL/6N (Charles River, Sulzfeld) als geeignetes Mausmodell identifiziert.

In einer Serie aus 11 Mäusen wurde die Implantation von CMT-93 Zellen mittels vier verschiedener Implantationsmethoden getestet und der Einfluss der Methoden auf die Metastasenformation und -größe verglichen (Tab. 3.1). Vierzehn Tage nach subkutaner 
Implantation von je 2,5 x $10^{6}$ CMT-93 Zellen in die rechte Flanke von zwei C57BL/6NCrl Mäusen war bereits ein Tumor mit einem Durchmesser von ca. $5 \mathrm{~mm}$ detektierbar. 35 Tage nach intraportaler und intrasplenischer Implantation von je 1 x $10^{6}$ CMT-93 Zellen waren 30 - 50 \% der Mausleber durch Tumorzellen kolonisiert. Lebermetastasen wiesen in beiden Fällen ein heterogenes Wachstumsmuster auf; in allen Leberlappen waren Metastasenherde mit einem Durchmesser von etwa 5 - $10 \mathrm{~mm}$ vorzufinden. Allerdings schwankte das Resultat der intrasplenischen Implantation mutmaßlich aufgrund der unkontrollierten Einflutung der Zellen in die Leber bzw. des verbleibenden Zellanteils im Injektionsorgan, so dass in 2 von 4 Fällen eine stark vergrößerte Milz mit einem großen Tumorherd (ca. $5 \mathrm{~mm}$ ) vorzufinden war. Nach subkapsulärer Implantation von 1 x $10^{6}$ Zellen konnten 44 Tage post injectionem makroskopisch keine Metastasen detektiert werden.

Tab. 3.1: Vergleich verschiedener Implantationsmethoden zur Formation von CRC-induzierten Lebermetastasen. Mit Ausnahme der subkapsulären Implantation von CMT-93 Zellen konnten alle Methoden erfolgreich etabliert werden. Semi-quantitative, makroskopische Beurteilung des Metastasenerfolgs/Engraftments von sehr wenig/kaum - bis sehr stark +++.

\begin{tabular}{llllll}
\hline Implantationstechnik & Zellzahl & Metastasen & Versuchsdauer & Engraftment & Mäuse [n] \\
\hline Intraportal & $1 \times 10^{6}$ & Leber & 35 Tage & +++ & 3 \\
Subkapsulär & $1 \times 10^{6}$ & - & 44 Tage & - & 2 \\
Intrasplenisch & $1 \times 10^{6}$ & Leber, Milz & 35 Tage & ++ & 4 \\
Subkutan & $2,5 \times 10^{6}$ & Haut & 14 Tage & +++ & 2 \\
\hline
\end{tabular}

\subsubsection{Die intraportale Injektion von CMT-93 Zellen}

Aufgrund der stabilen und reproduzierbaren Ergebnisse der intraportalen Implantation von CMT-93 Zellen wurde diese Methode bevorzugt. Somit konnte auch der biologisch natürliche Weg der CRC-induzierten Formation von Lebermetastasen simuliert werden. In einem nächsten Schritt wurden nun die Zahl der zu implantierenden Zellen und die Versuchsdauer variiert. Demnach konnten optimale Resultate erzielt werden, indem 1 x 106 CMT-93 Zellen in die Pfortader von 11 - 12-Wochen alten weiblichen C57BL/6NCrl Mäusen implantiert wurden. 28 Tage post injectionem waren Metastasen mit einem Anteil von etwa $30-50 \%$ an der Gesamtleber und einem Durchmesser bis zu $10 \mathrm{~mm}$ vorzufinden, so dass zu diesem Zeitpunkt auch noch genügend makroskopisch tumorfreies Gewebe vorhanden war. Bei 10 $20 \%$ der Versuchstiere beinhaltete der Eingriff technische Komplikationen (u.a. Blutverlust), so dass der Versuch während des Eingriffs mit Tötung des Tieres abgebrochen werden musste. 


\subsubsection{Phänotypische Eigenschaften von CMT-93 induzierten Lebermetastasen}

Vier Wochen nach einer intraportalen Implantation von 1 x $10^{6}$ CMT-93 Zellen zeigten 70 80 \% der Mäuse ein heterogenes Wachstumsmuster der Tumorzellen mit mehreren Metastasenherden in fast allen Leberlappen (Abb. 3.3 A). Zu diesem Zeitpunkt kolonisierten die Tumorzellen etwa 50 \% der murinen Leber und wiesen einen Durchmesser zwischen 5 $10 \mathrm{~mm}$ auf. Ein inhomogenes Kolonisationsmuster konnte zwischen dem linken und rechten Leberlappen detektiert werden, es zeigte sich aber keine Prädilektion eines Leberlappens.
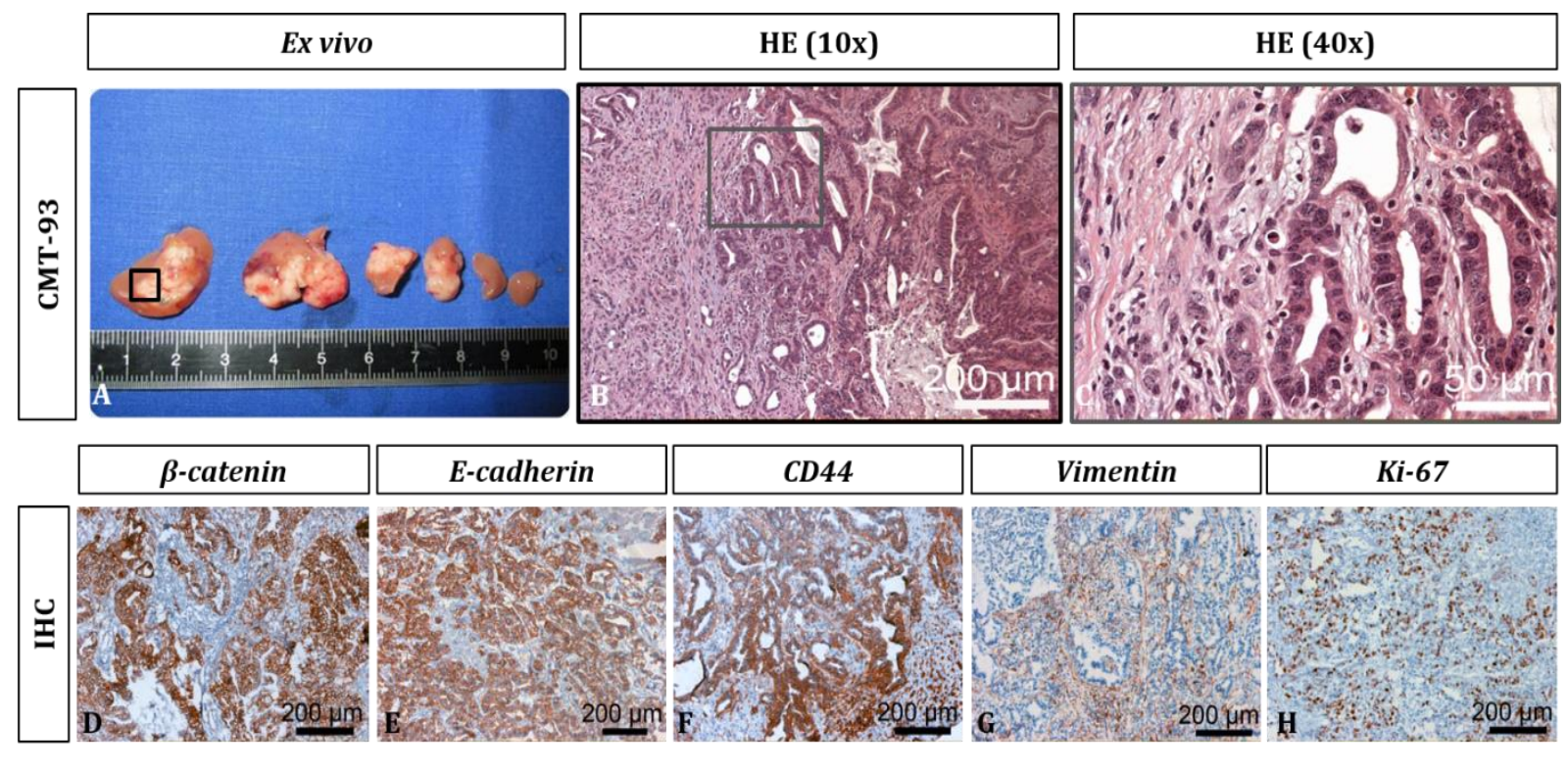

differenziert / epithelial
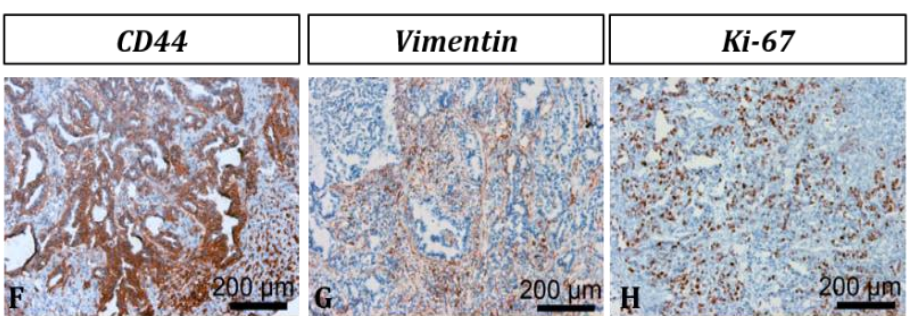

entdifferenziert / mesenchymal

Abb. 3.3: Makroskopische und mikroskopische Charakterisierung von CMT-93 induzierten Lebermetastasen. Darstellung von multiplen Metastasenherden in Lebern von C57BL/6NCrl Mäusen (A). Eine HE Färbung verdeutlichte die Formation von glandulären Strukturen (B, C). $\beta$-catenin (D) und $E$ cadherin (E) sind charakteristische Marker für ein epitheliales Wachstumsmuster, während eine antiVimentin Färbung Mesenchymzellen identifizierte (G). Weitere entdifferenzierte Bereiche der Metastasen und Tumorstammzellen wurden anhand einer CD44 Expression hervorgehoben (F). Proliferierende Zellen wurden mittels einer anti-Ki-67 Färbung visualisiert (H).

Anhand einer HE Färbung konnte das phänotypische Wachstumsmuster von Kolorektalkarzinomen mit der Formation von glandulären Strukturen in einem desmoplastischen Stroma gezeigt werden (B), dargestellt im Übergangsbereich zwischen Metastase und Lebergewebe (C). Weitere immunhistochemische Färbungen verdeutlichten, dass in diesem Modell bezüglich des Wachstumsmusters und der Expression von phänotypischen Markern zwei Metastasensubtypen zu unterscheiden sind. Der epitheliale 
Subtyp zeichnete sich durch die Formation von duktulären Strukturen aus, die anhand der Expression von E-cadherin und $\beta$-catenin identifiziert wurden. Während E-cadherin membrangebunden vorzufinden war (E), wies $\beta$-catenin eine überwiegend zytoplasmatische Expression auf (D). Der mesenchymale Subtyp wurde anhand einer anti-Vimentin Färbung visualisiert (G); der Antikörper zeigte eine heterogene, zytoplasmatische Färbung der Zellen, die sich vor allem in den glandulären Strukturen befanden. Das Adhäsionsmolekül CD44 konnte in beiden Metastasensubtypen detektiert werden (F). Zur Kontrolle des Proliferationstatus der Zellen wurde eine anti-Ki-67 Färbung durchgeführt, die im überwiegenden Anteil der Lebermetastasen nachweisbar war und ein zufälliges Verteilungsmuster zeigte $(\mathrm{H})$. In vier repräsentativen Metastasen-tragenden Lebern wurde ein Tumorzellgehalt von $39 \%$ ( $\pm 10 \%$ ) identifiziert; dabei lag der nekrotische Anteil bei ca. $2 \%( \pm 2 \%)$ und der Tumor-Stroma-Anteil bei $11 \%$ ( $\pm 3 \%$ ).

\subsection{Expression von Genen und Signalwegen assoziiert mit CRC-induzierten Lebermetastasen}

Die Charakterisierung der CRC-induzierten Lebermetastasen auf molekularbiologischer Ebene erfolgte mittels einer RNA Sequenzierung. Ziel war es auf Basis der Sequenzierungsdaten anhand von bioinformatischen Methoden zu analysieren, wie sich das Genexpressionsprofil der CMT-93 Zellen im Zuge der Leberkolonisation verändert und wie diese Veränderung das metastatische Verhalten der Tumorzellen beeinflusst haben könnte. Hierfür wurden in einem ersten Schritt Sequenzierungsdaten der CMT-93 Zelllinie mit Proben aus dem Tumorkern vergleichend analysiert und ein Expressionsprofil zur Identifizierung von relevanten Genen und Signalwegen erstellt.

\subsubsection{Vergleich von CMT-93 Zellen und CMT-93 induzierten Lebermetastasen anhand bioinformatischer Genexpressionsanalysen}

In einer Serie aus sieben Mäusen wurden $1 \times 10^{6}$ CMT-93 Zellen intraportal implantiert und 28 Tage post injectionem pro Tier jeweils ein Leberresektat aus folgenden Arealen entnommen: Tumorkern, Tumorrand, makroskopisch tumorfreier Rand und makroskopisch tumorfreies Gewebe (Abb. 3.4). Für vergleichende Analysezwecke wurden CMT-93 Zellen (n = 3) sowie Sham-operierte Lebern $(n=5)$ hinzugezogen. 


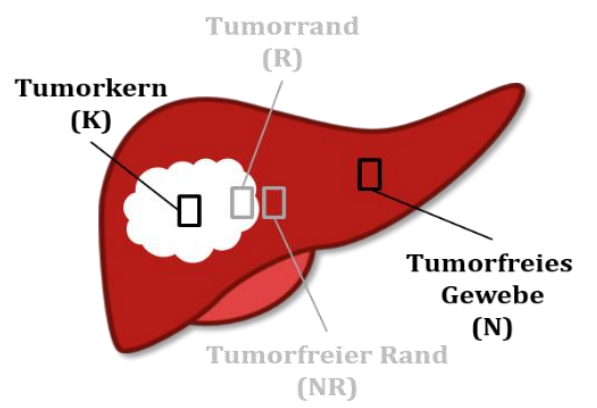

Abb. 3.4: Schematische Darstellung der Probenentnahme der CMT-93 induzierten Lebermetastasen. Die schematische Abbildung der Leber zeigt vier verschiedene Areale, aus denen Proben für eine RNA Sequenzierung entnommen wurden. Als Kontrolle dienten RNA Proben von CMT-93 Zellen sowie Shamoperierte Lebern.

Bei einer initialen makroskopischen Untersuchung der Lebern konnten diese aufgrund der Größe der Metastasen in zwei Gruppen unterteilt werden: die erste Gruppe umfasste vier Lebern mit Metastasen, die einen Durchmesser von bis zu knapp 10 mm aufwiesen; in eine zweite Gruppe konnten drei Lebern eingeordnet werden, die einen Durchmesser von maximal 5 mm erreichten.

Die RIN Werte der Proben entsprachen überwiegend intakter RNA; hier wurden Werte zwischen 6 - 8 gemessen. In den drei Tumorproben D213K, D214K und D215K (Tab. 3.2, grau hinterlegt) ließ sich nur ein geringer Anteil an Tumorgewebe detektieren. Des Weiteren wurde hier eine 4-20fach erhöhte Expression von Leberenzymen und eine damit einhergehende erhöhte Infiltration der Metastasen durch Lebergewebe nachgewiesen, weshalb diese drei Proben für weitere Untersuchungen ausgeschlossen wurden. Dabei handelte es sich um Leberproben, die zuvor in die Gruppe der Metastasen mit einem Durchmesser von maximal $5 \mathrm{~mm}$ eingeordnet wurden und technische Entnahmefehler nahelegen.

Tab. 3.2: Qualitätskontrolle der sequenzierten Maus- und Zelllinienproben. Die Zusammensetzung der Proben wurde anhand der Expression der leber- bzw. tumorspezifischen Gene PCK1, CYP, CPS1 (Leber) und Krt20 (kolorektales Karzinom) geprüft. Grau hinterlegte Tumorkernproben wurden aufgrund des erhöhten Lebergewebeanteils aus den Analysen herausgenommen (logFC = logarithmischer Fold Change; $\rho$ Wert $=$ Signifikanzwert; FDR = False Discovery Rate $Z L=$ CMT-93).

\begin{tabular}{|c|c|c|c|c|c|c|c|c|c|c|c|c|c|}
\hline Gen & $\log F C$ & $\rho$-Wert & FDR & ZL1 & ZL2 & ZL3 & D208K & D209K & D210K & D212K & D213K & D214K & D215K \\
\hline$\overline{C P S 1}$ & 12 & $9,7 \times 10^{-50}$ & $1,2 \times 10^{-48}$ & 0,02 & 0,02 & 0,03 & 24 & 135 & 173 & 68 & 749 & 651 & 380 \\
\hline СYРЗА25 & 513 & $1,4 \times 10^{-47}$ & $1,7 \times 10^{-46}$ & 0 & 0 & 0 & 8 & 36 & 37 & 25 & 186 & 181 & 137 \\
\hline PCK1 & 14 & $1,3 \times 10^{-73}$ & $3,2 \times 10^{-72}$ & 0,08 & 0 & 0 & 180 & 218 & 365 & 79 & 1304 & 838 & 342 \\
\hline Krt2o & 6 & $7,5 \times 10-8$ & $1,2 \times 10^{-6}$ & 0.68 & 0.87 & 0.87 & 60 & 47 & 43 & 58 & 15 & 9 & 5 \\
\hline
\end{tabular}


Im Anschluss an die Qualitätskontrolle wurde auf Basis der vier Tumorproben, die die Kontrolle bestanden haben (D208K - D210K, D212K), den entsprechenden makroskopisch tumorfreien Proben und den CMT-93 Zelllinienproben eine DEG durchgeführt. Nach Bereinigung des Leberhintergrundes von den Genexpressionsdaten, betrug die Anzahl herunterregulierter Gene im Tumorkern 1174 (35 \%), während 2155 (65 \%) hochregulierte Gene identifiziert wurden (Tab. 3.3, grau hinterlegt).

Tab. 3.3: Anzahl differentiell exprimierter Gene zum Vergleich der CMT-93 Zellen mit den CMT-93 induzierten Lebermetastasen. Im Zuge der Propagation der CMT-93 Zellen in der Leber wurden nach Bereinigung des Leberhintergrundes insgesamt 3329 Gene differentiell exprimiert (grau hinterlegt).

\begin{tabular}{lcccc}
\hline Genexpression & $\begin{array}{c}\text { CMT-93 } \\
\text { vs. } \\
\text { Lebermetastase }\end{array}$ & $\begin{array}{c}\text { Tumorfreie Leber } \\
\text { vs. } \\
\text { Lebermetastase }\end{array}$ & $\begin{array}{c}\text { CMT-93 } \\
\text { vs. } \\
\text { Tumorfreie } \\
\text { Leber }\end{array}$ & $\begin{array}{c}\text { CMT-93 } \\
\text { vs. } \\
\text { Lebermetastase } \\
\text { abzüglich des } \\
\text { Leberhintergrundes }\end{array}$ \\
\hline $\mathbf{- 1}=$ herunterreguliert & 5297 & 5163 & 5764 & 1174 \\
$\mathbf{0}=$ nicht reguliert & 3667 & 4157 & 2684 & 0 \\
$\mathbf{1}=$ hochreguliert & 6597 & 5749 & 6187 & 2155 \\
\hline
\end{tabular}

In Abb. 3.5 ist das Resultat einer Hauptkomponentenanalyse dargestellt. Die erste Hauptkomponente ist auf der x-Achse abgebildet und erfasst $74 \%$ der Varianz; die y-Achse stellt die zweite Hauptkomponente mit 19 \% der Varianz dar. Sowohl CMT-93 Zellen (CMT93V1 - V3) als auch CMT-93 induzierte Lebermetastasen (D208K - D2010K, D212K) zeigten eine klar voneinander abgegrenzte Clusterbildung im Vergleich zu dem entsprechenden makroskopisch tumorfreien Gewebe (D208N - D2010N, D212N - D215N). Auch innerhalb der Gruppen lagen die einzelnen Proben sehr nahe beieinander. Proben der Sham-operierten Tiere wurden ebenfalls berechnet; diese überlagerten sich mit den makroskopisch tumorfreien Gewebeproben und sind daher nicht abgebildet.

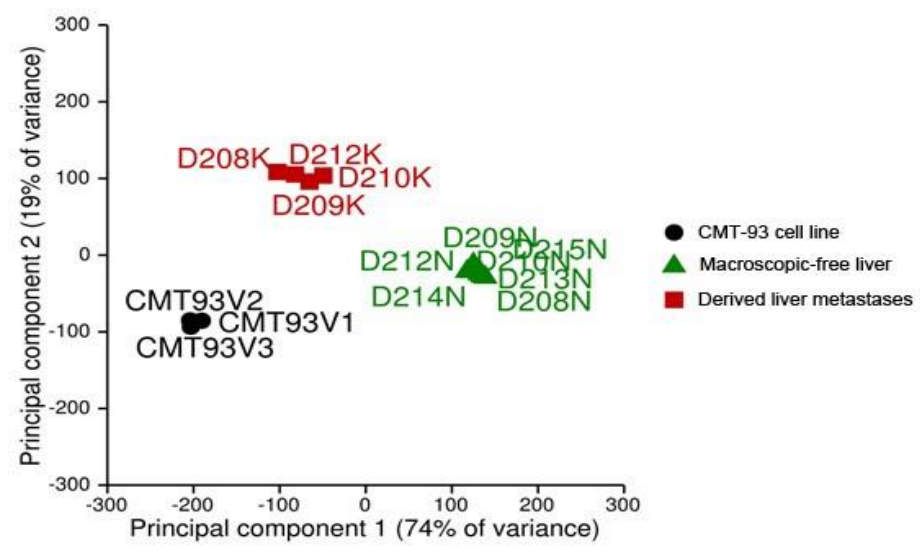

Abb. 3.5: Hauptkomponentenanalyse (PCA Plot). Graphische Darstellung von Ähnlichkeiten innerhalb einer Gruppe und Unterschiede zwischen den einzelnen Probengruppen. Schwarz = CMT-93 Zellen, grün = makroskopisch tumorfreies Gewebe, rot = Tumorkern. 


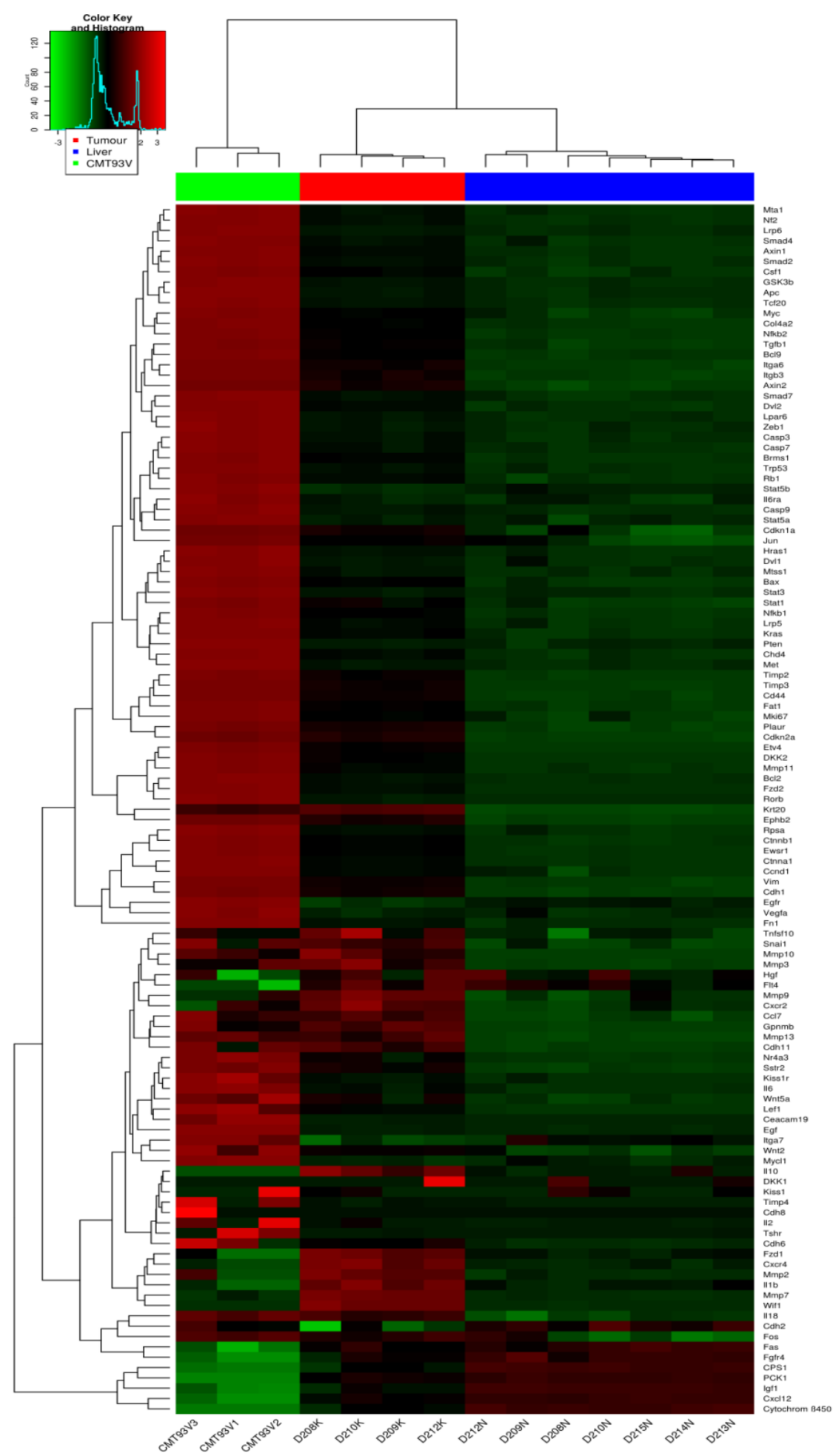

Abb. 3.6: Heatmap mit den Top 120 DEGs zwischen der CMT-93 Zellinie, den CMT-93 induzierten Lebermetastasen und den makroskopisch tumorfreien Mauslebern. Jede Zeile repräsentiert ein Gen und jede Spalte eine Probe. Der Farbbalken über der Heatmap identifiziert Probengruppen: CMT-93 Zellen in grün, CMT-93 induzierte Lebermetastasen in rot und makroskopisch tumorfreies Gewebe in blau. Rot und grün indizieren Expressionslevel über- bzw. oberhalb des Median. Zwischen den Gruppen sind Genexpressionsunterschiede vorhanden, die auf eine Evolution der CMT-93 Zellen zu Metastasen im hepatischen Milieu hindeuten. 
Aus dem leberbereinigten Datensatz der RNA Sequenzierung wurden die Top 120 hochsignifikant differentiell exprimierten Gene in CMT-93 Zellen und CMT-93 induzierten Lebermetastasen identifiziert und diese in Abb. 3.6 in Form einer Heatmap graphisch dargestellt.

Die Graphik veranschaulicht, dass Variationen zwischen der CMT-93 Zellinie, den CMT-93 induzierten Lebermetastasen und den entsprechenden makroskopisch tumorfreien Lebergeweben vorhanden sind. Die drei Gruppen können klar voneinander separiert werden, während innerhalb der Gruppen ein zum Großteil sehr ähnliches Genexpressionsprofil vorzufinden ist. Die Genexpressionsanalyse indiziert eine klare Entwicklung der Zelllinie zur Metastase im Zuge der Propagation im Leberparenchym. Das Dendrogramm über der Heatmap visualisiert den Beziehungsgrad der Genexpression; demnach weisen Lebermetastasen und makroskopisch tumorfreies Gewebe bezüglich ihrer Genexpression mehr Ähnlichkeiten auf und sind somit näher zueinander zuzuordnen.

\subsubsection{Anwendung einer Selektionsliste relevanter Metastasen-assoziierter Gene auf die Genexpressionsdaten}

Da im Zuge einer RNA Sequenzierung sehr große Datensätze bestehend aus Tausenden von Genen generiert werden können, wurde in einem nächsten Schritt eine Liste von 119 Genen aus zehn funktionellen Gengruppen erstellt, die assoziiert werden mit CRC-induzierten Lebermetastasen (Tab. 3.4).

Tab. 3.4: Liste von 119 Metastasen-assoziierten Genen aus zehn funktionellen Gengruppen. Einige Gene wurden in mehrere funktionelle Gengruppen zugeordnet. Gruppen wurden in absteigender Anzahl der Gene pro funktioneller Gengruppe aufgelistet (s. Anhang S. 145).

\begin{tabular}{lc}
\hline Funktionelle Gengruppe & Anzahl der Gene \\
\hline Zellwachstum und Proliferation & 35 \\
Transkriptionsfaktoren und -regulatoren & 23 \\
Zelladhäsion & 17 \\
Wht Signalweg (kanonisch) & 17 \\
Epithelial-Mesenchymale Transition & 13 \\
Zellzyklus & 12 \\
Apoptose & 11 \\
Extrazelluläre Matrixproteine & 10 \\
CRC-assoziierte Gene & 3 \\
Leberspezifische Gene & 3 \\
\hline
\end{tabular}


Durch Filterung des leberbereinigten RNA Sequenzierungsdatensatzes anhand dieser Liste wurden 32 Gene mit einer FDR $<5 \%$ identifiziert, die in CMT-93 Zellen und CMT-93 induzierten Lebermetastasen signifikant differentiell exprimiert werden. In Abb. 3.7 ist die entsprechende Heatmap dargestellt.

Tabelle 3.5 ist eine Übersicht der 32 differentiell exprimierten Gene zu entnehmen, die nach absteigender Reihenfolge des Signifikanzwertes aufgelistet wurden. Demnach gibt es die signifikantesten Genexpressionsunterschiede zwischen der CMT-93 Zelllinie und den entsprechenden Metastasen bezüglich der Expression von MMP-7, Krt20 und Wif1, wobei Krt20 als Surrogatparameter für Kolorektalkarzinome dient und MMP-7 sowie Wif1 Komponenten des Wht Signalweges repräsentieren. Die geringsten Unterschiede sind hingegen in der Expression von FN1, BCL9 und DKK2 vorzufinden; die letzten beiden können ebenfalls dem Wnt Signalweg zugeordnet werden. 


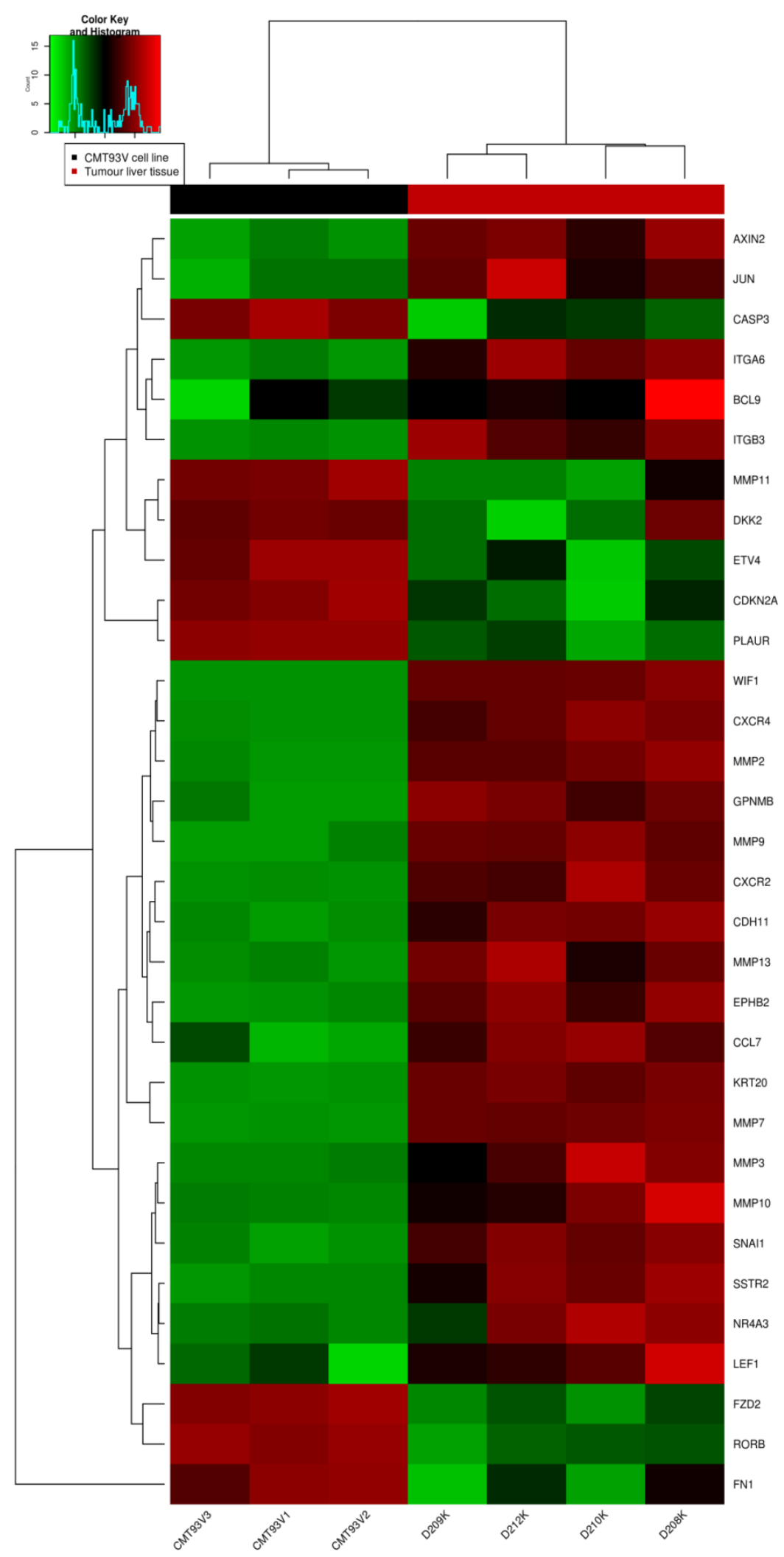

Abb. 3.7: Heatmap zur Darstellung des Expressionsmusters von 32 Genen, die mit der Entstehung von Lebermetastasen assoziiert werden. Eine Filterung der RNA Sequenzierungsdaten der CMT-93 Zellinie und entsprechender Lebermetastasen identifizierte 32 hochsignifikant differentiell exprimierte Gene, die relevant sein könnten für die Propagation der CMT-93 Zellen im murinen Leberparenchym (schwarzer Balken = CMT-93 Zellen, roter Balken = CMT-93 induzierte Lebermetastasen). 
Tab. 3.5: Überblick über die selektionierten, signifikanten Metastasen-assoziierten Gene zwischen Lebermetastasen und CMT-93 Zellen (FDR $<5 \%$ ). LogFC* beschreibt die Veränderungen der mittleren Intensität angegeben als Logarithmus zur Basis 2 bezogen auf die $T P M$ Werte, $\log F C^{\wedge}$ repräsentiert den Logarithmus zur Basis 2 berechnet anhand des R-Programmpakets EdgeR. Gene wurden nach ihrem Signifikanzwert der DEG sortiert.

\begin{tabular}{|c|c|c|c|c|c|c|c|}
\hline Gensymbol & $\begin{array}{l}\text { Funktionelle } \\
\text { Gengruppe }\end{array}$ & $\rho$-Wert & $\begin{array}{c}\text { Mittlere Intensität } \\
\text { CMT-93 }\end{array}$ & $\begin{array}{c}\text { Mittlere Intensität } \\
\text { Lebermetastasen }\end{array}$ & $\log F C^{*}$ & $\log F C^{\wedge}$ & FDR \\
\hline MMP7 & $\begin{array}{l}\text { Extracellular } \\
\text { Matrix Proteins }\end{array}$ & $1,7 \times 10^{-180}$ & 0,02 & 72,56 & 8,97 & 11,69 & $4,9 \times 10^{-178}$ \\
\hline KRT2O & $\begin{array}{l}\text { CRC Related } \\
\text { Genes }\end{array}$ & $2,9 \times 10^{-174}$ & 0,81 & 51,99 & 5,8 & 6,12 & $7,7 \times 10^{-172}$ \\
\hline WIF1 & $\begin{array}{l}\text { Wnt Signaling } \\
\text { (canonical) }\end{array}$ & $3,7 \times 10^{-126}$ & 0,00 & 20,68 & 7,37 & 12,85 & $3,3 \times 10^{-124}$ \\
\hline MMP9 & $\begin{array}{l}\text { Extracellular } \\
\text { Matrix Proteins }\end{array}$ & $3,8 \times 10^{-72}$ & 0,10 & 14,16 & 5,95 & 7,92 & $9 \times 10^{-71}$ \\
\hline CXCR4 & $\begin{array}{l}\text { Cell Growth and } \\
\text { Proliferation } \\
\text { Genes }\end{array}$ & $1,5 \times 10^{-71}$ & 0,02 & 19,29 & 7,06 & 10,50 & $3,4 \times 10^{-70}$ \\
\hline MMP2 & $\begin{array}{l}\text { Extracellular } \\
\text { Matrix Proteins }\end{array}$ & $1,8 \times 10^{-70}$ & 0,09 & 27,83 & 7,04 & 8,33 & $4,2 \times 10^{-69}$ \\
\hline ЕРНB2 & $\begin{array}{l}\text { Cell Growth and } \\
\text { Proliferation } \\
\text { Genes }\end{array}$ & $4,8 \times 10^{-59}$ & 1,06 & 10,86 & 3,2 & 3,65 & $8 \times 10^{-58}$ \\
\hline CXCR2 & $\begin{array}{l}\text { Cell Growth and } \\
\text { Proliferation } \\
\text { Genes }\end{array}$ & $1,110^{-40}$ & 0,04 & 7,53 & 5,51 & 7,75 & $9,7 \times 10^{-40}$ \\
\hline CDH11 & $\begin{array}{l}\text { Cell Adhesion } \\
\text { Genes }\end{array}$ & $8,8 \times 10^{-40}$ & 0,12 & 6,32 & 4,67 & 5,75 & $7,9 \times 10^{-39}$ \\
\hline AXIN2 & $\begin{array}{l}\text { Wnt Signaling } \\
\text { (canonical) }\end{array}$ & $2,2 \times 10^{-39}$ & 20,31 & 72,10 & 1,82 & 1,87 & $2 \times 10^{-38}$ \\
\hline ITGB3 & $\begin{array}{l}\text { Cell Adhesion } \\
\text { Genes }\end{array}$ & $1,6 \times 10^{-33}$ & 5,54 & 25,48 & 2,17 & 2,35 & $1,2 \times 10^{-32}$ \\
\hline ММР13 & $\begin{array}{l}\text { Extracellular } \\
\text { Matrix Proteins }\end{array}$ & $8,1 \times 10^{-29}$ & 0,22 & 7,45 & 4,43 & 5,20 & $4,8 \times 10^{-28}$ \\
\hline GPNMB & $\begin{array}{l}\text { Cell Adhesion } \\
\text { Genes }\end{array}$ & $3,9 \times 10^{-27}$ & 0,21 & 14,50 & 5,45 & 6,25 & $2,1 \times 10^{-26}$ \\
\hline SNAI1 & EMT Transition & $2,9 \times 10^{-26}$ & 0,12 & 3,05 & 3,62 & 4,66 & $1,5 \times 10^{-25}$ \\
\hline PLAUR & $\begin{array}{l}\text { Cell Growth and } \\
\text { Proliferation } \\
\text { Genes }\end{array}$ & $8,9 \times 10^{-20}$ & 191,38 & 71,50 & $-1,42$ & $-1,28$ & $3,6 \times 10^{-19}$ \\
\hline MMP3 & $\begin{array}{l}\text { Extracellular } \\
\text { Matrix Proteins }\end{array}$ & $3,7 \times 10^{-17}$ & 0,05 & 2,70 & 3,95 & 5,74 & $1,3 \times 10^{-16}$ \\
\hline ITGA6 & $\begin{array}{l}\text { Cell Adhesion } \\
\text { Genes }\end{array}$ & $5 \times 10^{-17}$ & 12,03 & 31,23 & 1,36 & 1,32 & $1,8 \times 10^{-16}$ \\
\hline MMP1O & $\begin{array}{l}\text { Extracellular } \\
\text { Matrix Proteins }\end{array}$ & $7,6 \times 10^{-17}$ & 0,06 & 2,68 & 3,83 & 5,37 & $2,7 \times 10^{-16}$ \\
\hline SSTR2 & $\begin{array}{l}\text { Cell Growth and } \\
\text { Proliferation } \\
\text { Genes }\end{array}$ & $5,7 \times 10^{-15}$ & 0,22 & 1,57 & 2,19 & 3,17 & $1,8 \times 10^{-14}$ \\
\hline$J U N$ & $\begin{array}{l}\text { Transcription } \\
\text { Factors and } \\
\text { Regulators }\end{array}$ & $7,8 \times 10^{-13}$ & 22,13 & 44,89 & 1,01 & 1,16 & $2,3 \times 10^{-12}$ \\
\hline$F Z D 2$ & $\begin{array}{l}\text { Wnt Signaling } \\
\text { (canonical) }\end{array}$ & $1,1 \times 10^{-12}$ & 6,88 & 2,16 & $-1,7$ & $-1,54$ & $3 \times 10^{-12}$ \\
\hline CCL 7 & $\begin{array}{l}\text { Cell Growth and } \\
\text { Proliferation } \\
\text { Genes }\end{array}$ & $2,4 \times 10^{-12}$ & 0,98 & 9,98 & 3,18 & 3,47 & $6,9 \times 10^{-12}$ \\
\hline \multirow[t]{2}{*}{$N R 4 A 3$} & $\begin{array}{l}\text { Transcription } \\
\text { Factors and } \\
\text { Regulators }\end{array}$ & $3,5 \times 10^{-12}$ & 0,16 & 1,22 & 2,1 & 3,31 & $1 \times 10^{-11}$ \\
\hline & $\begin{array}{l}\text { Cell Growth and } \\
\text { Proliferation } \\
\text { Genes }\end{array}$ & $2,6 \times 10^{-11}$ & 2,57 & 0,70 & $-1,94$ & $-1,68$ & $7 \times 10^{-11}$ \\
\hline RORB & $\begin{array}{l}\text { Transcription } \\
\text { Factors and } \\
\text { Regulators }\end{array}$ & $1,9 \times 10^{-8}$ & 179,73 & 91,40 & $-0,98$ & $-0,84$ & $4,4 \times 10^{-8}$ \\
\hline$C D K N 2 A$ & $\begin{array}{l}\text { Extracellular } \\
\text { Matrix Proteins }\end{array}$ & $6,6 \times 10^{-7}$ & 12,30 & 5,36 & $-1,21$ & $-1,19$ & $1,4 \times 10^{-6}$ \\
\hline MMP11 & $\begin{array}{l}\text { Transcription } \\
\text { Factors and } \\
\text { Regulators }\end{array}$ & $9,5 \times 10^{-7}$ & 21,60 & 10,13 & $-1,1$ & $-0,93$ & $1,9 \times 10^{-6}$ \\
\hline ETV4 & EMT Transition & $5,3 \times 10^{-5}$ & 0,37 & 1,19 & 1,26 & 1,69 & $9,3 \times 10^{-5}$ \\
\hline$L E F 1$ & Apoptosis Genes & 0,00027 & 48,58 & 29,55 & $-0,72$ & $-0,57$ & 0,00045 \\
\hline CASP3 & EMT Transition & 0,00085 & 1051,50 & 805,60 & $-0,38$ & $-0,74$ & 0,00134 \\
\hline$F N 1$ & $\begin{array}{l}\text { Wnt Signaling } \\
\text { (canonical) }\end{array}$ & 0,00222 & 15,50 & 19,20 & 0,3 & 0,42 & 0,00336 \\
\hline BCL9 & $\begin{array}{l}\text { Wnt Signaling } \\
\text { (canonical) }\end{array}$ & 0,02671 & 9,31 & 6,03 & $-0,65$ & $-0,50$ & 0,03566 \\
\hline
\end{tabular}


Die 32 hochsignifikant differentiell exprimierten Gene wurden anschließend ihren entsprechenden funktionellen Gengruppen zugeordnet und diese in hoch- sowie herunterregulierte Gruppen separiert. Demnach wurden insgesamt 23 Gene bei der Evolution von CMT-93 Zellen zu Lebermetastasen hochreguliert. Sechs dieser Gene konnten in die Gruppe der „Extrazellulären Matrixproteine“ eingeordnet werden und stellten somit die größte Gengruppe dar (Abb. 3.8).

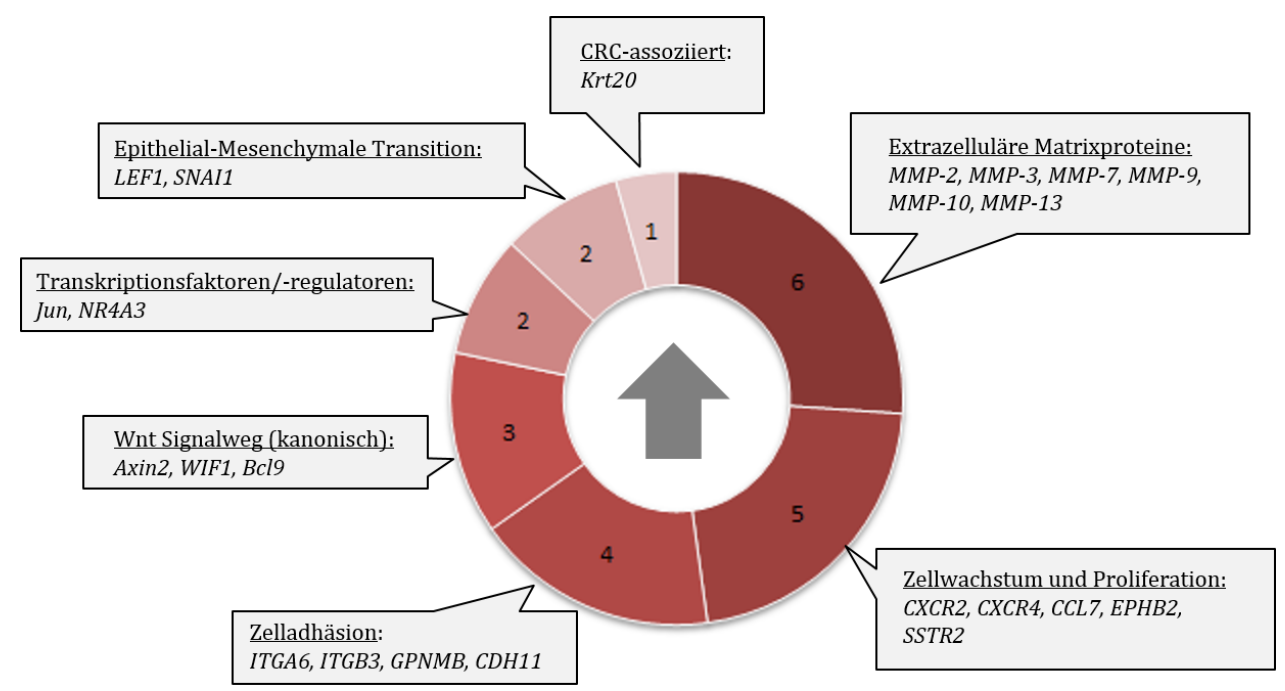

Abb. 3.8: Überblick der hochregulierten Gene in funktionellen Gruppen. 23 von 32 Genen wurden während der Entwicklung von CMT-93 Zellen in Lebermetastasen hochreguliert.

Neun Gene wurden hingegen herunterreguliert (Abb. 3.9). Diese verteilten sich relativ gleichmäßig mit jeweils zwei Genen bzw. einem Gen auf sechs funktionelle Gengruppen, wie beispielsweise PLAUR, FZD2 und CASP3.

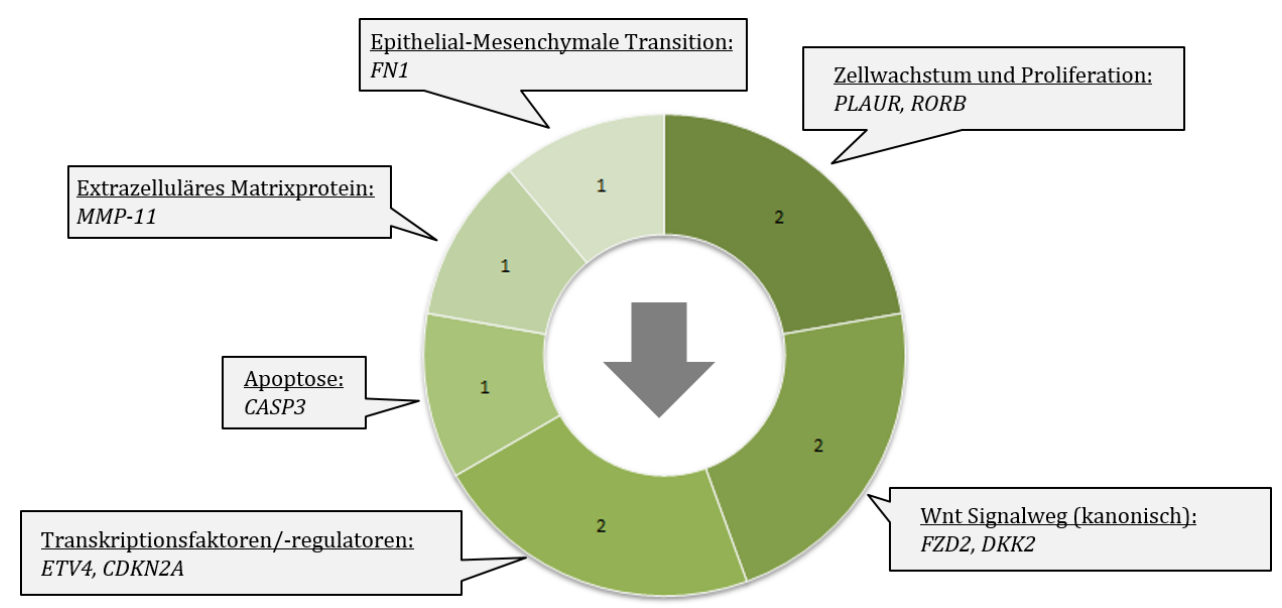

Abb. 3.9: Überblick der herunterregulierten Gene in funktionellen Gruppen. Neun von 32 Genen wurden während der Entwicklung von CMT-93 Zellen in Lebermetastasen herunterreguliert. 


\subsubsection{Gene Ontology Analyse zur Identifikation von besonders aktiven Signalwegen}

Zusätzlich zum Nachweis von Unterschieden in der Genexpression, wurde auf Basis des ursprünglichen Datensatzes ohne Leberbereinigung eine GO Analyse durchgeführt. Darauf basierend konnten Signalwege detektiert werden, die bei der Formation von Lebermetastasen durch CMT-93 Zellen besonders aktiv bzw. relevant sind.

In Abb. 3.10 sind die Top 20 signifikanten Signalwege nach $\rho$-Wert sortiert dargestellt. Demnach wurden für die GO-Kategorie „Biologische Prozesse“ die Signalwege „inflammatorische Antwort“, „Angiogenese“ und „Signaltransduktion“ als die Relevantesten für die Formation von Lebermetastasen identifiziert.
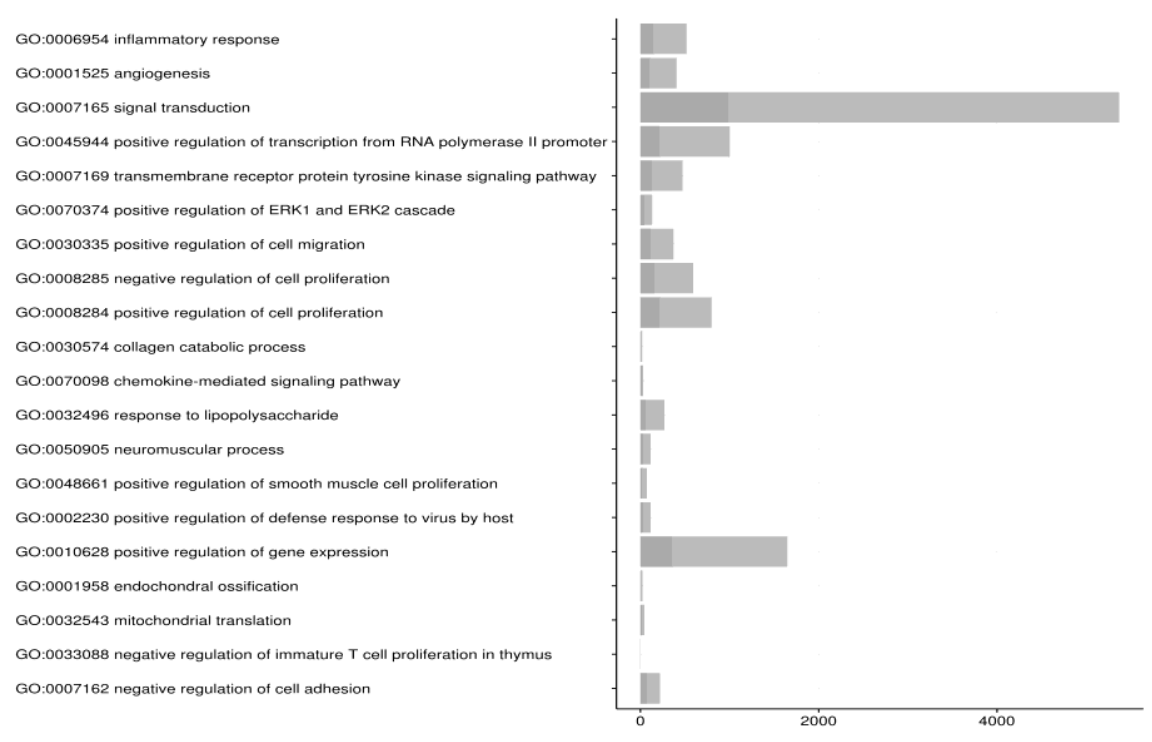

Number of significant genes from total genes in each GO geneset

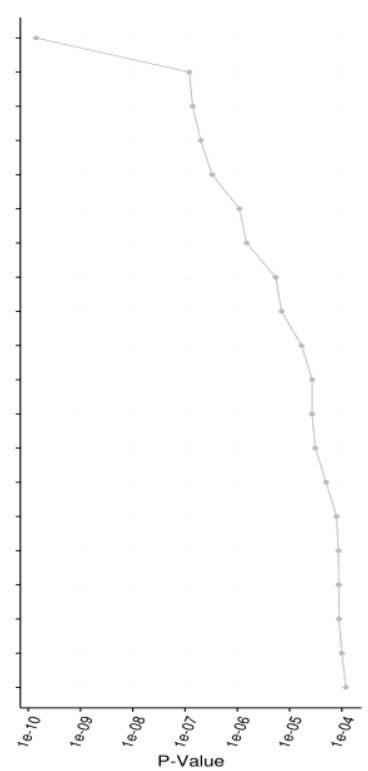

Abb. 3.10: Darstellung der Top 20 Signalwege aus der GO Kategorie „Biologische Prozesse“. Jeder Balken (dunkel- und hellgrauer Abschnitt) umfasst die Gesamtzahl der Gene aus den einzelnen Signalwegen. Der alleinige dunkelgraue Abschnitt indiziert die Anzahl der signifikant regulierten Gene pro Signalweg. Die Signalwege wurden in absteigender Reihenfolge nach dem $\rho$-Wert sortiert dargestellt.

\subsection{Analyse des frühen, mittleren und späten Metastasierungsstadiums während der Kolonisation der Mausleber durch CMT-93 Zellen}

Zur Charakterisierung der CMT-93 induzierten Lebermetastasen wurde neben einer RNA Sequenzierung auch eine $q R T-P C R$ sowie eine immunhistochemische Analyse durchgeführt, um die Expression einer Auswahl an Metastasen-assoziierten Genen in der Gesamtleber verifizieren zu können. 


\subsubsection{Makroskopische und mikroskopische Charakterisierung verschiedener Metastasierungsstadien im zeitabhängigen Verlauf der Leberkolonisation}

Im Anschluss an die Injektion von 1 x $10^{6}$ CMT-93 Zellen erfolgte die Organentnahme 3, 14 und 28 Tage nach Zellimplantation (Abb. 3.11, A - C). Als Kontrolle dienten Sham-operierte Mäuse (D - F). Während an Tag 3 post injectionem weiße Ablagerungen auf der Leberoberfläche zu erkennen waren (A), konnten diese ab Tag 14 nicht mehr beobachtet werden (B). Stattdessen begann ab diesem Zeitpunkt die Metastasenbildung durch CMT-93 Zellen, die nun makroskopisch sichtbar war (B - C). Der Durchmesser der Metastasen betrug an Tag 141 - $2 \mathrm{~mm}$; sie befanden sich mehrheitlich peripher in den einzelnen Leberlappen. An Tag 28 erreichten sie einen Diameter von bis zu $5 \mathrm{~mm}$ und dehnten sich verstärkt in Richtung des Leberlappenzentrums aus (C). Die PBS Injektion rief keine sichtbaren morphologischen Veränderungen in der Leber hervor. Nach der Dokumentation des Lebergewichts, wurden Proben möglichst aus dem Übergangsbereich zwischen Metastase und angrenzendem Lebergewebe für immunhistochemische Untersuchungen entnommen.

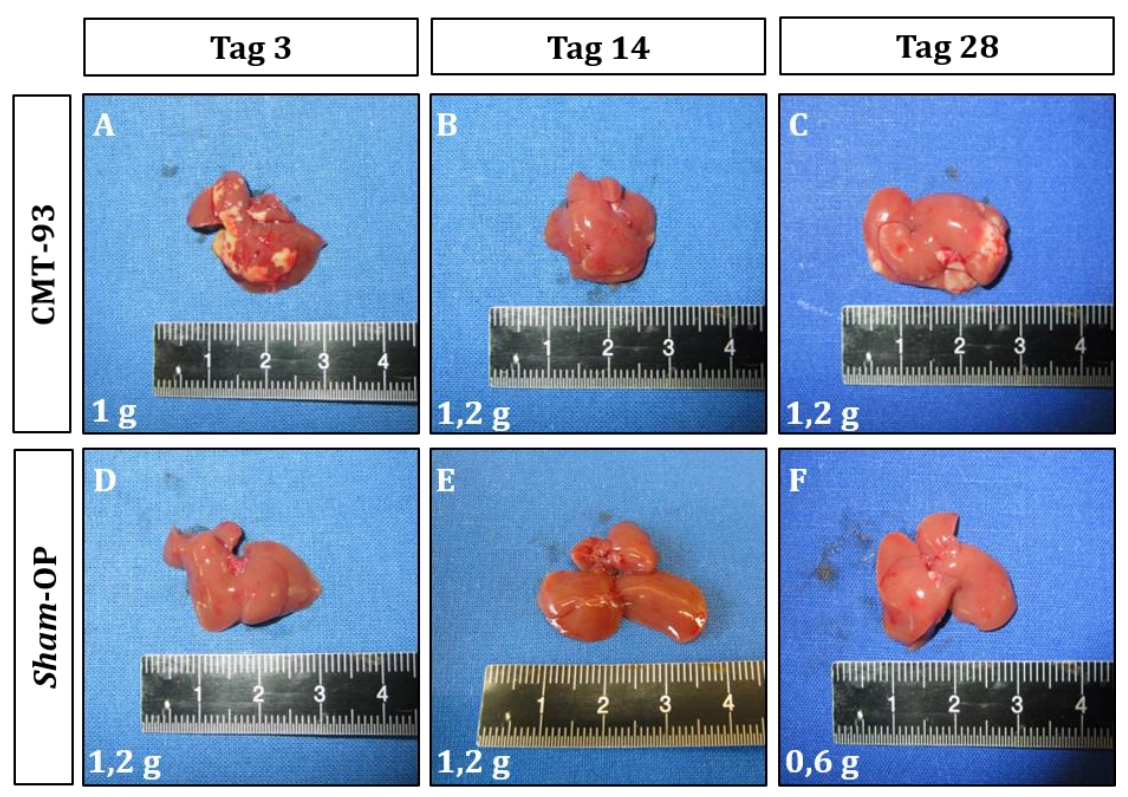

Abb. 3.11: Repräsentative ex vivo Aufnahmen von CMT-93 induzierten Lebermetastasen und entsprechenden Proben der Sham-operierten Mäuse. An Tag 3 waren lediglich weiße Ablagerungen ersichtlich (A), während die Metastasenbildung ab Tag 14 sichtbar wurde (B - C). Die PBS Injektion rief zu keinem Zeitpunkt makroskopisch sichtbare Veränderung hervor (D - F).

Für eine phänotypische Charakterisierung der Metastasen in verschiedenen Stadien, wurden die zuvor bereits erwähnten gängigen Marker E-cadherin, CD44, Vimentin und Ki-67 zur Unterscheidung von epithelialen und mesenchymalen Metastasensubtypen herangezogen 
(Abb. 3.12). Eine Keratin 20 Färbung wurde ebenfalls etabliert und durchgeführt; diese zeigte zwar eine spezifische, allerdings auch eine z.T. inhomogene/nicht-durchgängige Färbung des Tumors, weshalb entsprechende Aufnahmen hier nicht abgebildet sind.

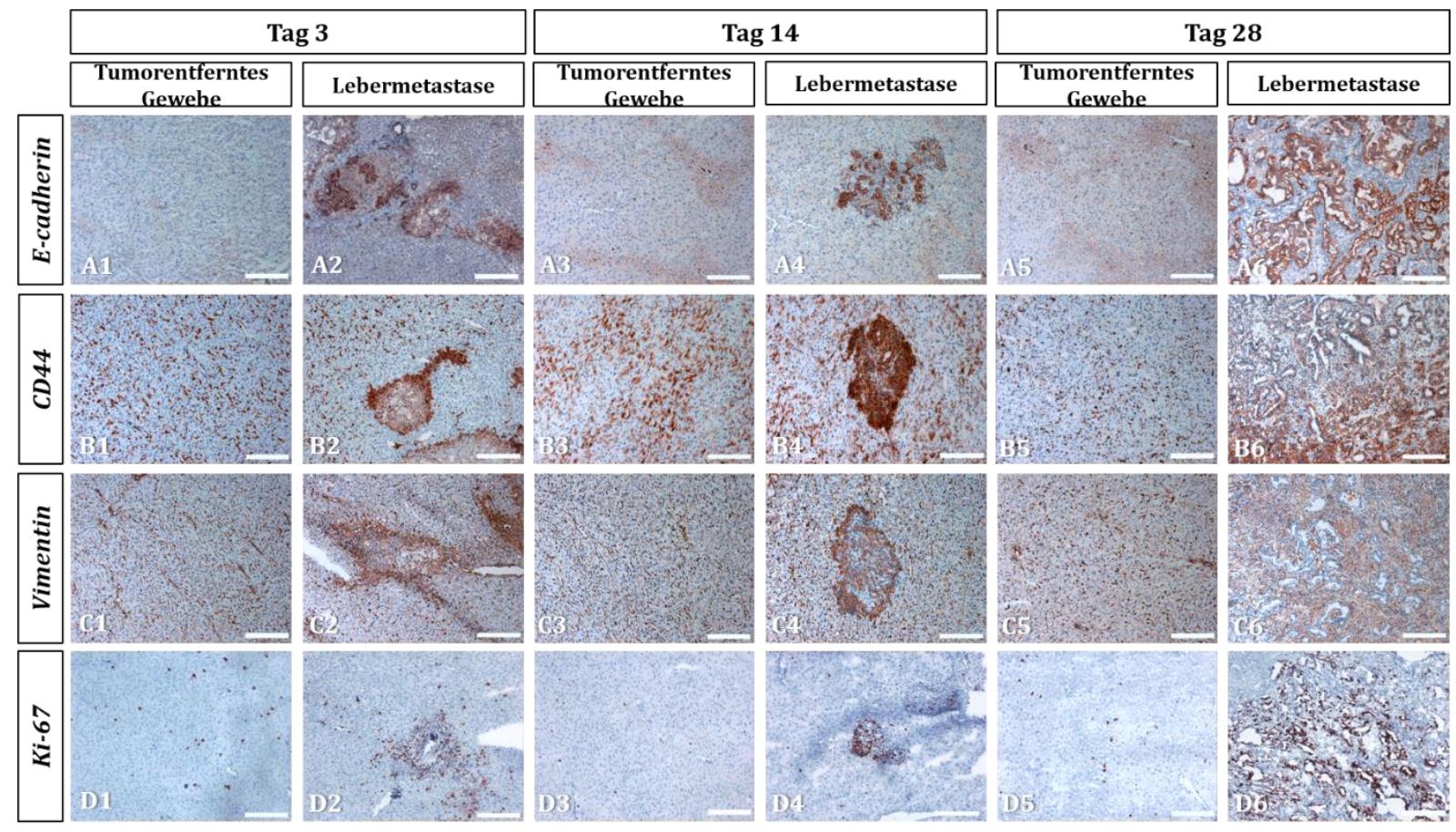

Abb. 3.12: Immunhistochemische Aufnahmen von CMT-93 induzierten Lebermetastasen und entsprechenden tumorentfernten Leberbereichen in verschiedenen Stadien der Metastasenformation. Die fortschreitende Metastasierung und die damit einhergehende Morphologie wurde anhand der Marker E-cadherin (A1 - A6), CD44 (B1 - B6), Vimentin (C1 - C6) und Ki-67 (D1 - D6) visualisiert. Eine Übersichtsaufnahme der Metastase wurde zu jedem Zeitpunkt durch eine repräsentative Aufnahme des tumorentfernten Gewebes ergänzt (siehe Anhang S. 149 für vergrößerte Aufnahmen der Metastasen). Größenbalken entsprechen einer Länge von $200 \mu \mathrm{m}$.

Während an Tag 3 und Tag 14 morphologische Gewebeveränderungen in Form von vereinzelten Zellansammlungen mit einem Durchmesser bis zu $800 \mu \mathrm{m}$ detektiert wurden, waren an Tag 28 deutlich Tumore und CRC-spezifische duktuläre Strukturen erkennbar. Diese und der epitheliale Charakter der Metastasen wurden durch die membrangebundene Färbung mit einem anti-E-cadherin Antikörper (A1 - A6) deutlich hervorgehoben. Anhand der CD44 Expression konnten Metastasen makroskopisch vom restlichen Lebergewebe separiert werden (B1 - B6). Neben der deutlich verstärkten Färbung der Metastase waren auch weitere vereinzelte $C D 44^{+}$Zellen im Leberparenchym vorzufinden. An Tag 3 und Tag 14 waren Vimentin+ Zellen insbesondere im Tumorrand erkennbar, doch die Expression schien sich im Laufe der fortschreitenden Metastasierung deutlich zu verstärken und über die gesamte Tumorfläche auszubreiten (C6). Im tumorentfernten Gewebe waren dagegen an Tag 
3 (C1) lediglich „durchgezogene Linien“ zu erkennen. Ki-67 ist im Zellkern lokalisiert und wird in der G1-, G2- und M-Phase der Mitose exprimiert, weshalb es sich für die Markierung von sich schnell teilenden Zellpopulationen eignet. Auch hier schien eine positive Korrelation zwischen $\mathrm{Ki}^{-67^{+}}$Zellen und dem Metastasierungsstadium bzw. der Metastasengröße vorzuliegen (D1 - D6). Je größer die Metastase wurde, desto mehr Ki-67+ Zellen wurden im Tumor detektiert (D6). Im umgebenden Lebergewebe waren ebenfalls einzelne proliferierende Zellen nachweisbar (z.B. D1).

\subsubsection{Molekularbiologische Charakterisierung von CMT-93 induzierten Metastasen im zeitabhängigen Verlauf der Leberkolonisation}

Von den 119 Metastasen-assoziierten Genen wurden 11 ausgewählt (Tab. 3.6) und ihre Expression im Verlaufe der Metastasenformation anhand einer qRT-PCR Analyse verifiziert. Die entsprechenden Resultate der Metastasen-tragenden Lebern wurden mit Shamoperierten Lebern verglichen und in Relation $\mathrm{zu}$ einer gesunden, unbehandelten C57BL/6NCrl Mausleber gesetzt, um Expressionsunterschiede anhand einer relativen Quantifizierung zu ermittelt.

Tab. 3.6: Genliste zur molekularen Charakterisierung der CMT-93 induzierten Lebermetastasen. 11 Gene aus acht funktionellen Gengruppen wurden ausgewählt und ihre Expression in CMT-93 kolonisierten Lebern, Sham-operierten Lebern und einer unbehandelten Leber mittels qRT-PCR quantifiziert. B2M und HPRT wurden als Housekeeping Gene verwendet.

\begin{tabular}{ll}
\hline Gengruppe & Genname \\
\hline CRC-assoziiertes Gen & Krt20 \\
Leberspezifisches Gen & $P C K 1$ \\
Zelladhäsion & $C D 44$ \\
Extrazelluläres Matrixprotein & $M M P-7$ \\
Zellwachstum und Proliferation & Cyclin D1, Ki-67 \\
Apoptose & Caspase-3 \\
Transkriptionsfaktoren und -regulatoren & NFkB1, Stat3 \\
Epithelial-Mesenchymale Transition & E-cadherin, Vimentin \\
\hline
\end{tabular}

\subsubsection{Einfluss verschiedener Metastasierungsstadien auf die Morphologie und das Gewicht der Leber}

In Abbildung 3.13 sind an Tag 3 weiße Strukturen in unterschiedlichem Ausmaß auf der Leberoberfläche erkennbar (A, D, G), gefolgt von der Formation von Metastasenherden in 
verschiedenen Leberlappen an Tag 14 (B, E, H). Auffällig war jedoch die unterschiedliche Größe und Streuung der einzelnen Metastasen. Während in Abbildung (B) eine Metastase mit einem Durchmesser von ca. $2 \mathrm{~mm}$ im Leberzentrum zu sehen ist, sind in Abbildung (E) mehrere kleine Metastasenherde mit einem Durchmesser von 0,5 - 1 mm erkennbar. In (H) hingegen ist die Leber zumindest makroskopisch stärker kolonisiert von CMT-93 Zellen. Hier waren kleine, aber auch großflächige Metastasen mit einem Durchmesser von ca. $5 \mathrm{~mm}$ detektierbar. Auch zu einem späten Zeitpunkt der Metastasierung waren deutliche Unterschiede zwischen den einzelnen Serien ersichtlich (C, F, I). Abbildung (C) zeigt eine Leber, die im Vergleich zur Tag 14 Probe (B) zwar etwas vergrößerte Metastasenherde aufweist (maximal $5 \mathrm{~mm}$ ), doch diese machten lediglich etwa 30 \% der Gesamtleber aus. In (F) hingegen ist eine stark vergrößerte Metastase abgebildet, die etwa $70 \%$ der gesamten Leber infiltriert hatte und eine großflächige, Leberkapsel-überschreitende, irreguläre Struktur bildete. Auch in der dritten Serie waren an Tag 28 im Vergleich zur Tag 3 und Tag 14 Probe größere Metastasen erkennbar, die einen Durchmesser von ca. $10 \mathrm{~mm}$ erreichten und 30 - 40 \% der Gesamtleber ausmachten (I). Diese Leber konnte bezüglich des Ausmaßes der Metastasierung zwischen die Lebern dargestellt in (C) und (F) eingeordnet werden.

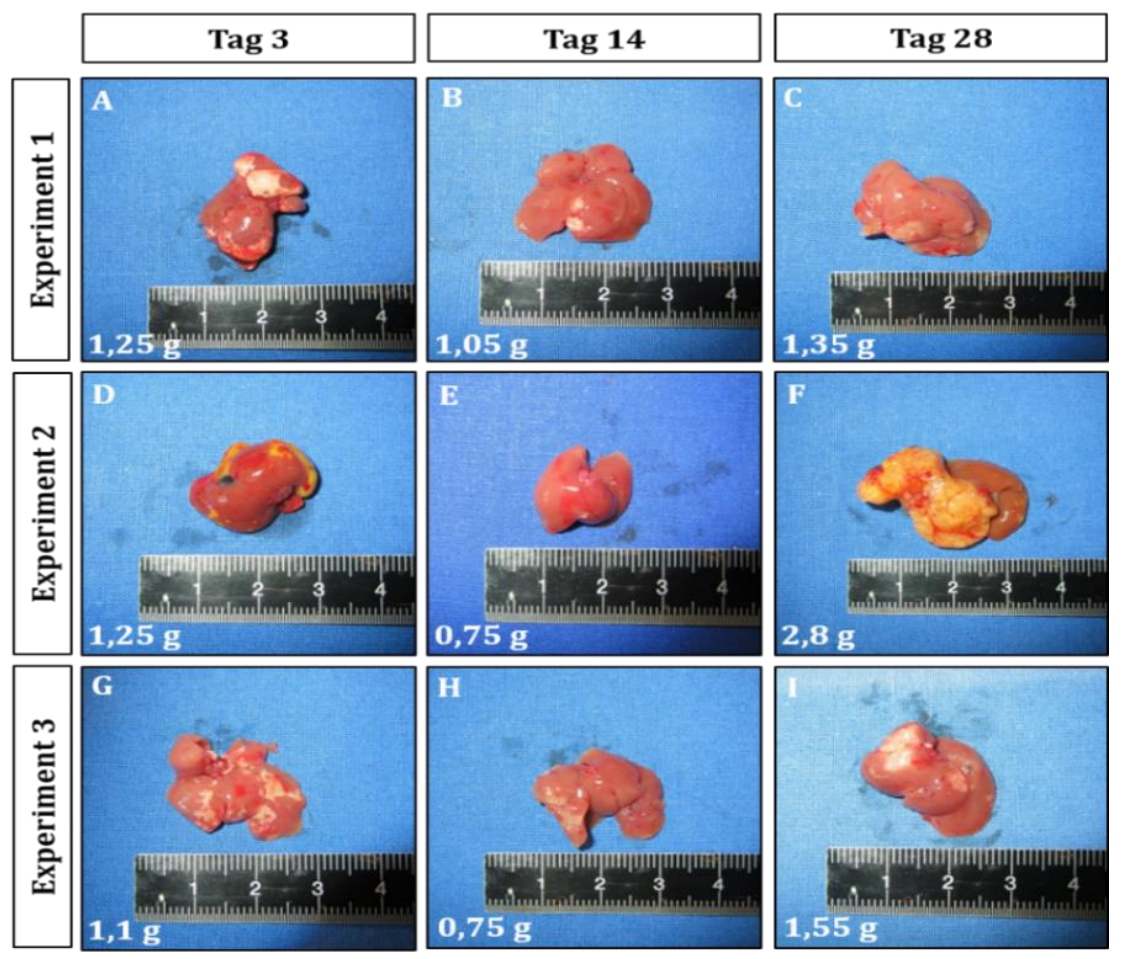

Abb. 3.13: Repräsentative ex vivo Aufnahmen von CMT-93 induzierten Lebermetastasen, die auf molekularbiologischer Ebene charakterisiert wurden. CMT-93 kolonisierte Lebern aus drei unabhängigen Experimenten wurden nach Zellimplantation an Tag 3, 14 und 28 explantiert, makroskopisch charakterisiert und für eine $q R T$-PCR Analyse verwendet. Im zeitabhängigen Verlauf der Leberkolonisation war insgesamt eine zunehmende Größenbildung der Metastasen bis Tag 28 erkennbar. 
Bei makroskopischer Betrachtung kolonisieren CMT-93 Zellen murine Lebern in unterschiedlichem Ausmaß und induzieren somit unterschiedlich stark gestreute Metastasen verschiedener Größe. Insgesamt ist jedoch eine Vergrößerung der Metastasen im zeitabhängigen Verlauf der Metastasierung erkennbar.

Der Einfluss der drei Metastasierungsstadien auf das Gewicht der Mausleber ist in Form eines Boxplots in Abb. 3.14 zusammengefasst. In den verschiedenen Zeitpunkten der Organentnahme waren (z.T. signifikante) Gewichtsunterschiede zwischen Metastasentragenden Lebern (dunkelgraue Box), Sham-operierten Lebern (hellgraue Box) und einer gesunden Leber (schwarze Box) ersichtlich. An Tag 28 wurde jedoch anhand der Ausreißer und der damit einhergehend hohen Standardabweichung der unterschiedliche Kolonisationserfolg bzw. Metastasierungsgrad am Gewicht deutlich erkennbar. Bei Lebern mit stark infiltriertem, metastatischem Gewebe 28 Tage nach Zellimplantation (wie z.B. in Abb. $3.13 \mathrm{~F}$ zu sehen) wurde ein fast 3fach erhöhtes Gewicht dokumentiert als bei einer unbehandelten Leber. Innerhalb der Tag 28 Proben war das Gewicht z.T. um das 2 fache erhöht (vergleiche Abb. 3.13 C und F).

Abb. 3.14: Boxplot zum Vergleich des Lebergewichts von C57BL/6NCrl Mäusen nach CMT-93 Injektion. Aus drei unabhängigen Experimenten wurde das durchschnittliche Gewicht der Metastasentragenden (dunkelgraue Box) und den Shamoperierten (hellgraue Box) Lebern ermittelt. Ihr Gewicht wurde gemeinsam mit dem Gewicht einer unbehandelten Leber gegen den
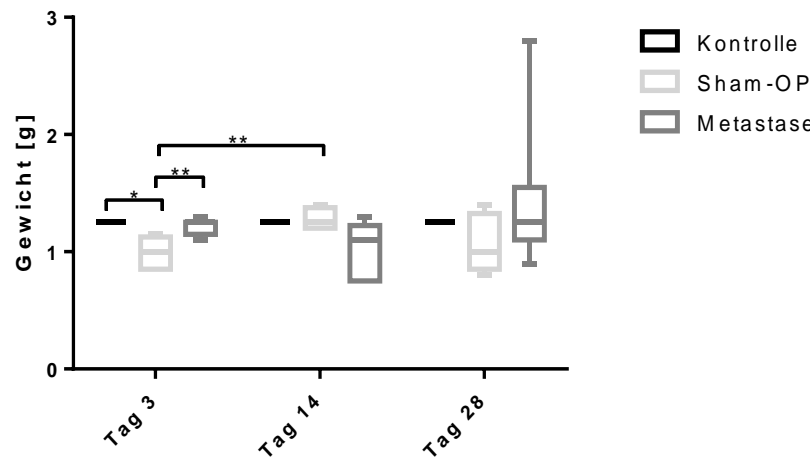
Zeitpunkt der Organentnahme aufgetragen. Signifikante Unterschiede wurden mit Sternchen markiert $\left(^{*}=\right.$ $\rho \leq 0,05 ; * *=\rho \leq 0,01)$.

\subsubsection{Expression von Metastasen-assoziierten Genen in verschiedenen Stadien der Metastasenformation}

Im Anschluss an die makroskopische Charakterisierung der Metastasen im zeitabhängen Verlauf der Leberkolonisation wurde anhand einer $q R T-P C R$ Analyse die Expression von 11 Metastasen-assoziierten Genen (s. Tab. 3.6) quantifiziert. Für die Untersuchungen wurden jeweils Homogenisate ganzer Leberorgane (gesamte Metastasen-tragende Leber) 
herangezogen. Das Resultat der Quantifizierung für einzelne Gene ist in Abb. 3.15 zusammengefasst.

\subsubsection{Expression von leber- und tumorspezifischen Genen und MMP-7 als Vertreter für „Extrazelluläre Matrixproteine“}

Analog zur Qualitätskontrolle der RNA Sequenzierungsproben wurde auch hier die Expression von PCK1 als leberspezifisches Gen ermittelt (A). In Metastasen-tragenden Lebern war an Tag 3 und Tag 14 im Vergleich zur gesunden Leber eine leicht erhöhte Expression messbar, die an Tag 28 signifikant reduziert wurde. In Sham-operierten Lebern wurde die PCK1 Expression zu allen Zeitpunkten reduziert und lag insbesondere an Tag 14 und Tag 28 unter dem Wert der gesunden Leber.

Als Surrogatparameter für die Tumorlast wurde die Expression von Krt20 und CD44 quantifiziert (B, C). Die Expression beider Gene in Metastasen-tragenden Lebern erhöhte sich deutlich zu jedem Zeitpunkt und erreichte an Tag 28 ihr Maximum. Bei Krt20 war zu diesem Zeitpunkt die Expression im Vergleich zur gesunden Leber um das ca. 2000fache erhöht; bei CD44 lag eine Erhöhung um das ca. 150fache vor.

Der Grad der ECM Degradation wurde anhand des MMP-7 Gens überprüft (D). In diesem Fall zeigte sich insbesondere in den Metastasen-tragenden Lebern an Tag 3 und Tag 28 eine erhöhte Expression.

\subsubsection{Quantifizierung von Zellwachstums-, Proliferations- und Apoptosegenen}

Die zellzyklisch aktiven und proliferierenden sowie die apoptotischen Eigenschaften in der Gesamtleber wurden anhand der Gene Cyclin D1, Ki-67 und Caspase-3 geprüft. Die Cyclin D1 Expression in Metastasen-tragenden Lebern war zu allen Zeitpunkten im Vergleich zu Shamoperierten und zur gesunden Leber erhöht (E). Innerhalb der Probengruppen zeigten sich zu den verschiedenen Zeitpunkten der Organentnahme nur geringe Schwankungen mit einer leichten Abnahme bis Tag 28.

Im Vergleich zur gesunden Leber konnte an Tag 3 in Metastasen-tragenden und Shamoperierten Lebern eine erhöhte Ki-67 Expression gemessen werden (F). In Letzteren nahm trotz eines Ausreißers an Tag 14 die Genexpression bis Tag 28 deutlich ab, während in Metastasen-tragenden Lebern zwischen Tag 14 und Tag 28 ein Anstieg gemessen wurde.

Der Apoptosegrad der Proben wurde anhand der Caspase-3 Expression überprüft (G). In allen Proben wurde im Vergleich zur gesunden Leber eine erhöhte Expression gemessen. Sowohl 
in Sham-operierten als auch in Metastasen-tragenden Lebern nahm die Expression dennoch im Laufe der Metastasenformation ab; bei Letzteren wurde eine signifikante Reduktion der Genexpression detektiert.

\subsubsection{Expression von Transkriptionsfaktoren/-regulatoren und EMT Markern}

Die NFkB1 Expression war in behandelten Lebern zu allen Zeitpunkten im Vergleich zur gesunden Leber erhöht $(\mathrm{H})$. Dennoch nahm ihre Genexpression mit der Versuchsdauer konstant ab. Zudem wiesen an Tag 3 und Tag 28 Metastasen-tragende Lebern im Vergleich zu Sham-operierten Lebern eine erhöhte NFkB1 Expression auf.

Bei der Expression des Stat3 Gens wurden die größten signifikanten Unterschiede gemessen (I). In Sham-operierten und Metastasen-tragenden Lebern war an Tag 3 die Expression im Vergleich zur gesunden Leber um das ca. 6 - 8fache erhöht. An Tag 14 nahm in beiden Gruppen die Expression signifikant ab und erreichte ein ähnliches Niveau. Während bei den Sham-operierten Lebern an Tag 28 erneut eine signifikante Abnahme festgestellt wurde, nahm die Expression in Metastasen-tragenden Lebern leicht zu. Verglich man nun beide Gruppen an Tag 28 miteinander, war die Stat3 Expression in Metastasen-tragenden Lebern signifikant erhöht.

Um den EMT Status auch auf molekularbiologischer Ebene prüfen zu können, wurde die Expression von E-cadherin und Vimentin quantifiziert (J, K). Die erhöhte E-cadherin Expression in Sham-operierten Tieren an Tag 3 nahm stätig ab bis Tag 28. In Metastasentragenden Lebern wurde zwischen Tag 3 und Tag 14 ebenfalls eine Abnahme detektiert, die an Tag 28 in einem leichten Anstieg resultierte, wobei insbesondere die Standardabweichung der E-cadherin Expression große Unterschiede zwischen den einzelnen Tieren verdeutlicht. Insgesamt war jedoch in Metastasen-tragenden Lebern an Tag 28 eine höhere E-cadherin Expression detektierbar als in den entsprechenden Sham-operierten Lebern. Die Vimentin Expression in Letzteren zeigte zwischen Tag 3 und Tag 14 einen Anstieg, wurde jedoch bis Tag 28 deutlich reduziert. In Metastasen-tragenden Lebern war insbesondere an Tag 3 und Tag 28 im Vergleich zu Sham-operierten Lebern eine höhere Expression des Mesenchymalmarkers ersichtlich.

Somit erlaubten eine RNA Sequenzierung und $q R T-P C R$ Analysen die Erstellung eines Profils der Metastasen-tragenden Lebern, indem Expressionsunterschiede gemessen wurden. Nichtsdestotrotz sollten beide Methoden separat betrachtet und ausgewertet werden. Denn während anhand der RNA Sequenzierung ein Profil des Tumorkerns im Vergleich zur CMT- 
93 Zelllinie erstellt wurde, ermöglichte die $q R T-P C R$ Analyse eine Charakterisierung der gesamten Metastasen-tragenden Leber im Vergleich zu einer Gesunden.

A

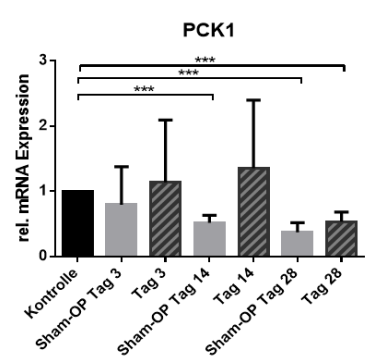

$\mathbf{E}$

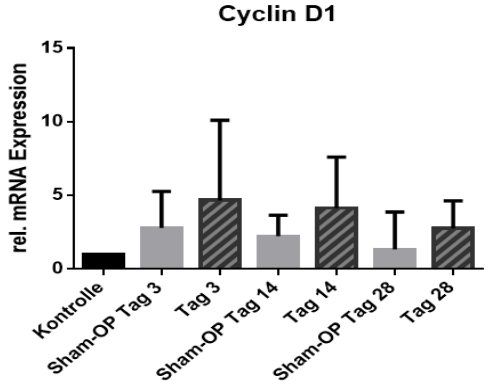

$\mathbf{H}$

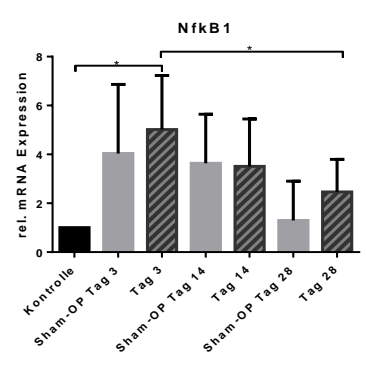

B

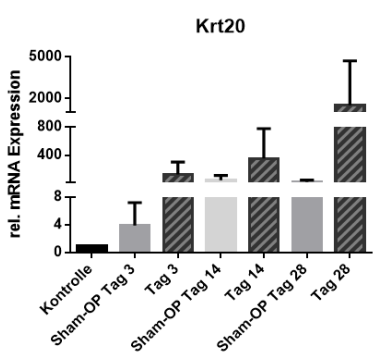

$\mathbf{F}$

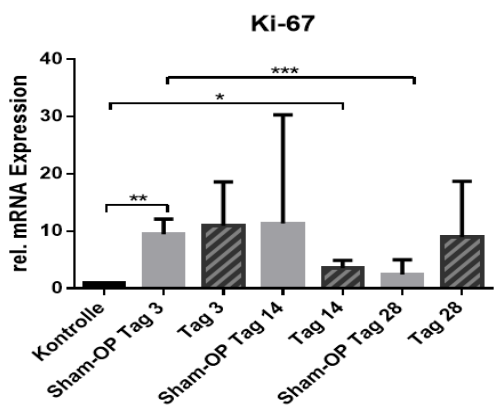

$\mathbf{J}$
C

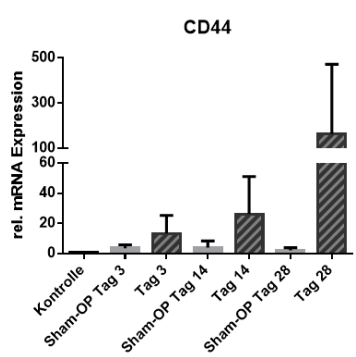

D

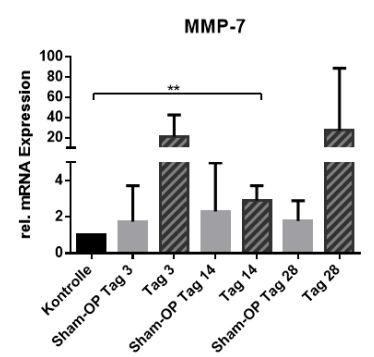

G

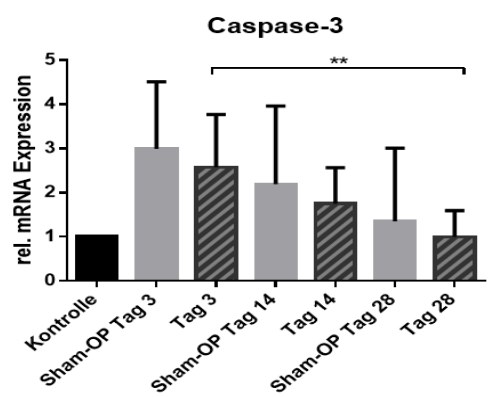

$\mathbf{K}$

Abb. 3.15: Expression von Metastasen-assoziierten Genen im zeitlichen Verlauf der Leberkolonisation. Die Expression von 11 Metastasen-assoziierten Genen wurde mittels $q R T$-PCR Analyse in Metastasen-tragenden und Sham-operierten Gesamtlebern quantifiziert. Auf der y-Achse ist die relative mRNA Expression dargestellt, die im Verhältnis zu einer gesunden, unbehandelten Leberkontrolle berechnet wurde. Pro Bedingung wurden 4 - 6 biologische Replikate verwendet; die entsprechenden technischen Replikate wurden als Triplet gemessen. Signifikante Unterschiede wurden mit Sternchen markiert $\left(*=\rho \leq 0,05 ;{ }^{* *}=\rho \leq 0,01 ;{ }^{* * *}=\rho \leq 0,001\right)$. 


\subsection{In vivo und in vitro Charakterisierung der Interaktion von Makrophagenphänotypen und CMT-93 Tumorzellen}

Im Rahmen dieser Arbeit wurde durch in vivo Experimente die Rekrutierung und die Kolonisierung durch Makrophagenphänotypen in der Tumormikroumgebung untersucht. Der indirekte Einfluss auf Tumorzellen wurde in vitro analysiert, indem Monozyten zu verschiedenen Makrophagenphänotypen differenziert und in einem Kokultursystem ihr Einfluss auf CMT-93 Zellen charakterisiert wurde.

\subsubsection{Bioinformatische Analysen zur Expression von Metastasen-assoziierten Genen und Makrophagenphänotypen}

Die Kolonisierung durch Makrophagenphänotypen wurde auf molekularbiologischer Ebene zunächst mittels einer RNA Sequenzierung überprüft. 28 Tage nach intraportaler Implantation von CMT-93 Zellen wurden Proben aus vier Arealen der Leber entnommen (siehe Abb. 3.4) und die Expression von Genen untersucht, die spezifisch sind für Makrophagenphänotypen und Immunzellen. Tabelle 3.7 fasst die entsprechenden Gene und Ensembl IDs zusammen.

Tab. 3.7: Genliste von Immunzellen für die RNA Sequenzierung. Aufgelistet ist eine Auswahl von Genen, die spezifisch sind für Makrophagensubtypen und weitere Immunzellen.

\begin{tabular}{lcl}
\hline Immunzellen & Genname & Ensembl ID \\
\hline \multirow{2}{*}{ Allgemeine Makrophagen } & $C D 11 b$ & ENSMUSG00000030786 \\
& $F 4 / 80$ & ENSMUSG00000004730 \\
M1 Makrophagen & $C D 68$ & ENSMUSG00000018774 \\
M2 Makrophagen & $C D 80$ & ENSMUSG00000075122 \\
& $C D 86$ & ENSMUSG00000022901 \\
& $C D 163$ & ENSMUSG00000008845 \\
Weitere Immunzellen & $C D 206$ & ENSMUSG00000026712 \\
& $C D 3 d$ & ENSMUSG00000032094 \\
& $C D 3 e$ & ENSMUSG00000032093 \\
& $C D 3 g$ & ENSMUSG00000002033 \\
& $C D 4$ & ENSMUSG00000023274 \\
& $C D 8 a$ & ENSMUSG00000053977 \\
\hline
\end{tabular}




\subsubsection{Expression von Metastasen-assoziierten Genen in verschiedenen Arealen von CMT-93 kolonisierten Mauslebern}

Auf Basis der RNA Sequenzierungsdaten wurde zunächst das Expressionslevel von 12 Metastasen-assoziierten und drei leberspezifischen Genen (CYP3A25, CPS1 und PCK1) in je vier Leberarealen von vier Mäusen untersucht (D208, D209, D210, D212). Auffällig ist, dass leberspezifische Gene überwiegend im makroskopisch tumorfreien Rand (NR) und im tumorfreien Gewebe (N) exprimiert wurden, während Metastasen-assoziierte Gene eine erhöhte Expression im Tumorkern (K) und im Tumorrand (R) zeigten (Abb. 3.16). Letztere können diesbezüglich in zwei Gruppen unterteilt werden: die erste Gruppe beinhaltet Gene, bei denen sich das Expressionslevel zwischen Tumorgewebe ( $K$ und $R$ ) und restlichem Lebergewebe (NR und N) nur geringfügig unterscheidet. Dazu gehören: $\beta$-catenin (CTNNB1), Cyclin D1 (CCND1), Stat3 und Caspase-3. In die zweite Gruppe können die Gene Vimentin, Ecadherin (CDH1), CD44, NFkB1, MMP-7, Krt20 und Ki-67 eingeordnet werden, da es hier einen deutlich größeren Unterschied im Expressionsprofil des Tumors und des restlichen Lebergewebes gibt. Bei diesen Genen handelt sich um tumor-, EMT- und Proliferationsspezifische Marker.

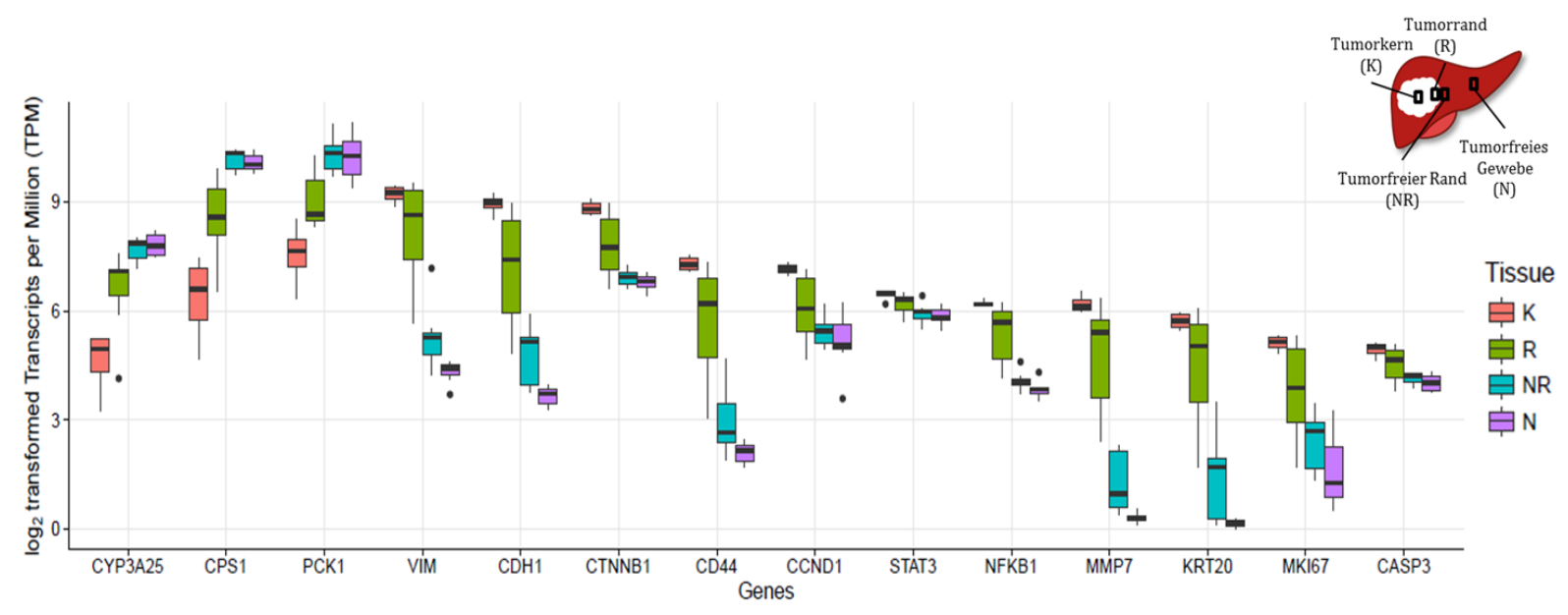

Abb. 3.16: Boxplot zur molekularbiologischen Charakterisierung der verschiedenen Leberareale. Die Expressionslevel von Metastasen-assoziierten und leberspezifischen Genen wurden normalisiert als TPMs berechnet und logarithmisch aufgetragen. Während leberspezifische Gene überwiegend im tumorumgebenden Gewebe exprimiert werden (NR, N), sind Metastasen-assoziierte Gene im Tumor verstärkt detektierbar $(\mathrm{K}, \mathrm{R})$.

Im nächsten Schritt wurde die CMT-93 Zelllinie anhand einer DEG mit den vier verschiedenen Leberarealen verglichen. Hierfür wurde die Genliste mit 119 Metastasen-assoziierten Genen gemeinsam mit den Immunzellgenen aus Tab. 3.7 als Filter eingesetzt (insgesamt 133 Gene) 
und 126 dieser Gene als differentiell exprimiert identifiziert. Es wurde der ursprüngliche Datensatz ohne Leberbereinigung verwendet, da Immunzellgene sonst aufgrund ihrer hohen Expression in normalem Lebergewebe durch diesen Schritt als Effekt des Leberhintergrundes herausgefiltert werden würden.

Aus Abbildung 3.17 wird zunächst ersichtlich, dass Genexpressionsunterschiede zwischen der CMT-93 Zelllinie im linken Drittel der Heatmap und den vier Leberarealen vorhanden sind, wobei Zelllinie und Tumorproben (K, R) offensichtlich mehr Ähnlichkeiten aufweisen im Vergleich zum restlichen Gewebe. Des Weiteren ist erkennbar, dass sich Proben aus dem Tumor (K, R) im rechten Drittel der Heatmap gut von den Proben aus dem restlichen Gewebe (NR, N) im mittleren Drittel der Heatmap separieren lassen. Diese Trennung indiziert, dass sich diese beiden Gruppen in ihrem Genexpressionsprofil unterscheiden. Als dritter Punkt ist anzumerken, dass innerhalb der Gruppen wenig Variationen ersichtlich sind. So grenzen sich beispielsweise Proben aus dem tumorfreien Gewebe (N) und dem tumorfreien Rand (NR) nicht klar voneinander ab; hier vermischt sich offensichtlich das Expressionsprofil. Bei den Proben aus dem Tumorgewebe ist ein ähnliches Muster erkennbar. Auch hier separieren sich Tumorkern $(\mathrm{K})$ und Tumorrand $(\mathrm{R})$ nicht eindeutig voneinander. Eine Probe aus dem Tumorrand (D210R) scheint sogar mehr Ähnlichkeiten mit dem restlichen Lebergewebe aufzuweisen als mit dem Tumor.

Somit konnte gezeigt werden, dass sich das Genprofil der CMT-93 Zellen zwar während der Propagation in der Leber verändert, der Tumor aber immer noch Ähnlichkeiten mit der Zelllinie aufweist und sich dabei jedoch klar vom restlichen Lebergewebe abgrenzt. Des Weiteren wurde ersichtlich, dass eine genaue Unterscheidung zwischen Tumorkern und rand bzw. Normalrand und -gewebe nicht essentiell ist, während eine Separation von Tumorgewebe und Normalgewebe aufgrund der divergierenden Expressionsprofile durchaus Sinn macht. 


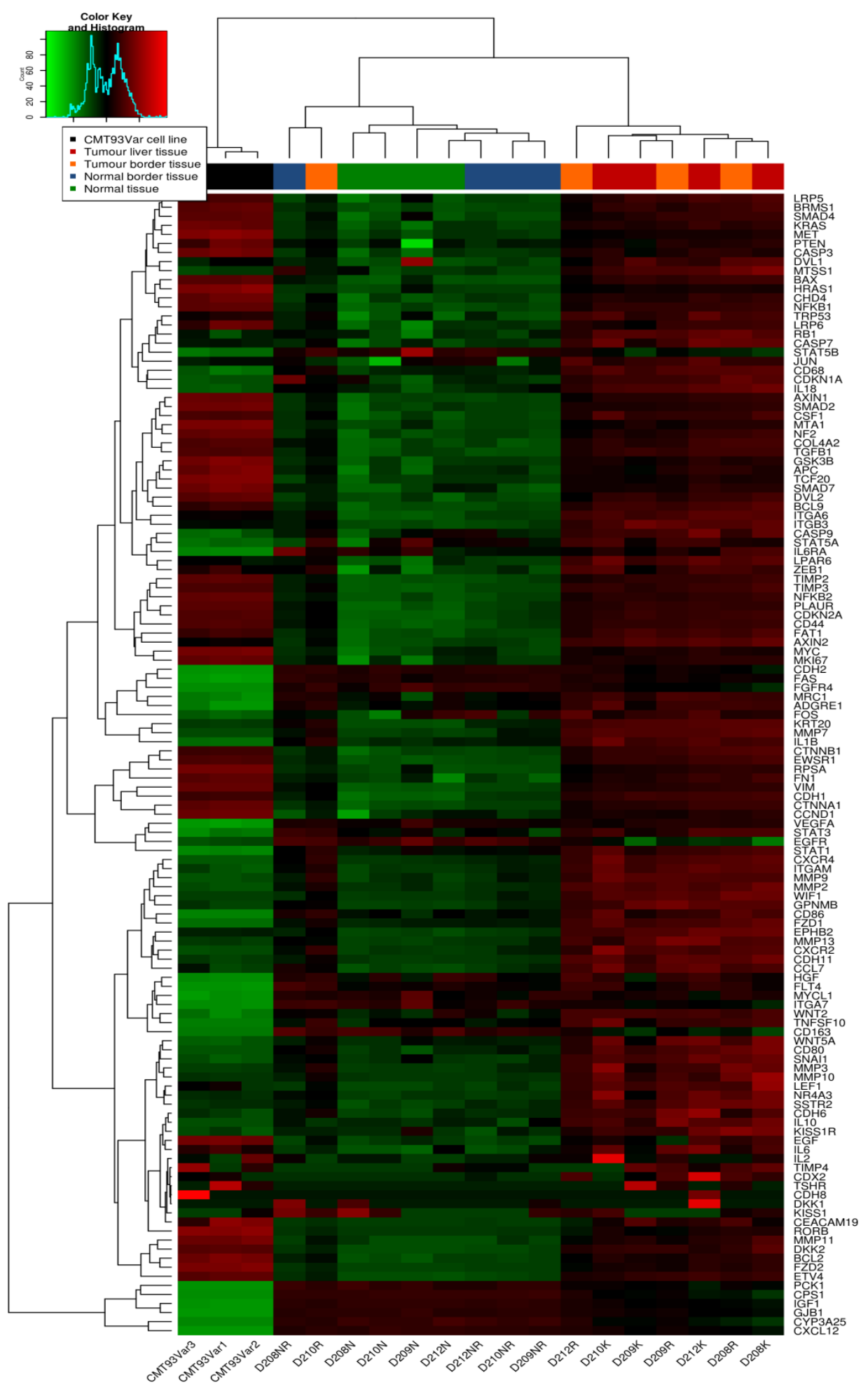

Abb. 3.17: Heatmap zur Darstellung von 126 differentiell exprimierten Genen in verschiedenen

Leberarealen. RNA Sequenzierungsdaten der CMT-93 Zellen und der Leberproben von vier Mäusen wurden ohne Korrektur für den Lebergewebeeffekt anhand einer Liste von Metastasen-assoziierten und Immunzell-spezifischen Genen gefiltert und 126 signifikant exprimierte Gene identifiziert. Tumorproben (orange \& rot) und Leberproben (blau \& grün) lassen sich klar voneinander separieren. Das Tumorgewebe $(\mathrm{K}, \mathrm{R})$ weist zwar Ähnlichkeiten mit der Zelllinie (schwarz) auf, entwickelt jedoch im Zuge der Metastasenformation ein deutlich divergierendes Genexpressionsprofil. 


\subsubsection{Expression von M1 und M2 Makrophagen in verschiedenen Arealen von CMT- 93 induzierten Lebermetastasen}

Die Lokalisation und spezifischen Expressionslevel der Makrophagenphänotypen in verschiedenen Arealen von Metastasen-tragenden Lebern sind in Abb. 3.18 in Form eines Boxplots dargestellt. Im Falle der CD80 und CD86 Expression lag im Tumorgewebe (K, R) im Gegensatz zum restlichen Lebergewebe (NR, N) eine erhöhte Genexpression vor (A). Insgesamt schien jedoch das CD86 Gen in Metastasen-tragenden Lebern stärker exprimiert zu werden als das $C D 80$ Gen.

Während die CD206 Expression überwiegend im Tumorgewebe detektiert wurde, kehrte sich dieses Muster im Falle der CD163 Expression um (B). Hier war die Expression des Gens im restlichen Lebergewebe (N, NR) erhöht. Metastasen-tragende Lebern exprimierten insgesamt das M2-spezifische Gen CD206 stärker als CD163.

Die Genexpression von allgemeinen Makrophagenmarkern wurde ebenfalls untersucht (C). Die drei Gene F4/80 (ADGRE1), CD68 und CD11b (ITGAM) zeigten eine erhöhte Expression im Tumorkern und im Tumorrand. Allerdings unterschied sich die Expression zwischen Tumorgewebe $(\mathrm{K}, \mathrm{R})$ und Lebergewebe (NR, R) unterschiedlich stark; die CD68 und CD11b Expression war im Lebergewebe (NR, N) deutlich geringer vorhanden als im Tumorgewebe (K, R). Im Falle des F4/80 Gens lagen die Expressionslevel beider Gewebegruppen deutlich näher beisammen.
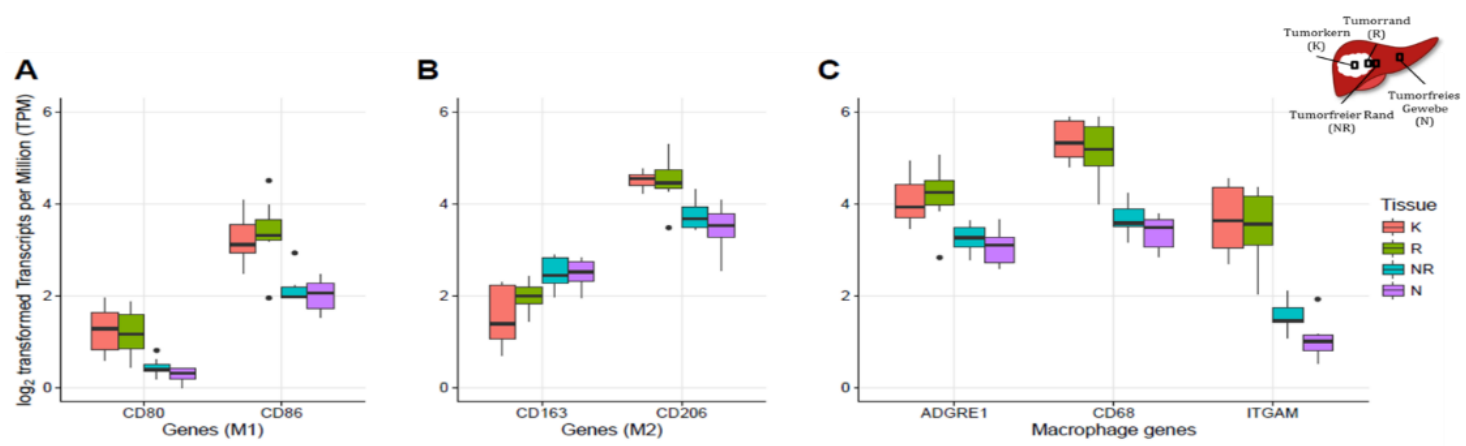

Abb. 3.18: Boxplot zur Genexpressionsanalysen von M1 und M2 Makrophagen in verschiedenen Leberarealen. Lokalisation und Expressionslevel von M1 (A)- und M2 (B)-spezifischen Genen sowie von allgemeinen Makrophagengenen (C). Die Expressionslevel wurden normalisiert als TPMs logarithmisch aufgetragen. Mit Ausnahme des CD163 Gens wurden alle Gene verstärkt im Tumorgewebe (K, R) exprimiert. 


\subsubsection{Histologische Untersuchungen zur Lokalisation von Makrophagenphänotypen im Verlauf der Metastasenformation}

Ergänzend zur RNA Sequenzierung wurde die Lokalisation der Makrophagenphänotypen in Metastasen-tragenden Lebern auch anhand einer histologischen Analyse untersucht. In Abb. 3.19 werden zunächst Färbungen der allgemeinen Makrophagenmarker CD11b (A1A6), F4/80 (B1 - B6) und CD68 (C1 - C6) gezeigt. Alle drei membranständigen Antigene konnten zu jedem Zeitpunkt insbesondere im Tumor, aber auch im umliegenden Lebergewebe detektiert werden. Es zeigten sich lediglich Unterschiede in der Färbung des umliegenden Lebergewebes. Während $C D 11 b^{+}$Zellen überwiegend im Tumor detektiert wurden, waren lediglich einzelne gefärbte Zellen im restlichen Gewebe zu erkennen. F4/80+ und $C D 68^{+}$Zellen hingegen waren zwar auch verstärkt im Tumor lokalisiert, wurden jedoch im Vergleich zur anti-CD11b Färbung in größerer Anzahl auch im umliegenden und tumorentfernten Gewebe visualisiert.

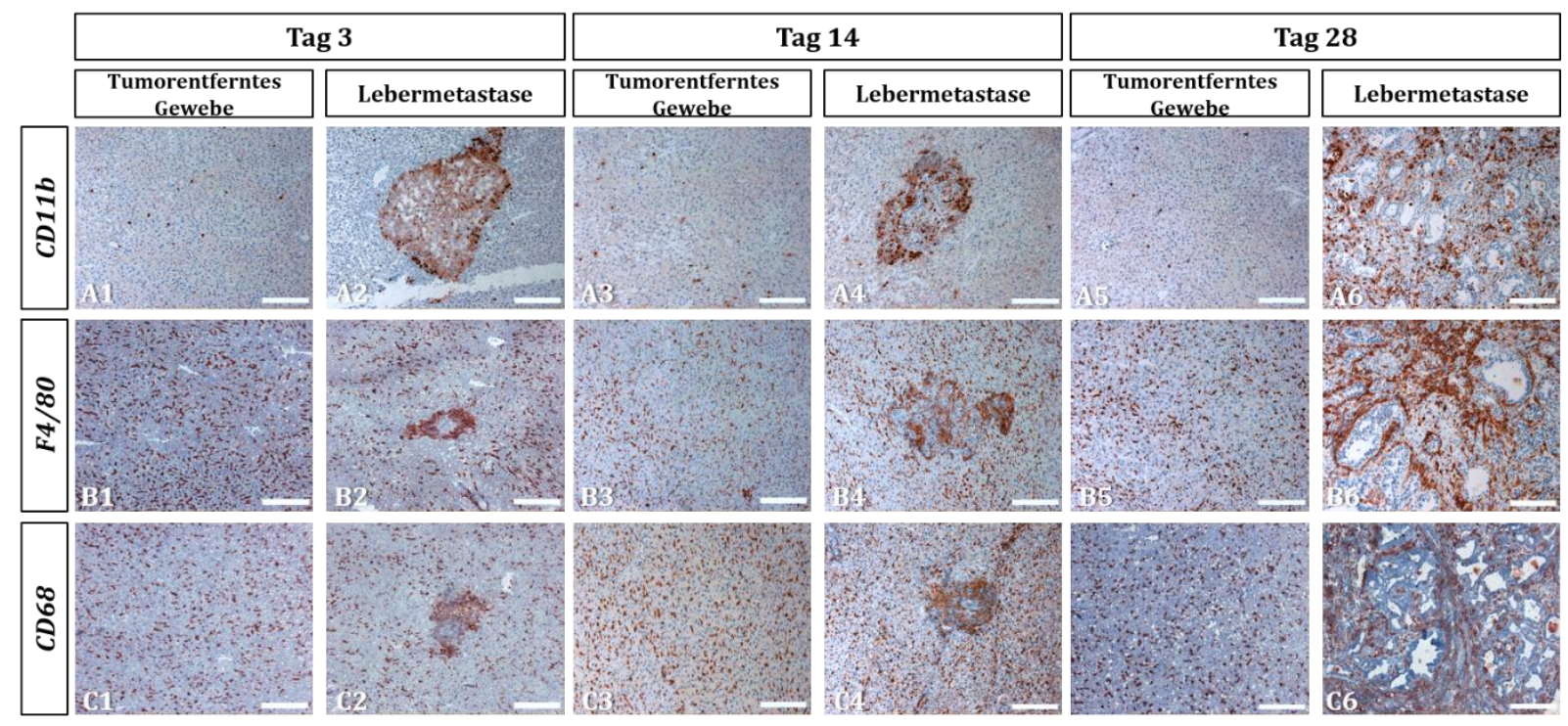

Abb. 3.19: Histologische Lokalisation von allgemeinen Makrophagenmarkern in verschiedenen Metastasierungsstadien. Lokalisation von $\mathrm{CD}_{11 b^{+}}(\mathbf{A}), F 4 / 80^{+}$(B) und $\mathrm{CD} 68^{+}$(C) Zellen an Tag 3, 14 und 28 nach CMT-93 Zellimplantation. Eine Übersichtsaufnahme der Metastase wurde zu jedem Zeitpunkt durch eine repräsentative Aufnahme des tumorentfernten Gewebes ergänzt (siehe Anhang S. 150 für vergrößerte Aufnahmen der Metastasen). Größenbalken entsprechen einer Länge von $200 \mu \mathrm{m}$.

Zur Identifizierung und Lokalisation der M1 Makrophagen wurde eine anti-CD86 Färbung durchgeführt (Abb. 3.20, A1 - A6). CD86+ Zellen waren fast ausschließlich im Tumor detektierbar; mit fortschreitender Metastasierung stieg ihre Anzahl im Tumorgewebe an (A6), während im restlichen Gewebe lediglich vereinzelt $C D 86^{+}$Zellen zu sehen waren (A5). 
Die Etablierung einer CD80 Färbung war trotz des Einsatzes verschiedener Antikörper nicht möglich. M2 Makrophagen wurden mit Hilfe einer anti-CD163 und einer anti-CD206 Färbung detektiert. Während an Tag 3 wenige $C D 163^{+}$Zellen im Tumor lokalisiert waren (B2), stieg ihre Anzahl mit fortschreitender Metastasierung deutlich an (B4, B6). An Tag 28 zeigten die Zellen eine intensive membranöse und zytoplasmatische Färbung im kompletten Tumorgewebe. Im Gegensatz zu $C D 86^{+}$Zellen, ließen sich $C D 163^{+}$Zellen auch verstärkt im tumorumliegenden und tumorentfernten Gewebe detektieren (s. B5). Im Tumor wurden zwar einzelne $C D 206^{+}$positive Zellen detektiert, der Großteil der CD206 Expression war jedoch in allen Metastasierungsstadien vor allem im tumorumliegenden und tumorentfernten Gewebe vorzufinden (C1 - C6).

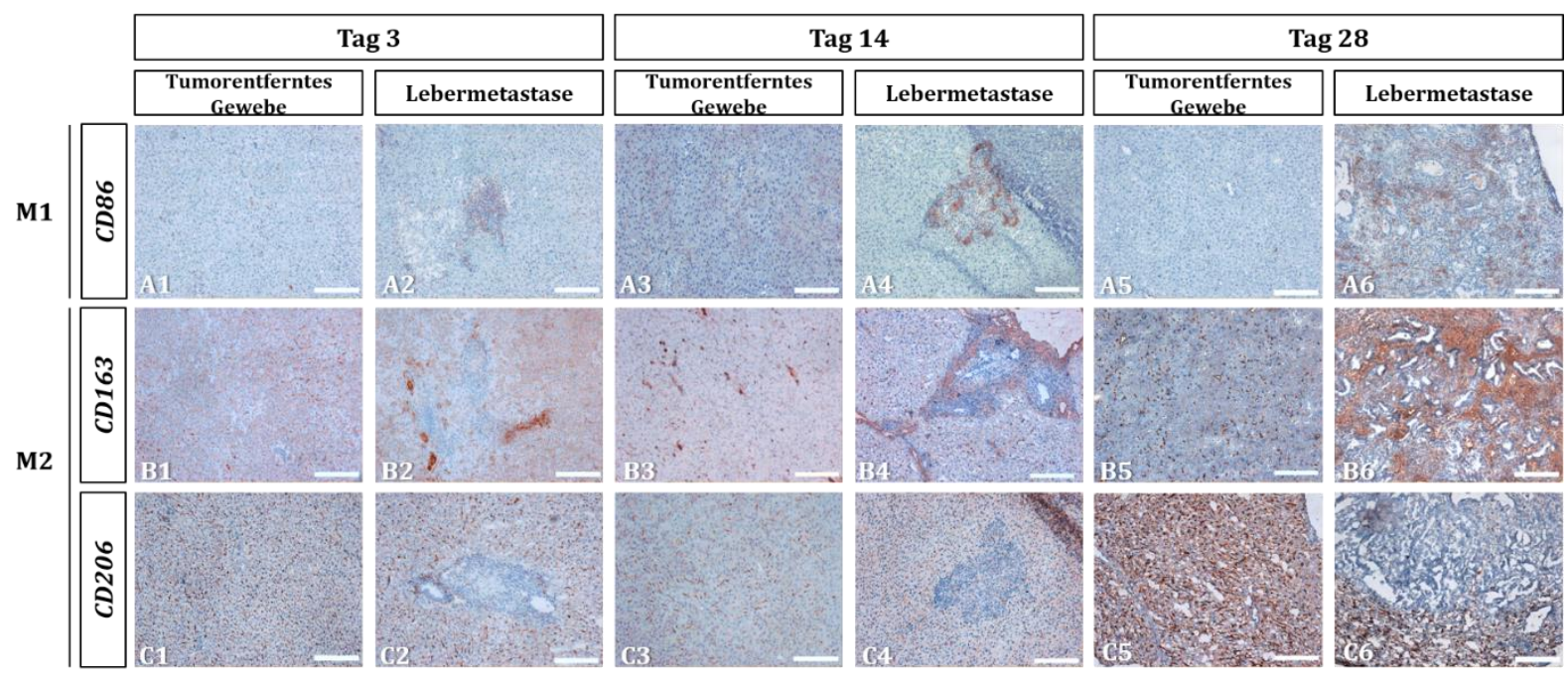

Abb. 3.20: Histologische Lokalisation von M1 und M2 Makrophagen im Verlauf der Metastasierung. Lokalisation von $\mathrm{CD} 86^{+}$(A), $\mathrm{CD} 163^{+}$(B) und $\mathrm{CD}^{206^{+}}$(C) Zellen an Tag 3, 14 und 28 nach CMT-93 Zellimplantation. Eine Übersichtsaufnahme der Metastase wurde zu jedem Zeitpunkt durch eine repräsentative Aufnahme des tumorentfernten Gewebes ergänzt (siehe Anhang S. 151 für vergrößerte Aufnahmen der Metastasen). Größenbalken entsprechen einer Länge von $200 \mu \mathrm{m}$.

\subsubsection{Quantifizierung der Expression von M1 und M2 Makrophagen im Verlauf der Metastasenformation}

Hierfür wurde mittels einer $q R T-P C R$ Analyse der Gesamtleber ein Expressionsprofil für allgemeine, M1 und M2 Makrophagen in Metastasen-tragenden Lebern erstellt (Abb. 3.21). Die eingesetzten Proben entsprachen denen aus Kapitel 3.3.2. Auch hier wurden zum Vergleich Sham-operierte Lebern und als Kontrolle eine unbehandelte Leber verwendet. 
A

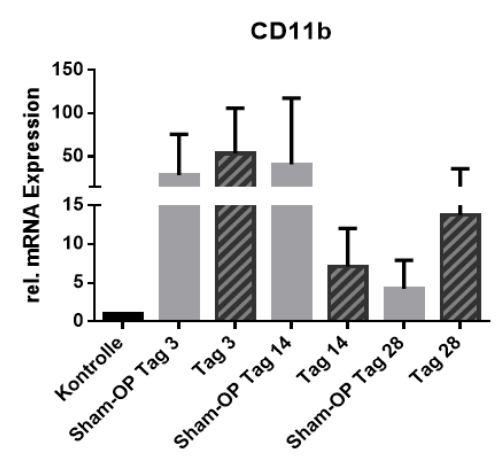

B

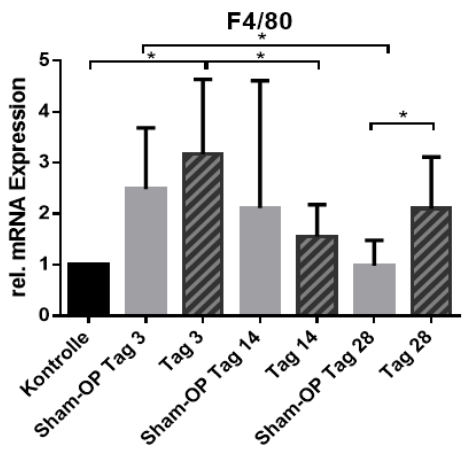

C

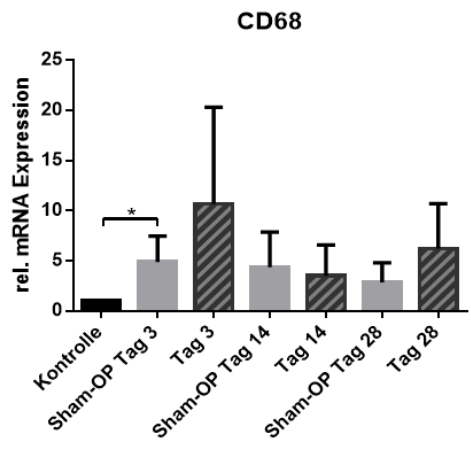

D

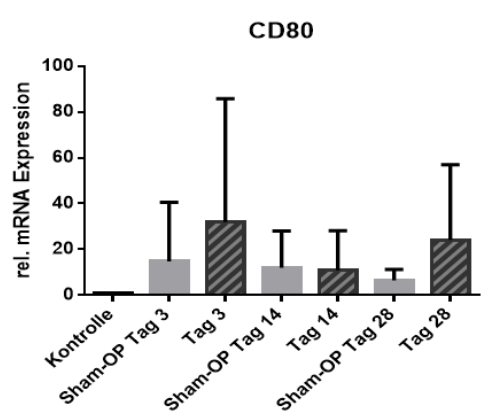

$\mathbf{F}$

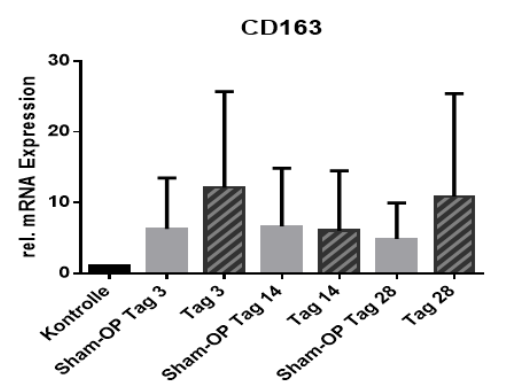

$\mathbf{E}$

CD86

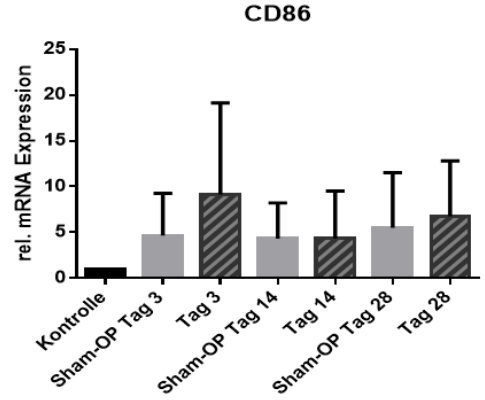

G

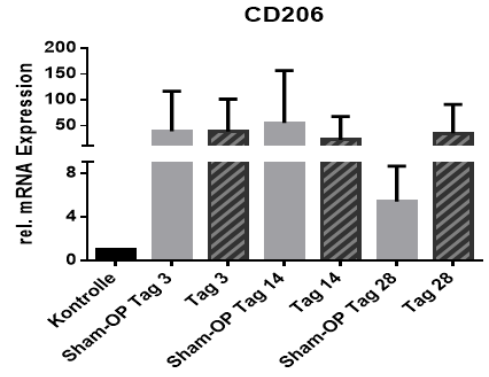

Abb. 3.21: Expression von Makrophagen-spezifischen Genen in verschiedenen Stadien der Metastasenformation. Die Expression von allgemeinen (A, B, C), M1- (D, E) und M2- (F, G) spezifischen Makrophagengenen wurde mittels einer $q R T-P C R$ Analyse in Metastasen-tragenden und Sham-operierten Lebern quantifiziert. Auf der y-Achse ist die relative mRNA Expression dargestellt, die im Verhältnis zu einer gesunden, unbehandelten C57BL/6NCrl Mausleber (Kontrolle) berechnet wurde. Pro Bedingung wurden 4 - 6 biologische Replikate verwendet; die entsprechenden technischen Replikate wurden als Triplet gemessen. Signifikante Unterschiede wurden mit Sternchen markiert $\left(^{*}=\rho \leq 0,05\right)$.

Die allgemeinen Makrophagengene $C D 11 b, F 4 / 80$ und $C D 68$ zeigten an Tag 3 eine starke Expression, die insbesondere in Metastasen-tragenden Lebern bis Tag 14 deutlich sank und an Tag 28 in unterschiedlichem Ausmaß erneut anstieg (Abb. 3.21 A - C). CD11b (A) wurde über die gesamte Zeit offensichtlich am stärksten exprimiert (bis zu ca. 50fach an Tag 3). Während an Tag 3 die Expression des Gens in Sham-operierten und Metastasen-tragenden 
Lebern nur leicht voneinander abwich, gab es an Tag 14 und Tag 28 deutlichere Unterschiede. An Tag 14 wurde in Sham-operierten Lebern eine höhere CD11b Expression gemessen; an Tag 28 kehrte sich dieses Profil um. Bei der CD68 Quantifizierung zeigten sich im Vergleich zur $C D 11 b$ Messung meist geringe Unterschiede zwischen den beiden Mausgruppen (C). F4/80 hingegen wurde an Tag 28 signifikant stärker exprimiert in Metastasen-tragenden Lebern; Tumorzellen induzieren hier offensichtlich eine vermehrte Expression des Gens (B).

Das CD80 Gen wurde an Tag 3 stärker exprimiert in Metastasen-tragenden Lebern als in Sham-operierten (D). Nichtsdestotrotz sank die Expression an Tag 14 ab, so dass zwischen beiden Mausgruppen ein fast identisches Expressionsniveau vorlag. Während in Shamoperierten Lebern die CD80 Expression bis Tag 28 erneut minimal absank, war im Falle der Metastasen-tragenden Lebern ein deutlicher Anstieg messbar. Die CD86 Messung ergab ein ähnliches Profil mit dem Unterschied, dass die Expression an Tag 28 in beiden Mausgruppen relativ ähnlich war (E). Insgesamt wurde jedoch das CD80 Gen über die Zeit am stärksten exprimiert (bis zu ca. 40fach an Tag 3).

In Sham-operierten Lebern zeigte sich im zeitlichen Verlauf ein recht einheitliches Expressionsniveau des CD163 Gens (F). In Metastasen-tragenden Lebern hingegen sank die Expression von Tag 3 bis Tag 14 bis auf das Niveau der Sham-operierten Lebern und stieg dann bis Tag 28 erneut an. Im Falle der CD206 Expression wurde das Gen in Metastasentragenden Lebern zu allen drei Zeitpunkten auf einem fast identischen Niveau sehr stark exprimiert (fast das 50fache). In Sham-operierten Mäusen war zwar an Tag 3 und Tag 14 eine ähnlich starke Expression messbar; diese wurde jedoch bis Tag 28 deutlich reduziert.

Insgesamt wurden die Gene $C D 11 b, C D 80$ und CD206 im Zuge der Metastasenformation am stärksten exprimiert. Des Weiteren wurde ersichtlich, dass Makrophagengene zu Beginn (Tag 3) sowie zu einem späten Zeitpunkt der Metastasierung (Tag 28) stärker exprimiert wurden als in Sham-operierten Lebern. Im Kontext der tumorinhibierenden und tumorfördernden Eigenschaften der Makrophagen fällt auf, dass die Expression des M1-spezifischen Gens CD80 und die des M2-spezifischen Gens CD206 im frühen Metastasierungsstadium (Tag 3) sehr stark hochreguliert ist ( 40fach bzw. 50fach). Während CD206 bis zum späten Metastasierungsstadium (Tag 28) dieses hohe Expressionsniveau in Metastasen-tragenden Lebern beibehält, wurde die $C D 80$ Expression fast um die Hälfte reduziert.

$\mathrm{Zu}$ erwähnen ist allerdings auch, dass anhand der Standardabweichungen auch die individuellen Unterschiede zwischen den einzelnen Mäusen ersichtlich werden, die wohlmöglich auf das Ausmaß des Kolonisierungserfolgs der CMT-93 Zellen zurückzuführen sind. 


\subsection{In vitro Analysen zur Charakterisierung der Interaktion von Makrophagenphänotypen und CMT-93 Tumorzellen}

Da M1 und M2 Makrophagen tumorinhibierende bzw. tumorfördernde Eigenschaften zugeschrieben werden, wurden CMT-93 Zellen mit konditioniertem Medium (KM) der Makrophagenphänotypen kultiviert und ihr indirekter Einfluss auf zellbiologisch/biochemischer und molekularbiologischer Ebene analysiert.

\subsubsection{Differenzierung und Polarisation von knochenmark-stämmigen Monozyten isoliert aus dem murinen Femur Richtung M1 und M2 Makrophagen}

Pro Isolation wurden knochenmark-stämmige Monozyten aus dem linken und rechten Femur von je drei C57BL/6NCrl Mäusen vereinigt. Im Schnitt konnten pro Tier ca. 19 x $10^{6}$ Zellen isoliert werden. Abbildung 3.22 zeigt repräsentative Aufnahmen der Zellen an Tag 1 und Tag 7 nach der Isolation. Innerhalb des angegebenen Zeitraums differenzierten sich kleine, vereinzelt liegende, kugelförmige Zellen mit einem Durchmesser von etwa $10 \mu \mathrm{m}$ (A) zu ca. 20 - $30 \mu \mathrm{m}$ großen, dicht aneinander gesiedelten Zellen mit langen, dünnen Zellausläufern (B, C).

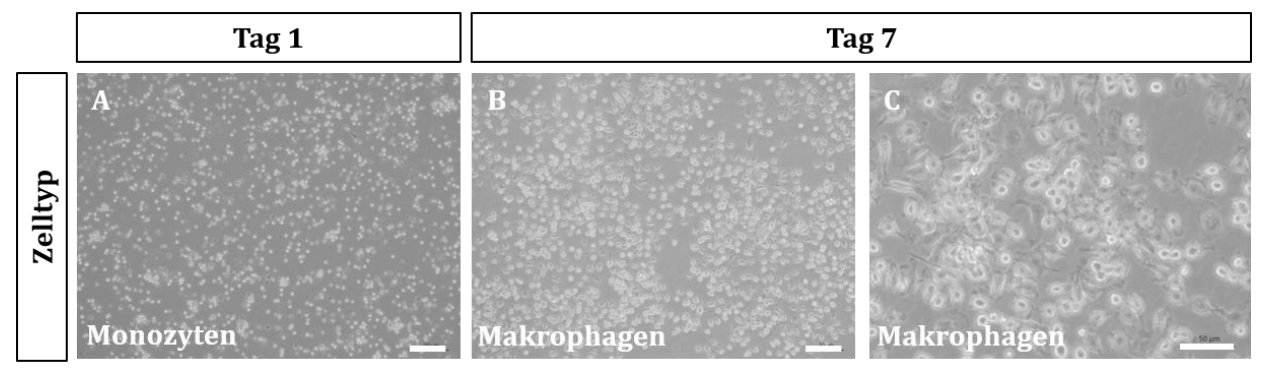

Abb. 3.22: Makroskopische Kontrolle des Differenzierungsstadiums von nicht-polarisierten Makrophagen. 7-tägige Inkubation von knochenmark-stämmigen Monozyten aus C57BL/6NCrl Mäusen mit $50 \mathrm{ng} / \mathrm{ml}$ M-CSF. Kleine, vereinzelt liegende Monozyten (A) differenzierten sich zu deutlich größeren Makrophagen mit Zellausläufern (B, C). Die Größenbalken entsprechen einer Länge von $50 \mu \mathrm{m}$.

An Tag 7 nach der Monozytenisolation wurde der Differenzierungsstatus der Makrophagen durchflusszytometrisch kontrolliert (Abb. 3.23). Gate Q4 in (A) kann der Anteil CD11 $b^{+}$Zellen entnommen werden (68,3 \%), F4/80+ Zellen kommen in Gate Q1 (B) zur Darstellung (85,7 \%). Das Resultat der Doppelfärbung ist Gate Q2 in (C) zu entnehmen $(64,4 \%)$. Demnach bestand die Zellpopulation zum Großteil aus reifen Makrophagen, die nun für eine Polarisation Richtung M1 und M2 Phänotyp eingesetzt werden konnten. 


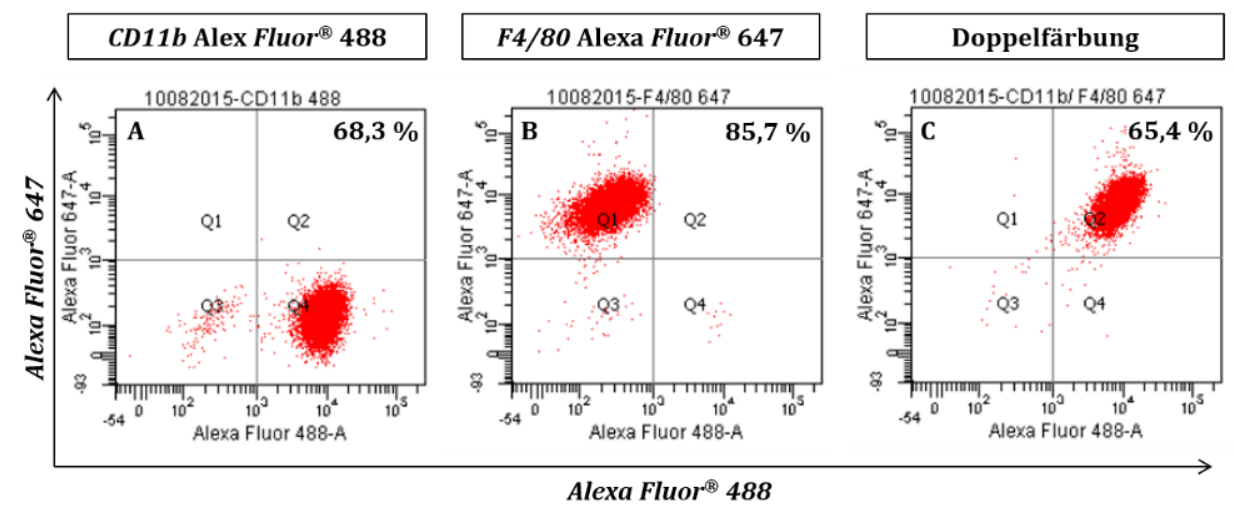

Abb. 3.23: Durchflusszytometrische Kontrolle des Differenzierungsstatus von nicht-polarisierten Makrophagen. Sieben Tage nach Monozytenisolation wurde in drei biologischen Replikaten eine Oberflächenfärbung mit anti-CD11b Alexa Fluor ${ }^{\circledR} 488$ (A), anti-F4/80 Alexa Fluor ${ }^{\circledR} 647$ (B) sowie eine entsprechende Doppelfärbung (C) durchgeführt. Auf der x-Achse ist der grüne Fluoreszenzkanal dargestellt, während die y-Achse den roten Fluoreszenzkanal widerspiegelt. 65,4 \% der Zellpopulation wurden als differenzierte Makrophagen identifiziert.

Nach 48-stündiger Zytokininkubation folgte eine durchflusszytometrische Kontrolle der Makrophagenpolarisation, indem die Oberflächenexpression spezifischer Marker untersucht wurde (s. Kapitel 2.2.4.3). Im Rahmen dieser Arbeit wurden konditionierte Medien aus zwei unabhängigen Zellisolationen hergestellt (Isolation I und II). Im Folgenden werden nun die durchflusszytometrischen Resultate beider Isolationen separat präsentiert, da die Qualität und somit der Einfluss des konditionierten Mediums auf CMT-93 Zellen unterschiedlich ausfiel.

\section{Monozytenisolation I:}

In Abb. 3.24 (links) ist eine Übersicht der durchflusszytometrischen Analyse der polarisierten Makrophagen aus Isolation I zu sehen. Anhand der einzelnen Streudiagramme konnte folgendes Expressionsprofil der Makrophagenphänotypen erstellt werden:

M0 Makrophagen: $\quad C D 11 b^{+}, F 4 / 80^{+}, C D 163^{+}, C D 206^{+}$

M1 Makrophagen: $\quad C D 11 b^{+}, F 4 / 80^{+}, C D 68^{+}, \underline{C D 86^{+}} C D 163^{+}$

M2 Makrophagen: $\quad C D 11 b^{+}, F 4 / 80^{+}, \underline{C D 163^{+}}, \underline{C D 206^{+}}$

Obwohl die einzelnen Populationen M1- bzw. M2- spezifische Marker exprimierten (unterstrichene Marker), ließen sie sich nicht eindeutig voneinander separieren. Die M2spezifischen Marker CD163 und CD206 wurden beispielsweise sowohl von M0 als auch von 
M2 Makrophagen exprimiert. In der M1 Population war ebenfalls ein großer Anteil an $C D 163^{+}$ (F2) Zellen vorhanden.

Ein t-Test zeigte bei fast allen Markern signifikante Unterschiede, mit Ausnahme der CD163 Expression (Tab. 3.8). Verglich man die M1 und M2 Populationen miteinander, so wurde der größte signifikante Unterschied bei der CD86 und CD206 Expression erfasst (dunkelgrau hinterlegt): während CD86 deutlich stärker in der M1 Population exprimiert wurde, konnte CD206 vor allem in der M2 Population detektiert werden. Der entsprechende Vergleich mit den nicht-polarisierten Zellen (M0) fiel ebenfalls signifikant zugunsten der M1 bzw. M2 Makrophagen aus (hellgrau hinterlegt). Obwohl die Zellen anhand der Expression dieser sieben Marker nicht eindeutig voneinander separiert werden konnten, impliziert dieses Resultat dennoch, dass die Polarisation Richtung M1 und M2 tendenziell funktioniert hat.

Tab. 3.8: Monozytenisolation I - Vergleich der Expressionsprofile der polarisierten (M1 und M2) und nicht-polarisierten Makrophagen (M0). Während die M1 Population den M1-sepzifischen Marker CD86 exprimierte, war der M2-spezifische Marker CD206 verstärkt in der M2 Population vorzufinden. Signifikante Unterschiede wurden mit Sternchen markiert $\left(^{*}=\rho \leq 0,05 ; * *=\rho \leq 0,01 ;{ }^{* * *}=\rho \leq 0,001\right)$.

\begin{tabular}{|c|c|c|c|c|c|c|}
\hline \multirow{2}{*}{$\begin{array}{l}\text { Marker } \\
C D 11 b\end{array}$} & \multicolumn{2}{|c|}{ M0 vs. M1 } & \multicolumn{2}{|c|}{ M0 vs. M2 } & \multicolumn{2}{|c|}{ M1 vs. M2 } \\
\hline & 0,0225 & $*$ & 0,0472 & $*$ & 0,0139 & * \\
\hline$F 4 / 80$ & 0,0050 & $* *$ & 0,0056 & $* *$ & 0,0363 & $*$ \\
\hline CD68 & 0,2949 & & 0,0432 & $*$ & 0,5388 & \\
\hline CD80 & 0,0176 & $*$ & 0,7706 & & 0,0171 & $*$ \\
\hline CD86 & 0,0003 & $* * *$ & 0,3793 & & 0,0069 & $* *$ \\
\hline CD163 & 0,4559 & & 0,0601 & & 0,0659 & \\
\hline$C D 206$ & 0,0026 & $* *$ & 0,0019 & $* *$ & 0,0016 & $* *$ \\
\hline
\end{tabular}

\section{Monozytenisolation II:}

Eine Übersicht der durchflusszytometrischen Analyse der polarisierten Makrophagen aus Isolation II ist Abb. 3.24 (rechts) zu entnehmen. Im Vergleich zu Isolation I waren hier weniger $C D 163^{+}(32,5 \%)$ und weniger $C D 206^{+}(65 \%)$ Zellen in der M2 Population vorhanden.

Auch hier exprimierte die M1 Population mehr CD86; vice versa lag in der M2 Population eine erhöhte CD206 Expression vor (Tab. 3.9). Da in dieser M2 Population weniger $C D 163^{+}$Zellen vorhanden waren als in Isolation I (32,5\%), wurde dementsprechend eine signifikant reduzierte $C D 163$ Expression gemessen.

Obwohl auch bei dieser Isolation die Populationen anhand der Makrophagenmarker nicht eindeutig voneinander separiert werden konnten, gelang hier ebenfalls eine tendenzielle Polarisation Richtung M1 und M2. 
Tab. 3.9: Monozytenisolation II - Vergleich der Expressionsprofile der polarisierten (M1 und M2) und nicht-polarisierten Makrophagen (M0). Die M2 Population exprimierte signifikant mehr CD206 und signifikant weniger CD163 im Vergleich zur M1 Population. Signifikante Unterschiede wurden mit Sternchen markiert $\left(*=\rho \leq 0,05 ;{ }^{* *}=\rho \leq 0,01 ; * * *=\rho \leq 0,001\right)$.

\begin{tabular}{|c|c|c|c|c|c|c|}
\hline \multirow{2}{*}{$\begin{array}{l}\text { Marker } \\
C D 11 b\end{array}$} & \multicolumn{2}{|c|}{ M0 vs. M1 } & \multicolumn{2}{|c|}{ M0 vs. M2 } & \multicolumn{2}{|c|}{ M1 vs. M2 } \\
\hline & 0,0132 & * & 0,0042 & ** & 0,0074 & $* *$ \\
\hline$F 4 / 80$ & 0,1518 & & 0,8897 & & 0,0342 & $*$ \\
\hline CD68 & 0,0955 & & 0,1994 & & 0,0878 & \\
\hline$C D 80$ & 0,3943 & & 0,4650 & & 0,2789 & \\
\hline$C D 86$ & 0,0012 & $* * *$ & 0,0065 & $* *$ & 0,0011 & $* * *$ \\
\hline$C D 163$ & 0,1302 & & 0,0192 & $*$ & 0,0119 & * \\
\hline CD206 & 0,0003 & $* * *$ & 0,0229 & $*$ & 0,0006 & $* * *$ \\
\hline
\end{tabular}

\section{Vergleich beider Isolationen:}

In Isolation II war die Expression der Makrophagenmarker CD11b und F4/80 in der nichtpolarisierten Population (M0) niedriger $(\rho \leq 0,05)$; folglich waren in dieser Population weniger differenzierte Makrophagen vorhanden als in Isolation I (Tab. 3.10). Beim Vergleich der M1 Populationen fällt auf, dass es kaum Unterschiede bezüglich der Expression der M1spezifischen Marker CD80 und CD86 gab, während beim M2-spezifischen Marker CD163 eine reduzierte Expression in Isolation II gemessen wurde $(\rho \leq 0,05)$. Im Falle der M2 Population wurden sowohl die Makrophagenmarker $C D 11 b(\rho \leq 0,05)$ und $F 4 / 80(\rho \leq 0,01)$ als auch der M2-spezifische Marker CD206 in Isolation II geringer exprimiert $(\rho \leq 0,01)$.

Folglich ergibt sich aus diesen Daten, dass insgesamt die Differenzierung von Monozyten zu Makrophagen und die anschließende Polarisation Richtung M2 in Isolation I tendenziell besser funktioniert hat als in Isolation II.

Tab. 3.10: Vergleich des Expressionsprofils der Makrophagen aus Isolation I und II. In der M2 Population aus Isolation I wurden die Makrophagengene CD11b und F4/80 sowie das M2-spezifische Gen CD206 signifikant stärker exprimiert. Signifikante Unterschiede wurden mit Sternchen markiert $\left(^{*}=\rho \leq\right.$ $0,05 ; * *=\rho \leq 0,01)$.

\begin{tabular}{llll}
\hline Marker & M0-I vs. M0-II & M1-I vs. M1-II & M2-I vs. M2-II \\
\hline$C D 11 b$ & $0,0050 *$ & 0,1542 & $0,0236 *$ \\
$F 4 / 80$ & $0,0306 *$ & 0,0721 & $0,0070 * *$ \\
$C D 68$ & 0,4343 & 0,2542 & 0,1090 \\
$C D 80$ & 0,3419 & 0,3233 & 0,0572 \\
$C D 86$ & $0,0307 *$ & 0,6341 & 0,5336 \\
$C D 163$ & $0,0363 *$ & $0,0519 *$ & 0,0656 \\
$C D 206$ & $0,0116 *$ & 0,0991 & $0,0131 * *$ \\
\hline
\end{tabular}




\section{Isolation I}
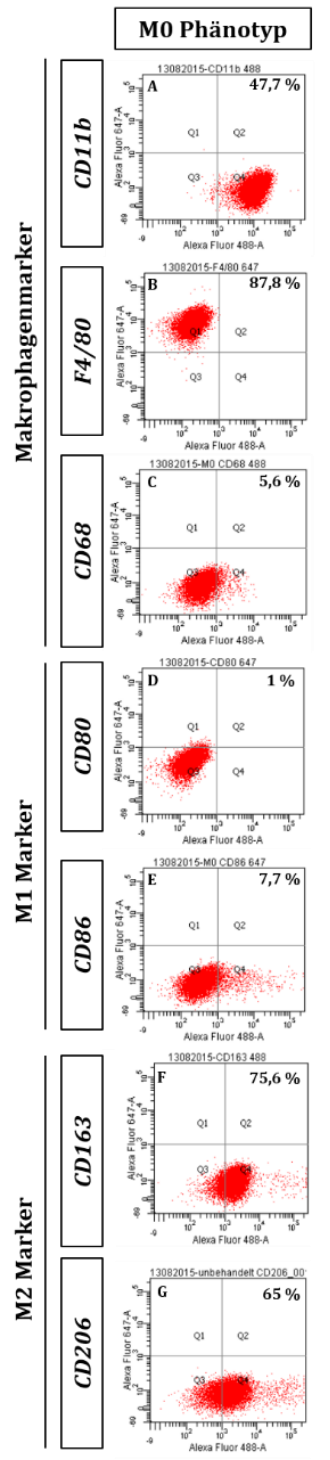
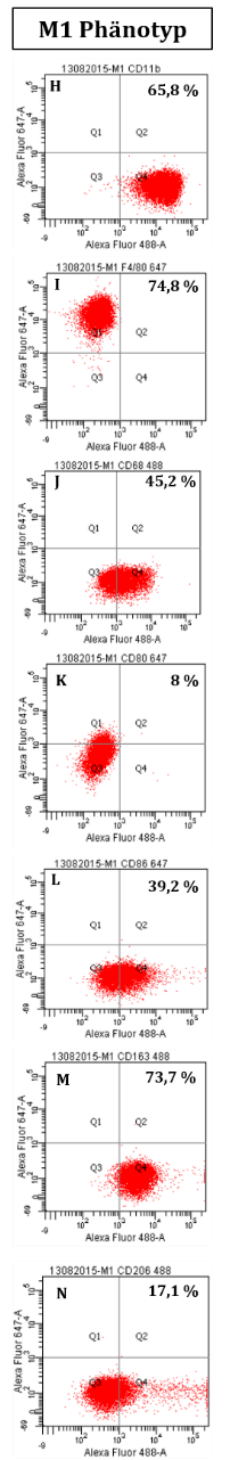
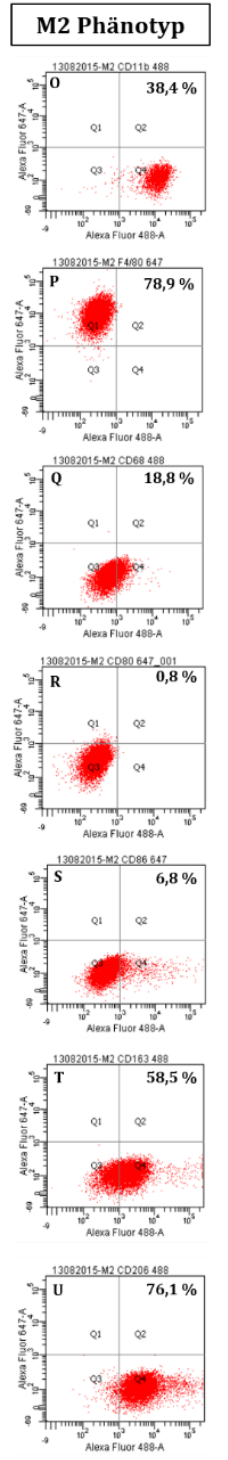

Isolation II
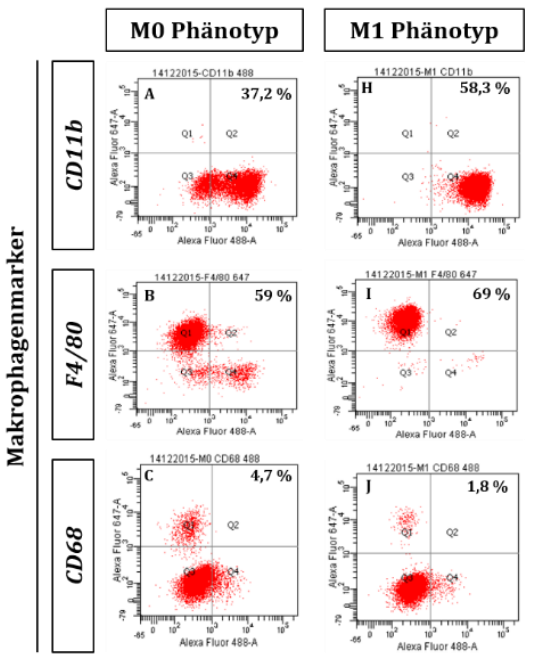

M2 Phänotyp
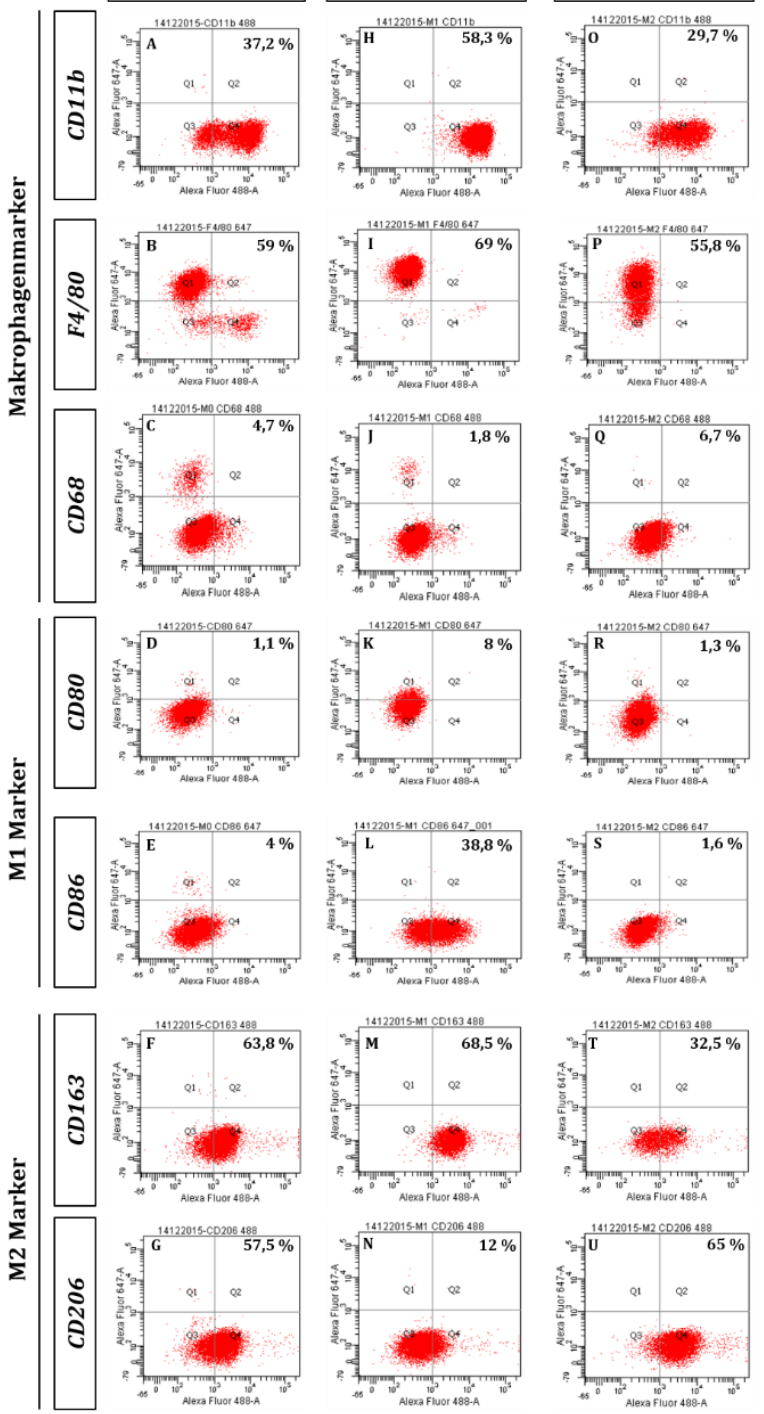

Abb. 3.24: Durchflusszytometrieanalyse zur Kontrolle der M1 und M2 Polarisation. An Tag zehn nach der Monozytenisolation (I \& II) wurde der Phänotyp der Makrophagen überprüft. Dargestellt ist das Expressionsmuster von M0 (linke Spalte), M1 (mittlere Spalte) und M2 (rechte Spalte) Makrophagen. Die Kontrolle erfolgte über die Expression der allgemeinen Makrophagenmarkern CD11b (A), F4/80 (B) und CD68 (C). Als M1 Marker wurden CD80 (D) und CD86 (E) verwendet. Der M2 Status wurden mit Hilfe von CD206 (G) und CD163 (F) kontrolliert. Auf der x-Achse ist der grüne Fluoreszenzkanal dargestellt, während der rote Fluoreszenzkanal auf der y-Achse abgebildet ist. Der Anteil der positiv-gefärbten Zellen ist der oberen rechten Ecke jeder Abbildung zu entnehmen. Es wurden jeweils zwei biologische Replikate gemessen und die Resultate eines Replikates repräsentativ dargestellt. 


\subsubsection{Einfluss des konditionierten Mediums von Makrophagenphänotypen auf die Zellviabilität von CMT-93 Tumorzellen}

Im Anschluss an die durchflusszytometrische Überprüfung der Makrophagenstimulation folgte eine Inkubation von CMT-93 Zellen mit den konditionierten Medien der Makrophagenphänotypen.

\subsubsection{Inkubation von CMT-93 Zellen mit konditionierten Medien aus Isolation I}

Der Einfluss der konditionierten Medien der Makrophagenphänotypen auf die Zellviabilität der CMT-93 Zellen wurde zunächst auf biochemischer Ebene anhand eines MTS Assays untersucht und der relative Anteil lebender Zellen ermittelt. Hierfür wurden in zwei unabhängigen Versuchen die konditionierten Medien aus Isolation I verwendet. Da zwischen den Proben mit 30 \% und 50 \% KM kaum Unterschiede messbar waren, wurden zugunsten der Übersicht nur Letztere in Abb. 3.25 dargestellt. Der Effekt des konditionierten Mediums wurde verglichen mit dem von reinem Kulturmedium mit $1 \%$ FBS und $10 \%$ FBS.

Abb. 3.25: Überprüfung der Zellviabilität von CMT-93 Zellen nach Inkubation mit konditioniertem Medium aus Isolation I. CMT-93 Zellen wurden 24, 48 und 72 Stunden mit dem konditionierten Medium der Makrophagen inkubiert. Nach 48 Stunden Inkubation mit M2 konditioniertem Medium waren signifikant mehr lebende Tumorzellen vorhanden. Es wurden $n \geq 6$

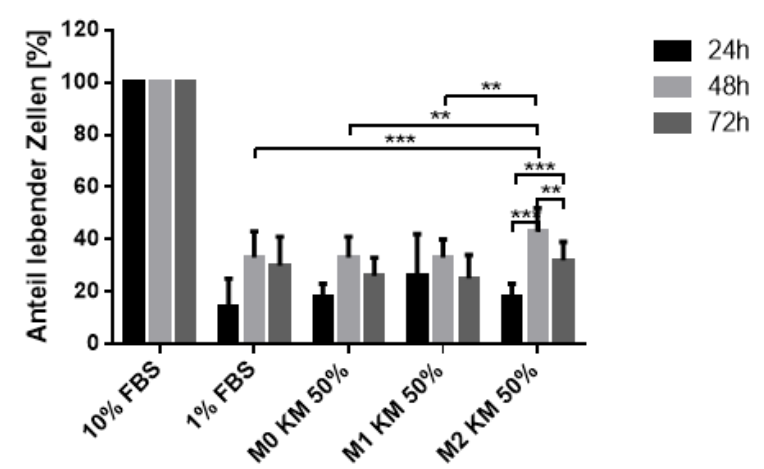
technische Replikate gemessen. Signifikante Unterschiede wurden mit Sternchen markiert $\left(^{* *}=\rho \leq 0,01 ; * * *=\rho \leq 0,001\right) . K M=$ konditioniertes Medium.

Der MTS Assay verdeutlichte, dass sich die Reduktion des Serums von $10 \%$ auf $1 \%$ deutlich auf die Zellviabilität der CMT-93 Zellen auswirkt. Durch Zugabe des M0 und M1 konditionierten Mediums waren kaum Unterschiede im Vergleich zur Inkubation mit 1 \% FBS messbar. Das M2 konditionierte Medium hingegen hatte offensichtlich im Vergleich zu den anderen Medien innerhalb der ersten 48 Stunden einen positiven Einfluss auf die Zellviabilität. Im Vergleich zum M0 und M1 konditionierten Medium waren signifikant mehr lebende Zellen vorhanden. Nach 48 Stunden schien dieser positive Einfluss jedoch rückläufig; 
der Anteil lebender Zellen sankt signifikant ab, lag aber immer noch leicht über dem Anteil der restlichen Medien.

\subsubsection{Inkubation von CMT-93 Zellen mit konditionierten Medien aus Isolation II}

In einem dritten unabhängigen Versuch wurden die konditionierten Medien aus Isolation II eingesetzt und ihr Einfluss auf CMT-93 Zellen auf biochemischer und molekularbiologischer Ebene untersucht.

Bei diesem Experiment hatte das M2 konditionierte Medium innerhalb der ersten 24 Stunden im Vergleich zum M1 konditionierten Medium zwar einen signifikant positiven Einfluss auf die Tumorzellen (Abb. 3.26). Allerdings war hier der Anteil lebender Zellen vergleichbar mit dem in M0 konditionierten Medium. Nach 48 und 72 Stunden war eine signifikante Reduktion der Anzahl lebender Zellen in M2 konditioniertem Medium messbar. Das M1 konditionierte Medium wirkte sich offensichtlich innerhalb der ersten 48 Stunden etwas besser auf die Zellviabilität aus, signifikante Unterschiede konnten hier jedoch nicht ermittelt werden.

Abb. 3.26: Überprüfung der Zellviabilität von CMT-93 Zellen nach Inkubation mit konditioniertem Medium aus Isolation II. CMT93 Zellen wurden 24, 48 und 72 Stunden mit dem konditionierten Medium der Makrophagen inkubiert. Nach 24 Stunden Inkubation mit M2 konditioniertem Medium waren signifikant mehr lebende Tumorzellen vorhanden. Es wurden $n \geq 6$ technische Replikate gemessen. Signifikante

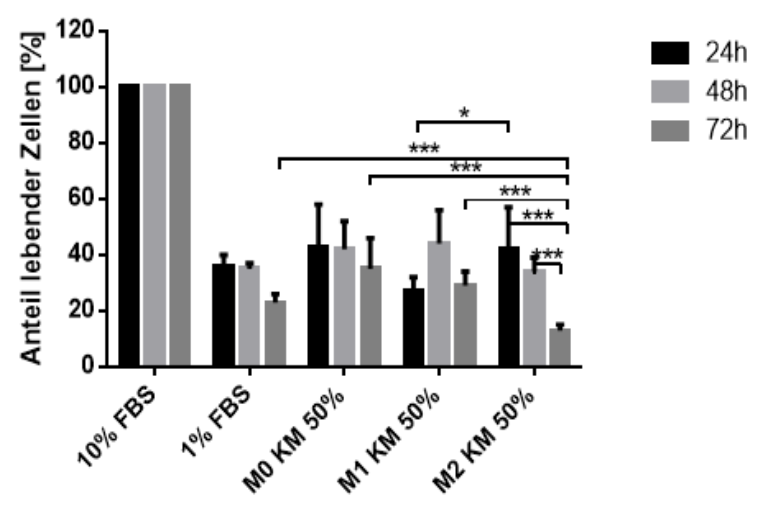
Unterschiede wurden mit Sternchen markiert $\left(^{*}=\rho \leq 0,05 ;^{* * *}=\rho \leq 0,001\right) . K M=$ konditioniertes Medium.

Der Vergleich der Medien aus beiden Isolationen impliziert, dass das konditionierte Medium der als tumorfördernd beschriebenen M2 Makrophagen auf zellbiologisch/biochemischer Ebene einen positiven Einfluss auf die Viabilität von CMT-93 Zellen haben kann. Wie stark oder signifikant und wie schnell dieser Effekt eintritt (24 oder 48 Stunden), hängt demnach wohlmöglich von der Qualität des konditionierten Mediums und somit vom Erfolg der Makrophagenpolarisation ab. Aufgrund des identischen Isolations- und Inkubationsprotokolls wurden technische Ursachen ausgeschlossen. 


\subsubsection{Einfluss der konditionierten Medien von Makrophagenphänotypen auf die Expression von Metastasen-assoziierten Genen in CMT-93 Zellen}

Der indirekte Einfluss der Makrophagenphänotypen auf die Expression von zehn Metastasenassoziierten Genen in CMT-93 Zellen wurde nach einer 48- und 72-stündigen Inkubation mit $50 \%$ konditionierten Medien der Makrophagen mittels einer qRT-PCR Analyse untersucht (Abb. 3.27).

Die Krt20 Expression war in Zellen, die lediglich 1 \% FBS erhalten haben nach 72 Stunden Inkubation signifikant erhöht im Vergleich zu den restlichen Proben (A). Die Messung des Ecadherin Gens ergab insbesondere nach 48 Stunden Inkubation eine erhöhte Expression in den Zellen, die das M2 konditionierte Medium bekommen haben (B). Nach 72 Stunden war in fast allen Proben eine z.T. signifikant erhöhte Expression messbar (mit Ausnahme der 10 \% FBS und M2 KM Proben). Die Vimentin Expression wurde in den ersten 48 Stunden offensichtlich vom M1 konditionierten Medium positiv beeinflusst, während nach 72 Stunden eine erhöhte Expression in Zellen mit 1 \% FBS gemessen wurde (C). Das 1 \% FBS Medium wirkte sich nach 72 Stunden und das M2 konditionierte Medium über die gesamte Zeit positiv auf die $C D 44$ Genexpression aus (D). Die MMP-7 Expression wurde in allen Proben nach 72stündiger Inkubation z.T. signifikant erhöht, vor allem jedoch in $1 \%$ FBS Proben (E). Beim Vergleich der Zellen mit M1 und M2 konditioniertem Medium lag MMP-7 in Letzteren ebenfalls leicht erhöht vor. Bezüglich der NFkB1 und Stat3 Expression war vom 10 \% FBS Medium bis zum M2 konditionierten Medium in absteigender Reihenfolge eine Reduktion der Genexpression messbar (F, G). Die signifikanteste Reduktion wurde für beide Gene in Zellen gemessen, die das M2 konditionierte Medium erhalten haben. Der Zellproliferationsmarker Cyclin D1 war in den ersten 48 Stunden in den 1 \% FBS Proben am meisten erhöht und in den Proben mit dem M2 konditionierten Medium am wenigsten exprimiert (H). Nach 72 Stunden erhöhte sich die Expression erneut signifikant in den 1 \% Proben. In den restlichen Zellen war die Genexpression eher rückläufig. Die Ki-67 Expression zeigte in den ersten 48 Stunden ein recht ähnliches Expressionsniveau in allen Proben. Nach 72 Stunden war in den Zellen, die das M2 konditionierte Medium erhalten haben, eine erhöhte Expression messbar, genauso wie in den 1 \% FBS Proben. Der Apoptosemarker Caspase-3 war in den ersten 48 Stunden in allen Proben verstärkt exprimiert, vor allem jedoch in den Zellen, die mit dem M2 konditionierten Medium inkubiert wurden (J). Nach 72 Stunden konnte in allen Proben eine (z.T. signifikante) Reduktion der Genexpression gemessen werden. 
A

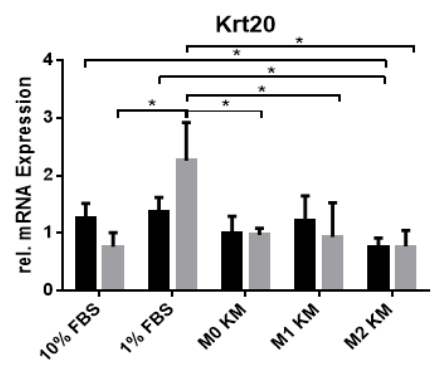

D

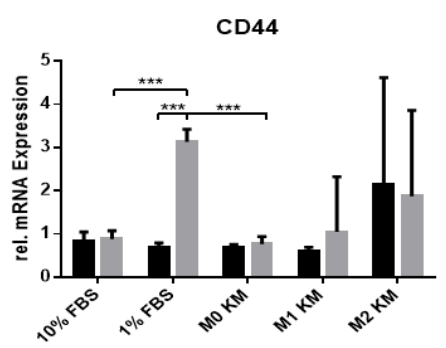

F

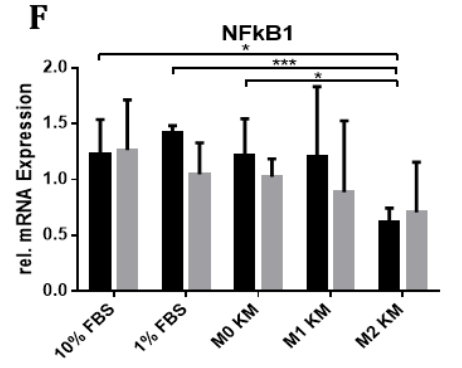

H

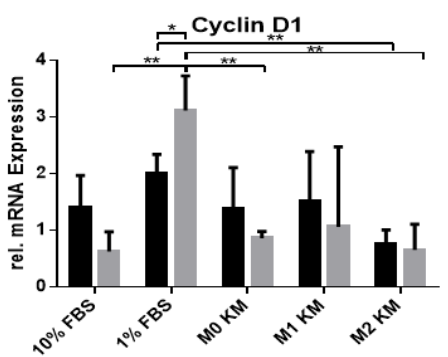

B

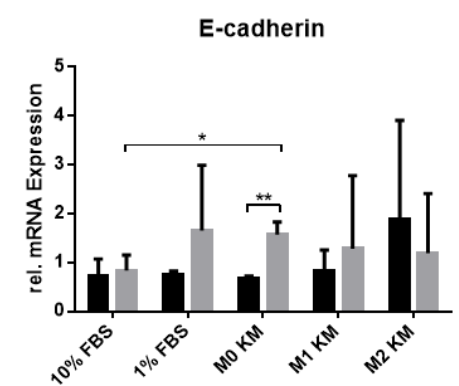

C

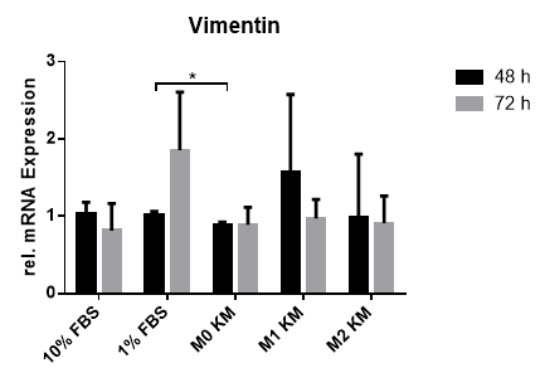

E

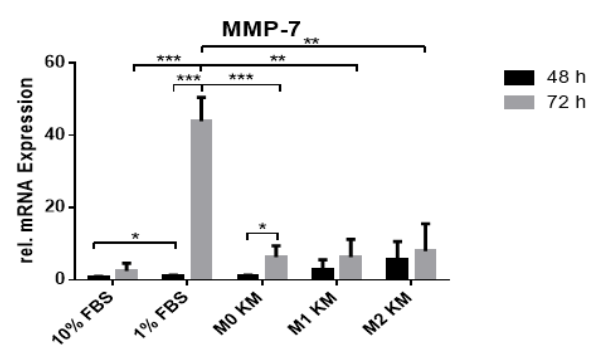

G

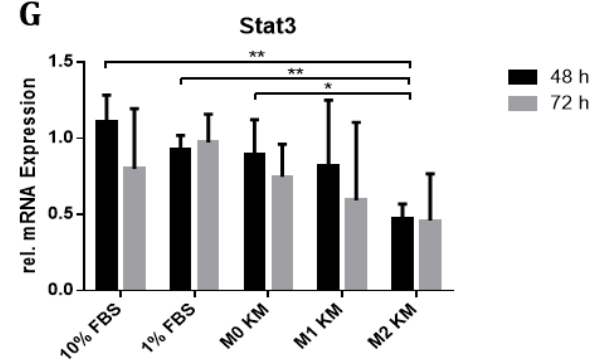

I
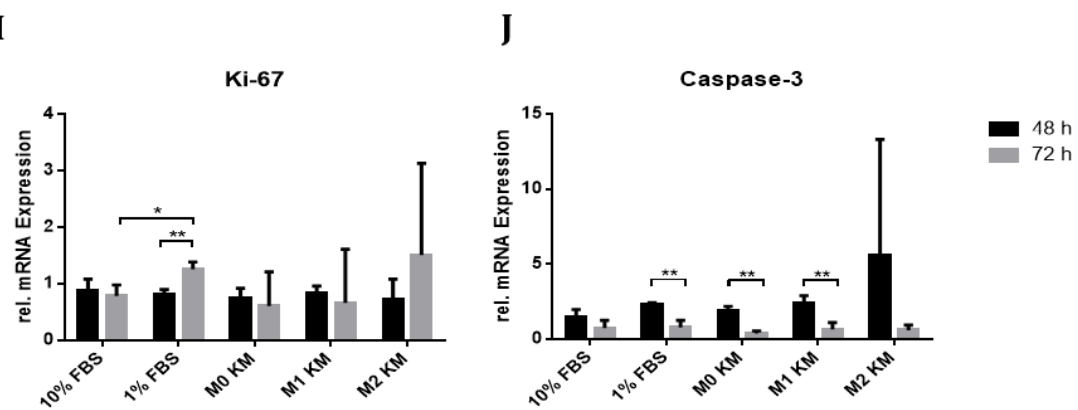

Abb. 3.27: Expression von zehn Metastasen-assoziierten Genen nach Inkubation mit konditionierten

Medien der Makrophagenphänotypen. Auf der y-Achse ist die relative mRNA Expression dargestellt, die im Verhältnis zu Zellen berechnet wurde, die in Medium mit 10 \% FBS inkubiert wurden. Pro Bedingung wurden zwei biologische Replikate verwendet; die entsprechenden technischen Replikate wurden als Triplet gemessen. Signifikante Unterschiede wurden mit Sternchen markiert $\left(^{*}=\rho \leq 0,05\right.$; ** $=\rho \leq 0,01$;** $=\rho \leq 0,001)$. 
Zusammengefasst ergibt sich aus diesen Daten folgendes Expressionsprofil: zum einen wirkt sich alleine die Inkubation mit dem 1 \% FBS Medium signifikant auf die Genexpression aus; hier waren fast alle Gene, insbesondere jedoch Krt20, CD44, Vimentin, MMP-7 und Cyclin D1, deutlich stärker exprimiert als in den restlichen Proben.

Das Profil der Zellen, die das M1 konditionierte Medium erhalten haben, weist im Vergleich zum M2 konditionierten Medium vor allem in den ersten 48 Stunden eine erhöhte Expression der immunregulatorischen Transkriptionsfaktoren NFkB1 und Stat3 sowie des Proliferationsmarkers Cyclin D1 auf. Im Vergleich dazu scheint das M2 konditionierte Medium hingegen durch die verstärkte Expression von E-cadherin, CD44, MMP-7 und Ki-67 und die reduzierte Expression von Caspase-3 die Aggressivität und Proliferation der Zellen zu verstärken. Gleichzeitig reduziert es auch die Expression von Transkriptionsfaktoren, die eine besondere Rolle bei der Immunantwort spielen.

Obwohl die statistische Auswertung der beiden Monozytenisolationen eine im Vergleich zu Isolation I geringere Makrophagendifferenzierung und -polarisation in Isolation II implizierte, hatte Letzteres nichtsdestotrotz einen positiven Einfluss auf die Expression von Metastasenassoziierten Genen in CMT-93 Zellen. 


\section{$4 \quad$ Diskussion}

Im Rahmen dieser Arbeit wurden mittels RNA Sequenzierung, $q R T-P C R$ und Immunhistochemie die Expression von Metastasen-assoziierten Genen in verschiedenen Leberarealen sowie in der Gesamtleber untersucht. Ziel war es, anhand des Genexpressionsprofils der kolorektalen Zelllinie CMT-93 und Metastasen-tragenden Lebern biologische Informationen zu generieren, um Rückschlüsse auf die Interaktion zwischen der CRC Zelllinie und ihrer Mikroumgebung sowie den von Paget beschriebenen Organotropismus ziehen zu können (Paget, 1889). Die bimodale Rolle der Makrophagen als Bestandteil der komplexen Interaktion zwischen Tumorzellen, Mikroumgebung und Immunsystem wurde ebenfalls in diesem Kontext untersucht.

\subsection{CMT-93 induziertes, syngenes und orthotopes Lebermetastasenmodell}

In CMT-93 Zellen konnte der epitheliale Charakter, eine Hochregulation von $\beta$-catenin und die Expression von Komponenten des Wht Signalweges (u.a. Axin2 und c-Jun), die eine besondere Rolle in der kolorektalen Karzinogenese einnehmen, nachgewiesen werden (WP2; Arackal, 2016). Somit erfüllte sie grundlegende Voraussetzungen für die Etablierung eines CRCinduzierten Metastasenmodells.

Im Rahmen dieser Arbeit konnte anhand einer intraportalen Implantation der Zelllinie in C57BL/6N Mäuse ein syngenes Lebermetastasenmodell erfolgreich etabliert werden. Somit wurde der biologisch natürliche Weg der hämatogenen Streuung von disseminierten CRC Zellen in das hepatische Milieu simuliert und reproduzierbare sowie stabile Ergebnisse erzielt (siehe Tab. 3.1). Durch die Implantation einer hohen Zellzahl von $1 \times 10^{6}$ Zellen wurde der höchst ineffiziente Vorgang der Metastasierung berücksichtigt, der u.a. durch mechanische Scherkräfte und Immunzellangriffen erheblich beeinflusst werden kann (Kapitel 1.4). Um den Zellverlust während des Eingriffs möglichst gering halten zu können, wurde die Applikationstechnik ebenfalls angepasst (Abb. 3.2).

\subsection{Kolonisation der CMT-93 Zelllinie in der Leber}

Die intraportale Implantation der CMT-93 Zelllinie induzierte in 70 - 80 \% der Mäuse multiple Lebermetastasen mit einem Durchmesser von 5 - $10 \mathrm{~mm}$, die ein heterogenes Verteilungsmuster im Leberorgan zeigten (Abb. 3.3). Zwar wurden 30 - 50 \% der Leber 
kolonisiert, eine Prädilektion eines Leberlappens konnte jedoch nicht festgestellt werden. Anhand immunhistochemischer Analysen wurden CMT-93 induzierte Lebermetastasen als moderat differenziertes kolorektales Adenokarzinom charakterisiert. Die Formation von CRC-typischen, azinär-glandulären Strukturen konnte immunhistochemisch nachgewiesen werden; sie sind in etwa 40 - 75 \% des metastatischen Gewebes vorzufinden und liegen in ein desmoplastisches Stroma eingebettet vor, welches invasive und proliferierende Eigenschaften von Tumorzellen stimuliert. Obwohl der verwendete Maussubstamm C57BL/6N nicht der ursprünglichen Herkunft der CMT-93 Zelllinie entspricht (C57BL/icrf; siehe Kapitel 2.1.8.2), wurden Tumorzellen nicht abgestoßen, so dass aufgrund der genetischen Ähnlichkeit beider Substämme ein reproduzierbares, syngenes Modell etabliert werden konnte.

\subsection{Epitheliales und invasives Wachstumsmuster der CMT-93 induzierten Lebermetastasen}

Der epitheliale Charakter der Lebermetastasen wurde anhand der Expression von $\beta$-catenin und E-cadherin bestätigt (Abb. 3.3). $\beta$-catenin ist beteiligt an der Organogenese sowie der Gewebemorphogenese (Haegel et al., 1995) und stellt eine essentielle Komponente des Wht Signalweges dar, da es im Zuge der Wht Aktivierung die Transkription von Targetgenen initiiert (Logan \& Nusse, 2004). Zu diesen Genen gehören u.a. das Protoonkogen $c$-Myc, der Wht Negativregulator Axin2 und das Transmembranglykoprotein CD44 (He et al., 1998; Jho et al., 2002; Wielenga et al., 1999). Die $\beta$-catenin Expression korreliert hier zwar mit einer Hochregulation des entsprechenden Gens CTNNB1 in der CMT-93 Zellinie (Arackal, 2016), die zytoplasmatische Färbung spricht jedoch für einen inaktiven Status des Proteins. Demnach erfolgt keine Translokation von $\beta$-catenin in den Zellkern, so dass keine Transkription für Wnt Targetgene induziert wird, die u.a. eine unkontrollierte Zellproliferation stimulieren würden (Ikeda et al., 1998). Für eine abschließende Beurteilung wird daher eine gezielte Färbung des aktiven $\beta$-catenins vorgeschlagen. Brabletz et al. konnten jedoch zeigen, dass Tumorzellen in der Invasionsfront eine nukleäre $\beta$-catenin Expression aufweisen, während in Zellen im Tumorzentrum eine membranöse Lokalisation des Proteins dominiert; vermutlich löst ein Signal die Translokation in den Zellkern aus, so dass Invasionsprozesse initiiert werden (Brabletz et al., 1998). Unabhängig vom Wnt Signalweg konnten proliferierende Zellen in den Metastasen anhand einer anti-Ki-67 Färbung nachgewiesen werden. 
Als Adhäsionsprotein ist E-cadherin essentiell für die Herstellung von Zell-Zell-Kontakten und beeinflusst maßgeblich die Integrität epithelialer Strukturen (Takeichi, 1991). Somit trägt das Protein erheblich zur Stabilität des metastatischen Zellverbandes bei. Eine Herunterregulation wird mit einer Auflösung von Zell-Zell-Kontakten, neoplastischen Prozessen, invasiven Wachstumsmustern von Tumoren und einer stimulierten Zellproliferation assoziiert (Frixen et al., 1991; Pignatelli et al., 1992). Eine einwandfreie Funktionalität des E-cadherins erfordert die Formation eines E-cadherin-Catenin Komplexes, an dem u.a. auch $\beta$-catenin beteiligt ist. Eine reversible Herunterregulation der E-cadherin Expression durch die Phosphorylierung von Cateninen induziert eine Destabilisierung von adhärenten Zellkontakten (Shibamoto et al., 1994).

Vimentin wird in mesenchymalen Zellen, wie Fibroblasten, Chondrozyten, Makrophagen und endothelialen Zellen exprimiert und eignete sich somit zur Überprüfung des mesenchymalen Anteils der Lebermetastasen. Mesenchymale Zellen werden durch eine geringe Zellpolarität charakterisiert, weshalb sie keine Zell-Zell-Kontakte eingehen können (Osborn, 1993). Vimentin dient als Gerüstprotein (scaffolding protein) der Stabilisierung von Geweben sowie Zellen und ist an Signaltransduktionsprozessen beteiligt (Herrmann et al., 2003; Eriksson et al., 2004). Neben dem epithelialen Charakter konnten anhand der Vimentin Expression auch mesenchymale Eigenschaften der Lebermetastasen nachgewiesen werden. Vimentin ${ }^{+}$Zellen waren überwiegend in den glandulären Strukturen der Metastasen und somit im desmoplastischen Stroma vorzufinden. Die stromale Mikroumgebung stellt eine Art Schnittstelle zwischen malignen und organspezifischen Zellen (z.B. Fibroblasten) dar (Bissel \& Radisky, 2001). Eine dortige Hochregulation des Vimentins wird assoziiert mit dynamischen Veränderung im Tumorstroma während der Tumorprogression; Vimentin wird daher als prognostischer Marker für eine schlechte Prognose bei CRC Patienten vorgeschlagen (Ngan et al., 2007). Der Nachweis von Vimentin und E-cadherin ist im Zuge der Metastasierung im Kontext eines Phänotypenwechsels zu betrachten. Während der Dissemination maligner Zellen erfolgt eine Auflösung des Zellverbandes im Zuge einer EMT, die mit einer Herunterregulation von E-cadherin und einer Hochregulation von mesenchymalen Markern (Vimentin, SNAI1, Twist) einhergeht. Um im Anschluss an eine Extravasation in das Zielgewebe wieder Zell-Zell-Kontakte herstellen zu können, durchlaufen Zellen erneut einen Phänotypenwechsel in Form einer MET, so dass nun E-cadherin hochreguliert und mesenchymale Marker herunterreguliert vorliegen. Der Nachweis von $E$ cadherin und Vimentin impliziert, dass in Lebermetastasen ein Phänotypenwechsel zum epithelialen Charakter stattgefunden hat und der metastatische Zellverband somit stabilisiert wird. Zu diesem Zeitpunkt sind jedoch auch noch mesenchymale Zellen vorhanden, die das 
invasive Wachstumsmuster der Tumorzellen stimulieren, so dass sich maligne Zellen im hepatischen Milieu weiter ausbreiten können. Um epitheliale und mesenchymale Bereiche besser separieren zu können, wird daher eine Doppelfärbung beider Marker vorgeschlagen. Der putative Tumorstammzellmarker CD44 war im überwiegenden Anteil der Metastasen lokalisiert. Der Membranrezeptor ist an Zell-Zell- sowie Zell-Matrix-Kontakten beteiligt und kann somit eine Zellmigration oder den Verbleib von Zellen im Gewebe initiieren (Marhaba \& Zöller, 2004). CD44 wird sowohl von Tumorzellen als auch von nicht entarteten Zellen, wie beispielsweise Immunzellen, exprimiert. Tumorzellen nutzen dies aus, indem sie ihre CD44 Expression hochregulieren und diese als eine Art Tarnung vor dem Immunsystem nutzen, so dass ihre Migration und Ausbreitung begünstigt wird (Borland et al., 1998). Des Weiteren wird die $C D 44$ Genexpression im Zuge des Wnt Signalweges durch $\beta$-catenin initiiert (Schmitt et al., 2015; Wielenga et al., 1999).

Die immunhistochemisch untersuchten Proteine sind gängige Marker in der klinischen Routinediagnostik. Somit konnte nachgewiesen werden, dass CMT-93 induzierte Lebermetastasen phänotypische Ähnlichkeiten mit humanen Kolorektalkarzinomen aufweisen. Demnach bestehen sie aus einem stark epithelialen, stabilen Zellverband, der durch die Expression von CD44 und Vimentin ein starkes Invasions- und Metastasierungspotential aufweist.

\subsection{Metastasierungspotential durch eine adaptive Hoch- und Herunterregulation von Genen}

Im Zuge der Metastasenformation im hepatischen Milieu wurden mithilfe eines Algorithmus der Leberhintergrund bereinigt und 32 Gene identifiziert, die im Vergleich zur reinen Zelllinie im Zentrum der Lebermetastasen von CMT-93 Zellen signifikant differentiell exprimiert werden (Abb. 3.8 \& 3.9). Diese werden mit Gewebeumbau, Zellproliferations- und Adhäsionsprozessen assoziiert, sind jedoch auch an der Aktivität des Wnt Signalweges, an der Transkription/Regulation von Genen sowie an der Apoptoseinhibition beteiligt.

\subsubsection{MMPs und SNAI1 stimulieren Invasion}

Tumorzellen sind angewiesen auf eine Interaktion mit der ECM, um einen strukturellen Gewebeumbau zu initiieren, so dass eine Migration von malignen Zellen aus dem Primärtumor ermöglicht wird (Said et al., 2014). Der Metastasierungsvorgang beinhaltet eine Reihe sequentieller Schritte, die mit der Dissemination maligner Zellen aus dem Zellverband 
des Primärtumors beginnt und zur Invasion in das Zielgewebe führt. Hierbei benötigen Tumorzellen MMPs für proteolytische und Integrine für adhäsive Vorgänge (Said et al., 2014). MMPS sind als proteolytische Enzyme maßgebliche Mediatoren der ECM Degradation und unterstützen Tumorzellen bei der Zersetzung von gesundem Gewebe (Egeblad \& Werb, 2002; Hua et al., 2011). In experimentellen Tiermodellen konnte vielfach gezeigt werden, dass die Invasions- und Metastasierungsfähigkeit maligner Zellen mit einer vermehrten Sekretion von MMPs durch Tumorzellen und/oder Stromazellen korreliert und diese einen starken Einfluss auf die Patientenprognose haben (Mignatti \& Rifkin, 1993; Zucker \& Vacirca, 2004; Said et al., 2014). Eine tumorprotektive Rolle der MMPs wurde ebenfalls beschrieben (Van der Jagt et al., 2010); von Tumorzellen sezernierte MMPs können beispielsweise Wachstumsfaktoren aus der ECM freisetzen und dadurch eine Signalkaskade zur Sekretion von weiteren Wachstumsfaktoren, Chemokinen und Adhäsionsmolekülen initiieren, die wiederum progressive Eigenschaften maligner Zellen stimulieren können (Said et al., 2014). Eine DEG im Rahmen dieser Arbeit identifizierte sechs MMPs, die im Gegensatz zur CMT-93 Zelllinie in Lebermetastasen hochreguliert werden (siehe Abb. 3.8). Darunter sind die Gelatinasen MMP2 und MMP-9, deren Überexpression in Patienten mit metastasiertem CRC mit einer schlechten Prognose korreliert (Langenskiold et al., 2005; Said et al., 2014). Das Expressionslevel beider MMPs wurde im präoperativen Serum von CRC Patienten als prognostischer Marker für die Tumorzellinvasion identifiziert (Dragutinovic et al., 2011). Eine Hochregulation der Kollagenase MMP-13 korreliert mit einer verminderten Überlebensprognose von CRC Patienten (Leeman et al., 2002). In Patienten mit einem fortgeschrittenen Stadium der Tumorprogression und einer stark erhöhten MMP-13 Expression konnte ein ca. 8fach erhöhtes Risiko für postoperative Rezidive festgestellt werden (Huang et al., 2010). Eine MMP-7 Überexpression ist in 80 \% der Kolorektalkarzinome nachweisbar und wurde als wichtiger Faktor für das frühe Tumorwachstum mit einer potentiellen Funktion für die Invasion und Metastasierung des CRC identifiziert (Brabletz et al., 1999). In SCID Mäusen führte eine MMP-7 Überexpression zu einer verstärkten Invasionsund Metastasierungsfähigkeit von Tumorzellen (Adachi et al., 1999). In prä-klinischen Studien konnten MMP Inhibitoren (MMPIs) die Tumorprogression und die Metastasierung des CRC in Lunge und Leber reduzieren, in klinischen Studien konnten diese Ergebnisse jedoch nicht bestätigt werden. Neuere Studien indizieren eine tumorfördernde und inhibierende Rolle der MMPs (Wagenaar-Miller et al., 2004; Hua et al., 2011).

Eine verstärkte SNAI1 Expression wird assoziiert mit einer Herunterregulation des Adhäsionsproteins E-cadherin; folglich kann es als EMT Marker herangezogen werden 
(Davidson \& Sukumar, 2005). Ein Phänotypenwechsel von epithelial zu mesenchymal ist essentiell für eine Dissemination und Migration maligner Zellen (Guarino et al., 2007).

\subsubsection{Chemokinrezeptoren und -liganden fördern Zellmigration und -wachstum}

In CMT-93 induzierten Lebermetastasen wurde eine Hochregulation der Chemokinrezeptoren CXCR2 und CXCR4 und eine verstärkte Expression des Chemokins CCL7 identifiziert. Chemokinrezeptoren sind Membranproteine, die mit Chemokinen interagieren und chemotaktisch die Migration von Zellen, aber auch immunregulatorische Prozesse initiieren (Van den Eynden et al., 2013). Sie sind somit an der Tumorprogression, der metastatischen Streuung, aber auch an der Resistenz gegenüber krebsgerichteter Therapien beteiligt (Dessein et al., 2010; Verbeke et al., 2011; Oladipo et al., 2011). Der Organotropismus von metastatischen Zellen wird mit Chemokinen assoziiert; ihre lokale Expression könnte Tumorzellen über ihre Chemokinrezeptoren in bestimmte Organe leiten (Muller et al., 2001; Zlotnik, 2004). Im Zuge der Extravasation von CRC Zellen in das hepatische Milieu werden Kupfferzellen in Folge einer pro-inflammatorischen Signalkaskade angeregt Chemokine zu sezernieren, die wiederum Tumorzellen chemotaktisch bei ihrer Migration durch das Gewebe unterstützen (Wen et al., 2013). In Mamma- und Kolorektalkarzinomen wurde die Expression von CXCR4 als prognostischer Marker identifiziert (Kim et al., 2005; Burger \& Kipps, 2006), da das Membranprotein durch die Interaktion mit dem Chemokin CXCL12 das Tumorwachstum, die Angiogenese und die Metastasierung fördert (Teicher \& Fricker, 2010; Muller et al., 2001; Vandercappellen et al., 2008). Eine Überexpression von CXCR4 konnte zudem in Lebermetastasen von CRC Patienten nachgewiesen werden, die eine neoadjuvante Chemotherapie erhalten haben (Dessein et al., 2010). Offensichtlich stimuliert eine derartige Therapie die Aggressivität und Metastasierungsfähigkeit maligner Zellen, indem sie über eine Hochregulation ihrer Chemokinrezeptoren verstärkt mit Liganden interagieren. Die Aktivierung von CXCR2 durch seinen Liganden CXCL8 in der Tumormikroumgebung stimuliert die Proliferation und Dissemination von CRC Zellen und hat somit einen erheblichen Einfluss auf die Metastasierung (Lee et al., 2012; Heidemann et al., 2003). Desurmont et al. konnten zeigen, dass CXCR2 und CXCL7 in Patienten mit CRC-induzierten Lebermetastasen unabhängige prognostische Faktoren für Rezidive und die Patientenprognose darstellen; ihre Überexpression korrelierte mit verkürzten Überlebensraten (Desurmont et al., 2015). Der Ligand CCL7 wird sowohl von Monozyten als auch von Tumorzellen sezerniert und ist durch die Rekrutierung von Monozyten an inflammatorischen Prozessen beteiligt. McQuibban et al. beschreiben eine Interaktion 
zwischen CCL7 und MMP-2, die eine Abschwächung von inflammatorischen Reaktionen induziert und die bimodale Rolle der MMPs als Effektoren und Regulatoren der Immunantwort bestätigt (McQuibban et al., 2000).

\subsubsection{Integrine und Komponenten des Wnt Signalweges steuern Zelladhäsion und Signaltransduktion}

Integrine unterstützen maßgeblich die Migration disseminierter Zellen zum Zielgewebe, da sie ihre Anheftung an die ECM und die Basalmembran gewährleisten. Somit sind sie an Adhäsions- und Signaltransduktionsprozessen zwischen Tumorzellen, aber auch zwischen Tumorzelle und ECM beteiligt, die in einer tumorstimulierenden Veränderung der Zellpolarität, -proliferation-, -migration und -invasion resultiert (Bissel et al., 2011). Mit Hilfe von Cadherinen und Selektinen vermitteln sie die Interaktion zwischen Tumorzellen und ihrer Umgebung (Haeuselmann et al., 2016). Im Rahmen dieser Arbeit wurden u.a. die Integrine ITGA6 (CD49f) und ITGB3 (CD61) identifiziert, die an der Migration und Signalweiterleitung von CMT-93 Zellen beteiligt sind.

Auch Komponenten des Wht Signalweges insbesondere Wif1 und Axin2 waren in Lebermetastasen signifikant hochreguliert. Wif1 ist an der Feinregulation des kanonischen Wht Signalweges beteiligt und inhibiert durch die Bindung von Wht Proteinen die Transkription von Wnt Targetgenen (Malinauskas et al., 2011). Axin2 bildet gemeinsam mit GSK3 $\beta$ einen $\beta$-catenin-Degradationskomplex, so dass $\beta$-catenin im Zytoplasma abgebaut wird. Die Wif1 Hochregulation korreliert mit dem immunhistochemischen Nachweis der zytoplasmatischen Akkumulation von $\beta$-catenin. Eine Hochregulation des Protoonkogens $c$ Jun indiziert die Aktivität des nicht-kanonischen Wnt/JNK Signalweges. Als onkogener Transkriptionsfaktor ist es an Apoptose- und Zellzyklus-spezifischen Prozessen beteiligt (Wisdom et al., 1999). Die Transkription von Wht Targetgenen in CMT-93 induzierten Lebermetastasen erfolgt somit möglicherweise über den nicht-kanonischen $W n t$ Signalweg.

\subsubsection{Verminderte Caspase-3 und Fibronektin Expression}

Um im Leberparenchym überleben zu können, benötigen CRC Zellen die Interaktion mit Wachstumsfaktoren und müssen gleichzeitig der Immunantwort und dem programmierten Zelltod entgehen, die durch das hepatische Milieu ausgeübt werden (Bacac \& Stamenkovic, 2008). Apoptose wird durch intrinsische und extrinsische Signalwege kaskadenartig initiiert. T-Zellen sezernieren die Liganden FasL und TNF, die an entsprechende Rezeptoren maligner 
Zellen binden können; es folgt eine Aktivierung von Caspasen, die schließlich den programmierten Zelltod der Tumorzellen einleiten (Creagh, 2014). Eine Herunterregulation von apoptotischen Prozessen und insbesondere von Caspasen im Zuge der kolorektalen Karzinogenese ist beschrieben (Palmerini et al., 2001). Tumorzellen überexprimieren beispielsweise den Apoptose-Inhibitor Survivin, was eine Inhibition von Caspase-3 zur Folge hat. Auf diese Weise können maligne Zellen ihre Vitalität steigern, was u.a. zu einer Resistenz gegenüber immunologischen und zytotoxischen Therapien führen kann (Tamm et al., 1998). In der vorliegenden Arbeit ist in der Gruppe der herunterregulierten Gene u.a. Caspase-3 zu finden. Eine Herunterregulation der Fas Expression in Lebermetastasen wurde von Ogawa et al. beschrieben, die vermutlich in einer verminderten Caspase-3 Expression resultiert (Ogawa et al., 2004). Das Fas Gen ist hier im Tumorkern herunterreguliert, während es im umliegenden Gewebe überexprimiert vorliegt (Abb. 3.17).

Das Adhäsionsprotein Fibronektin stellt die Verbindung zwischen malignen Zellen und der ECM her und unterstützt sie bei ihrer Migration durch das Gewebe, weshalb es als mesenchymaler Marker verwendet wird (Park \& Schwarzbauer, 2014). Eine Herunterregulation von Fibronektin korreliert folglich mit dem epithelialen Charakter der CMT-93 induzierten Lebermetastasen.

Zusammengefasst konnte gezeigt werden, dass im Zuge der Metastasierung und der Interaktion mit der hepatischen Mikroumgebung eine fein abgestimmte Adaptation bzw. Veränderung in CMT-93 Zellen erfolgt, so dass sie ihr Genexpressionsprofil an ihre Mikroumgebung anpassen. Daraus resultieren schließlich divergierende Genexpressionsprofile zwischen Zelllinie und Metastase. Insbesondere MatrixMetalloproteasen, Chemokinrezeptoren und Zelladhäsionsgene nehmen hier eine exponierte Rolle ein und tragen zum Invasions- und Metastasierungsprofil von CMT-93 Zellen unter dem Einfluss des Lebermilieus bei.

\subsection{Relevante Signalwege für die Formation von Lebermetastasen}

Die Leber kann als immunologisches Organ anhand einer Reihe von Immunzellen immunregulatorische Prozesse in Gang setzen bzw. eine immunologische Toleranz initiieren. Da disseminierte Tumorzellen eine potentielle Gefahr darstellen, werden in Folge der Leberkolonisation pro-inflammatorische Prozesse induziert, wie beispielsweise die Rekrutierung von Makrophagen (Tacke \& Randolph, 2006). Diese können durch die Sekretion von pro-inflammatorischen Zytokinen eine antigenspezifische Immunantwort von T-Helfer- 
Zellen initiieren und weitere Immunzellen rekrutieren (Mantovani et al., 2004). Tumorzellen nutzen die funktionelle Plastizität der Makrophagen aus, indem sie durch die Sekretion von Zytokinen Monozyten und Makrophagen rekrutieren und einen Phänotypenwechsel induzieren, so dass Makrophagen tumorstimulierende Eigenschaften annehmen können (Mosser \& Edwards, 2008). Somit findet eine rege Interaktion zwischen Tumorzelle, Immunsystem und Mikroumgebung statt, die eine Tumorprogression begünstigen kann. So wurde „inflammatorische Antwort“ als einer der relevantesten Signalwege für die Formation von CMT-93 induzierten Lebermetastasen identifiziert.

Die Angiogenese nimmt ebenfalls eine bedeutende Rolle im Zuge der Metastasenformation ein, da durch die Formation von neuen Blutgefäßen aus bereits Vorhandenen die Versorgung von Tumorzellen mit Nährstoffen gewährleistet und gleichzeitig der Kontakt zwischen Tumorzellen und der Blutzirkulation hergestellt wird, so dass maligne Zellen in weitere Organe disseminieren können (Folkman \& Klagsbrun, 1987; Nadal et al., 2007). An der komplexen Regulation der Angiogenese sind u.a. VEGF, Angiopoetine, Notch sowie Integrine beteiligt. Die Bindung von VEGF-A an den VEGF Rezeptor (VEGFR)-2 wird als ein Schlüsselsignalweg betrachtet; so kann das metastasierte CRC beispielsweise mit dem gegen VEGF gerichteten Antikörper Bevacizumab behandelt werden (Ferrara, 2004; Rmali et al., 2007; Sun, 2012). Im Kontext von CRC-induzierten Metastasen wurde von van der Wal et al. gezeigt, dass das tumorumgebende Leberparenchym Angiogenese-fördernde Eigenschaften aufweist (van der Wal et al., 2012). Die ECM Degradation durch MMP-2 und MMP-9 korreliert mit der Verfügbarkeit von Angiogeneseaktivatoren (Nadal et al., 2007). Signaltransduktionsprozesse werden an der Zellmembran durch intra- und extrazelluläre Stimuli eingeleitet und führen zu einer kaskadenartigen Aktivierung von Signalwegen, die zu jedem Zeitpunkt vielfach in einer Zelle bzw. einem Organ sattfinden, weshalb „Signaltransduktion“ hier ebenfalls als prominenter Signalweg identifiziert wurde.

\subsection{Aggressivität von CMT-93 Zellen in verschiedenen Metastasierungsstadien}

Der Einfluss verschiedener Metastasierungsstadien auf das gesamte Organ wurde eruiert, indem die Gesamtleber zu verschiedenen Zeitpunkten der Metastasenformation makroskopisch, immunhistochemisch und molekularbiologisch analysiert wurde. 


\subsubsection{Fibrin und Entzündungsreaktionen als initiale Mediatoren der Tumorinvasion}

Im Zuge der hämatogenen Streuung haften sich Tumorzellen zunächst an die Mikrovaskulatur des Zielorgans an (Al-Mehdi et al., 2000). Die darauffolgende endotheliale Adhäsion und das Metastasierungspotential der Zellen wird assoziiert mit einer Formation einer Bindung aus Thrombozyten, Fibrin und Tumorzellen (Chew \& Wallace, 1976; Cavanaugh et al., 1988). Fibrin geht aus der Polymerisation von Fibrinogen hervor und bildet gemeinsam mit Thrombozyten ein hämostatisches Gerinnsel, das den Wundverschluss initiiert. Fibrinablagerungen konnten bereits 5 min nach Tumorzellinokulation zur Induktion von Lungenmetastasen detektiert werden und waren mindestens 9 Stunden danach nachweisbar (Chew \& Wallace, 1976; Crissman et al., 1985). Bei den weißen Ablagerungen auf der Leberoberfläche an Tag 3 nach Implantation von CMT-93 Zellen handelt es sich daher höchstwahrscheinlich um Fibrinreste, die ab Tag 14 nicht mehr detektierbar waren. Palumbo et al. konnten in fibrinogendefizienten Mäusen zeigen, dass Fibrin die Adhäsion und das Überleben maligner Zellen begünstigt und ein bestimmender Faktor des metastatischen Potentials zirkulierender Tumorzellen ist (Palumbo et al., 2000). Ebenfalls beschrieben ist, dass Fibrinmatrizen die Zellmigration begünstigen und somit die Invasion von Tumorzellen erleichtern (Dvorak et al., 1992).

Der Zellimplantationsvorgang an sich kann inflammatorische Prozesse in Gang setzen, da das Einführen einer Insulinspritze eine Wunde in der Pfortader hervorruft und somit Entzündungs- und Wundheilungsreaktionen hervorgerufen werden. Infolgedessen werden Monozyten chemotaktisch aus der Blutzirkulation in die Leber rekrutiert und dort durch proinflammatorische Zytokine, wie z.B. IFN- $\gamma$, zu M1 Makrophagen differenziert, die ebenfalls pro-inflammatorische Faktoren sezernieren (Arnold et al., 2014). Da M2 Makrophagen an der Wundheilung und Gewebehomöostase beteiligt sind, werden diese ebenfalls rekrutiert (Mantovani et al., 2007), so dass zu diesem Zeitpunkt höchstwahrscheinlich eine gemischte Makrophagenpopulation vorhanden ist.

Bei einer erfolgreichen Zellinvasion und Metastasierung waren ab Tag 14 makroskopisch einzelne Mikrometastasen sichtbar, die sich bis Tag 28 zu Makrometastasen mit einem 5 fach größeren Durchmesser entwickelten. Eine Korrelation zwischen Lebergewicht und Metastasierungserfolg wurde an Tag 14 und 28 ersichtlich (Abb. 3.13 \& 3.14). Lebern mit stark infiltriertem, metastatischem Gewebe hatten an Tag 28 z.T. ein 3fach höheres Gewicht im Vergleich zu einer unbehandelten Leber. Die große Varianz insbesondere innerhalb der Tag 28 Gruppe spricht für einen individuell unterschiedlichen Kolonisationserfolg der CMT93 Zelllinie, die auch zu deutlichen Varianzen in Genexpressionsanalysen führten. 


\subsubsection{E-cadherin und Vimentin als Hauptmediatoren des zunehmend metastatischen Potentials}

Die phänotypischen Eigenschaften der Lebermetastasen in verschiedenen Stadien der Metastasierung deckten sich mit den Beschreibungen in Kapitel 4.3. Die CRC-typischen duktulären Strukturen der Lebermetastasen wurden anhand der E-cadherin Expression insbesondere an Tag 28 nachgewiesen. Hier wurde E-cadherin ausschließlich von Tumorzellen exprimiert, die in den duktulären Strukturen lokalisiert waren. CD44 erlaubte eine eindeutige Identifizierung von malignen Zellansammlungen im frühen und von Mikrosowie Makrometastasen in späteren Metastasierungsstadien. So konnte die Migration maligner Zellen dokumentiert werden, die zu einer größeren metastatischen Läsion wachsen und dabei hepatisches Gewebe verdrängen. Da auch Kupfferzellen, Gallengangepithelien und Mesenchymzellen der Leber CD44 exprimieren, waren im umgebenden Gewebe ebenfalls $C D 44^{+}$Zellen detektierbar. Die verstärkte Expression von Vimentin in der invasiven Front an Tag 3 und 14 indizieren besonders aggressive Eigenschaften der Tumorzellen im frühen Metastasierungsstadium. An Tag 28 ist Vimentin insbesondere in der Tumor-Stroma-Region exprimiert, die bei CRC Patienten mit einer schlechten Prognose korreliert (Ngan et al., 2007). Eine Korrelation zwischen einer EMT und dem Fortschreiten der Metastasierung wurde bereits beschrieben und konnte im Rahmen dieser Arbeit anhand von E-cadherin und Vimentin ebenfalls beobachtet werden (Thiery, 2002). Im Zuge der Karzinogenese werden Entzündungsreaktionen initiiert; mit Hilfe von Tumor-assoziierten Fibroblasten und Makrophagen resultieren sie in Wachstums- und Zellproliferationsvorgängen, so dass in Metastasen $\mathrm{Ki}^{-67^{+}}$, proliferierende Zellen in großer Anzahl detektiert werden (Tlsty \& Coussens, 2006).

\subsubsection{Aggressivität und das Invasionspotential von CMT-93 Zellen im frühen und späten Metastasierungsstadium}

Eine Auswahl signifikant differentiell exprimierter Gene aus der RNA Sequenzierung wurde anhand einer $q R T-P C R$ Analyse verifiziert. Das aggressive Invasionspotential von CMT-93 Zellen wurde vor allem im frühen und späten Metastasierungsstadium nachgewiesen. Der wachsende Tumoranteil mit fortschreitendem Metastasierungsstadium (Krt20, CD44) korrelierte mit einer Reduktion des leberspezifischen Gens PCK1. Krt20 ist ein gängiger Marker aus der klinischen Routinediagnostik für kolorektale Adenokarzinome, da das Protein vor allem von Epithelzellen der Magen- und Darmschleimhaut exprimiert wird. Mit 
fortschreitendem Karzinogenesestadium nimmt die Krt20 Expression deutlich zu und ermöglicht somit die Bestimmung des Differenzierungsgrads von Tumorgewebe, der entscheidend ist für Therapie und Prognose (Chu et al., 2000; Kummar et al., 2002; Hernandez et al., 2005). Eine hochregulierte MMP-7 Expression in CRC induzierten Lebermetastasen konnte bestätigt werden (Zeng et al., 2002). CRC Zellen nutzen eine verstärkte $M M P-7$ Expression und Sekretion für einen proteolytischen Abbau der ECM, um auf diese Weise ihr invasives Metastasierungspotential steigern zu können (Ochiai et al., 2008; Fang et al., 2009; Lee et al., 2012). Die Hochregulation der Genexpression an Tag 3 und Tag 28 impliziert, dass das Enzym vor allem bei der anfänglichen Initiation des Tumorwachstums und bei der weiteren Invasion in einem späten Metastasierungsstadium von besonderer Bedeutung ist (Brabletz et al., 1999). Die verstärkte Expression von Cyclin D1 und Ki-67 sowohl in Shamoperierten als auch Metastasen-tragenden Lebern bestätigt, dass der Eingriff an sich Entzündungsreaktionen initiiert und in Folge dessen Wachstumsreize gesetzt werden. Dies hat zur Folge, das Zellwachstum und -proliferation stimuliert werden, wobei Tumorzellen diesen Reiz offensichtlich verstärken und die Genexpression hier vermehrt hochreguliert wird. Die Ki-67 Quantifizierung zeigt den Einfluss des Eingriffs am deutlichsten; in Shamoperierten Lebern nimmt die Expression trotz eines Ausreißers an Tag 14 im zeitlichen Verlauf deutlich ab. Dies spricht für eine verstärkte Zellproliferation als Antwort auf Entzündungsreaktionen in Folge des Eingriffs, die mit Dauer der postoperativen Versuchslaufzeit eingedämmt wird. In Metastasen-tragenden Lebern hingegen indiziert die Hochregulation von Ki-67 und die Herunterregulation von Caspase-3 an Tag 28, dass Tumorzellen in der Lage sind, im Laufe der Metastasenformation ihre proliferierenden und apoptose-inhibierenden Eigenschaften zu stimulieren, um auf diese Weise ihre invasiven und aggressiven Eigenschaften aufrechterhalten zu können. Eine verstärkte NFkB1 Expression war in Sham-operierten und Metastasen-tragenden Lebern detektierbar, da der Transkriptionsfaktor an verschiedenen Prozessen wie Zellproliferation, Zelltod und insbesondere an immunregulatorischen Prozessen beteiligt ist und das Gen somit schon durch den Eingriff an sich hochreguliert wird. Nichtsdestotrotz indiziert eine im Vergleich erhöhte Genexpression in Metastasen-tragenden Lebern an Tag 3 und Tag 28, dass vor allem im frühen und späten Metastasierungsstadium immunregulatorische und zellproliferative Prozesse induziert werden. Die $N F k B$ Expression wird assoziiert mit einer Aktivierung von M1 Makrophagen, die pro-inflammatorische und tumorinhibierende Eigenschaften aufweisen (Tugal et al., 2013). Diese werden offensichtlich in erster Linie bei der Initiation des Tumorwachstums, aber auch als Reaktion auf die Sham-OP benötigt. Stat3 ist ein kritischer Mediator der kolorektalen Karzinogenese (Grivennikov et al., 2009). Der 
Transkriptionsfaktor wird assoziiert mit der Polarisation von Makrophagen Richtung M2 Phänotyp und ist an Zellwachstums-, Apoptose- und immunregulatorischen Prozessen beteiligt (Abb.1.3; Yuan et al., 2004). Im Zuge des Jak-Stat Signalweges wird Stat3 durch Zytokine wie $I L-6,-10$ und -11 sowie Wachstumsfaktoren wie $E G F$ aktiviert und agiert dann im Zellkern als Transkriptionsaktivator (Grivennikov et al., 2009; Putoczki et al., 2013). Die qRT-PCR Analyse zeigte hier die größten Unterschiede im Verlaufe der Metastasenformation. Auch hier induzierte der Eingriff an sich eine erhöhte Stat3 Expression, die im Zuge von proinflammatorischen Prozessen stimuliert wurde. Während in Sham-operierten Lebern dieser Effekt im Laufe des Versuches nachließ, lag in Metastasen-tragenden Lebern an Tag 28 eine signifikant hohe Stat3 Expression vor. Verursacht könnte dies durch Immunzellen und Fibroblasten des Tumorgewebes sein, die eine kontinuierliche Stat3 Aktivierung bewirken. TGF $\beta$ stimulierte Fibroblasten sezernieren $I L-11$ und aktivieren somit Stat3, während Makrophagen durch die Ausschüttung von IL-6 Stat3 aktivieren und Zellen somit vor Apoptose schützen (Calon et al., 2012; Grivennikov et al., 2009). Die Aktivierung von NFkB und Stat3 wird als Schlüsselfaktor für die CRC-assoziierte Inflammation betrachtet (Erreni et al., 2011). Auch E-cadherin und Vimentin liegen in Metastasen-tragenden Lebern hochreguliert vor; insgesamt zeichnet sich jedoch im Einklang mit der RNA Sequenzierung ein eher mesenchymaler und somit invasiver/aggressiver Charakter ab. Die Ursache für eine leicht höhere Vimentin Expression im Vergleich zu E-cadherin kann jedoch auch darauf beruhen, dass Vimentin von Fibroblasten, Makrophagen und endothelialen Zellen ebenfalls exprimiert wird, die in der Leber in großer Anzahl vorzufinden sind (Osborn, 1993).

\subsection{Divergierende Genexpressionsprofile von Tumor- und Lebergewebe}

Anhand der RNA Sequenzierungsdaten verschiedener Areale von Metastasen-tragenden Lebern konnte eruiert werden, ob und wie stark sich Tumorkern, der Übergangsbereich zwischen Tumor und Lebergewebe und das umliegende makroskopisch tumorfreie Gewebe von der CMT-93 Zelllinie unterscheiden. Hierfür wurde der ursprüngliche Datensatz ohne Leberbereinigung verwendet; so konnte ein Genexpressionsprofil erstellt werden, das die tatsächliche Interaktion zwischen Tumorzellen und hepatischen Zellen bzw. Faktoren widerspiegelt.

Insgesamt zeigte ein Vergleich verschiedener Leberareale, dass CMT-93 induzierte Lebermetastasen insbesondere im Tumorkern und -rand ein epitheliales und invasives Wachstumsmuster aufweisen, das eine weitere Tumorprogression im hepatischen Milieu begünstigt. Es wurde jedoch auch deutlich, dass eine detaillierte Unterscheidung zwischen 
Tumorkern und -rand sowie Normalrand und -gewebe nicht gewinnbringend/erkenntnisreich ist, da hier kaum Unterschiede detektierbar sind. Im Gegensatz dazu ist eine separate Betrachtung von Tumorgewebe und umliegendem Gewebe durchaus sinnvoll, da eindeutig divergierende Genexpressionsprofile identifiziert wurden. Während das Tumorgewebe sehr viele Übereinstimmungen mit der CMT-93 Zelllinie aufweist, unterscheidet es sich fast komplett vom umliegenden Gewebe. Im Tumorgewebe nahmen Metastasen-assoziierte Gene eine exponierte Stellung ein; hier werden insbesondere tumorspezifische Gene wie Krt20 und CD44, die EMT Marker Vimentin und E-cadherin, MMP7 sowie NFkB1 hochreguliert. Wie zuvor bereits diskutiert, haben diese Gene einen erheblichen Einfluss auf die Tumorprogression.

Interessanterweise sind im tumorumgebenden Gewebe lediglich der Transkriptionsfaktor Stat5B, der Wachstumsrezeptor EGFR und der M2 Marker CD163 im Vergleich zur Zelllinie und zum Tumorgewebe hochreguliert (Abb. 3.17). Stat5 Proteine werden durch Zytokine und Wachstumsfaktoren aktiviert und sind an der zytoplasmatischen Signalweiterleitung beteiligt, indem sie Vorgänge wie Zellwachstum, -proliferation und Inflammation initiieren (Nosaka et al., 1999). Eine konstante und verstärkte Expression des Proteins führt zu einer erhöhten Expression von anti-apoptotischen Genen, die Zellen vor einem programmierten Zelltod bewahren und diese sich somit zu malignen Zellen entwickeln (Cumaraswamy \& Gunning, 2012). EGFR ist an der Signalweiterleitung für Zellwachstum beteiligt und verhindert ebenfalls den apoptotischen Zelltod, so dass eine Überexpression in Tumoren mit einem unkontrollierten Wachstum der Tumorzellen und einer verstärkten Metastasenbildung assoziiert wird (Dutta \& Maity, 2007). Eine gleichzeitige Sekretion von $M$ CSF durch epitheliale Tumorzellen und EGF durch Makrophagen wird assoziiert mit einer gezielten Migration von Tumorzellen (Noy \& Pollard, 2014), so dass maligne Zellen vermutlich die Hochregulation des EGF-Rezeptors für Migrationszwecke nutzen oder sogar initiieren. Somit liegt nahe, dass Tumorzellen auch das umgebende Gewebe derartig manipulieren, dass ihre Migration und Invasion begünstigt wird.

Unterschiedliche Genexpressionsprofile eines Organs sollten bei der Therapie von Metastasen berücksichtigt werden. Denn eine tumorinhibierende Wirkung im Tumorgewebe könnte im umgebenden Organgewebe tumorfördernde Faktoren stimulieren, so dass die Invasion und Progression maligner Zellen stimuliert wird. Dieser scheinbare Gegensatz trifft insbesondere auf die Rolle der Makrophagen zu, die im nächsten Abschnitt diskutiert wird. 


\subsection{Natur der Makrophagen mit zweischneidiger Interaktion}

Im Tumorstroma sind Makrophagen die am häufigsten vorkommenden Immunzellen (Pollard, 2004; Qian \& Pollard, 2010) und haben somit einen erheblichen Einfluss auf die Tumorentstehung und -progression (Hao et al., 2012; Solinas et al., 2009). Ihre hohe Anzahl in soliden Tumoren korreliert mit einer hohen Dichte an Blutgefäßen und mit der Tumorprogression (Bingle et al., 2002; Mantovani et al., 2003). In Mamma- und Bronchialkarzinomen korreliert eine hohe Anzahl an M2 Makrophagen mit einer schlechten Prognose und fortschreitender Erkrankung (Lewis \& Pollard, 2006; Zhang et al., 2011). In Kolorektalkarzinomen wird eine hohe M1 Dichte mit weniger Metastasen und erhöhten Überlebensraten assoziiert (Bögels et al., 2012). Folglich liegt eine klinische Relevanz der Makrophagenpolarisation vor. Im Zusammenhang mit CRC-induzierten Metastasen lassen sich jedoch keine eindeutigen Korrelationen erkennen, weshalb im Fokus dieser Arbeit die Rekrutierung und das Kolonisierungsverhalten von Makrophagenphänotypen stand. Da die Leber das Hauptzielorgan für das metastasierende CRC darstellt, ist das Wissen und das Verstehen der Tumorimmunbiologie und der Makrophagenpolarisation als prognostischer Faktor von besonderer Bedeutung.

\subsubsection{Assoziation der Tumorprogression mit dem Zytokinprofil der Metastasen und der Mikroumgebung}

Die Genexpressionsprofile ohne Bereinigung des Leberhintergrundes spiegeln sehr gut die komplexe, vielschichtige Interaktion und den wechselseitigen Einfluss zwischen Tumorzelle und Mikroumgebung wieder. Gene, die im Gegensatz zur Zelllinie im Tumorgewebe (Tumorkern und -rand) hochreguliert vorliegen, sind insbesondere in die Gruppe der immunregulatorischen Faktoren einzuordnen. Dazu gehören u.a. die Makrophagengene CD68, CD206 und F4/80, die Zytokine CSF1 (M-CSF), IL-1- $\beta, I L-10$ und $I L-18$ sowie der Chemokinrezeptor CXCR4. Angiogenesefördernde Komponenten wie Integrine (ITGA6, ITGB3) und VEGF-A sowie proteolytische Enzyme wie MMP-7, MMP-9 und MMP-2 sind ebenfalls als Mediatoren der Tumorprogression zu erwähnen.

Durch eine rege Interaktion werden kaskadenartig immunregulatorische Prozesse initiiert (Abb. 3.17): eine verstärkte Expression des $N F k B$ Gens wird mit einer M1 Aktivierung assoziiert, die schließlich in einer hochregulierten Expression der M1-spezifischen Marker CD80 und CD86 resultiert (Tugal et al., 2013); die M1 Expression korreliert mit einer erhöhten Expression der pro-inflammatorischen Zytokine $I L-1-\beta$ und $I L-18$, die eine antigenspezifische 
Antwort von T-Helfer-Zellen initiieren. Gleichzeitig nutzen CMT-93 Zellen ihre ohnehin hohe CSF1 Expression, um Monozyten aus dem Blut zu rekrutieren. Regulatorische T-Helferzellen, Fibroblasten und neoplastische Zellen des Tumorgewebes schütten in Folge dessen vermehrt TGF $\beta$ und $I L-10$ aus, so dass Makrophagen zum M2 Phänotypen differenzieren (Allavena et al., 1998; Solinas et al., 2009); diese lassen sich schließlich anhand der Gene CD163 und CD206 (MRC1) identifizieren. Eine bevorzugte Expression von MMP-2 und MMP-9 in M2Makrophagen wurde von Heusinkveld \& van Der Burg beschrieben, die an einer proteolytischen Degradation des ECM und somit an einem invasiven Tumorwachstum beteiligt sind (Heusinkveld \& van Der Burg, 2011). Bei der Initiation des Tumorwachstums ist der sogenannte „angiogenic switch“ von zentraler Bedeutung; der Vorgang wird vor allem von M2 Makrophagen reguliert, indem diese proangiogene Faktoren wie VEGF-A sezernieren, so dass der wachsende Tumor anhand eines tumorassoziierten Gefäßsystems versorgt wird (Baeriswyl \& Christofori, 2009; Lin et al., 2006). VEGF-A ist in der vorliegenden Arbeit sowohl im Tumor als auch im umliegenden Gewebe hochreguliert, so dass die Dissemination und Migration maligner Zellen begünstigt wird. Chemokine und ihre Rezeptoren sind ebenfalls hervorzuheben, da sie die Tumormikroumgebung entscheidend formen, indem sie an Prozessen wie der Zellproliferation, -überleben, Angiogenese und metastatischen Ausdehnung des Tumors beteiligt sind (Van den Eynden et al., 2013). Beispielsweise wird eine hohe Expression von CXCR4 und CXCL12 im kolorektalen Primärtumor assoziiert mit einer erhöhten Wahrscheinlichkeit von Lebermetastasen und einer schlechten Patientenprognose (Kim et al., 2005; Murakami et al., 2013). Während CXCR4 hier vor allem im Tumorgewebe verstärkt exprimiert wird, ist CXCL12 fast ausschließlich im tumorumgebenden Gewebe vorzufinden; der Chemokinligand wird dabei höchstwahrscheinlich von Leber sinusoidalen Endothelzellen, Kupfferzellen und Ito-Zellen sezerniert und ist mit CXCR4 ein entscheidender Mediator der Extravasation von Tumorzellen (Gassmann et al., 2009; Matsusue et al., 2009). Diese Interaktion spricht für einen wechselseitigen Einfluss zwischen Tumorzellen und Mikroumgebung und würde die zuvor beschriebene Theorie stützen, dass die lokale Expression von Chemokinliganden Tumorzellen chemotaktisch in bestimmte Organe leitet (Muller et al., 2001; Zlotnik, 2004).

\subsubsection{Tendenziell M2 geprägter Charakter der CMT-93 induzierten Lebermetastasen}

Die Analyse der lokalen Expression von M1- (CD80, CD86) und M2- (CD163, CD206) spezifischen Genen indiziert, dass im Tumorgewebe eine Mischpopulation bestehend aus M1 und M2 Makrophagen vorliegt (Abb. 3.18). Beim Vergleich beider Phänotypen fällt auf, dass 
im tumorumgebenden Gewebe eine erhöhte $C D 163$ und CD206 Expression detektierbar ist. Gemeinsam mit der leicht erhöhten Expression von CD206 im Tumor würde dies tendenziell für einen eher M2 geprägten Charakter der Lebermetastasen sprechen, der eine Tumorprogression durch Zellinvasion und -migration in das umliegende Gewebe fördern würde. Eine eindeutige lokale Separation der Phänotypen liegt jedoch nicht vor. Begünstigt wird diese Mischung durch die wechselseitigen Einflüsse zwischen Tumorzelle und Mikroumgebung sowie der stark ausgeprägten Plastizität der Makrophagen, die schließlich in einer Aktivierung des M1 und M2 Phänotypen resultieren. Die allgemeinen Makrophagenmarker F4/80, CD68 und CD11b wurden ebenfalls verstärkt im Tumor exprimiert. Ein deutlich größerer Expressionsunterschied zwischen Tumorgewebe und tumorumgebendem Gewebe bezüglich der CD68 und CD11b Expression deutet eine Assoziation dieser Gene mit dem Tumor und eine verstärkte Rekrutierung von $C D 68^{+}$und $C D 11 b^{+}$Zellen in das metastatische Gewebe an. CD68 markiert sowohl M1 als auch M2 Makrophagen, eignet sich jedoch auch insbesondere zur Identifizierung von TAMs im Tumorgewebe, die tendenziell einen M2 Phänotypen aufweisen (Solinas et al., 2009; Qian \& Pollard, 2010). Holness und Simmons haben bereits 1993 beschrieben, dass CD68 wohlmöglich an gewebe- und organspezifische Lektine oder Selektine bindet, um Makrophagensubtypen in bestimmte Gewebe/Organe zu leiten (Holness \& Simmons, 1993). Qian et al. zeigten, dass $C D 11 b^{+}$Makrophagen migrierende Brustkrebszellen erkennen und sie bei der Invasion in das Zielgewebe unterstützen (Qian et al., 2009). Möglicherweise nutzen hier CMT-93 Zellen beide Membranproteine für eine effektive Leberinvasion und eine Kolonisation der Metastasen mit tumorstimulierenden Makrophagen. Eine immunhistochemische Analyse in der vorliegenden Arbeit bestätigte die verstärkte Lokalisation der allgemeinen Makrophagenmarker im Tumorgewebe, wobei CD11b tatsächlich tumorspezifisch zu sein scheint mit vereinzelten gefärbten Zellen im umgebenden Gewebe, während CD68 und F4/80 auch stark im tumorumgebenden Bereich lokalisiert vorzufinden ist. $C D 11 b$ wird von Monozyten, Makrophagen und Granulozyten exprimiert, während F4/80 und CD68 vor allem in Kupfferzellen vorzufinden sind, weshalb hier gefärbte Zellen in großer Anzahl auch im tumorumgebenden Gewebe nachgewiesen wurden. $C D 86^{+}$ Zellen waren ebenfalls fast ausschließlich im Tumor vorzufinden. Vermutlich wird hier die CD86 Expression auf der Oberfläche von M1 Makrophagen hochreguliert, so dass der Kostimulator gemeinsam mit CD80 die Liganden CD28 und CTLA-4 auf der Oberfläche von THelfer-Zellen bindet und somit pro-inflammatorische (tumorhemmende) Reaktionen initiiert. T-Helfer-Zellen sezernieren daraufhin verstärkt Interleukine, insbesondere $I L-6$, welches hier im Tumorkern hochreguliert vorliegt, und eine Aktivierung von M2 
Makrophagen zur Folge hat. Eine Bindung an CTLA-4 hingegen führt zu einer Herunterregulation der Immunantwort, so dass die Tumorprogression ebenfalls begünstigt wird. Die M2 Marker CD163 und CD206 zeigten immunhistochemisch ein unterschiedliches Profil. Die RNA Sequenzierung zeigte, dass CD163 überwiegend im tumorumgebenden Gewebe exprimiert wird. In den frühen Metastasierungstadien an Tag 3 und Tag 14 bestätigte sich dies auch in der IHC, an Tag 28 war jedoch auch eine sehr starke Expression im Tumor vorzufinden. Eine mögliche Erklärung dafür könnte sein, dass CD163 überwiegend von Makrophagen exprimiert wird, die in einer späten Phase der Inflammation rekrutiert bzw. aktiviert vorliegen (Van den Heuvel et al., 1999; Fabriek et al., 2005; Onofre et al., 2003). Denn in frisch rekrutierten Makrophagen ist eine CD163 Expression kaum messbar (Backe et al., 1991; Kowal et al., 2011; Sulahiam et al., 2000). CD206 ${ }^{+}$Zellen waren immunhistochemisch in allen Metastasierungsstadien nur in geringer Anzahl im Tumor vorzufinden, während die Expression im umliegenden Gewebe mit fortschreitender Metastasierung stark hochreguliert wurde. CD206 wird neben Makrophagen auch von Epithel- und Endothelzellen der Leber exprimiert; in verschiedenen Studien wurden in pathologischen Geweben TAMs mit M2 Polarisation identifiziert, die $C D 206^{+}$Zellen in hoher Anzahl umfassten (Allavena et al., 2010; Azad et al., 2014). Eine mögliche Erklärung für dieses abweichende Ergebnis von der RNA Sequenzierung könnte sein, dass der Antikörper zusätzlich Epithel- und Endothelzellen der Leber und eine kleine Anzahl von Monozyten detektiert hat, die im Zuge der Metastasierung aus der Blutzirkulation rekrutiert wurden (Martinez-Pomares, 2006). Die Hochregulation von CCL7 und MMP-2 indiziert eine Mobilisierung von Monozyten (Abb. 3.17).

Anhand einer $q R T$-PCR Analyse der Gesamtleber konnte insbesondere im späten Stadium der Metastasenformation (Tag 28) der tumorspezifische Einfluss auf die Genexpression nachgewiesen werden. An Tag 3 und Tag 14 waren alle Makrophagengene sowohl in Shamoperierten als auch in Metastasen-tragenden Lebern zwar deutlich hochreguliert, da durch den Eingriff an sich Monozyten/Makrophagen rekrutiert, polarisiert und Entzündungsreaktionen initiiert werden, doch lagen die Expressionslevel in Metastasentragenden Lebern deutlich höher vor. Eine Reduktion der Genexpression an Tag 14, vor allem in Metastasen-tragenden Lebern, deutet eine Abschwächung der Immunantwort an, die von Tumorzellen vermutlich für die weitere Invasion und Migration genutzt wird. Durch die Produktion von anti-inflammatorischen Zytokinen verhindern sie eine adäquate Immunantwort, da sie die T-Zell-Proliferation inhibieren (Mosser, 2003). Die Hochregulation aller Gene in Metastasen-tragenden Lebern an Tag 28 kann als tumorspezifischer Einfluss interpretiert werden. Im Zuge der Metastasenformation nehmen CD11b, CD80 und CD206 eine exponierte Rolle ein, da sie am stärksten exprimiert werden. Die Expression des M1 Markers 
CD80 und des M2 Markers CD206 im frühen Metastasierungsstadium könnte so interpretiert werden, dass zu diesem Zeitpunkt M1 und M2 Phänotypen noch im Gleichgewicht sind und aufgrund des Eingriffs sowohl pro- als auch anti-inflammatorische Reaktionen initiiert werden (Kapitel 4.4.1). Die konstant hochregulierte CD206 Expression und die Herunterregulation des $C D 80$ Gens bis Tag 28 indiziert zwar den tendenziell M2 geprägten Charakter der CMT-93 induzierten Lebermetastasen, der sich bereits anhand der RNA Sequenzierung angedeutet hatte; dennoch bestätigt sich auch hier das Vorhandensein einer Mischpopulation an Makrophagenphänotypen.

Für eine Validierung dieser Resultate im Rahmen folgender Experimente würde sich ein Vergleich mit Sequenzierungsdaten anbieten, die auch anhand von Proben der Gesamtleber $\mathrm{zu}$ den entsprechenden Zeitpunkten generiert wurden. Um den Status der Makrophagenpolarisation noch genauer $\mathrm{zu}$ analysieren, wird ergänzend $\mathrm{zu}$ den Makrophagengenen eine qRT-PCR Analyse von Genen vorgeschlagen, die spezifisch sind für pro- und anti-inflammatorische Eigenschaften. Für den M1 Phänotypen würden sich die Zytokine IL-1 $\beta, I L-12, I L-13$ und TNF- $\alpha$, die Chemokine CXCL9 und CXCL10 sowie interferonregulatorische Faktoren (IRF-1, -5, -8) anbieten (Ying et al., 2013; Mantovani et al., 2013; Murray et al., 2014). Der M2 Phänotyp könnte anhand der Expression von IL-10, CCL4, CCL17, Arginase und CD204 überprüft werden (Bronte \& Zanovello, 2005; Murray et al., 2014; Peiser \& Gordon, 2001).

\subsubsection{Tumorstimulierender Einfluss von M2 konditioniertem Medium auf CMT-93 Zellen}

Eine Analyse des Expressionsprofils der polarisierten Makrophagen bestätigte, dass es sich bei den Phänotypen nicht um eine einheitliche Zellpopulation, sondern um eine Mischpopulation mit phänotypischen Ausprägungen und Tendenzen handelt. Folglich lassen sie sich nicht eindeutig voneinander separieren; je nach Stimuli sind jedoch M1- und M2spezifische Merkmale bzw. Genexpressionsmuster detektierbar, so dass eine Generierung von M1 und M2 Makrophagen grundsätzlich möglich ist.

Kokulturversuche von CMT-93 Zellen mit konditionierten Medien der Makrophagenphänotypen führten je nach Polarisationserfolg der Makrophagen zu divergierenden Resultaten bezüglich der Vitalität von Tumorzellen. M2 konditionierte Medien aus zwei Isolationen verursachten eine Steigerung der Zellvitalität, was im Einklang ist mit den tumorfördernden Eigenschaften des M2 Phänotyps. Dies indiziert, dass nicht der direkte, physische Kontakt zwischen Tumorzelle und Makrophage essentiell ist für die 
Interaktion. Ein indirekter Kontakt über Faktoren, die durch M2 bzw. M1 Makrophagen in das Medium sezerniert werden, wie z.B. Zytokine, Wachstumsfaktoren, Chemokine oder Hormone, sind ausreichend, um die Vitalität der Tumorzellen zu fördern bzw. zu hemmen. Folglich bietet sich in diesem Zusammenhang eine weitere Untersuchung der konditionierten Medien an, um phänotypisch sezernierte Bestandteile und Faktoren zu identifizieren. Der Vergleich der Medien aus beiden Isolationen zeigte jedoch auch, dass das Ausmaß dieses Effekts und die Dauer bis zum Effekteintritt stark vom Erfolg der Makrophagenpolarisation und dem Spendertier abhängig ist. Technische bzw. methodische Ursachen konnten aufgrund des identischen Isolations- und Polarisationsprotokolls ausgeschlossen werden. Je nachdem, wie stark Monozyten bzw. Makrophagen auf Stimuli reagierten, funktionierte die Differenzierung von Monozyten zu Makrophagen und die anschließende Polarisation zum M1 und M2 Phänotypen unterschiedlich gut, so dass signifikante Unterschiede insbesondere bezüglich der M2 Marker CD163 und CD206 messbar waren (Kapitel 4.9).

Molekularbiologische Genexpressionsanalysen bestätigten insgesamt den positiven Einfluss des M2 konditionierten Mediums auf Tumorzellen. Es konnte jedoch ebenfalls gezeigt werden, dass eine fast komplette Entfernung des Serums aus dem Medium einen mesenchymalen und somit invasiven Charakter der Zellen hervorruft. Die erhöhte NFkB1, Stat3 und Cyclin D1 Expression in CMT-93 Zellen mit M1 konditioniertem Medium impliziert eine Hochregulation von immunregulatorischen und proliferativen Prozessen in Tumorzellen, welches nicht den tumorinhibierenden Eigenschaften der M1 Makrophagen entspricht. Höchstwahrscheinlich hat hier die Polarisation Richtung M1 nicht gut funktioniert oder die verwendeten Marker sind nicht ausreichend für eine Identifikation. Das M2 Medium verstärkte hingegen die Aggressivität und Proliferationsfähigkeit der Tumorzellen offensichtlich etwas mehr, da hier vor allem CD44, MMP-7 und Ki-67 hochreguliert wurden.

\subsection{Einfluss verschiedener Faktoren auf die Makrophagenpolarisation}

Die Makrophagenpolarisation wird durch eine Reihe von Faktoren stark beeinflusst, so dass auf zell- und molekularbiologischer Ebene nur Tendenzen bzw. auch unerwartete Resultate generiert werden. Die Differenzierung von Monozyten zu Makrophagen wurde anhand einer Inkubation mit M-CSF induziert, welches das aktuelle und prädominante in vitro System zur Generierung von Makrophagen darstellt (Murray et al., 2014). Während M-CSF mit der Polarisation von Makrophagen Richtung M2 Phänotyp assoziiert wurde, betrachtete man GMCSF als Initiator der M1 Polarisation. Studien verdeutlichten, dass eine derartig eindeutige Assoziation von $M-C S F$ mit M2 Makrophagen bzw. GM-CSF mit M1 Makrophagen nicht möglich 
ist; dennoch führen verschiedene Stimuli transkriptomweit zu signifikanten Unterschieden in Makrophagen (Joshi et al., 2014; Fleetwood et al., 2009; Murray et al., 2014). Eine Transkriptomanalyse humaner Makrophagen zeigte, dass eine Aktivierung durch 28 verschiedene Stimuli, alleine oder in Kombination, in 49 verschiedenen Genexpressionsclustern resultierte, die aus 27 - 884 Genen bestanden. Basierend auf diesen Daten konnten die Autoren sieben weitere vom M1/M2 Modell abweichende Funktionszustände der Makrophagen identifizieren (Xue et al., 2014; Niedobitek et al., 2015). Neben dem verwendeten Stimulus gestaltet auch der Einfluss des Maushintergrundes die aktuelle Datenlage noch komplexer. Während Balb/c Mäuse eher M2-dominante Immunantworten initiieren und somit eine erhöhte Krebshäufigkeit aufweisen, wird der C57BL/6 Mausstamm als eher M1-geprägt betrachtet, so dass verminderte Krebsraten vorzufinden sind (Mills et al., 2016). Des Weiteren wurden in beiden Mausstämmen große Unterschiede bezüglich ihrer Argininverwertung identifiziert. Sans-Fons et al. konnten nachweisen, dass in C57BL/6 Mäusen eine Deletion in der Promoterregion des Slc7a2 Gens besteht, welches das Schlüsselgen für den Arginintransport in Makrophagen darstellt. Folglich ist der Arginintransport in diesen Mäusen beeinträchtigt und eingedämmt (SansFons et al., 2013). Das Protein wird für das Wachstum und die Polarisation der Makrophagen benötigt. Infolge der Interaktion mit Zytokinen nehmen Makrophagen verstärkt Arginin auf; $I F N-\gamma$ und LPS induzieren die Expression von NOS2, so dass Arginin zu NO metabolisiert wird, welches toxisch und antimikrobiell ist (M1 Phänotyp). Anti-inflammatorische Zytokine hingegen katalysieren mit Hilfe von Arginase I die Umsetzung von Arginin zu Ornithin, dessen Abbauprodukte für Zellproliferations- und Regenerationsprozesse von Bedeutung ist (M2 Phänotyp). Auf Grundlage dessen wurde schließlich das M1/M2 Modell von Mills et al. definiert (Mills et al., 2000). Die Deletion in C57BL/6 Mäusen führt nun dazu, dass unabhängig vom Stimulus weniger Arginin in Makrophagen gelangt. Folglich wird auch die Differenzierung und Polarisation von Makrophagen stark beeinträchtigt. Dies würde erklären, weshalb polarisierte Makrophagen im Rahmen dieser Arbeit nur phänotypische Tendenzen entwickelten und keine eindeutige Polarisation möglich war. In der Studie von Sans-Fons et al. resultierte eine Leishmaniose in Balb/c Mäusen in einem wesentlich akuteren Krankheitsverlauf als in C57BL/6 Mäusen, was im Kontext der Karzinogenese ebenfalls zu divergierenden Resultaten führen könnte. Da die CMT-93 Zelllinie auf einen C57BL Substamm zurückzuführen ist, war ein Wechsel zum Balb/c Mausstamm in diesem Rahmen nicht möglich.

In der vorliegenden Arbeit ergibt sich daraus, dass der Erfolg und das Ausmaß der Polarisation sehr stark vom verwendeten Stimulus und der Quelle, aus der die Makrophagen 
stammen, abhängig ist. Eine Isolation von Monozyten aus Balb/c Mäusen oder der Einsatz von anderen Zytokinen hätte möglicherweise wiederum in einem anderen Genexpressionsprofil resultiert. Aufgrund des breiten Spektrums und den unzähligen Möglichkeiten zur Aktivierung und Polarisation von Makrophagen, schlugen renommierte Makrophagenexperten um Murray et al. 2013 einen Konsens vor, wonach statt dem allzu einfach zusammengefassten M1/M2 Modell Details zum Isolationsprotokoll genannt werden sollten, um generierte Daten und Resultate besser vergleichen zu können. Eine Auswahl dieser Angaben betreffen u.a. den Mausstamm, die Monozytenquelle/das Isolationsorgan, die Anzahl isolierter Zellen, die Mediumzusammensetzung, verwendete Zellkulturflaschen/schalen und Zytokine (Quelle, Konzentration, Inkubationsdauer) (Murray et al., 2013).

Die ausgeprägte Plastizität der Makrophagen und die schwierige Separation der Phänotypen resultiert in einer vielschichtigen Interaktion mit Tumorzellen, die je nach Tumorentität zu unterschiedlichen Ergebnissen führen kann. Eine Reihe derartiger Kokulturversuche mit verschiedenen Tumorentitäten wurde bereits durchgeführt (Cho et al., 2012; Pahl et al., 2014; Engström et al., 2014; Sprinzl et al., 2015), doch die sehr unterschiedlichen und teilweise individuell angepassten Protokolle erschweren die Interpretation der Resultate. Durch ein vertieftes Verständnis und Wissen über das Spektrum und die Polarisation der Makrophagen, könnten bessere/eindeutigere Marker generiert werden, so dass eine exakte Identifikation und Separation der Phänotypen ermöglicht wird.

\subsection{Ausblick}

Das CMT-93 induzierte Lebermetastasenmodell bietet somit den Vorteil in einem immunkompetenten System die Metastasenformation und die Interaktion zwischen Tumorzellen und ihrer Mikroumgebung zu analysieren. So wird die Identifikation von Faktoren und Prozessen ermöglicht, die relevant sein können für den von Paget beschriebenen Organotropismus (Paget, 1889) und die Entstehung von Lebermetastasen. Nichtsdestotrotz sollten die Gegebenheiten des C57BL/6 Mausstammes (M1 geprägtes Zytokinprofil, eingeschränkter Arginintransport) insbesondere im Zusammenhang mit immunregulatorischen Prozessen nicht außer Acht gelassen werden. Die generierten Daten der Zelllinie und der murinen Metastasen werden nun in humanen Proben des MetastaSys Konsortiums verifiziert und zur Formulierung prädiktiver Modelle der Metastasierungsvorgänge genutzt.

Aufgrund individueller Unterschiede der Mäuse, sollten die Daten, die im Rahmen dieser Arbeit generiert wurden, anhand einer größeren Kohorte rigoros validiert werden. In diesem 
Kontext könnten anhand von weiteren, extensiven Genexpressionsanalysen eventuell Gene identifiziert werden, die bisher im Zusammenhang mit der CRC Progression nicht bekannt waren und als prädiktive und prognostische Biomarker genutzt werden könnten. Des Weiteren sollten auf bioinformatischer Ebene Algorithmen und Selektionskriterien (Leberbereinigung, Normalisierung, Fold change, Signifikanzwert etc.) validiert und ggf. Tests implementiert werden, um eine hohe Genauigkeit und Reproduzierbarkeit der Daten zu erreichen.

Aufgrund des breiten Spektrums und der ausgeprägten Plastizität der Makrophagen muss die Auswahl an Markern erweitert werden, um Phänotypen klarer separieren zu können. Doppelfärbungen anhand dieser Marker würden sich für eine genaue Lokalisation von M1 und M2 Makrophagen anbieten. Die Zusammensetzung des konditionierten Mediums kann anhand eines ELISA-Verfahrens untersucht und der Einfluss des Zytokinprofils auf Tumorzellen somit genauer verifiziert werden. Ergänzend dazu war ein weiteres Kokultursystem in Planung, welches methodisch bisher noch nicht optimiert werden konnte. Nicht-polarisierte Makrophagen wurden hierfür mit Homogenaten von gesunden oder Metastasen-tragenden Lebern sowie mit CMT-93 konditioniertem Medium inkubiert, um auf zell- und molekularbiologischer Ebene das Genexpressionsprofil von sogenannten „tumoreducated" Makrophagen untersuchen zu können (Pollard, 2004).

Für Validierungszwecke wären weitere in vivo Experimente denkbar, wie beispielsweise eine Isolation von TAMs aus CMT-93 kolonisierten Lebern zur Überprüfung ihres Genexpressionsprofils, eine Depletion von Kupfferzellen durch Clodronat-Liposomen, um den Einfluss von leberresidierenden Makrophagen auf die Tumorprogression untersuchen zu können, sowie eine Implantation von Tumorzellen gemeinsam mit M2 Makrophagen, bei der ein verstärktes Tumorwachstum zu erwarten wäre.

Im Rahmen des MetastaSys Konsortiums wurden CMT-93 Zellen und die Mammakarzinomzellinie 410.4 genetisch modifiziert, so dass ein Knockdown oder eine Überexpression von EGFR bzw. $\beta$-catenin erzielt werden sollte, um den Einfluss des EGFR und Wht Signalweges auf den Metastasierungserfolg untersuchen zu können. Auf diese Weise soll eruiert werden, wie sich genetische Modifikationen auf das Genexpressionsprofil der genannten Tumorzelllinien und der entsprechenden Metastasen auswirken. Ein Knockdown und eine Überexpression von EGFR konnte sowohl in 410.4 als auch in CMT-93 Zellen etabliert werden. Eine kongruente Modifikation von $\beta$-catenin hatte einen erheblichen Einfluss auf die Zellviabilität, so dass keine stabil transfizierte Zelllinie generiert werden konnte (Arackal, 2016). Die ersten Implantationsversuche mit EGFR überexprimierenden 410.4 respektive CMT-93 Zellen resultierten wider Erwarten in einem inhibierten 
Tumorwachstum. Lässt sich dieses Resultat in zukünftigen in vivo Experimenten und auf molekularbiologischer Ebene bestätigen, müsste die Therapie mit anti-EGFR Antikörpern grundsätzlich überdacht werden. 


\section{$5 \quad$ Fazit}

Mit vorrangig bioinformatischen und molekularbiologischen Methoden wurde gezeigt, dass CMT-93 Zellen im Zuge der Metastasierung mit ihrem Genexpressionsprofil auf die Mikroumgebung reagieren; dadurch steigern sie ihr Invasions- und Metastasierungspotential und erhalten dabei molekulare Eigenschaften der Zelllinie. Dies impliziert, dass die Metastasenformation durch CMT-93 Zellen nach dem linearen Progressionsmodell erfolgt (siehe Kapitel 1.4). Die Leber als passende Nische ermöglicht offensichtlich eine genetische Adaptation der Tumorzellen an die Mikroumgebung, um sich einen Überlebenssvorteil zu verschaffen. Metastase und Zelllinie weisen dennoch aufgrund des gemeinsamen Ursprungs Ähnlichkeiten in ihrem Genexpressionsprofil auf.

Mittels statistischer Analysen wurden basierend auf einer Selektionsliste 32 signifikant exprimierte Gene und drei relevante Signalwege identifiziert, die eine hohe Korrelation mit der kolorektalen Karzinogenese und der Aggressivität von metastasierten Tumorzellen aufweisen. Die Interaktion zwischen Tumorzellen und Mikroumgebung führte zu einer erheblichen Veränderung des Genexpressionsprofils der Metastasen im Vergleich zur originären Zelllinie, was bei der Therapie von Lebermetastasen berücksichtig werden sollte. Eine Auswahl dieser Gene konnte anhand einer qRT-PCR Analyse verifiziert werden (z.B. MMP-7, Krt20, Casp-3). Ebenfalls konnte gezeigt werden, dass Metastasen-tragende Lebern aus einer M1 und M2 Makrophagenpopulation bestehen, allerdings einen tendenziell M2 geprägten Charakter aufweisen, der die invasiven Eigenschaften stimuliert. Durch die Quantifizierung und Lokalisation der Makrophagenphänotypen wurde auch ersichtlich, dass nicht explizit ihre Quantität oder spezifische Lokalisation, sondern eher das Zytokinprofil des Tumors und der Mikroumgebung und damit einhergehend der Polarisationsstatus der Makrophagen zum Metastasierungserfolg beiträgt. Wohlmöglich muss kein signifikanter Unterschied zwischen der Anzahl von M1 und M2 Makrophagen vorliegen; das Vorhandensein des M2 Phänotyps in Kombination mit einer Hochregulation von Genen wie u.a. Vimentin, CD44, MMP-7 und NFkB1 ist möglicherweise schon hinreichend für ein erhöhtes Metastasierungspotential. Da allerdings die Makrophagenpolarisation in C57BL/6 Mäusen offensichtlich beeinträchtigt ist, sollte ehrlicherweise erwähnt werden, dass dieses in vivo Modell möglicherweise kein optimales System zur Untersuchung des M1/M2 Modells darstellt. Gleichzeitig bekräftigt es dennoch unabhängig von der Makrophagenpolarisation den erheblichen Einfluss des individuellen Immunsystems bzw. der Nische. Denn die makroskopische Auswertung, das Gewicht und die molekularbiologische Analyse der Lebern einzelner Mäuse resultierte teilweise in großen Standardabweichungen. Diese Unterschiede 
beruhen höchstwahrscheinlich auf der Interaktion zwischen Tumorzellen und ihrer Mikroumgebung und könnten zudem teilweise durch die Immunantwort einzelner Mäuse beeinflusst sein. Das Immunsystem ist pro Individuum einzigartig und stellt eine Art Fingerabdruck dar. Es kann einen erheblichen Einfluss auf die Invasion und Ausbreitung maligner Zellen sowie die Entstehung eines stabilen epithelialen Zellverbandes haben und die einzelnen beteiligten Schritte unterschiedlich stark inhibieren. Der ineffiziente Vorgang der Metastasierung ist ebenfalls $\mathrm{zu}$ berücksichtigen. Wenn Tumorzellen infolge von mechanischem Druck oder der Immunzellantwort bereits die Blutzirkulation nicht überleben, keine erfolgreiche Extravasation in das hepatische Milieu oder kein Zellwachstum im Zielorgan initiieren können, sinkt die Wahrscheinlichkeit einer erfolgreichen Metastasierung. Auch die Zusammensetzung der Mikroumgebung trägt entscheidend zu diesem Erfolg bei; finden Tumorzellen keine passende Nische, erfolgt keine Organkolonisation (Nguyen et al., 2009). Verlagert sich das Gleichgewicht zwischen tumorfördernden und -inhibierenden Faktoren (z.B. Zytokine) auf die eine oder andere Seite, könnte sich das ebenfalls erheblich auf den Grad der Metastasierung auswirken. Die exponierte Rolle des Zytokinprofils konnte anhand der Kokulturversuche bestätigt werden, da ein indirekter, nicht-physischer Kontakt zwischen Tumorzellen und M2 Makrophagen offensichtlich ausreicht, um die Vitalität maligner Zellen zu steigern.

Folglich kann in der vorliegenden Arbeit bestätigt werden, dass die Initiation der Metastasenformation, ihr Ausmaß und ihre weitere Ausbreitung nicht nur von den Eigenschaften maligner Zellen, sondern auch von den Gegebenheiten des Individuums und der Mikroumgebung des Zielorgans abhängig ist (Seed-and-Soil-Theorie). 


\section{Literaturverzeichnis}

Abdel-Misih SR, Bloomston M (2010): Liver anatomy. Surg Clin North Am 90 (4): S. 634-653. DOI: 10.1016/jsuc.2010.04.017.

Adachi Y, Yamamoto H, Itoh F, Hinoda Y, Okada Y, Imai K (1999): Contribution of matrilysin (MMP-7) to the metastatic pathway of human colorectal cancer. Gut 45 (2): S. 252-258.

Alexa A, Rahnenfuhrer J (2016): topGO: Enrichment Analysis for Gene Ontology. R package version 2.24.0.

Al-Mehdi AB, Tozawa K, Fisher AB, Shientag L, Lee A, Muschel RJ (2000): Intravascular origin of metastasis from the proliferation of endothelium-attached tumor cells: a new model for metastasis. Nat Med 6 (1): S. 100-102. DOI: $10.1038 / 71429$.

Andreyev HJ, Norman AR, Cunningham D, Oates JR, Clarke PA (1998): Kirsten ras mutations in patients with colorectal cancer: the multicenter "RASCAL" study. J Natl Cancer Inst. 90 (9): S. 675-684.

Allan AL, Vantyghem SA, Tuck AB, Chambers AF (2006): Tumor dormancy and cancer stem cells: implications for the biology and treatment of breast cancer metastasis. Breast Dis 26: S. 87-98.

Allavena P, Chieppa M, Bianchi G, Solinas G, Fabbri M, Laskarin G, Mantovani A (2010): Engagement of the mannose receptor by tumoral mucins activates an immune seuppressive phenotype in human tumorassociated macrophages. Clin Dev Immunol 2010: S.5471-5479. DOI: 10.1155/2010/547179.

Allavena P, Piemonti L, Longoni D, Bernasconi S, Stoppacciaro A et al. (1998): IL-10 prevents the differentiation of monocytes to dendritic cells but promotes their maturation to macrophages. Eur J Immunol 28 (1): S. 359-369. DOI: 10.1002/(SICI)1521-4141)199801)28:01\&\#60;359::AIDIMMU359\&\#62;3.0.CO;2-4.

Allavena P, Sica A, Solinas G, Porta G, Mantovani A (2008): The inflammatory micro-environment in tumor progression: the role of tumor-associated macrophages. Crit Rev Oncol Hematol 66 (1): S. 1-9. DOI: 10.1016/j.critrevonc.2007.07.004.

Arackal J (2016): Analyse molekularer Marker und Signalwege in soliden Tumorzelllinien und ihre Bedeutung für die Tumorprogression und Metastasierung. http://hdl.handle.net/11858/00-1735-00000028-8768-A.

Arnold CE, Whyte CS, Gordon P, Barker RN, Rees AJ, Wilson HM (2014): A critical role for suppressor of cytokine signaling 3 in promoting M1 macrophage activation and function in vitro and in vivo. Immunology 141 (1): S. 96-110. DOI: 10.1111/imm.12173. 
Austyn JM, Gordon S (1981): F4/80, a monoclonal antibody directed specifically against the mouse macrophage. Eur J Immunol 11 (10): S. 805-815. DOI: 10.1002/eji.1830111013.

Azad AK, Rajaram MV, Schlesinger LS (2014): Exploitation of the Macrophage Mannose Receptor (CD206) in Infectious Disease Diagnostics and Therapeutics. J Cytol Mol Biol 1 (1): S. pii 1000003. DOI: 10.13188/2325-4653.1000003.

Bacac M, Stamenkovic I (2008): Metastatic cancer cell. Annu Rev Pathol 3: S. 221-247. DOI: 10.1146/annurev.pathmechdis.3.121806.151523.

Backe E, Schwarting R, Gerdes J, Ernst M, Stein H (1991): Ber-MAC3: new monoclonal antibody that defines human monocyte/macrophage differentiation antigen. J Clin Pathol 44 (11): S. 936-945.

Bacman D, Merkel S, Croner R, Papadopoulos T, Brueckl W, Dimmler A (2007): TGF-beta receptor 2 downregulation in tumour-associated stroma worsens prognosis and high-grade tumours show more tumour-associated macrophages and lower TGF-beta1 expression in colon carcinoma: a retrospective study. BMC Cancer 7: 156. DOI: 10.1186/1471-2407-7-156.

Baeriswyl V, Christofori G (2009): The angiogenic switch in carcinogenesis. Semin Cancer Biol 19 (5): S. 329-339. DOI: 10.1016/j.semcancer.2009.05.003.

Bailey C, Negus R, Morris A, Ziprin P, Goldin R et al. (2007): Chemokine expression is associated with the accumulation of tumour associated macrophages (TAMs) and progression in human colorectal cancer. Clin Exp Metastasis 24 (2): S. 121-130. DOI: 10.1007/s10585-007-9060-3.

Balkwill F (2004): Cancer and the chemokine network. Nat Rev Cancer 4 (7): S. 540-550. DOI: $10.1038 / \mathrm{nrc} 1388$.

Barbera-Guillem E, Nyhus JK, Wolford CC, Friece CR, Sampsel JW (2002): Vascular endothelial growth factor secretion by tumor-infiltrating macrophages essentially supports tumor angiogenesis, and IgG immune complexes potentiate the process. Cancer Res 62 (23): S. 7042-7049.

Barkan D, Green JE, Chambers AF (2010): Extracellular matrix: a gatekeeper in the transition from dormancy to metastatic growth. Eur J Cancer 46 (7): S. 1181-1188. DOI: 10.1016/j.ejca.2010.02.027.

Bentrem DJ, Dematteo RP, Blumgart LH (2005): Surgical therapy for metastatic disease to the liver. Annu Rev Med 56: S. 139-156. DOI: 10.1146/annurev.med.56.082103.104630.

Bingle L, Brown NJ, Lewis CE (2002): The role of tumor-associated macrophages in tumor progression: implications for new anticancer therapies. J Pathol 196: S. 254-265. DOI: 10.1002/path.1027. 
Bissell MJ, Hines WC (2011): Why don't we get more cancer? A proposed role of the microenvironment in restraining cancer progression. Nat Med 17 (3): S. 320-329. DOI: 10.1038/nm.2328.

Bissell MJ, Radisky D (2001): Putting tumours in context. Nat Rev Cancer 1 (1): S. 46-54. DOI: 10.1038/35094059.

Bögels M, Braster R, Nijland PG, Gül N, van de Luijtgaarden W et al. (2012): Carcinoma origin dictates differential skewing of monocyte function. Oncoimmunology 1 (6): S. 798-809. DOI: 10.4161/onci.20427.

Borland G, Ross JA, Guy K (1998): Forms and functions of CD44. Immunology 93 (2): S. 139-148.

Bos JL, Fearon ER, Hamilton SR, Verlaan-de Vries M, van Boom JH, van der Eb AJ, Vogelstein B (1987): Prevalence of ras gene mutations in human colorectal cancers. Nature 327 (6120): S. 293-297. DOI: 10.1038/327293a0.

Bosetti C, Levi F, Rosato V, Bertuccio P, Lucchini F, Negri E, La Vecchia C (2011): Recent trends in colorectal cancer mortality in Europe. Int J Cancer 129 (1): S. 180-191. DOI: 10.1002/ijc.25653.

Bottazzi B, Polentarutti N, Acero R, Balsari A, Boraschi D et al. (1983): Regulation of the macrophage content of neoplasms by chemoattractants. Science 220 (4593): S. 210-212.

Bowen DG, McCaughan GW, Bertolino P (2005): Intrahepatic immunity: a tale of two sites? Trends Immunol 26 (10): S. 512-517. DOI: 10.1016/j.it.2005.08.005.

Brabletz T, Jung A, Dag S, Hlubek F, Kirchner T (1999): beta-catenin regulates the expression of the matrix metalloproteinase-7 in human colorectal cancer. 155 (4): S. 1033-1038.

Brabletz T, Jung A, Hermann K, Günther K, Hohenberger W, Kirchner T (1998): Nuclear overexpression of the oncoprotein beta-catenin in colorectal cancer is localized predominantly at the invasion front. Pathol Res Pract 194 (10): S. 701-704.

Bronte V, Zanovello P (2005): Regulation of immune responses by L-arginine metabolism. Nat Rev Immunol 5 (8): S. 641-654. DOI: 10.1038/nri1668.

Brooks SA, Lomax-Browne HJ, Carter TM, Kinch CE, Hall DM (2010): Molecular interactions in cancer cell metastasis. Acta Histochem 112 (1): S. 3-15. DOI: 10.1016/j.acthis.2008.11.022.

Burger JA, Kipss TJ (2006): CXCR4: a key receptor in the crosstalk between tumor cells and their microenvironment. Blood 107 (5): S. 1761-1767. DOI: 10.1182/blood-2005-08-3182. 
Calon A, Espinet E, Palomo-Ponce S, Tauriello DV, Iglesias M et al. (2012): Dependency of colorectal cancer on a TGF- $\beta$-driven program in stromal cells for metastasis initiation. Cancer Cell 22 (5): S. 571-584. DOI: 10.1016/j.ccr.2012.08.013.

Cardona K, Mastrodomenico P, D’Amico F, Shia J, Gönen M et al. (2013): Detailed pathological characteristics of the primary colorectal tumor independently predict outcome after hepatectomy for metastases. Ann Surg Oncol 20 (1): S. 148-54. DOI: 10.1245/s10434-012-2540-y.

Cavanaugh PG, Sloane BF, Honn KV (1988): Role of the coagulation system in tumor-cell-induced platelet aggregation and metastasis. Haemostasis 18 (1): S. 37-46.

Chambers AF, Groom AC, MacDonald IC (2002): Dissemination and growth of cancer cells in metastatic sites. Nat Rev Cancer 2 (8): S. 563-572. DOI: 10.1038/nrc865.

Chambers AF, MacDonald IC, Schmidt EE, Koop S, Morris VL, Khokha R, Groom AC (1995): Steps in tumor metastasis: new concepts from intravital videomicroscopy. Cancer Metastasis Rev 14 (4): S. 279-301.

Chew EC, Wallace AC (1976): Demonstration of fibrin in early stages of experimental metastases. Cancer Res 36 (6): S. 1904-1909.

Cho HJ, Jung JI, Lim DY, Kwon GT, Her S et al. (2012): Bone marrow-derived, alternatively activated macrophages enhance solid tumor growth and lung metastasis of mammary carcinoma cells in a Balb/C mouse orthotopic model. Breast Cancer Res 14 (3): R81. DOI: 10.1186/bcr3195.

Chu P, Wu E, Weiss LM (2000): Cytokeratin 7 and cytokeratin 20 expression in epithelial neoplasms: a survey of 435 cases. Mod Pathol 13 (9): S. 962-972. DOI: 10.1038/modpathol.3880175.

Coleman WB, Tsongalis GJ (2006): Molecular mechanisms of human carcinogenesis. EXS (96), S. 321-349.

Creagh EM (2014): Caspase crosstalk: integration of apoptotic and innate immune signaling pathways. Trends Immunol 35 (12): S. 631-640. DOI: 10.1016/j.it.2014.10.004.

Crissman JD, Hatfield J, Schaldenbrand M, Sloane BF, Honn KV (1985): Arrest and extravasation of B16 amelanotic melanoma in murine lungs. A light and electron microscopic study. Lab Invest 53 (4): S. 470 478.

Cumaraswamy AA, Gunning PT (2012): Progress towards direct inhibitors of Stat5 protein. Horm Mol Biol Clin Investig 10 (2): S. 281-286. DOI: 10.1515/hmbci-2012-0009. 
Davidson NE, Sukumar S (2005): Of Snail, mice, and women. Cancer Cell 8 (3): S. 173-174. DOI: 10.1016/j.ccr.2005.08.006.

Davies LC, Jenkins SJ, Allen JE, Taylor PR (2013): Tissue-resident macrophages. Nat Immunol 14 (10): S. 986-995. DOI: 10.1038/ni.2705.

Davies RJ, Miller R, Coleman N (2005): Colorectal cancer screening: prospects for molecular stool analysis. Nat Rev Cancer 5 (3): S. 199-209. DOI: 10.1038/nrc1545.

Davis MJ, Tsang TM, Qiu Y, Dayrit JK, Freij JB (2013): Macrophage M1/M2 polarization dynamically adapts to changes in cytokine microenvironments in Cryptococcus neoformans infection. MBio 4 (3): S. e0026413. DOI: $10.1128 / \mathrm{mBio.00264-13.}$

Deyhle P (1980): Results of endoscopic polypectomy in the gastrointestinal tract. Endoscopy (Suppl), S. 3546.

Dessein AF, Stechly L, Jonckheere N, Dumont P, Monte D (2010): Autocrine induction of invasive and metastatic phenotypes by the MIF-CXCR4 axis in drug-resistant human colon cancer cells. Cancer Res 70 (1): S. 4644.4654. DOI: 10.1158/0008-5472.CAN-09-3828.

Desurmont T, Skrypek N, Duhamel A, Jonckheere N, Millet G et al. (2015): Overexpression of chemokine receptor CXCR2 and ligand CXCL7 in liver metastases from colon cancer is correlated to shorter diseasefree and overall survival. Cancer Sci 106 (3): S. 262-269. DOI: 10.1111/cas.12603.

Dobin A, Davis CA, Schlesinger F, Drenkow J, Zaleski C et al. (2013): STAR: ultrafast universal RNA-seq aligner. Bioinformatics 29 (1): S. 15-21. DOI: 10.1093/bioinformatics/bts635.

Dragutinovic VV, Radonjic NV, Petronijevic ND, Tatic SB, Dimitrijevic IB et al. (2011): Matrix metalloproteinase-2 (MMP-2) and -9 (MMP-9) in preoperative serum as independent prognostic markers in patients with colorectal cancer. Mol Cell Biochem 355 (1-2): S. 173-178. DOI: 10.1007/s11010-011-08540 .

Dutta PR, Maity A (2007): Cellular responses to EGFR inhibitors and their relevance to cancer therapy. Cancer Lett 254 (2): S. 165-177. DOI: 10.1016/j.canlet.2007.02.006.

Durst J, Rohen JW (1998): Bauchchirurgie - Operationslehre mit topographischer Anatomie - Standards der Viszeralchirurgie. Schattauer Verlag Stuttgart, 2. Auflage, S. 200.

Dvorak HF, Nagy JA, Berse B, Brown LF, Yeo TK et al. (1992): Vascular permeability factor, fibrin, and the pathogenesis of tumor stroma formation. Ann N Y Acad Sci 667: S. 101-111. 
Edwards BK, Ward E, Kohler BA, Eheman C, Zauber AG et al. (2010): Annual report to the nation on the status of cancer, 1975-2006, featuring colorectal cancer trends and impact of interventions (risk factors, screening, and treatment) to reduce future rates. Cancer 116 (3): S. 544-573. DOI: 10.1002/cncr.24760.

Egeblad M, Werb Z (2002): New functions for the matrix metalloproteinases in cancer progression. Nat Rev Cancer 2 (3): S. 161-174. DOI: 10.1038/nrc745.

Engström A, Erlandsson A, Delbro D, Wijkander J1 (2014): Conditioned media from macrophages of M1, but not M2 phenotype, inhibit the proliferation of the colon cancer cell lines HT-29 and CACO-2. Int J Oncol 44 (2): S. 385-392. DOI: 10.3892/ijo.2013.2203.

Erreni M, Mantovani A, Allavena P (2011): Tumor-associated Macrophages (TAM) and Inflammation in Colorectal Cancer. Cancer Microenviron 4 (2): S. 141-154. DOI: 10.1007/s12307-010-0052-5.

Eriksson JE, He AV, Trejo-Skalli AV, Harmala-Brasken AS, Hellman J et al. (2004): Specific in vivo phosphorylation sites determine the assembly dynamics of vimentin intermediate filaments. J Cell Sci 117 (Pt 6): S. 919-932. DOI: 10.1242/jcs.00906.

Fabriek B0, Dijkstra CD, van den Berg TK (2005): The macrophage scavenger receptor CD163. Immunobiology 210 (2-4): S. 153-160. DOI: 10.1016/j.imbio.2005.05.010.

Fang YJ, Lu ZH, Wang GQ, Pan ZZ, Zhou ZW et al. (2009): Elevated expressions of MMP7, TROP2, and surviving are associated with survival, disease recurrence, and liver metastasis of colon cancer. Int J Colorectal Dis 24 (8): S. 875-884. DOI: 10.1007/s00384-009-0725-z.

Fearon ER (2011): Molecular genetics of colorectal cancer. Annu Rev Pathol 6: S. 479-807. D0I: 10.1146/annurev-pathol-011110-130235.

Fearon ER, Vogelstein B (1990): A genetic model for colorectal tumorigenesis. Cell 61 (5), S. 759-767.

Ferrara N (2004): Vascular endothelial growth factor: basic science and clinical progress. Endocr Rev 25 (4): S. 581-611. DOI: 10.1210/er.2003-0027.

Fidler IJ (1970): Metastasis: quantitative analysis of distribution and fate of tumor emboli labeled with 125 I-5-iodo-2'-deoxyuridine. J Natl Cancer Inst 45 (4): S. 773-782.

Fleetwood AJ, Dinh H, Cook AD, Hertzog PJ, Hamilton JA (2009): GM-CSF- and M-CSF-dependent macrophage phenotypes display differential dependence on type I interferon signaling. J Leukoc Biol 86 (2): S. 411-421. DOI: $10.1189 / \mathrm{jlb} .1108702$. 
Fleming NI1, Jorissen RN, Mouradov D, Christie M, Sakthianandeswaren A, Palmieri M et al. (2013): SMAD2, SMAD3 and SMAD4 mutations in colorectal cancer. Cancer Res 73 (2): S. 725-735. DOI: 10.1158/00085472.CAN-12-2706.

Folkman J, Klagsbrun M (1987): Angiogenic factors. Science 235 (4787). S. 442-447.

Fong Y, Kemeny N, Paty P, Blumgart LH, Cohen AM (1996): Treatment of colorectal cancer: hepatic metastasis. Semin Surg Oncol $12 \quad$ (4): $\quad$ S. 219-252. DOI: 10.1002/(SICI)10982388(199607/08)12:4<219::AID-SSU3>3.0.CO;2-8.

Forssell J, Oberg A, Henriksson ML, Stenling R, Jung A, Palmqvist R (2007): High macrophage infiltration along the tumor front correlates with improved survival in colon cancer. Clin Cancer Res 13 (5): S. 14721479. DOI: 10.1158/1078-0432.CCR-06-2073.

Francke A, Herold J, Weinert S, Strasser RH, Brau-Dullaeus RC (2011): Generation of mature murine monocytes from heterogeneous bone marrow and description of their properties. J Histochem Cytochem 59 (9): S. 813-825. DOI: 10.1359/0022155411416007.

Franks LM, Hemmings VJ (1978): A cell line from an induced carcinoma of mouse rectum. J Pathol 124 (1): S. 35-38. DOI: $10.1002 /$ path.1711240108.

Frixen UH, Behrens J, Sachs M, Eberle G, Voss B et al. (1991): E-Cadherin-mediated cell-cell adhesion prevents invasiveness of human carcinoma cells. J Cell Biol 113 (1): S. 173-185.

Gassmann P, Haier J, Schlüter K, Dominowsky B, Wendel C et al. (2009): CXCR4 regulates the early extravasation of metastatic tumor cells in vivo. Neoplasia 11 (7): S. 651-661.

Geissmann F, Manz MG, Jung S, Sieweke MH, Merad M, Ley K (2010): Development of monocytes, macrophages, and dendritic cells. Science 327 (5966): S. 656-661. DOI: 10.1126/sience.1178331.

GLOBOCAN 2012: Estimated Cancer Incidence, Mortality and Prevalence Worlwide in 2012.

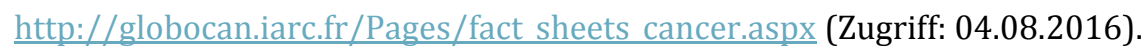

Goerdt S, Orfanos CE (1999): Other functions, other genes: alternative activation of antigen-presenting cells. Immunity 10 (2): S. 137-142.

Gordon S, Taylor PR (2005): Monocyte and macrophage heterogeneity. Nat Rev Immunol 5 (12): S. 953-964. DOI: $10.1038 /$ nri1733. 
Grivennikov S, Karin E, Terzic J, Mucida D, Yu GY (2009): IL-6 and Stat3 are required for survival of intestinal epithelial cells and development of colitis-associated cancer. Cancer Cell 15 (2): S. 103-113. DOI: 10.1016/j.ccr.2009.01.001.

Guarino M, Rubino B, Ballabio G (2007): The role of epithelialmesenchymal transition in cancer pathology. Pathology 39 (3): S. 305-318. DOI: 10.1080/00313020701329914.

Haegel H, Larue L, Ohsugi M, Fedorov L, Herennknecht K, Kemler R (1995): Lack of catenin affects mouse development at gastrulation. Development 121 (11): S. 3529-3537.

Haeuselmann I, Roblek M, Protsyuk D, Huck V, Knopfova L et al. (2016): Monocyte induction of E-selectinmediated endothelial activation releases VE-cadherin junctions to promote tumor cell extravasation in the metastasis cascade. Cancer Res [Epub ahead of print]. DOI: 10.1158/0008-5472.CAN-16-0784.

Haggar FA, Boushey RP (2009): Colorectal cancer epidemiology: incidence, mortality, survival, and risk factors. Clin Colon Rectal Surg 22 (4): S. 191-197. DOI: 10.1055/s-0029-1242458.

Hao NB, Lü MH, Fan YH, Cao YL, Zhang ZR, Yang SM (2012): Macrophages in tumor micronevironments and the progression of tumors. Clin Dev Immunol 2012: 948098. DOI: 10.1155/2012/948098.

Harun N, Costa P, Christophi C (2014): Tumour growth stimulation following partial hepatectomy in mice is associated with increased upregulation of c-Met. Clin Exp Metastasis 31 (1): S. 1-14. DOI: 10.1007/s10585-013-9604-7.

He TC, Sparks AB, Rago C, Hermeking H, Zawel L et al. (1998): Identification of c-MYC as a target of the APC pathway. Science 281 (5382): S. 1509-1512.

Heidemann J, Ogawa H, Dwinell MB, Rafiee P, maaser C et al. (2003): Angiogenic effects of interleukin 8 (CXCL8) in human intestinal microvascular endothelial cells are mediated by CXCR2. J Biol Chem 278 (10): S. 8508-8515. DOI: 10.1074/jbc.M208231200.

Hernandez BY, Frierson HF, Moskaluk CA, Li YJ, Clegg L et al. (2005): CK20 and CK7 protein expression in colorectal cancer: demonstration oft he utility of a population-based tissue microarray. Hum Pathol 36 (3): S. 275-281. DOI: 10.1016/j-humanpath.2005.01.013.

Herrmann H, Hesse M, Reichenzeller M, Aebi U, Magin TM (2003): Functional complexity of intermediate filament cytoskeletons: from structure to assembly to gene ablation. Int Rev Cytol 223: S. 83-175.

Heusinkveld M, van der Burg SH (2011): Identification and manipulation of tumor associated macrophages in human cancers. J Transl Med 9: S. 216. DOI: 10.1186/1479-5876-9-216. 
Hirata Y, Tabata M, Kurobe H, Motoki T, Akaike M et al. (2011): Coronary atherosclerosis is associated with macrophage polarization in epicardial adipose tissue. J Am Coll Cardiol 58 (3): S. 248-255. DOI: 10.1016/j.jacc.2011.01.048.

Holness CL, Simmons DL (1993): Molecular cloning of CD68, a human macrophage marker related to lysosomal glycoproteins. Blood 81 (6): S. 1607-1613.

Hua H, Li M, Luo T, Yin Y, Jiang Y (2011): Matrix metalloproteinases in tumorigenesis: an evolving paradigm. Cell Mol Life Sci 68 (23): S. 3853-3868. DOI: 10.1007/s00018-011-0763-x.

Huang MY, Chang HJ, Chung FY, Yang MJ, Yang YH et al. (2010): MMP13 is a potential prognostic marker colorectal cancer. Oncol Rep 24 (5): S. 1241-1247.

Humblet Y (2004): Cetuximab: an IgG(1) monoclonal antibody for the treatment of epidermal growth factor receptor-expressing tumours. Expert Opin Pharmacother 5 (7): S. 1621-1633. DOI: 10.1517/14656566.5.7.1621.

Iacopetta B (2003): TP53 mutation in colorectal cancer. Hum Mutat 21 (3): S. 271-276. DOI: 10.1002/humu.10175.

Ikeda S, Kishida A, Yamamoto H, Murai H, Koyama S, Kikuchi A (1998): Axin, a negative regulator of the Wnt signaling pathway, forms a complex with GSK-3beta and beta-catenin and promotes GSK-3beta-dependent phosphorylation of beta-catenin. EMBO J 17 (5): S. 1371-1384. DOI: 10.1093/emboj/17.5.1371.

Ito A, Nakajiama S, Sasaguir Y, Nagase H, Mori J (1995): Co-culture of human adenocarcinoma MCF-7 cells and human dermal fibroblasts enhances the production of matrix metalloproteinases 1, 2 and 3 in fibroblasts. Br J Cancer 71(5): S. 1039-1045.

Jackman RJ, Mayo CW (1951): The adenoma-carcinoma sequence in cancer of the colon. Surg Gynecol Obstet 93 (3): S. 327-330.

Jemal A, Siegel R, Ward E, Murray T, Xu J, Thun MJ (2007): Cancer statistics, 2007. CA Cancer J Clin 57 (1): S. 43-66.

Jho EH, Zhang T, Domon C, Joo CK, Freund JN, Costantini F (2002): Wnt/beta-catenin/Tcf signaling induces the transcription of Axin2, a negative regulator of the signaling pathway. Mol Cell Biol 22 (4): S. 1172-1183.

Jolliffe IT, Cadima J (2016): Principal component analysis: a review and recent developments. Philos Trans A Math Phys Eng Sci 374 (2065): 20150202. DOI: 10.1098/rsta.2015.0202. 
Jonas S, Thelen A, Benckert C, Spinelli A, Sammain S, Neumann U, Rudolph B, Neuhaus P (2007): Extended resections of liver metastases from colorectal cancer. World J Surg 31 (3), S. 511-521. DOI: 10.1007/s00268-006-0140-3.

Joshi S, Singh AR, Zulcic M, Bao L, Messer K et al. (2014): Rac2 controls tumor growth, metastasis and M1M2 macrophage differentiation in vivo. PLoS One 9 (4): e95893. DOI: 10.1371/journal.pone.0095893.

Kawasaki H, Altieri DC, Lu CD, Toyoda M, Tenjo T, Tanigawa N (1998): Inhibition of apoptosis by surviving predicts shorter survival rates in colorectal cancer. Cancer Res 58 (22): S. 5071-5074.

Kemeny N (2006): Management of liver metastases from colorectal cancer. Oncology (Williston Park) 20 (10): S. 1161-1176, 1179; discussion S. 1179-1180, S. 1185-116.

Kim J, Takeuchi H, Lam ST, Turner RR, Wang HJ et al. (2005): Chemokine receptor CXCR4 expression in colorectal cancer patients increases the risk for recurrence and for poor survival. 23 (12): S. 2744-2753. DOI: $10.1200 / J C 0.2005 .07 .078$.

Kinzler KW, Vogelstein B (1996): Lessons from hereditary colorectal cancer. Cell 87 (2), S. 159-170.

Kinzler KW, Vogelstein B (1997): Cancer-susceptibility genes. Gatekeepers and caretakers. Nature 386 (6627): S. 761-763. DOI: 10.1038/386761a0.

Kitamura T, Fujishita T, Loetscher P, Revesz L, Hashida H et al. (2010): Inactivation of chemokine (C-C motif) receptor 1 (CCR1) suppresses colon cancer liver metastasis by blocking accumulation of immature myeloid cells in a mouse model. Proc Natl Acad Sci USA 107 (29): S. 13063-13068. DOI: 10.1073/pnas.1002372107.

Klein CA (2009): Parallel progression of primary tumours and metastases. Nat Rev Cancer 9 (4): S. 302-312. DOI: $10.1038 / \mathrm{nrc} 2627$.

Koshariya M, Jagad RB, Kawamoto J, Papastratis P, Kefalourous H et al. (2007): An update and our experience with metastatic liver disease. Hepatogastroenterology 54 (80): S. 2232-2239.

Kowal K, Silver R, Slawinska E, Bielecki M Chyczewski L, Kowal-Bielecka O (2011): CD163 and its role in inflammation. Folia Histochem Cytobiol 49 (3): S. 365-374.

Kozuka S, Nogaki M, Ozeki T, Masumori S (1975): Premalignancy of the mucosal polyp in the large intestine: II. Estimation of the periods required for malignant transformation of mucosal polyps. Dis Colon Rectum 18 (6): S. 494-500. 
Kudo S, Kashida H, Tamura T (2000): Early colorectal cancer: flat or depressed type. J Gastroenterol Hepatol 15 (Suppl): S. D66-70.

Kummar S, Fogarasi M, Canova A, Mota A, Ciesielski T (2002): Cytokeratin 7 and 20 staining for the diagnosis of lung and colorectal adenocarcinoma. Br J Cancer 86 (12): S. 1884-1887. DOI: 10.1038/sj.bjc.6600326.

Kurahara H, Takao S, Maemura K, Mataki Y, Kuwahata T (2013): M2-polarized tumor-associated macrophage infiltration of regional lymph nodes is associated with nodal lymphangiogenesis and occult nodal involvement in pN0 pancreatic cancer. Pancreas 42 (1): S. 155-159. DOI: 10.1097/MPA.0b013e318254f2d1.

Langley RR, Fidler IJ (2007): Tumor cell-organ microenvironment interactions in the pathogenesis of cancer metastasis. Endocr Rev 28 (3): S. 297-321. DOI: 10.1210/er.2006-0027.

Langenskiöld M, Holmdahl L, Falk P, Ivarsson ML (2005): Increased plasma MMP-2 protein expression in lymph node-positive patients with colorectal cancer. Int J Colorectal Dis 20 (3): S. 245-252. DOI: 10.1007/s00384-004-0667-4.

Lee SK, Han YM, Yun J, Lee CW, Shin DS et al. (2012): Phosphatase of regenerating liver-3 promotes migration and invasion by upregulating matrix metalloproteinase-7 in human colorectal cancer cells. Int J Cancer 131 (3): S. E190-203. DOI: 10.1002/ijc.27381.

Lee YS, Choi I, Ning Y, Kim NY, Khatchadourian V (2012): Interleukin-8 and its receptor CXCR2 in the tumour microenvironment promote colon cancer growth, progression and metastasis. Br J Cancer 106 (11): S. 1833 1841. DOI: $10.1038 /$ bjc.2012.177.

Leeman MF, McKay JA, Murray GI (2002): Matrix metalloproteinase 13 activity is associated with poor prognosis in colorectal cancer. J Clin Pathol 55 (10): S. 758-762.

Leporrier J, Maurel J, Chiche L, Bara S, Segol P, Launoy G (2006): A population-based study of the incidence, management and prognosis of hepatic metastases from colorectal cancer. Br J Surg 93 (4): S. 465-74. DOI: 10.1002/bjs.5278.

Lewis CE, Pollard JW (2006): Distinct role of macrophages in different tumor microenvironments. Cancer Res 66 (2): S. 605-612. DOI: 10.1158/0008-5472.CAN-05-4005.

Li B, Dewey CN (2011): RSEM: accurate transcript quantification from RNA-Seq data with or without a reference genome. BMC Bioinformatics 12: S. 323. DOI: 10.1186/1471-2105-12-323.

Li F, Tiede B, Massagué J, Kang Y (2007): Beyond tumorigenesis: cancer stem cells in metastasis. Cell Res 17 (1): S. 3-14. DOI: 10.1038/sj.cr.7310118. 
Lièvre A, Bachet JB, Le Corre D, Boige V, Landi B et al. (2006): KRAS mutation status is predictive of response to cetuximab therapy in colorectal cancer. Cancer Res 66 (8): S. 3992-3995. DOI: 10.1158/0008-5472.CAN06-0191.

Lim B, Mun J, Kim JH, Kim CW, Roh SA, Cho DH, Kim YS, Kim SY, Kim JC (2015): Genome-wide mutation profiles of colorectal tumors and associated liver metastases at the exome and transcriptome levels. Oncotarget 6 (26): S. 22179-22190. DOI: 10.18632/oncotarget.4246.

Linsley PS, Ledbetter JA (1993): The role of CD28 receptor during T cell responses to antigen. Annu Rev Immunol 11: S. 191-212. DOI: 10.1146/annurev.iy.11.040193.001203.

Lin EY, Li JF, Gnatovskiy L, Deng Y, Zhu L et al. (2006): Macrophages regulate the angiogenic switch in a muse model of breast cancer. Cancer Res 66 (23): S. 11238-11246. DOI: 10.1158/0008-5472.CAN-06-1278.

Liu W, Dong X, Mai M, Seelan RS, Taniguchi K et al. (2000): Mutations in AXIN2 cause colorectal cancer with defective mismatch repair by activating beta-catenin/TCF signaling. Nat Genet 26 (2): S. 146-147. DOI: $10.1038 / 79859$.

Logan CY, Nusse R (2004): The Wnt signaling pathway in development and disease. Annu Rev Cell Dev Biol 20: S. 781-810. DOI: 10.1146/annurev.cellbio.20.010403.113126.

Lynch HT, de la Chapelle A (2003). Hereditary colorectal cancer. N Engl J Med 348 (1): S. 919-932. DOI: 10.1056/NEJMra012242.

Ma J, Liu L, Che G, Yu N, Dai F, You Z (2010): The M1 from of tumor-associated macrophages in non-small cell lung cancer is positively associated with survival time. BMC Cancer 10: 112. DOI: 10.1186/1471-240710-112.

Machii R, Saika K (2014): Five-year relative survival rate of colon cancer in the USA, europe and japan. Jpn J Clin Oncol 44 (1): S. 105-106. DOI: 10.1093/jjco/hyt227.

MacMicking J, Xie QW, Nathan C (1997): Nitric oxide and macrophage function. Annu Rev Immunol 15: S. 323-350. DOI: 10.1146/annurev.immunol.15.1.323.

Malinauskas T, Aricescu AR, Lu W, Siebold C, Jones EY (2011): Modular mechanism of Wnt signaling inhibition by Wnt inhibitory factor 1. Nat Struct Mol Biol. 18 (8): S. 886-893. DOI: 10.1038/nsmb.2081.

Mantovani A (1994): Timor-associated macrophages in neoplastic progression: a paradigm for the in vivo function of chemokines. Lab Invest 71 (1): S. 5-16. 
Mantovani A, Biswas SK, Galdiero MR, Sica A, Locati M (2013): Macrophage plasticity and polarization in tissue repair and remodeling. J Pathol 229 (2): S. 176-185. DOI: 10.1002/path.4133.

Mantovani A, Bottazzi B, Colotta F, Sozzani S, Ruco L (1992): The origin and function of tumor-associated macrophages. Immunol Today 13 (7): S. 265-270. DOI: 10.1016/0167-5699(92)90008-U.

Mantovani A, Schioppa T, Biswas SK, Marchesi F, Allavena P, Sica A (2003): Tumor-associated macrophages and dendritic cells as prototypic type II polarized myeloid populations. Tumori 89 (5): S. 459-468.

Mantovani A, Sica A, Locati M (2007): New vistas on macrophage differentiation and activation. Eur J Immunol 37 (1): S. 14-16. DOI: 10.1002/eji.200636910.

Mantovani A, Sica A, Sozzani S, Allavena P, Vecchi A, Locati M (2004): The chemokine system in diverse forms of macrophage activation and polarization. Trends Immunol 25 (12): S. 677-686. DOI: 10.1016/j.it.2004.09.015.

Marhaba R, Zöller M (2004): CD44 in cancer progression: adhesion, migration and growth regulation. J Mol Histol 35 (3): S. 211-231.

Martinez-Pomares L (2012): The mannose receptor. J Leukoc Biol 92 (6): S. 1177-1186. DOI: $10.1189 / \mathrm{jlb} .0512231$.

Martinez FO, Gordon S (2014): The M1 and M2 paradigm of macrophage activation: time for reassessment. F1000Prime Rep 6 (13): S. 1-13. DOI: 10.12703/P6-13.

Martinez FO, Sica A, Mantovani A, Locati A (2008): Macrophage activation and polarization. Front Biosci 13: S. 453-461.

Massagué J (2008): TGFbeta in Cancer. Cell 134 (2): S. 215-230. DOI: 10.1016/j.cell.2008.07.001.

McKnight AJ, Gordon S (1998): The EGF-TM7 family: unusual structures at the leukocyte surface. J Leukoc Biol 63 (3): S. 271-280.

Matsusue R, Kubo H, Hisamori S, Okoshi K, Takagi H et al. (2009): Hepatic stellate cells promote liver metastasis of colon cancer cells by the action of SDF-1/CXCR4 axis. Ann Surg Oncol 16 (9): S. 2645-2653. DOI: $10.1245 /$ s10434-009-0599-x.

McLoughlin JM, Jensen EH, Malafa M (2006): Resection of colorectal liver metastases: current perspectives. Cancer Control 13 (1): S. 32-41. 
McQuibban GA, Gong JH, Tam EM, McCulloch CA, Clark-Lewis I, Overall CM (2000): Inflammation dampened by gelatinase A cleavage of monocyte chemoattractant protein-3. Science 289 (5482): S. 1202-1206.

Meng F, Li C, Li W, Gao Z, Guo K, Song S (2014): Interaction between pancreatic cancer cells and tumorassociated macrophages promotes the invasion of pancreatic cancer cells and the differentiation and migration of macrophages. IUBMB Life 66 (12): S. 835-846. DOI: 10.1002/iub.1336.

Mignatti P, Rifkin DB (1993): Biology and biochemistry of proteinases in tumor invasion. Physiol Rev 73 (1): S. 161-195.

Mills CD, Kincaid K, Alt JM, Heilman MJ, Hill AM (2000): M-1/M-2 macrophages and the Th1/Th2 paradigm. J Immunol 164 (12): S. 6166-6173.

Mills CD, Lenz LL, Harris RA (2016): A Breakthrough: Macrophage-Directed Cancer Immunotherapy. Cancer Res 76 (3): S. 513-516. DOI: 10.1158/0008-5472.

Miyoshi Y, Nagase H, Ando H, Horii A, Ichii S, Nakatsuru S, Aoki T, Miki Y, Mori T, Nakamura Y (1992): Somatic mutations of the APC gene in colorectal tumors: mutation cluster region in the APC gene. Hum Mol Genet 1 (4): S. 229-233.

Morin PJ, Sparks AB, Korinek V, Barker N, Clevers H, Vogelstein B, Kinzler KW (1997): Activation of betacatenin-Tcf signaling in colon cancer by mutations in beta-catenin or APC. Science 275 (5307): S. 17871790.

Mosser DM (2003): The many faces of macrophage activation. J Leukoc Biol 73 (2): S. 209-212.

Mosser DM, Edwards JP (2008): Exploring the full spectrum of macrophage activation. Nat Rev Immunol 8 (12): S. 958-969. DOI: $10.1038 /$ nri2448.

Mukhtar RA, Nseyo O, Campbell MJ, Esserman LJ (2011): Tumor-associated macrophages in breast cancer as potential biomarkers for new treatments and diagnostics. Expert Rev Mol Diagn 11 (1): S. 91-100. DOI: 10.1586/erm.10.97.

Müller A, Homey B, Soto H, Ge N, Catron D (2001): Involvement of chemokine receptors in breast cancer metastasis. Nature 410 (6824): S. 50-56. DOI: 10.1038/35065016.

Murakami T, Kawada K, Iwamoto M, Akagami M, Hida K et al. (2013): The role of CXCR and CXCR4 in colorectal cancer metastasis. Int J Cancer 132 (2): S. 276-287. DOI: 10.1002/ijc.27670. 
Murray PJ, Allen JE, Biswas SK, Fisher EA, Gilroy DW et al. (2014): Macrophage activation and polarization:

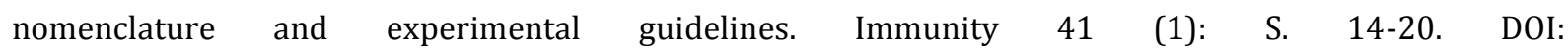
10.1016/j.immuni.2014.06.008.

Murray PJ, Wynn TA (2011): Obstacles and opportunities for understanding macrophage polarization. J Leukoc Biol 89 (4): S. 557-563. DOI: 10.1189/jlb.0710409.

Murray PJ, Wynn TA (2011): Protective and pathogenic functions of macrophage subsets. Nat Rev Immunol 11 (11): S. 723-737. DOI: 10.1038/nri3073.

Muto T, Bussey HJ, Morson BC (1975): The evolution of cancer of the colon and rectum. Cancer 36 (6): S2251-2270.

Nadal C, Maurel J, Gascon P (2007): Is there a genetic signature for liver metastasis in colorectal cancer. World J Gastroenterol 13 (44): S. 5832-5844.

Nagase H, Nakamura Y (1993): Mutations of the APC (Adenomatous Polyposis Coli) Gene. Hum Mutat 2 (6): S. 425-434. DOI: 10.1002/humu.1380020602.

Nathan C (2008): Metchnikoff's Legacy in 2008. Nat Immunol 9 (7): S. 695-698. DOI: 10.1038/ni0708-695.

Negus RP, Stamp GW, Relf MG, Burke F, Malik ST (1995): The detection and localization of monocyte chemoattractant protein-1 (MCP-1) in human ovarian cancer. J Clin Invest 95 (5): S. 2391-2396. DOI: 10.1172/JCI1117933.

Ngan CY, Yamamoto H, Seshimo I, Tsujino T, Man-i M et al. (2007): Quantitative evaluation of vimentin expression in tumour stroma of colorectal cancer. Br J Cancer 96 (6): S. 986-992. DOI: 10.1038/sj.bjc.6603651.

Nguyen DX, Bos PD, Massagué J (2009): Metastasis: from dissemination to organ-specific colonization. Nat Rev Cancer 9 (4): 274-284. DOI: 10.1038/nrc2622.

Niedobitek G, Barros MH, Dreyer JH, Hauck F, Al-Sheikhyaqoob D (2015): Tumorasoziierte Makrophagen. Pathologe 36: S. 477-484. DOI: 10.1007/s00292-015-0054-7.

Nosaka T, Kawashima T, Misawa K, Ikuta K, Mui AL, Kitamura T (1999): STAT5 as a molecular regulator of proliferation, differentiation and apoptosis in hematopoietic cells. EMBO J 18 (17): S. 4764-4765. DOI: 10.1093/emboj/18.17.4754.

Noy R, Pollard JW (2014): Tumor-associated macrophages: from mechanisms to therapy. Immunity 41 (1): S. 49-61. DOI: 10.1016/j.immuni.2014.06.010. 
O'Brien MJ, Winawer SJ, Zauber AG, Gottlieb LS, Sternberg SS et al. (1990): The National Polyp Study. Patient and polyp characteristics associated with high-grade dysplasia in colorectal adenomas. Gastroenterology 98 (2): S. 371-379.

Ochiai H, Nakanishi Y, Fukusawa Y, Sato Y, Yoshimura K et al. (2008): A new formula for predicting liver metastasis in patients with colorectal cancer: immunohistochemical analysis of a large series of 439 surgically resected cases. Oncology 75 (1-2): S. 32-41. DOI: 10.1159/000151667.

Ogawa S, Nagao M, Kanehiro H, Hisanaga M, Ko et al. (2004): The breakdown of apoptotic mechanism in the development and progression of colorectal carcinoma. Anticancer Res 24 (3a): S. 1569-1579.

Oladipo O, Conlon S, O'Grady A, Purcell C, Wilson C et al. (2011): The expression and prognostic impact of CXC-chemokines in stage II and III colorectal cancer epithelial and stromal tissue. Br J Cancer 104 (3): S. 480-487. DOI: 10.1038/sj.bjc.6606055.

Onofre G, Kolácková M, Jankovicová K, Krejsek J (2009): Scavenger receptor CD163 and its biological functions. Acta Medica (Hradec Kralove) 52 (2): S. 57-61.

Osborn M (1983): Intermediate filaments as histology markers: an overview. J Invest Dermatol 81 (1 Suppl): S. $104 s-109 s$

Paget S (1889): The distribution of secondary growths in cancer of the breast. 1889. Cancer Metastasis Rev 8 (2): S. 98-101.

Pahl JH, Kwappenberg KM, Varypataki EM, Santos SJ, Kuijjer ML et al. (2014): Macrophages inhibit human osteosarcoma cell growth after activation with the bacterial cell wall derivative liposomal muramyl tripeptide in combination with interferon- $\gamma$. J Exp Clin Cancer Res 33: 27. DOI: 10.1186/1756-9966-33-27.

Palmerini F, Devilard E, Jarry A, Birg F, Xerri L (2001): Caspase 7 downregulation as an immunohistochemical marker of colonic carcinoma. Hum Pathol 32 (5): S. 461-467. DOI: 10.1053/hupa.2001.24328.

Palumbo JS, Kombrinck KW, Drew AF, Grimes TS, Kiser JH (2000): Fibrinogen is an important determinant of the metastatic potential of circulating tumor cells. Blood 96 (10): S. 3302-3309.

Park J, Schwarzbauer JE (2014): Mammary epithelial cell interactions with fibronectin stimulate epithelialmesenchymal transition. Oncogene 33 (13): S. 1649-1657. DOI: 10.1038/onc.2013.118.

Paschos KA, Majeed AW, Bird NC (2010): Role of Kupffer cells in the outgrowth of colorectal cancer liver metastases. Hepatol Res 40 (1): S. 83-94. DOI: 10.1111/j.1872-034X.2009.00578.x. 
Peiser L, Gordon S (2001): The function of scavenger receptors expressed by macrophages and their role in the regulation of inflammation. Microbes Infect 3 (2): S. 149-159.

Pignatelli M, Liu D, Nasim MM, Stamp GW, Hirano S, Takeichi M (1992): Morphoregulatory activities of E cadherin and beta 1 integrins in colorectal tumour cells. Br J Cancer 66 (4): S. 629-634.

Pollard JW (2004): Tumor-educated macrophages promote tumour progression and metastasis. Nat Rev Cancer 4 (1): S. 71-78. DOI: 10.1038/nrc1256.

Powell SM, Zilz N, Beazer-Barclay Y, Bryan TM, Hamilton SR et al. (1992): APC mutations occur early during colorectal tumorigenesis. Nature 259 (6392): S. 235-237. DOI: 10.1038/359235a0.

Putoczki TL, Thiem S, Loving A, Busuttil RA, Wilson NJ et al. (2013): Interleukin-11 is the dominant IL-6 family cytokine during gastrointestinal tumorigenesis and can be targeted therapeutically. Cancer Cell 24 (2): S. 257-271. DOI: 10.1016/j.ccr.2013.06.017.

Qian B, Deng Y, Im JH, Muschel RJ, Zou Y, Li J, Lang RA, Pollard JW (2009): A distinct macrophage population mediates metastatic breast cancer cell extravasation, establishment and growth. PLoS One 4 (8): S. e6562. DOI: 10.1371/journal.pone.0006562.

Qian BZ, Pollard JW (2010): Macrophage diversity enhances tumor progression and metastasis. Cell 141 (1): S. 39-51. DOI: 10.1016/j.cell.2010.03.014.

Racanelli V, Rehermann B (2006): The liver as an immunological organ. Hepatology 43 (2 Suppl 1): S. 5462. DOI: $10.1002 /$ hep. 21060 .

Ramaswamy S, Ross KN, Lander ES, Golub TR (2003): A molecular signature of metastasis in primary solid tumors. Nat Genet 33 (1): S. 49-54. DOI: 10.1038/ng1060.

Ransohoff DF, Lang CA (1991): Screening for colorectal cancer. N Engl J Med 325 (1): S. 37-41. DOI: 10.1056/NEJM199107043250107.

Ringnér M (2008): What is principal component analysis? Nat Biotechnol 26 (3): S. 303-304. DOI: 10.1038/nbt0308-303.

Rmali KA, Puntis MC, Jiang WG (2007): Tumour-associated angiogenesis in human colorectal cancer. Colorectal Dis 9 (1): S. 3-14. DOI: 10.1111/j.1463-1318.2006.01089.x.

Robert Koch Institut und die Gesellschaft der epidemiologischen Krebsregister in Deutschland e.V. (2015): Krebs in Deutschland 2011/2012. 10. Ausgabe. Berlin 2015, 38-41. 
Roberts S, Long L, Jonasson O, McGrath R, McGrew E, Cole WH (1960): The isolation of cancer cells from the blood stream during uterine curettage. Surg Gynecol Obstet 111: S. 3-11.

Robinson MD, McCarthy DJ, Smyth GK (2010): edgeR: a Bioconductor package for differential expression analysis of digital gene expression data. Bioinformatics 26 (1): S. 139-140. DOI: 10.1093/bioinformatics/btp616.

Said AH, Raufman JP, Xie G (2014): The role of matrix metalloproteinases in colorectal cancer. Cancers (Basel) 6 (1): S. 366-375. DOI: 10.3390/cancers6010366.

Sans-Fons MG, Yeramian A, Pereira-Lopes S, Santamaria-Babi LF, Modolell M et al. (2013): Arginine transport is impaired in $\mathrm{C} 57 \mathrm{Bl} / 6$ mouse macrophages as a result of a deletion in the promoter of Slc7a2 (CAT2), and susceptibility to Leishmania infection is reduced. J Infect Dis 207 (11): S. 1684-1693. DOI: 10.1093/infdis/jit084.

Saunus JM, Momeny M, Simpson PT, Lakhani SR, Da Silva L (2011): molecular aspects of breast cancer metastasis to the brain. Genet Res Int 2011: 219189. DOI: 10.4061/2011/219189.

Sasson AR, Sigurdson ER (2002): Surgical treatment of liver metastases. Semin Oncol 29 (2): S. 107-118.

Sato K, Kuratsu J, Takeshima H, Yoshimura T, Ushio Y (1995): Expression of monocyte chemoattractant protein-1 in meningioma. J Neurosurg 82 (5): S. 874-878. DOI: 10.3171/jns.1995.82.5.0874.

Schmitt M, Metzger M, Gradl D, Davidson G, Orian-Rousseau V (2015): CD44 functions in Wnt signaling by regulating LRP6 localization and activation. Cell Death Differ 22 (4): S. 677-689. DOI: 10.1038/cdd.2014.156.

Schouten LJ, Rutten J, Huveneers HA, Twijnstra A (2002): Incidence of brain metastases in a chort of patients with carcinoma oft the breast, colon, kidney, and lung and melanoma. Cancer 94 (10): S. 2698-2705.

Schroeder A, Mueller O, Stocker S, Salowsky R, Leiber et al. (2006): The RIN: an RNA integrity number for assigning integrity values to RNA measurements. BMC Mol Biol 7: S. 3. DOI: 10.1186/1471-2199-7-3.

Shah SP, Morin RD, Khattra J, Prentice L, Pugh T (2009): Mutational evolution in a lobular breast tumour profiled at single nucleotide resolution. Nature 461 (7265): S. 809-813. DOI: 10.1038/nature08489.

Shibamoto S, Hayakawa M, Takeuchi K, Hori T, Oku N et al. (1994): Tyrosine phosphorylation of betacatenin and plakoglobin enhanced by hepatocyte growth factor and epidermal growth factor in human carcinoma cells. Cell Adhes Commun 1 (4): S. 295-305. 
Sica S, Larghi P, Mancino A, Rubino L, Porta C (2008): Macrophage polarization in tumour progression. Semin Cancer Biol 18 (5): S. 349-355. DOI: 10.1016/j.semcancer.2008.03.004.

Sica A, Mantovani A (2012): Macrophage plasticity and polarization: in vivo veritas. J Clin Invest 122 (3): S. 787-795. DOI: $10.1172 / J C I 59643$.

Sindrilaru A, Peters T, Wieschalka S, Baican C, Baican A et al. (2011): An unrestained proinflammatory M1 macrophage population induced by iron impairs wound healing in humans and mice. J Clin Invest 121 (3): S. 985-997. DOI: 10.1172/JCI44490.

Siveen KS, Kuttan G (2009): Role of macrophages in tumour progression. Immunol Lett. 123 (2): S. 97 102.DOI: 10.1016/j.imlet.2009.02.011.

Slavjansky K (1863): Experimentelle Beiträge zur Pneumonokoniosis-Lehre. Archiv für pathologische Anatomie und Physiologie und für klinische Medici. 48 (2): S. 326-332. DOI: 10.1007/BF01986371.

Smith KJ, Johnson KA, Bryan TM, Hill DE, Markowitz S et al. (1993): The APC gene product in normal and tumor cells. Proc Natl Acad Sci USA 90 (7): S. 2846-2850.

Smits R, Kartheuser A, Jagmohan-Changur S, Leblanc V, Breukel C et al. (1997): Loss of Apc and the entire chromosome 18 but absence of mutations at the Ras and Tp53 genes in intestinal tumors from Apc1638N, a mouse model for Apc-driven carcinohenesis. Carcinogenesis 18 (2): S. 321-327.

Smits R, Kielman MF, Breukel C, Zurcher C, Neufeld K et al. (1999): Apc1638T: a mouse model delineating critical domains of the adenomatous polyposis coli protein involved in tumorigenesis and development. Genes Dev 13 (10): S. 1309-1321.

Solinas G, Germano G, Mantovani A, Allavena P (2009): Tumor-associated macrophages (TAM) as major players of the cancer-related inflammation. J Leukoc Biol 86 (5): S. 1065-1073. DOI: 10.1189/jlb.0609385.

Solovjov DA, Pluskota E, Plow EF (2005): Distinct roles for the alpha and beta subunits in the functions of integrin alphaMbeta2. J Biol Chem 280 (2): S. 1336-1345. DOI: 10.1074/jbc.M406968200.

Sporn MB (1996): The war on cancer. Lancet 347 (9012): S. 1377-1381.

Sprinzl MF, Puschnik A, Schlitter AM, Schad A, Ackermann K (2015): Sorafenib inhibits macrophage-induced growth of hepatoma cells by interference with insulin-like growth factor-1 secretion. J Hepatol 62 (4): S. 863-870. DOI: 10.1016/j.jhep.2014.11.011. 
Stein M, Keshav S, Harris N, Gordon S (1992): Interleukin 4 potently enhances murine macrophage mannose receptor activity: a marker of alternative immunologic macrophage activation. J Exp Med 176 (1): S. 287 292.

Stintzing S, Heinemann V, Jung A, Moosmann N, Hiddemann W, Kirchner T (2009): The Treatment of Colorectal Carcinoma With Monoclonal Antibodies - The Importance of KRAS Mutation Analysis and EGFR Status. Dtsch Arztebl Int 106 (12): S. 202-206. DOI: 10.3238/arztebl.2009.0202.

Sulahian TH, Högger P, Wahner AE, Wardwell K, Goulding NJ et al. (2000): Human monocytes express CD163, which is upregulated by IL-10 and identical to p155. Cytokine 12 (9): S. 1312-1321. DOI: 10.1006/cyto.2000.0720.

Sun W (2012): Angiogenesis in metastatic colorectal cancer and the benefits of targeted therapy. J Hematol Oncol 5 (63). DOI: 10.1186/1756-8722-5-63.

Swallow CJ, Murray MP, Guillem JG (1996): Metastatic colorectal cancer cells induce matrix metalloproteinase release by human monocytes. Clin Exp Metastasis 14 (1): S. 3-11.

Swirski FK, Nahrendorf M, Etzrodt M, Wildgruber M, Cortez-Retamozo V et al. (2009): Identification of splenic reservoir monocytes and their deployment to inflammatory sites. Science 325 (5940): S. 612-616. DOI: $10.1126 /$ science.1175202.

Tacke F, Randolph GJ (2006): Migratory fate and differentiation of blood monocyte subsets. Immunobiology 211 (6-8): S. 609-618. DOI: 10.1016/j.imbio.2006.05.025.

Takeichi M (1991): Cadherin cell adhesion receptors as a morphogenetic regulator. Science 251 (5000): S. 1451-1455.

Talmadge JE, Benedict K, Madsen J, Fidler IJ (1984): Development of biological diversity and susceptibility to chemotherapy in murine cancer metastases. Cancer Res 44 (9): S. 3801-3805.

Talmadge JE, Fidler IJ (2010): AACR centennial series: the biology of cancer metastasis: historical perspective. Cancer Res 70 (14): S. 5649-5669. DOI: 10.1158/0008-5472.CAN-10-1040.

Tamm I, Wang Y, Sausville E, Scudiero DA, Vigna N, Oltersdorf T, Reed JC (1998): IAP-family protein surviving inhibits caspase activity and apoptosis induced by Fas (CD95), Bax, caspase, and anticancer drugs. Cancer Res 58 (23): S. 5315-5320.

Teicher BA, Fricker SP (2010): CXCL12 (SDF-1)/CXCR4 pathway in cancer. Clin Cancer Res 16 (11): S. 2927 2931. DOI: 10.1158/1078-0432.CCR-09-2329. 
Thiery JP (2002): Epithelial-mesenchymal transitions in tumour progression. Nat Rev Cancer 2 (6): S. 442 454. DOI: $10.1038 / \mathrm{nrc} 822$.

Tichopad A, Dilger M, Schwarz G, Pfaffl MW (2003): Standardized determination of real-time PCR efficiency from a single reaction set-up. Nucleic Acids Res 31 (20): e112.

Tlsty TD, Coussens LM (2006): Tumor stroma and regulation of cancer development. Annu Rev Pathol 1: S. 119-150. DOI: 10.1146/annurev.pathol.1.110304.100224.

Tsou CL, Peters W, Si Y, Slaymaker S, Aslanian AM et al. (2007): Critical roles for CCR2 and MCP-3 in monocyte mobilization from bone marrow and recruitment to inflammatory sites. J Clin Invest 117 (4): S. 902-909. DOI: $10.1172 / J C I 29917$.

Tugal D, Liao X, Jain MK (2013): Transcriptional control of macrophage polarization. Arterioscler Thromb Vasc 33 (6): S. 1135-1144. DOI: 10.1161/ATVBAHA.113.301453.

Umetani N, Sasaki S, Masaki T, Watanabe T, Matsuda K, Muto T (2000): Involvement of APC and K-ras mutation in non-polypoid colorectal tumorigenesis. Br J Cancer 82 (1): S. 9-15. DOI: 10.1054/bjoc.1999.0868.

Van den Eynden GG, Majeed AW, Illemann M, Vermeulen PB, Bird NC et al. (2013): The multifaceted role of the microenvironment in liver metastasis: biology and clinical implications. Cancer Res 73 (7): S. 2031 2043. DOI: $10.1158 / 0008-5472 . C A N-12-3931$.

Van den Heuvel MM, Tensen CP, van As JH, Van den Berg TK, Fluitsma DM et al. (1999): Regulation of CD 163 on human macrophages: cross-linking of CD163 induces signaling and activation.

Van der Jagt MF, Wobbes T, Strobbe LJ, Sweep FC, Span PN (2010): Metalloproteinases and their regulators in colorectal cancer. J Surg Oncol 101 (3): S. 259-269. DOI: 10.1002/jso.21462.

Van der Wal GE, Gouw AS, Kamps JA, Moorlag HE Bulthius ML, Molema G, de Jong KP (2012): Angiogenesis in synchronous and metachronous colorectal liver metastases: the liver as a permissive soil. Ann Surg 255 (1): S. 86-94. DOI: 10.1097/SLA.0b013e318238346a.

Vandercappellen J, Van Damme J, Struyf S (2008): The role of CXC chemokines and their receptors in cancer. Cancer Lett 267 (2): S. 226-244. DOI: 10.1016/j. canlet.2008.04.050.

Vecchi M, Confalonieri S, Nuciforo P, Viganò MA, Capra M et al. (2008): Breast cancer metastases are molecularly distinct from their primary tumors. Oncogene 27 (5): S. 2148-2158. DOI: 10.1038/sj.onc.1210858. 
Vekemans K, Braet F (2005): Structural and functional aspects of the liver and liver sinusoidal cells in relation to colon carcinoma metastasis. World J Gastroenterol 11 (33): S. 5095-5102.

Verbeke H, Struyf S, Laureys G, Van Damme J (2011): The expression and role of CXC chemokines in colorectal cancer. Cytokine Growth Factor Rev 22 (5-6): S. 345-358. DOI: 10.1016/j.cytogfr.2011.09.002.

Vogelstein B, Fearon ER, Hamilton SR, Kern SE, Preisinger AC et al. (1988): Genetic alterations during colorectal-tumor development. N Engl J Med 319 (9): S. 525-532. DOI: 10.1056/NEJM198809013190901.

Vogelstein B, Kinzler KW (1993): The multistep nature of cancer. Trends Genet 9 (4), S. 138-141.

Vogelstein B, Kinzler KW (2004): Cancer genes and the pathways they control. Nat Med 10 (8): S. 789-799. DOI: $10.1038 / \mathrm{nm} 1087$.

Wagenaar-Miller RA, Gorden L, Matrisian LM (2004): Matrix metalloproteinases in colorectal cancer: is it worth talking about? Cancer Metastasis Rev 23 (1-2): S. 119-135.

Wan L, Pantel K, Kang Y (2013): Tumor metastasis: moving new biological insights into the clinic. Nat Med 19 (11): S. 1450-1465. DOI: 10.1038/nm.3391.

Wang Z, Gerstein M, Snyder M (2009): RNA-Seq: a revolutionary tool for transcriptomics. Nat Rev Genet 10 (1): S. 57-63. DOI: $10.1038 / \mathrm{nrq} 2484$.

Wen SW, Ager EI, Christophi C (2013): Bimodal role of Kupffer cells during colorectal cancer liver metastasis. Cancer Biol Ther 14 (7): S. 606-613. DOI: 10.4161/cbt.24593.

Weigelt B, Glas AM, Wessels LF, Witteveen AT, Peterse JL, van't Veer LJ (2003). Gene expression profiles of primary breast tumors maintained in distant metastases. Proc Natl Acad Sci USA 100 (26): S. 15901-15905. DOI: $10.1073 /$ pnas.2634067100.

Weitz J, Knaebel HP, Büchler MW. (2003): Sporadic and hereditary colorectal cancer. Pathogenetically different with different therapeutic indications. Chirurg 74 (8): S. 717-725). DOI: 10.1007/s00104-0030702-y.

Weitz J, Koch M, Debus J, Höhler T, Galle PR, Büchler MW (2005): Colorectal cancer. Lancet 165 (9454): S. 153-165. DOI: 10.1016/S0140-6736(05)17706-X.

Wielenga VJ, Smits R, Korinek V, Smit L, Kielman M (1999): Expression of CD44 in Apc and Tcf mutant mice implies regulation by the WNT pathway. Am J Pathol 154 (2): S. 515-523. DOI: 10.1016/S00029440(10)65297-2. 
Wisdom R, Johnson RS, Moore C (1999): c-Jun regulates cell cycle progression and apoptosis by distinct mechanisms. EMBO J 18 (1): S. 188-197. DOI: 10.1093/emboj/18.1.188.

Wittekind C, Meyer HJ (2010): TNM Klassifikation maligner Tumoren. 7. Auflage. Wiley-VCH, Weinheim.

Wynn TA (2004): Fibrotic disease and the T(H)1/T(H)2 paradigm. Nat Rev Immnol 4 (8): S. 583-594. DOI: $10.1038 /$ nri1412.

Yang J, Weinberg RA (2008): Epithelial-mesenchymal transition: at the crossroads of development and tumor metastasis. Dev Cell 14 (6): S. 818-829. DOI: 10.1016/j.devcel.2008.05.009.

Ying W, Cheruku PS, Bazer FW, Safe SH, Zhou B (2013): Investigation of macrophage polarization using bone marrow derived macrophages. J Vis Exp 76. DOI: 10.3791/50323.

Yokota J (2000): Tumor progression and metastasis. Carcinogenesis 21 (3): S. 497-503.

Yuan ZL, Guan YJ, Wang L, Wei W, Kane AB, Chin YE (2004): Central role of the theorine residue within the p+1 loop of receptor tyrosine kinase in STAT3 constitutive phosphorylation in metastatic cancer cells. Mol Cell Biol 24 (21): S. 9390-9400. DOI: 10.1128/MCB.24.21.9390-9400.2004.

Zeng ZS, Shu WP, Cohen AM, Guillem JG (2002): Matrix metalloproteinase-7 expression in colorectal cancer liver metastases: evidence for involvement of MMP-7 activation in human cancer metastases. Clin Cancer Res 8 (1): S. 144-148.

Zetter BR (1993): Adhesion molecules in tumor metastasis. Semin Cancer Biol 4 (4): S. 219-229.

Zhang B, Yao G, Zhang Y, Gao J, Yang B, Rao Z, Gao J (2011): M2-polarized tumor-associated macrophages are associated with poor prognoses resulting from accelerated lymphangiogenesis in lung adenocarcinoma. Clinics (Sao Paulo) 66 (11): S. 1879-1886.

Zhang Y, Sime W, Juhas M, Sjölander A (2013): Crosstalk between colon cancer cells and macrophages via inflammatory mediators and CD47 promotes tumour cell migration. Eur J Cancer 49 (15): S. 3320-3334. DOI: 10.1016/j.ejca.2013.06.005.

Zhou Q, Peng RQ, Wu XJ, Xia Q, Hou JH (2010): The density of macrophages in the invasive front is inversely correlated to liver metastasis in colon cancer. J Transl Med 8: 13. DOI: 10.1186/1479-5876-8-13.

Zlotnik A (2004): Chemokines in neoplastic progression. Semin Cancer Biol 14 (3): S. 181-185. DOI: 10.1016/j.semcancer.2003.10.004. 
Zucker S, Vacirca J (2004): Role of matrix metalloproteinases (MMPs) in colorectal cancer. Cancer Metastasis Rev 23 (1-2): S. 101-117.

Xue J, Schmidt SV, Sander J, Draffehn A, Krebs W et al. (2014): Transcriptome-based network analysis reveals a spectrum model of human macrophage activation. Immunity 40 (2): S. 274-288. DOI: 10.1016/j.immuni.2014.01.006. 


\section{$7 \quad$ Anhang}

Tab. 8.1: Liste von 119 Metastasen-assoziierten Genen mit Angabe der entsprechenden

funktionellen Gengruppe und EnsembI ID. Einige Gene wurden in mehrere funktionelle Gengruppen eingeordnet.

\begin{tabular}{|c|c|c|c|}
\hline Funktionelle Gengruppe & Genname & Gensymbol & Ensembl ID \\
\hline \multirow{17}{*}{ Zelladhäsionsgene } & Catenin & Ctnna1 & ENSMUSG00000037815 \\
\hline & Cadherin 1 & Cdh1 & ENSMUSG00000000303 \\
\hline & Cadherin 11 & Cdh11 & ENSMUSG00000031673 \\
\hline & Cadherin 6 & Cdh6 & ENSMUSG00000039385 \\
\hline & Cadherin 8 & Cdh8 & ENSMUSG00000036510 \\
\hline & FAT atypical cadherin 1 & Fat1 & ENSMUSG00000070047 \\
\hline & Neurofibromatosis 2 & $N f 2$ & ENSMUSG00000009073 \\
\hline & CD44 antigen & $C d 44$ & ENSMUSG00000005087 \\
\hline & Integrin alpha 6 & Itga6 & ENSMUSG00000027111 \\
\hline & Integrin alpha 7 & $\operatorname{Itga7}$ & ENSMUSG00000025348 \\
\hline & Integrin beta 3 & $\operatorname{Itgb3}$ & ENSMUSG00000020689 \\
\hline & Ribosomal protein SA & Rpsa & ENSMUSG00000032518 \\
\hline & Adenomatosis polyposis coli & $A p c$ & ENSMUSG00000005871 \\
\hline & Fibronectin 1 & Fn1 & ENSMUSG00000026193 \\
\hline & Glycoprotein (transmembrane) $\mathrm{nmb}$ & Gpnmb & ENSMUSG00000029816 \\
\hline & Collagen, type IV, alpha 2 & Col4a2 & ENSMUSG00000031503 \\
\hline & Metastasis suppressor 1 & Mtss1 & ENSMUSG00000022353 \\
\hline \multirow{10}{*}{$\begin{array}{l}\text { Extrazelluläre } \\
\text { Matrixproteine }\end{array}$} & Matrix metallopeptidase 10 & Mmp10 & ENSMUSG00000047562 \\
\hline & Matrix metallopeptidase 11 & Mmp11 & ENSMUSG00000000901 \\
\hline & Matrix metallopeptidase 13 & Mmp13 & ENSMUSG00000050578 \\
\hline & Matrix metallopeptidase 2 & Mmp2 & ENSMUSG00000031740 \\
\hline & Matrix metallopeptidase 3 & Mmp3 & ENSMUSG00000043613 \\
\hline & Matrix metallopeptidase 7 & $M m p 7$ & ENSMUSG00000018623 \\
\hline & Matrix metallopeptidase 9 & Mmp9 & ENSMUSG00000017737 \\
\hline & Tissue inhibitor of metalloproteinase 2 & Timp2 & ENSMUSG00000017466 \\
\hline & Tissue inhibitor of metalloproteinase 3 & Timp3 & ENSMUSG00000020044 \\
\hline & Tissue inhibitor of metalloproteinase 4 & Timp4 & ENSMUSG00000030317 \\
\hline \multirow{12}{*}{ Zellzyklusgene } & Harvey rat sarcoma virus oncogene & Hras1 & ENSMUSG00000025499 \\
\hline & Interleukin 1 beta & $I l 1 b$ & ENSMUSG00000027398 \\
\hline & Kirsten rat sarcoma viral oncogene homolog & Kras & ENSMUSG00000030265 \\
\hline & Transforming growth factor, beta 1 & Tgfb1 & ENSMUSG00000002603 \\
\hline & Vascular endothelial growth factor A & Vegfa & ENSMUSG00000023951 \\
\hline & Adenomatosis polyposis coli & $A p c$ & ENSMUSG00000005871 \\
\hline & Breast cancer metastasis-suppressor 1 & Brms1 & ENSMUSG00000080268 \\
\hline & Cyclin-dependent kinase inhibitor $2 \mathrm{~A}$ & Cdkn2a & ENSMUSG00000044303 \\
\hline & Neurofibromatosis 2 & Nf2 & ENSMUSG00000009073 \\
\hline & Phosphatase and tensin homolog & Pten & ENSMUSG00000013663 \\
\hline & Retinoblastoma 1 & $R b 1$ & ENSMUSG00000022105 \\
\hline & Transformation related protein 53 & $\operatorname{Trp53}$ & ENSMUSG00000059552 \\
\hline \multirow{3}{*}{$\begin{array}{l}\text { Zellwachstums- und } \\
\text { Proliferationsgene }\end{array}$} & KISS1 receptor & Kiss1r & ENSMUSG00000035773 \\
\hline & Cyclin D1 & Ccnd1 & ENSMUSG00000070348 \\
\hline & Interleukin 18 & Il18 & ENSMUSG00000039217 \\
\hline
\end{tabular}




\begin{tabular}{|c|c|c|c|}
\hline & KiSS-1 metastasis-suppressor & Kiss1 & ENSMUSG00000102367 \\
\hline & $\begin{array}{l}\text { Antigen identified by monoclonal antibody Ki } \\
67\end{array}$ & Mki67 & ENSMUSG00000031004 \\
\hline \multirow{30}{*}{$\begin{array}{l}\text { Zellwachstums- und } \\
\text { Proliferationsgene }\end{array}$} & Myelocytomatosis oncogene & Myc & ENSMUSG00000022346 \\
\hline & Neurofibromatosis 2 & Nf2 & ENSMUSG00000009073 \\
\hline & Transforming growth factor, beta 1 & $T g f b 1$ & ENSMUSG00000002603 \\
\hline & Transformation related protein 53 & $\operatorname{Trp53}$ & ENSMUSG00000059552 \\
\hline & Colony stimulating factor 1 (macrophage) & Csf1 & ENSMUSG00000014599 \\
\hline & Epidermal growth factor & Egf & ENSMUSG00000028017 \\
\hline & Hepatocyte growth factor & $H g f$ & ENSMUSG00000028864 \\
\hline & Insulin-like growth factor 1 & Igf1 & ENSMUSG00000020053 \\
\hline & Vascular endothelial growth factor A & Vegfa & ENSMUSG00000023951 \\
\hline & Chemokine (C-C motif) ligand 7 & Ccl7 & ENSMUSG00000035373 \\
\hline & Chemokine (C-X-C motif) ligand 12 & Cxcl12 & ENSMUSG00000061353 \\
\hline & Interleukin 18 & Il18 & ENSMUSG00000039217 \\
\hline & Interleukin 1 beta & $I l 1 b$ & ENSMUSG00000027398 \\
\hline & Interleukin 2 & $I l 2$ & ENSMUSG00000027720 \\
\hline & Interleukin 10 & $I l 10$ & ENSMUSG00000016529 \\
\hline & $\begin{array}{l}\text { Tumor necrosis factor (ligand) superfamily, } \\
\text { member } 10\end{array}$ & $\operatorname{Tnfsf} 10$ & ENSMUSG00000039304 \\
\hline & Chemokine (C-X-C motif) receptor 4 & Cxcr4 & ENSMUSG00000045382 \\
\hline & Eph receptor B2 & Ephb2 & ENSMUSG00000028664 \\
\hline & Fibroblast growth factor receptor 4 & Fgfr4 & ENSMUSG00000005320 \\
\hline & FMS-like tyrosine kinase 4 & Flt4 & ENSMUSG00000020357 \\
\hline & Epidermal growth factor receptor & $E g f r$ & ENSMUSG00000020122 \\
\hline & KISS1 receptor & Kiss1r & ENSMUSG00000035773 \\
\hline & Chemokine (C-X-C motif) receptor 2 & Cxcr2 & ENSMUSG00000026180 \\
\hline & Met proto-oncogene & Met & ENSMUSG00000009376 \\
\hline & $\begin{array}{l}\text { Nuclear receptor subfamily } 4 \text {, group A, } \\
\text { member } 3\end{array}$ & Nr4a3 & ENSMUSG00000028341 \\
\hline & Lysophosphatidic acid receptor 6 & Lpar6 & ENSMUSG00000033446 \\
\hline & Plasminogen activator, urokinase receptor & Plaur & ENSMUSG00000046223 \\
\hline & RAR-related orphan receptor beta & Rorb & ENSMUSG00000036192 \\
\hline & Somatostatin receptor 2 & Sstr2 & ENSMUSG00000047904 \\
\hline & Thyroid stimulating hormone receptor & Tshr & ENSMUSG00000020963 \\
\hline \multirow{12}{*}{ Apoptosegene } & Interleukin 18 & Il18 & ENSMUSG00000039217 \\
\hline & Myelocytomatosis oncogene & Myc & ENSMUSG00000022346 \\
\hline & Phosphatase and tensin homolog & Pten & ENSMUSG00000013663 \\
\hline & $\begin{array}{l}\text { Tumor necrosis factor (ligand) superfamily, } \\
\text { member } 10\end{array}$ & $\operatorname{Tnfsf} 10$ & ENSMUSG00000039304 \\
\hline & BCL2-associated X protein & Bax & ENSMUSG00000003873 \\
\hline & B cell leukemia/lymphoma 2 & Bcl2 & ENSMUSG00000057329 \\
\hline & Caspase 3 & Casp3 & ENSMUSG00000031628 \\
\hline & Caspase 7 & Casp7 & ENSMUSG00000025076 \\
\hline & Caspase 9 & Casp9 & ENSMUSG00000028914 \\
\hline & Cyclin-dependent kinase inhibitor 1A (P21) & Cdkn1a & ENSMUSG00000023067 \\
\hline & Transformation related protein 53 & $\operatorname{Trp53}$ & ENSMUSG00000059552 \\
\hline & Cyclin-dependent kinase inhibitor $2 \mathrm{~A}$ & Cdkn2a & ENSMUSG00000044303 \\
\hline
\end{tabular}




\begin{tabular}{|c|c|c|c|}
\hline \multirow{22}{*}{$\begin{array}{l}\text { Transkriptionsfaktoren } \\
\text { und -regulatoren }\end{array}$} & Ets variant 4 & Etv4 & ENSMUSG00000017724 \\
\hline & $\begin{array}{l}\text { V-myc avian myelocytomatosis viral } \\
\text { oncogene lung carcinoma derived }\end{array}$ & Mycl1 & ENSMUSG00000028654 \\
\hline & Metastasis associated 1 & Mta1 & ENSMUSG00000021144 \\
\hline & Myelocytomatosis oncogene & Myc & ENSMUSG00000022346 \\
\hline & $\begin{array}{l}\text { Nuclear receptor subfamily } 4 \text {, group A, } \\
\text { member } 3\end{array}$ & $\mathrm{Nr} 4 a 3$ & ENSMUSG00000028341 \\
\hline & RAR-related orphan receptor beta & Rorb & ENSMUSG00000036192 \\
\hline & SMAD family member 4 & Smad4 & ENSMUSG00000024515 \\
\hline & Transcription factor 20 & Tcf20 & ENSMUSG00000041852 \\
\hline & Transformation related protein 53 & $\operatorname{Trp53}$ & ENSMUSG00000059552 \\
\hline & $\begin{array}{l}\text { Chromodomain helicase DNA binding } \\
\text { protein } 4\end{array}$ & Chd4 & ENSMUSG00000063870 \\
\hline & Ewing sarcoma breakpoint region 1 & Ewsr1 & ENSMUSG00000009079 \\
\hline & Retinoblastoma 1 & $R b 1$ & ENSMUSG00000022105 \\
\hline & Jun proto-oncogene & Jun & ENSMUSG00000052684 \\
\hline & Fas (TNF receptor superfamily member 6) & Fas & ENSMUSG00000024778 \\
\hline & FBJ osteosarcoma oncogene & Fos & ENSMUSG00000021250 \\
\hline & $\begin{array}{l}\text { Signal transducer and activator of } \\
\text { transcription } 1\end{array}$ & Stat1 & ENSMUSG00000026104 \\
\hline & $\begin{array}{l}\text { Signal transducer and activator of } \\
\text { transcription } 3\end{array}$ & Stat3 & ENSMUSG00000004040 \\
\hline & $\begin{array}{l}\text { Signal transducer and activator of } \\
\text { transcription } 5 \mathrm{~A}\end{array}$ & Stat5a & ENSMUSG00000004043 \\
\hline & $\begin{array}{l}\text { Signal transducer and activator of } \\
\text { transcription } 5 \mathrm{~B}\end{array}$ & Stat $5 b$ & ENSMUSG00000020919 \\
\hline & $\begin{array}{l}\text { Nuclear factor of kappa light polypeptide } \\
\text { gene enhancer in B cells 1, p105 }\end{array}$ & $N f k b 1$ & ENSMUSG00000028163 \\
\hline & $\begin{array}{l}\text { Nuclear factor of kappa light polypeptide } \\
\text { gene enhancer in B cells 2, p49/p100 }\end{array}$ & $N f k b 2$ & ENSMUSG00000025225 \\
\hline & SMAD family member 2 & Smad2 & ENSMUSG00000024563 \\
\hline \multirow{12}{*}{ EMT-spezifische Gene } & Vimentin & Vim & ENSMUSG00000026728 \\
\hline & Cadherin 1 & Cdh1 & ENSMUSG00000000303 \\
\hline & Cadherin 2 & Cdh2 & ENSMUSG00000024304 \\
\hline & Fibronectin 1 & Fn1 & ENSMUSG00000026193 \\
\hline & Interleukin 6 & II6 & ENSMUSG00000025746 \\
\hline & Interleukin 6 receptor, alpha & Il6ra & ENSMUSG00000027947 \\
\hline & Snail family zinc finger 1 & Snai1 & ENSMUSG00000042821 \\
\hline & Lymphoid enhancer binding factor 1 & Lef1 & ENSMUSG00000027985 \\
\hline & SMAD family member 4 & Smad4 & ENSMUSG00000024515 \\
\hline & SMAD family member 7 & Smad7 & ENSMUSG00000025880 \\
\hline & Transforming growth factor, beta 1 & $T g f b 1$ & ENSMUSG00000002603 \\
\hline & Zinc finger E-box binding homeobox 1 & Zeb1 & ENSMUSG00000024238 \\
\hline \multirow{3}{*}{ CRC-spezifische Gene } & Caudal type homeobox 2 & $C d x 2$ & ENSMUSG00000029646 \\
\hline & $\begin{array}{l}\text { Carcinoembryonic antigen-related cell } \\
\text { adhesion molecule } 19\end{array}$ & Ceacam19 & ENSMUSG00000049848 \\
\hline & Keratin 20 & Krt20 & ENSMUSG00000035775 \\
\hline Wnt Signaling (kanonisch) & Adenomatosis polyposis coli & $A p c$ & ENSMUSG00000005871 \\
\hline
\end{tabular}


Anhang

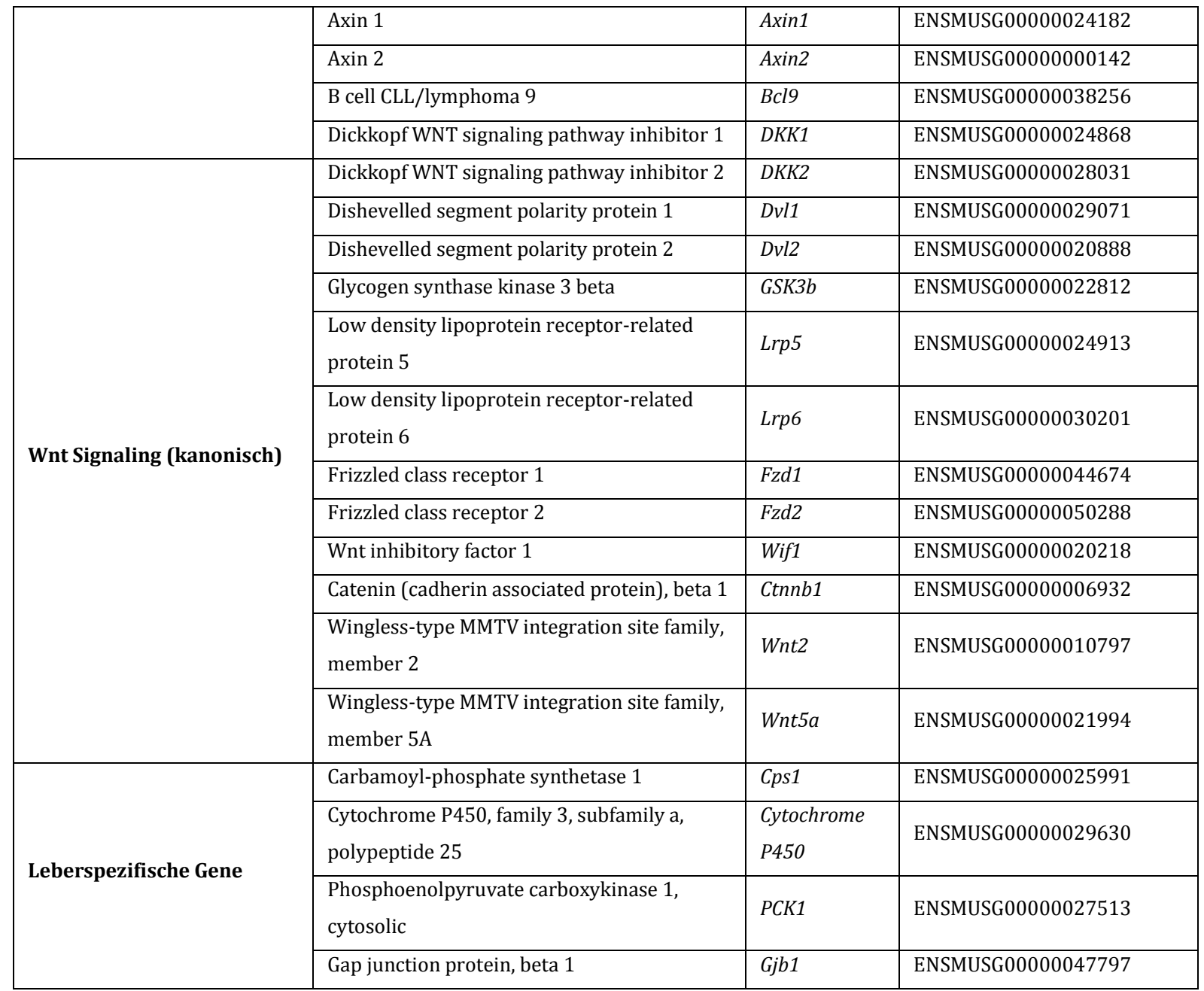




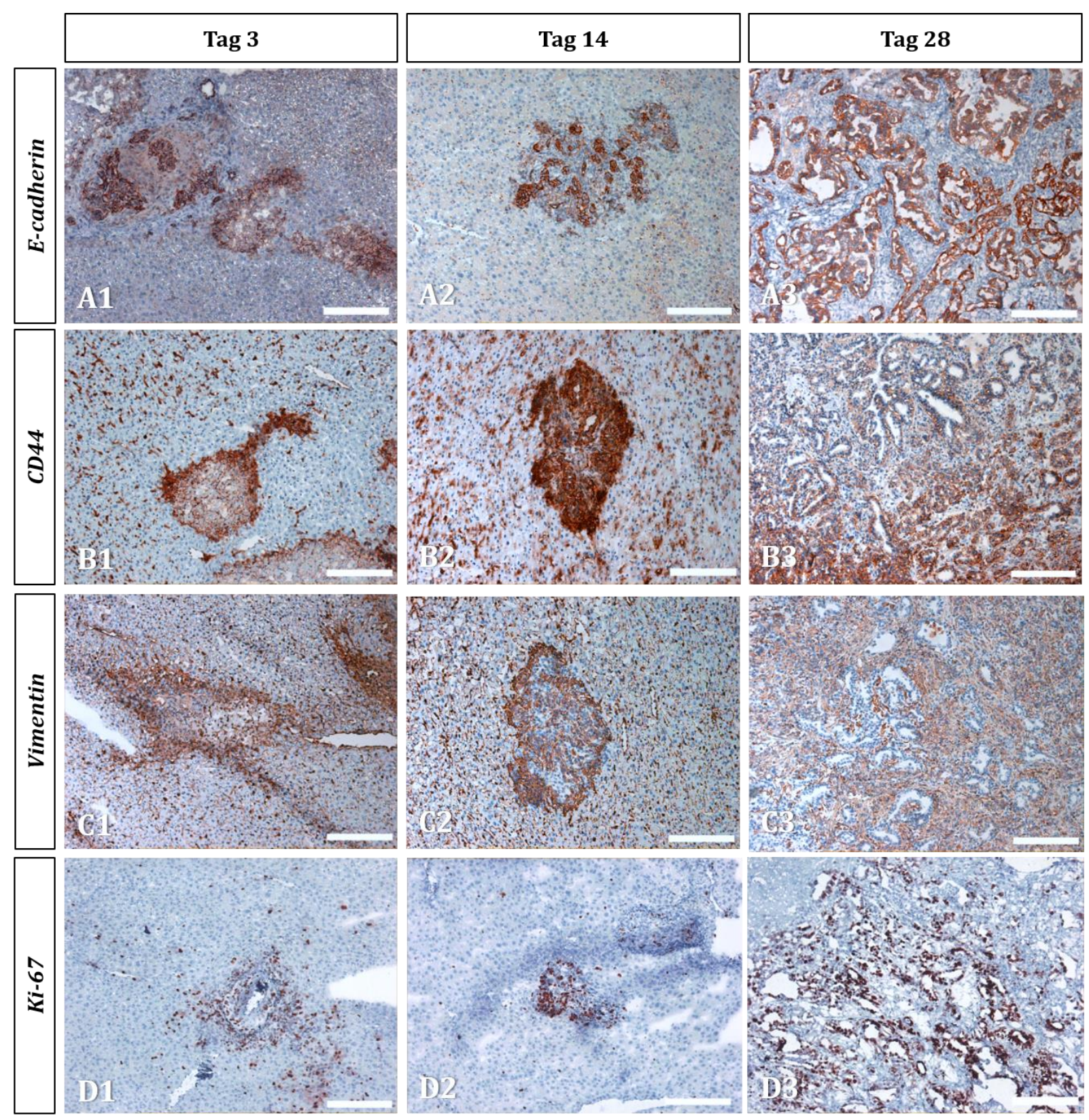

Abb. 8.1: Vegrößerte Aufnahmen der Metastasen aus Abb. 3.12. Größenbalken entsprechen einer Länge von $200 \mu \mathrm{m}$. 

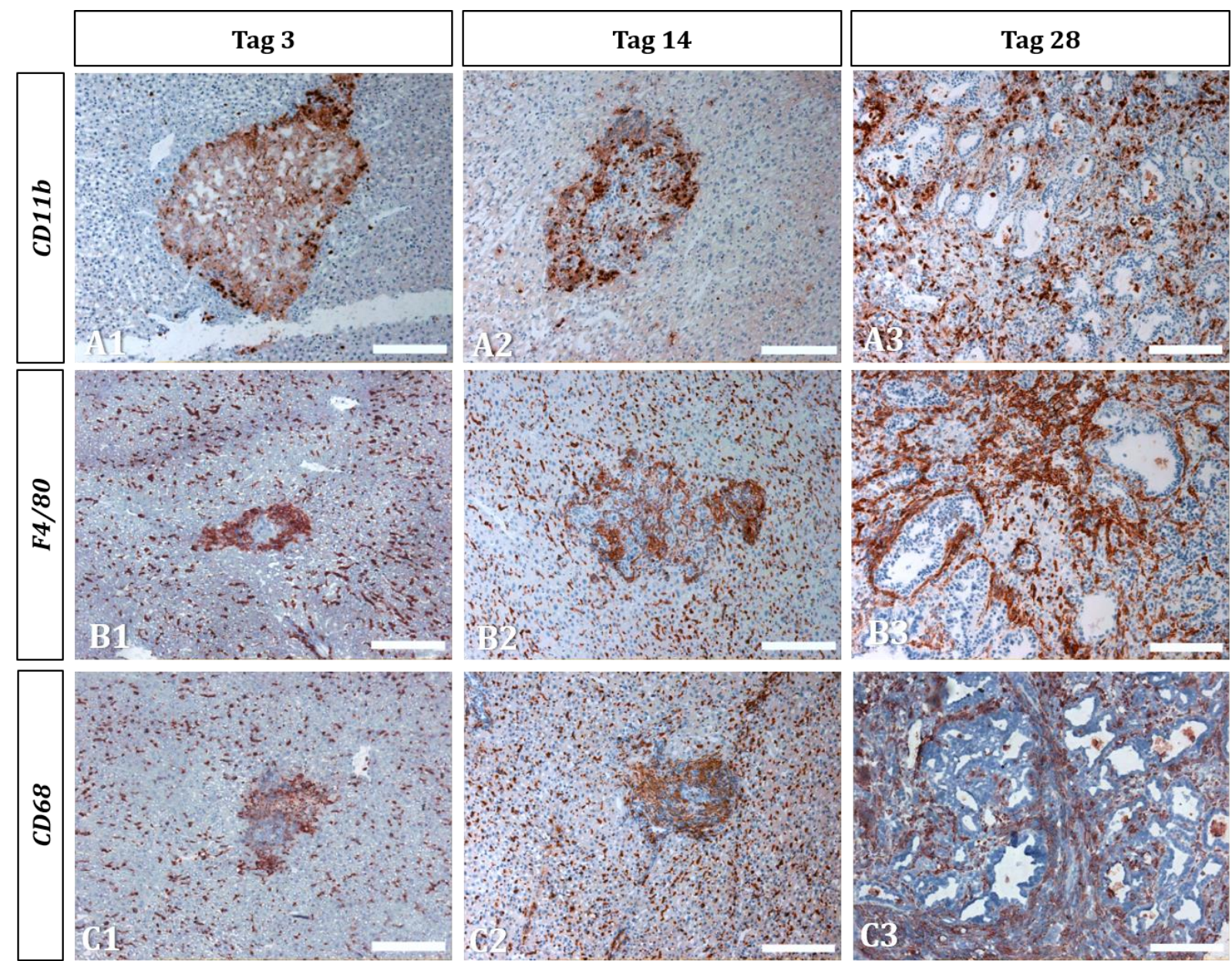

Abb. 8.2: Vegrößerte Aufnahmen der Metastasen aus Abb. 3.19. Größenbalken entsprechen einer Länge von $200 \mu \mathrm{m}$. 


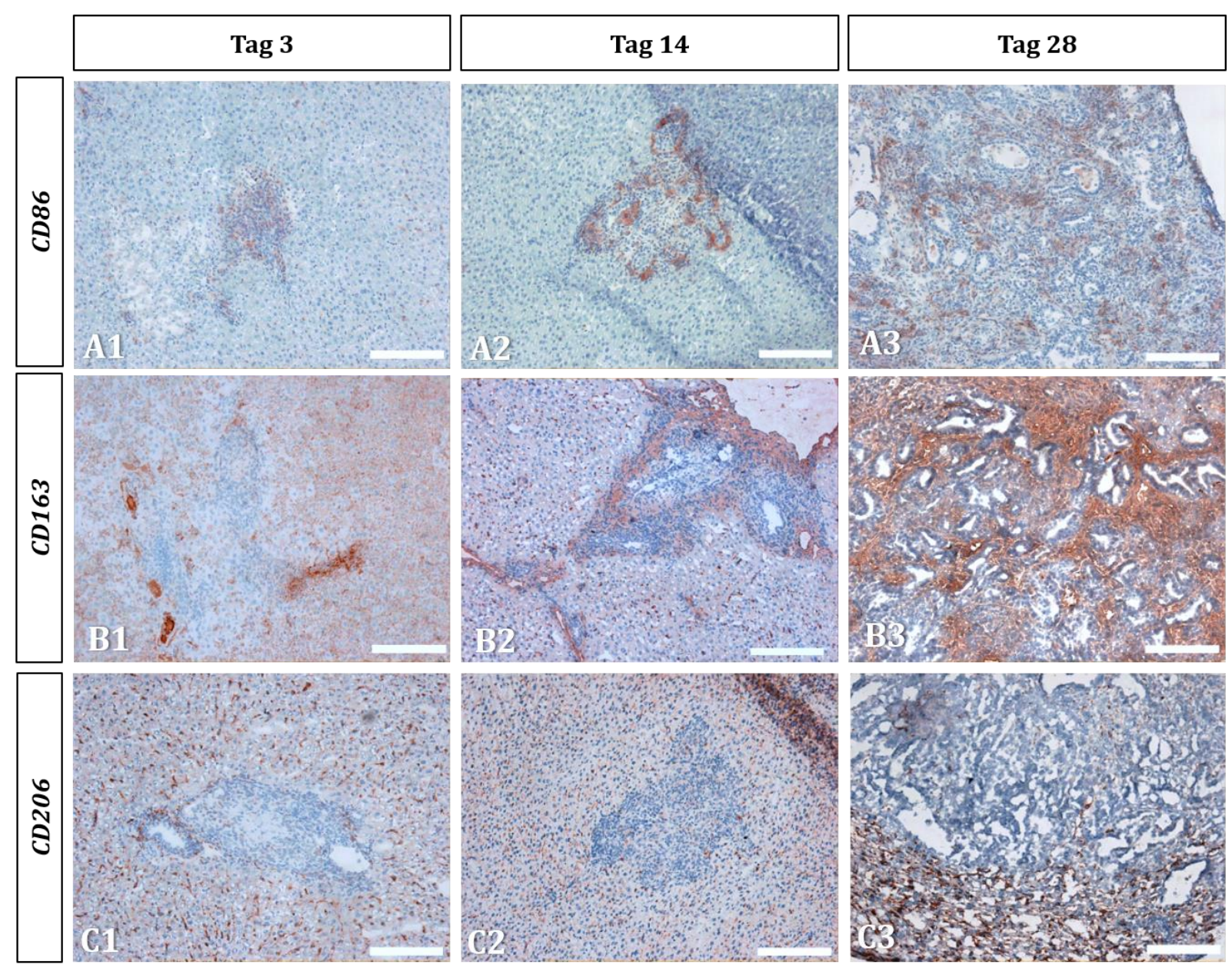

Abb. 8.3: Vegrößerte Aufnahmen der Metastasen aus Abb. 3.20. Größenbalken entsprechen einer Länge von $200 \mu \mathrm{m}$. 